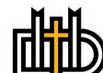

\section{Photocatalytic Degradation of NOx by Concrete Pavement Containing $\mathrm{TiO}_{2}$}

Joel K. Sikkema

Dordt College, joel.sikkema@dordt.edu

Follow this and additional works at: https://digitalcollections.dordt.edu/faculty_work

Part of the Civil and Environmental Engineering Commons

\section{Recommended Citation}

Sikkema, J. K. (2013). Photocatalytic Degradation of NOx by Concrete Pavement Containing $\mathrm{TiO}_{2}$.

Retrieved from https://digitalcollections.dordt.edu/faculty_work/98

This Dissertation is brought to you for free and open access by Dordt Digital Collections. It has been accepted for inclusion in Faculty Work Comprehensive List by an authorized administrator of Dordt Digital Collections. For more information, please contact ingrid.mulder@dordt.edu. 


\title{
Photocatalytic Degradation of NOx by Concrete Pavement Containing $\mathrm{TiO}_{2}$
}

\begin{abstract}
Emissions from motor vehicles cause the concentrations of nitrogen oxides (NOX) in the immediate vicinity of highways to be $30-100 \%$ higher than background concentrations. Photocatalytic pavements have been proposed to address this localized pollution problem. Bench-scale evaluation of environmental variables confirmed that nitric oxide (NO) oxidation rate positively correlated with influent NO concentration and irradiance and negatively correlated with relative humidity. However, comparison of the slope of these correlations found significant differences between this study and other published work. Slab water loss, a variable not investigated in prior work, positively correlated with NO oxidation rate at water losses of $0-2 \%$ of saturated mass, but negatively correlated at losses greater than $2 \%$. A positive correlation was documented for slab temperature; this finding contrasts previous assertions which considered this variable insignificant. Overall, oxidation rates ranged from $6.2-57 \mathrm{nmole} \bullet \mathrm{m}-2 \bullet \mathrm{s}-1$. This sensitivity demonstrates that selecting a field location requires exceptionally careful review of environmental conditions. Comparison of photocatalytic slabs of pervious concrete and mortar manufactured with the same photocatalytic cement and water-to-cement ratio found no evidence of a difference in NO oxidation rate at a confidence level greater than $90 \%$. This finding contrasts previous speculation, which asserted superior pervious concrete performance due to increased specific surface area. In a second contrast to previous work, no evidence of a correlation was found between NO oxidation rate and photocatalytic layer depth in two-lift pervious slabs. Although pervious slabs were not superior to mortar slabs, they are another material that could address NOX pollution. Lab investigation of blinding by prevailing roadway pollutants did not find evidence of a substantial decrease in performance at normally observed field loadings. Reaction products did cause blinding; however, the performance decrease was asymptotic and a complete loss of activity was not observed. In disagreement with previous reports, preliminary results did not observe easy photoactivity regeneration. The first phase of an ongoing field study did not find evidence that NO concentration in a photocatalytic section was lower than NO concentration in a control section. The most probable explanations for this observation are excess vibration, which caused mixture segmentation, and insufficient NO oxidation rate.
\end{abstract}

\section{Keywords}

concrete, photocatalytic oxidation, pavement, nitrogen oxides, sustainability, transportation

Disciplines

Civil and Environmental Engineering

\section{Comments}

- A dissertation submitted to the graduate faculty in partial fulfillment of the requirements for the degree of DOCTOR OF PHILOSOPHY, Iowa State University.

- James E. Alleman and Say Kee Ong, Co-major Professors

- ㄷ 2013 Joel Kenyon Sikkema

\section{Creative Commons License}

(c) (i) $\Theta$

This work is licensed under a Creative Commons Attribution-NonCommercial-No Derivative Works 4.0 International License. 
Photocatalytic degradation of $\mathrm{NO}_{x}$ by concrete pavement containing $\mathrm{TiO}_{2}$

by

\section{Joel Kenyon Sikkema}

A dissertation submitted to the graduate faculty in partial fulfillment of the requirements for the degree of

DOCTOR OF PHILOSOPHY

Major: Civil Engineering (Environmental Engineering)

Program of Study Committee:

James E. Alleman, Co-major Professor

Say Kee Ong, Co-major Professor

Jacek A. Koziel

Peter C. Taylor

Michael L. Thompson

lowa State University

Ames, lowa

2013

Copyright () Joel Kenyon Sikkema, 2013. All rights reserved. 


\section{TABLE OF CONTENTS}

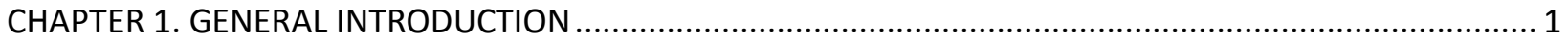

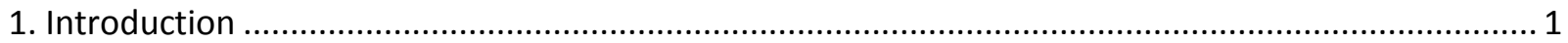

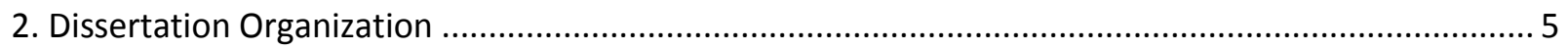

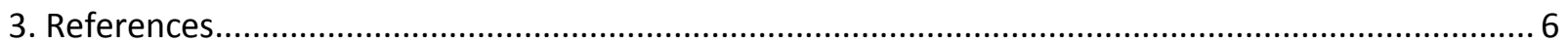

CHAPTER 2. PHOTOCATALYTIC OXIDATION OF NO $\mathrm{N}_{\mathrm{X}}$ BY PAVEMENT CONTAINING TiO ${ }_{2}:$ REVIEW ............... 8

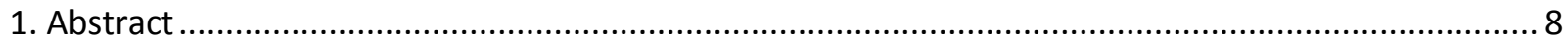

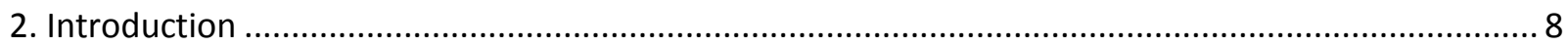

3. Regulatory Drivers and Conventional Mitigation Strategies....................................................... 10

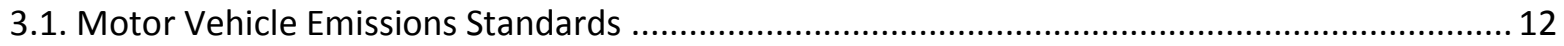

4. Principles of $\mathrm{NO}_{x}$ Oxidation by Photocatalytic Pavement........................................................... 12

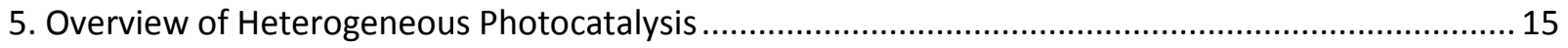

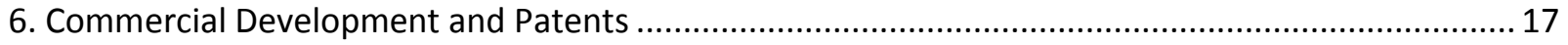

7. Laboratory Evaluation of Photocatalytic Pavements .................................................................... 19

7.1. Experimental Apparatus and Testing Approach ................................................................ 19

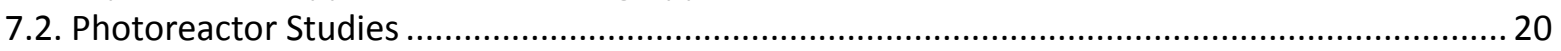

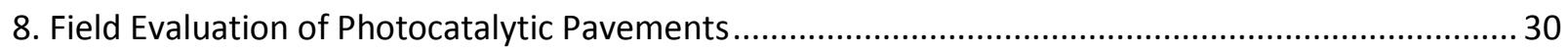

8.1. Field Comparison of Photocatalytic and Control Pavement Sections ...................................... 31

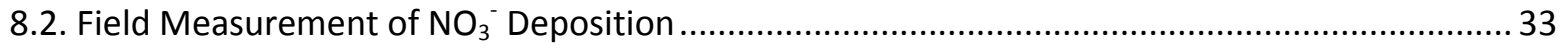

8.3. Modeling Efforts to Predict Field Observations .................................................................. 33

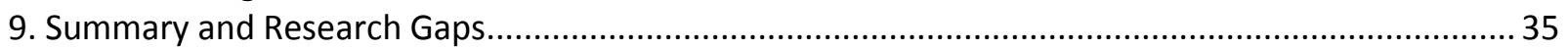

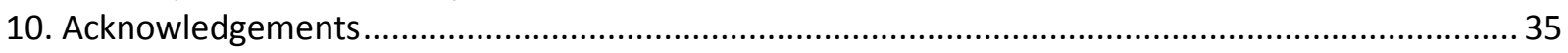

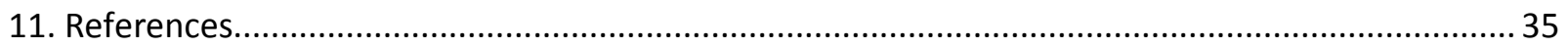

CHAPTER 3. MASS TRANSFER AND KINETICS OF NO MITIGATION BY PHOTOCATALYTIC

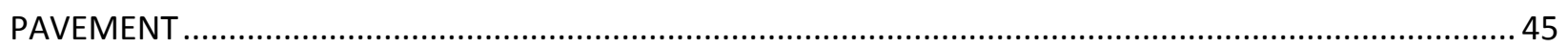

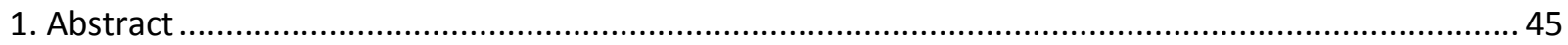

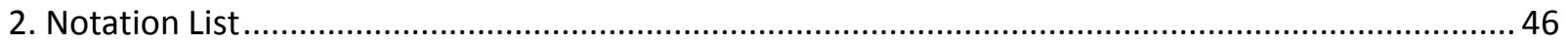

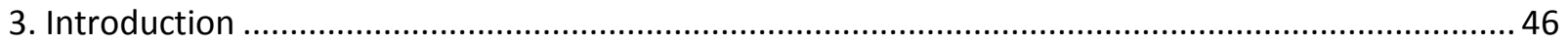

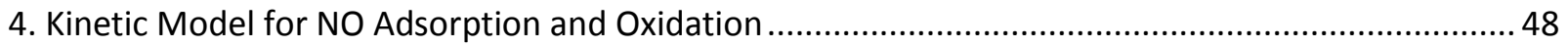

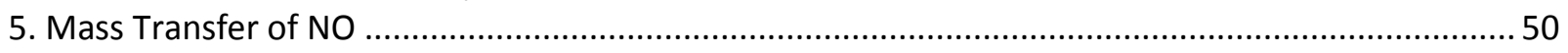

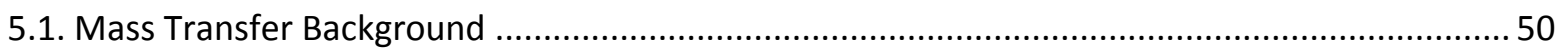

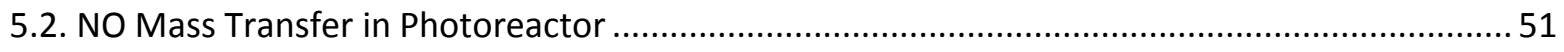

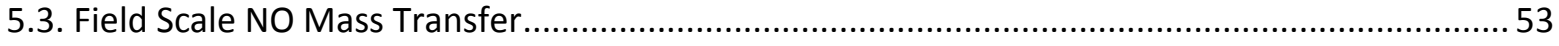

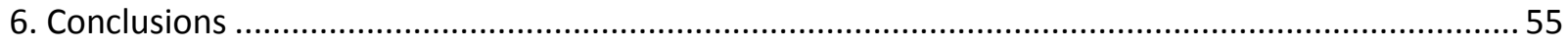

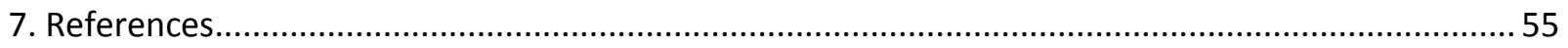


CHAPTER 4. PHOTOCATALYTIC CONCRETE PAVEMENTS: LABORATORY INVESTIGATION OF NO OXIDATION RATE UNDER VARIED ENVIRONMENTAL CONDITIONS …............................................. 58

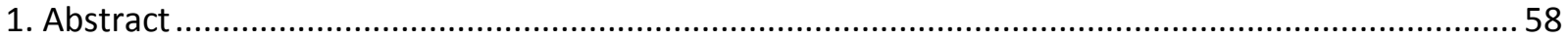

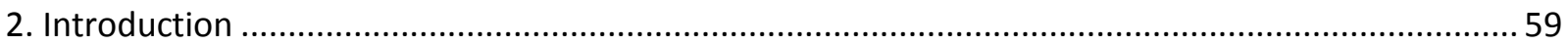

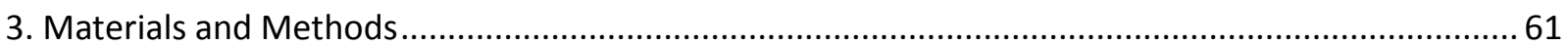

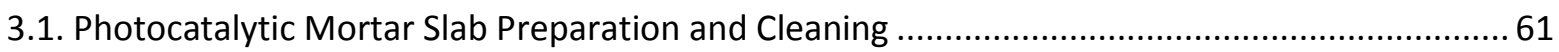

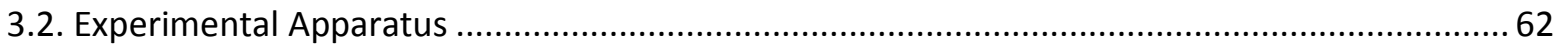

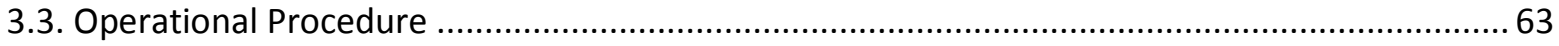

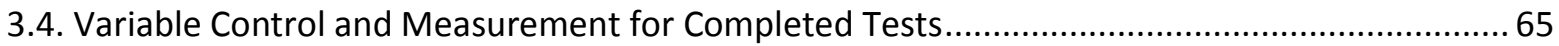

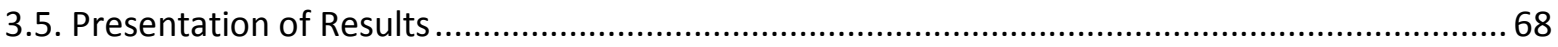

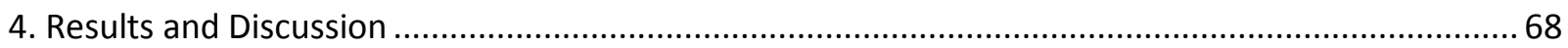

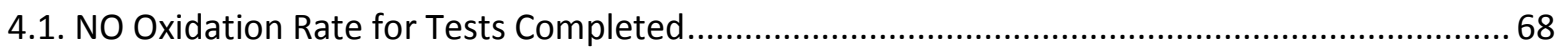

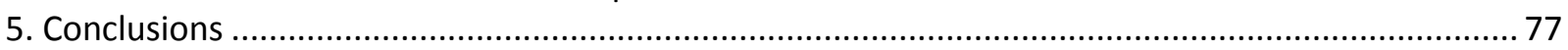

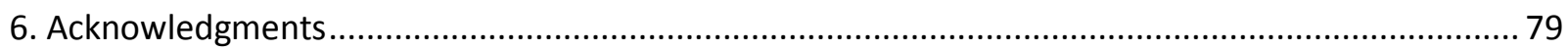

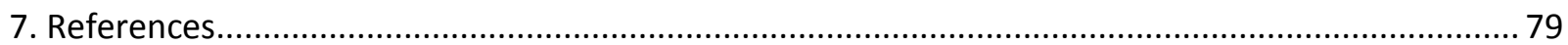

CHAPTER 5. PERVIOUS PHOTOCATALYTIC CONCRETE PAVEMENT: LABORATORY INVESTIGATION OF THE EFFECT OF PHOTOCATALYTIC LAYER DEPTH ON NO OXIDATION RATE AND COMPARISON

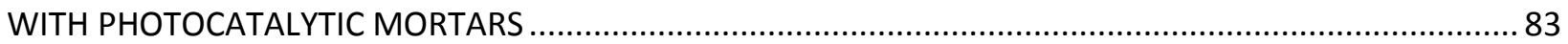

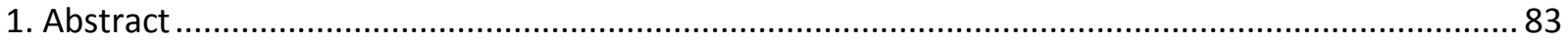

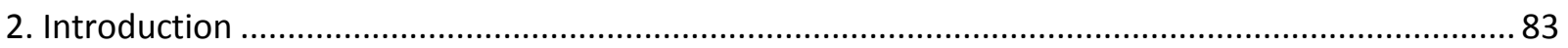

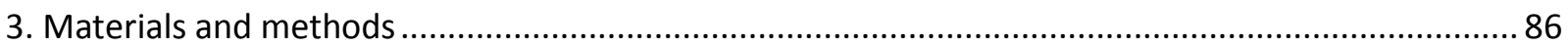

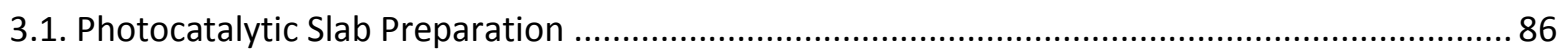

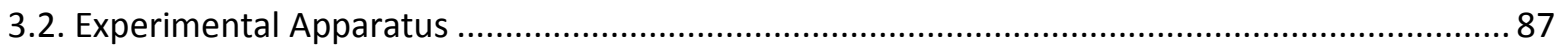

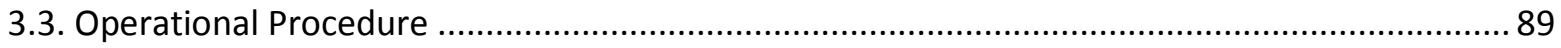

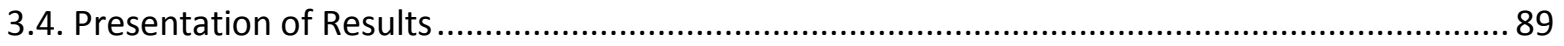

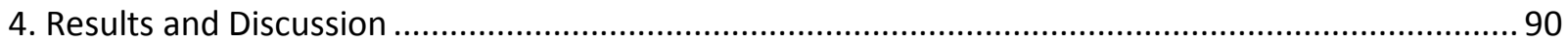

4.1. NO removal rate of photocatalytic pervious concrete cubes and mortar slabs......................... 90

4.2. Existence of Difference in NO Removal by Pervious Cubes Versus Mortar Slabs ...................... 95

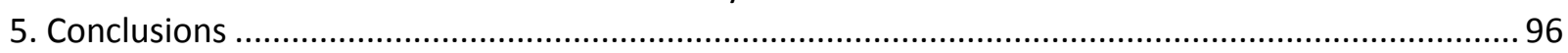

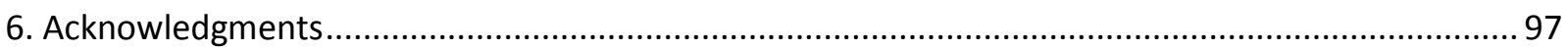

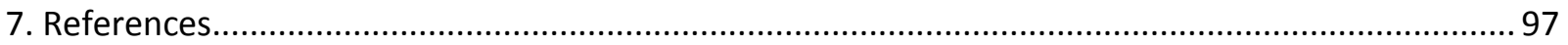

CHAPTER 6. PHOTOCATALYTIC CONCRETE PAVEMENTS: LABORATORY EVALUATION OF

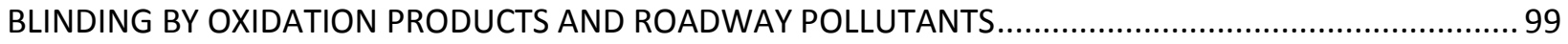

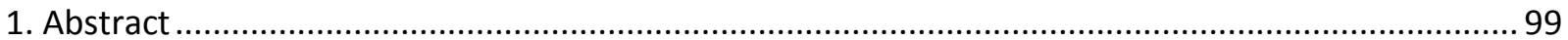

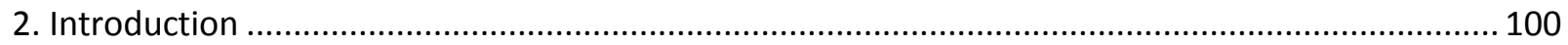

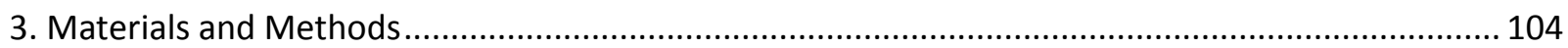

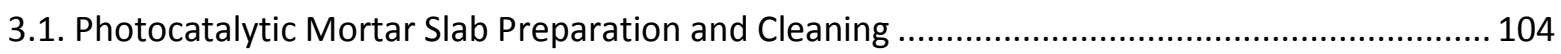

3.2. Tests Completed for Reaction Products Blinding Study ...................................................... 105

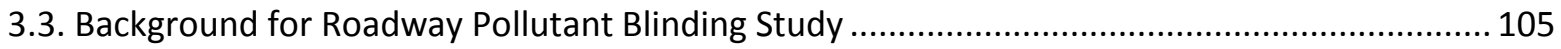

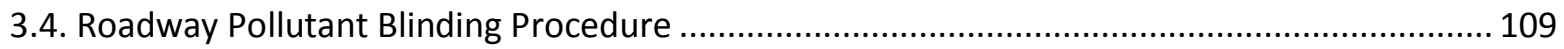

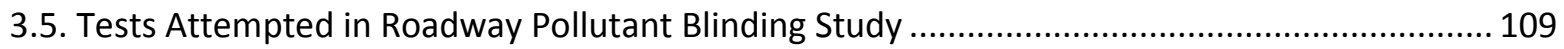

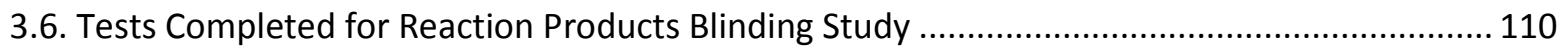

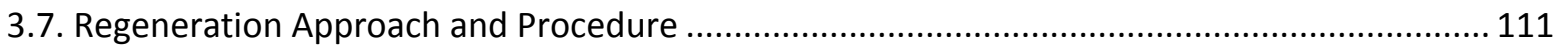

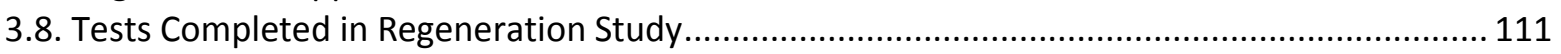

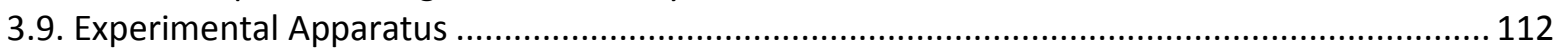




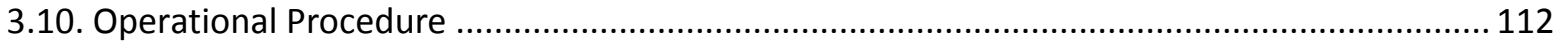

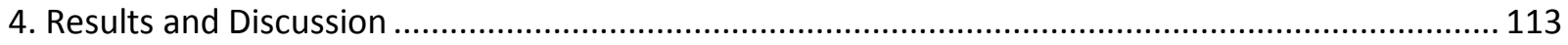

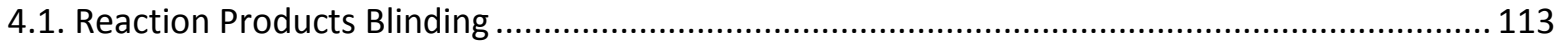

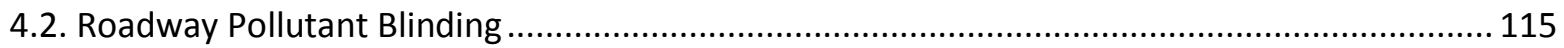

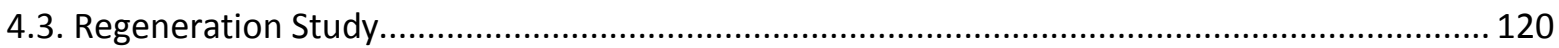

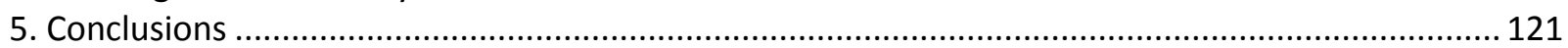

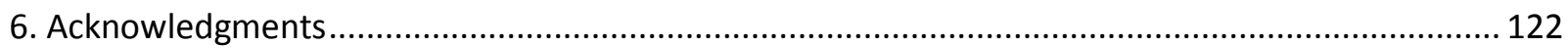

7. Appendix: Alternative Approach for Pollutant Loading Rate Determination ............................... 122

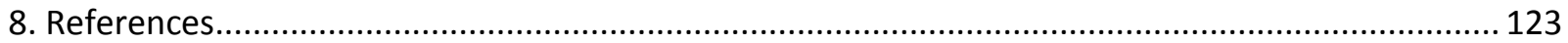

CHAPTER 7. PHOTOCATALYTIC CONCRETE PAVEMENTS: PRELIMINARY RESULTS OF FIELD

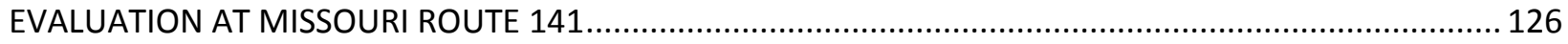

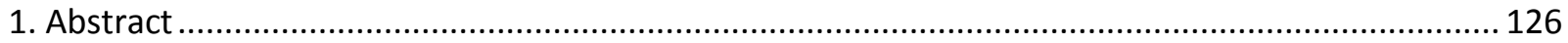

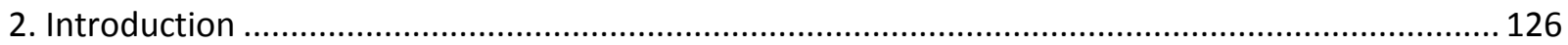

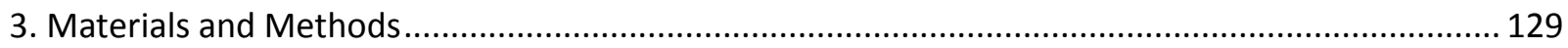

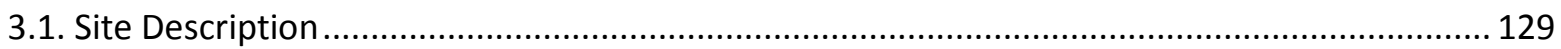

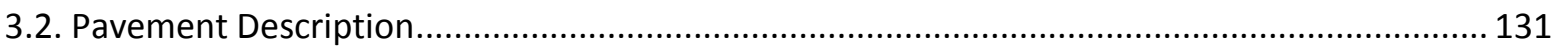

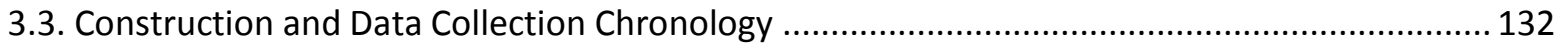

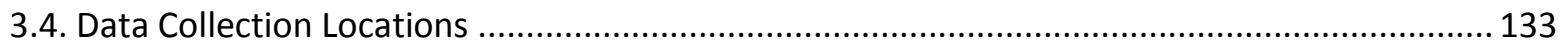

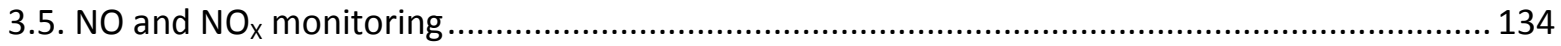

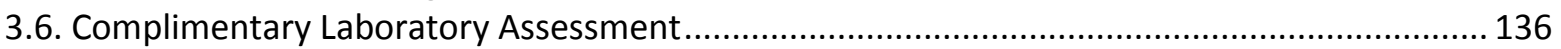

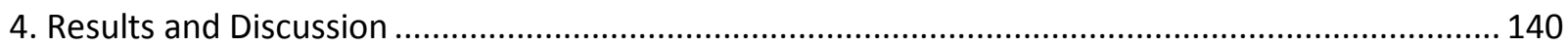

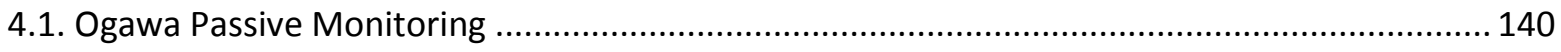

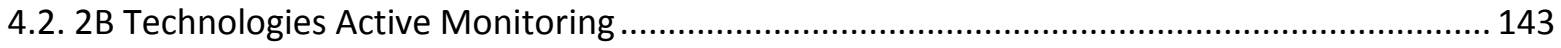

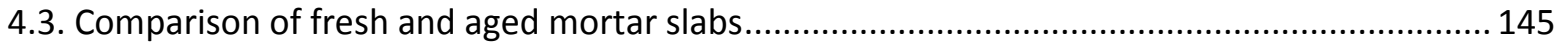

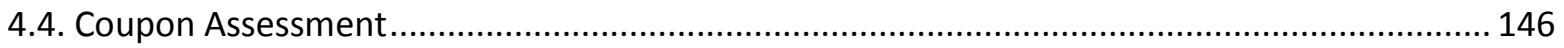

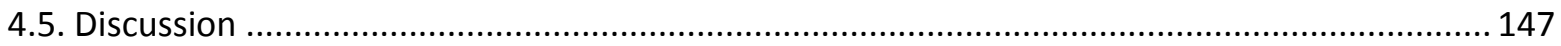

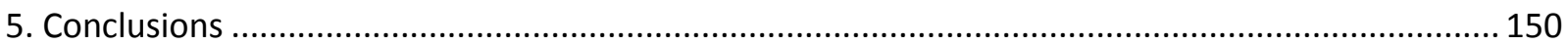

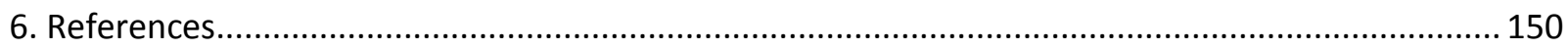

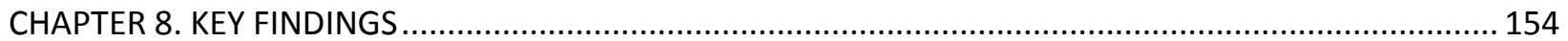




\section{LIST OF TABLES}

Table 2.1. Emissions and $\mathrm{TiO}_{2}$-based photocatalytic reactions for mobile source pollutant indicators.

Table 2.2. Patent synopsis relative to $\mathrm{TiO}_{2}$-containing paving materials.

Table 2.3. Summary of photoreactor tests for mortars containing $\mathrm{TiO}_{2}$ (unless noted, values are presented with the reported number of significant digits).

Table 2.4. Photocatalytic pavement field studies. 30

Table 4.1. Environmental conditions and results of tests completed. .66

Table 5.1. Environmental conditions of and results for tests completed. 91

Table 6.1. Reaction products blinding testing program parameters. 105

Table 6.2. Highway pollution yields (values and categories from Burton and Pitt, 2002)..... 107

Table 6.3. Pollutant species loading mass. 109

Table 6.4. Tests attempted in roadway pollutant blinding study.

Table 6.5. Reaction products blinding testing program parameters.

Table 6.6. Tests completed in regeneration study.

Table 7.1. Photocatalytic pavement field studies that compared a photocatalytic pavement test section with a control test section made of conventional pavement materials.

Table 7.2. Other photocatalytic pavement field sites.

Table 7.3. Photocatalytic and conventional concrete mixture proportions.

Table 7.4. Construction chronology and highlights.

Table 7.5. Average $\mathrm{NO}_{x}$ and $\mathrm{NO}$ concentration and number of observations at Ogawa passive samplers 12 in above pavement in photocatalytic and control test sections (90\% confidence interval displayed for $\mathrm{NO}_{\mathrm{x}}$ observations). 
Table 7.6. Average $\mathrm{NO}_{x}$ and $\mathrm{NO}$ concentration and number of observations at samplers 40 in above pavement photocatalytic and control test sections ( $90 \%$ confidence interval displayed for $\mathrm{NO}_{\mathrm{x}}$ observations). 


\section{LIST OF FIGURES}

Figure 1.1. Photocatalytic pavement research activity within North America.

Figure 1.2. Photocatalytic pavement research activity within Europe.

Figure 2.1. Photocatalytic oxidation of $\mathrm{NO}$ and $\mathrm{NO}_{2}$ by concrete pavement containing $\mathrm{TiO}_{2}$. 14

Figure 2.2. Photocatalytic oxidation steps (adapted from Tompkins et al., 2005). 16

Figure 2.3. Schematic of experimental apparatus (adapted from ISO, 2007).

Figure 3.1. Mass transfer, adsorption, and reaction steps of a $\mathrm{TiO}_{2}$-based heterogeneous catalytic reaction that results in the oxidation of $\mathrm{NO}$ (subsequent reactions oxidize $\mathrm{HNO}_{2, \text { ads }}$ to $\left.\mathrm{HNO}_{3, \mathrm{ads}}\right)$.

Figure 4.1. Photocatalytic oxidation of $\mathrm{NO}$ and $\mathrm{NO}_{2}$ by pavement containing $\mathrm{TiO}_{2}$ (partially adapted from Ballari et al., 2011).

Figure 4.2. Diagram of experimental apparatus (partially adapted from Ballari et al., 2011).....

Figure 4.3. Typical $\mathrm{NO} / \mathrm{NO}_{\mathrm{x}}$ monitor data from testing procedure. 64

Figure 4.4. Effect of influent NO concentration on NO oxidation rate. 69

Figure 4.5. Effect of UV-A irradiance on NO oxidation rate. 72

Figure 4.6. Effect of flow rate on NO oxidation rate. 73

Figure 4.7. Effect of relative humidity on NO oxidation rate.

Figure 4.8 Effect of slab water loss due to water evaporation on NO oxidation rate. 76

Figure 4.9. Effect of temperature on NO oxidation rate.

Figure 5.1. Photocatalytic oxidation of $\mathrm{NO}$ and $\mathrm{NO}_{2}$ by pavement containing $\mathrm{TiO}_{2}$ (partially adapted from Ballari et al., 2011 from).

Figure 5.2. Diagram of experimental apparatus (adapted from Ballari et al., 2011). 88

Figure 5.3. Typical NO monitor data from testing procedure. 89 
Figure 5.4. Effect of photocatalytic layer thickness on NO oxidation rate (average of observations plotted for 75 and $150 \mathrm{~mm}$ data points; error bars on $150 \mathrm{~mm}$ data point provide $90 \%$ confidence interval).

Figure 5.5. Images of UV-sensitive paper placed beneath $150 \mathrm{~mm} \times 150 \mathrm{~mm}$ pervious slabs of varying thicknesses, which were irradiated with UV-A light at $10 \mathrm{~W} \cdot \mathrm{m}^{-2}$ (colorization within the slab footprint indicates UV penetration).

Figure 5.6. Comparison of mean value and $90 \%$ confidence intervals for pervious $(n=3)$ and mortar $(n=6)$ samples.

Figure 6.1. Photocatalytic generation of ${ }^{\bullet} \mathrm{OH}$ (adapted from Tompkins et al., 2005)

Figure 6.2. Photocatalytic oxidation of $\mathrm{NO}$ and $\mathrm{NO}_{2}$ by pavement containing $\mathrm{TiO}_{2}$ (oxidation steps from Ballari et al., 2011).

Figure 6.3. $\mathrm{NO}_{\mathrm{x}}$ oxidation rate versus time for photoreactor tests.

Figure 6.4. Change in NO oxidation rate due to blinding by roadway pollutants vs. loading rate. Dashed horizontal lines plot $90 \%$ confidence interval for the $0 \%$ baseline; error bars provide $90 \%$ confidence interval for blinded observations.

Figure 6.5. Change in NO oxidation rate due to blinding by roadway pollutants vs. loading rate. Dashed horizontal lines plot $90 \%$ confidence interval for the $0 \%$ baseline; error bars provide $90 \%$ confidence interval for blinded observations.

Figure 6.6. Change in percent removal between blinded and regenerated mortar slab.

Figure 7.1. Field site overview within St. Louis metropolitan region (Google Maps, 2013). 130

Figure 7.2. Rte. 141 test site profile schematic (shldr = shoulder).

Figure 7.3. Data collection locations, numbering, and station numbers (P3 and C1 were placed at the midpoint of a pervious concrete shoulder section used for other research efforts).

Figure 7.4. Ogawa passive sampler installation and mounting on concrete barrier (12 in spacing between samplers).

Figure 7.5. Coupon samples placed within TX Active test section.

Figure 7.6. Coupon placement atop the concrete barrier (elevation slightly greater than $1 \mathrm{~m}$ above the roadway) and in wells formed in the concrete shoulder. 
Figure 7.7. Observations of $\mathrm{NO}_{\mathrm{x}}(\mathrm{x})$ and $\mathrm{NO}(\Delta)$ concentration at Ogawa passive samplers 12 in above pavement in photocatalytic and control test sections.

Figure 7.8. Observations of $\mathrm{NO}_{x}(x)$ and $\mathrm{NO}(\Delta)$ concentration at Ogawa passive samplers 40 in above pavement in photocatalytic and control test sections.

Figure 7.9. 30-minute average of observations of $\mathrm{NO}_{\mathrm{x}}$ and $\mathrm{NO}$ concentration in photocatalytic and control test sections

Figure 7.10. NO oxidation rate versus slab age. 145

Figure 7.11. NO oxidation rate of photocatalytic coupons placed in road and atop the roadway barrier. 


\section{ACKNOWLEDGEMENTS}

Research is communal activity. The research contained within this dissertation was no exception. As I complete this effort and my doctoral education, I would like to acknowledge the following people and organizations:

- The National Concrete Pavement Technology Center, the United States Department of Transportation, Essroc Italcementi Group, and Lehigh Hanson, Inc.-for providing funding to pursue this study.

- James E. Alleman and Say Kee Ong-for serving as my major professors, providing thoughtful guidance to design this study, helping to modify my objectives as new knowledge was revealed, and critiquing my explanation of observations.

- Jacek A. Koziel, Peter C. Taylor, and Michael L. Thompson-for serving as members of my committee and thoughtfully critiquing my preliminary findings in a manner that raised the quality of this dissertation.

- Ben Bai-for working alongside me in this effort and helping me troubleshoot problems as they arose.

- Bob Steffes-for offering practical insight into the design of my research methods.

- Tom Cackler-for working to secure funding for this study and serving as a liaison to the project's stakeholders.

- Mom and Dad-for teaching me to think critically and holistically and for demonstrating how to work with diligence and focus.

- Krista-for supporting and encouraging me as I pursued this degree and for showing care and respect to all.

- Kaelyn and Terran-for being great kids and providing an opportunity for me to relax and focus on my work as a father.

- The Lord-for creating an intricate universe full of potential ready to be unlocked and unfolded and for providing me with the ability to open up this potential for your glory. 


\begin{abstract}
Emissions from motor vehicles cause the concentrations of nitrogen oxides ( $\mathrm{NO}_{\mathrm{x}}$ ) in the immediate vicinity of highways to be $30-100 \%$ higher than background concentrations. Photocatalytic pavements have been proposed to address this localized pollution problem. Bench-scale evaluation of environmental variables confirmed that nitric oxide (NO) oxidation rate positively correlated with influent NO concentration and irradiance and negatively correlated with relative humidity. However, comparison of the slope of these correlations found significant differences between this study and other published work. Slab water loss, a variable not investigated in prior work, positively correlated with NO oxidation rate at water losses of $0-2 \%$ of saturated mass, but negatively correlated at losses greater than 2\%. A positive correlation was documented for slab temperature; this finding contrasts previous assertions which considered this variable insignificant. Overall, oxidation rates ranged from 6.2-57 $\mathrm{nmole} \cdot \mathrm{m}^{-2} \cdot \mathrm{s}^{-1}$. This sensitivity demonstrates that selecting a field location requires exceptionally careful review of environmental conditions. Comparison of photocatalytic slabs of pervious concrete and mortar manufactured with the same photocatalytic cement and water-to-cement ratio found no evidence of a difference in NO oxidation rate at a confidence level greater than $90 \%$. This finding contrasts previous speculation, which asserted superior pervious concrete performance due to increased specific surface area. In a second contrast to previous work, no evidence of a correlation was found between NO oxidation rate and photocatalytic layer depth in two-lift pervious slabs. Although pervious slabs were not superior to mortar slabs, they are another material that could address $\mathrm{NO}_{\mathrm{x}}$ pollution. Lab investigation of blinding by prevailing roadway pollutants did not find evidence of a substantial decrease in performance at normally observed field loadings. Reaction products did cause blinding; however, the performance decrease was asymptotic and a complete loss of activity was not observed. In disagreement with previous reports, preliminary results did not observe easy photoactivity regeneration. The first phase of an ongoing field study did not find evidence that NO concentration in a photocatalytic section was lower than NO concentration in a control section. The most probable explanations for this observation are excess vibration, which caused mixture segmentation, and insufficient NO oxidation rate.
\end{abstract}




\section{CHAPTER 1. GENERAL INTRODUCTION}

\section{Introduction}

Nitrogen dioxide $\left(\mathrm{NO}_{2}\right)$ is a hazardous air pollutant subject to National Ambient Air Quality Standards (NAAQS). Multiple reports have found an association between $\mathrm{NO}_{2}$ exposure and adverse respiratory symptoms such as asthma and chronic obstructive pulmonary disease (USEPA, 2008). In the 2010 revisions of NAAQs, the $\mathrm{NO}_{2}$ standard was strengthened by supplementing the existing annuallyaveraged $53 \mathrm{ppbv} \mathrm{NO}$. primary and secondary standard with a primary standard that designates an area as nonattainment if the 3-year average of the $98^{\text {th }}$ percentile of the annual distribution of the daily maximum 1-hour average $\mathrm{NO}_{2}$ concentrations exceeds 100 ppbv (Primary National Ambient Air Quality Standards for Nitrogen Dioxide: Final Rule, 2010).

When discussing $\mathrm{NO}_{2}$ pollution, the term $\mathrm{NO}_{\mathrm{x}}$ (which denotes oxides of nitrogen) is used. This term is used because $\mathrm{NO}_{2}$ is easily transformed into different species. In fact within the $\mathrm{NO}_{\mathrm{x}}$ category, $\mathrm{NO}_{2}$ represents only about $5 \%$ of the $\mathrm{NO}_{\mathrm{x}}$ emissions (USEPA, 2001). Therefore, if overall $\mathrm{NO}_{2}$ concentrations are to be lowered, efforts must target the primary $\mathrm{NO}_{\mathrm{x}}$ species emitted, nitric oxide (NO).

Near-road environments represent a significant area of concern for $\mathrm{NO}_{\mathrm{x}}$ pollution. In these areas, the motor vehicle emissions of $\mathrm{NO}$ raises the overall concentration of $\mathrm{NO}_{\mathrm{x}}$ by $30 \%$ to $100 \%$ in comparison to area-wide concentrations (USEPA, 2010). USEPA considers approximately 48 million people (i.e., more than $15 \%$ of the U.S. population) to be at risk of $\mathrm{NO}_{2}$-associated health effects because they live within $90 \mathrm{~m}$ (300 ft) of a four-lane (or greater) highway, railroad, or airport (Primary National Ambient Air Quality Standards for Nitrogen Dioxide: Proposed Rule, 2009).

The localized nature of this $\mathrm{NO}_{\mathrm{x}}$ pollution issue has driven the development of novel technologies to maintain ambient concentrations at below the NAAQS standards. Photocatalytic pavements represent an innovative approach to pollution mitigation which is uniquely suited to near-road environments. When exposed to sunlight, titanium dioxide $\left(\mathrm{TiO}_{2}\right)$ contained within these pavements generates hydroxyl radicals $\left({ }^{\circ} \mathrm{OH}\right)$. This compound initiates oxidation reactions that convert $\mathrm{NO}$ or $\mathrm{NO}_{2}$ into nitrate $\left(\mathrm{NO}_{3}{ }^{-}\right)$, a species that remains on the pavements surface.

The great potential of photocatalytic pavements has drawn multiple academic, government, and industrial bodies to recently invest resources into the development and application of this technology in 
North America and Europe (see Figure 1.1 and Figure 1.2). Research by academic institutions in particular has found that $\mathrm{NO}$ oxidation reactions catalyzed by $\mathrm{TiO}_{2}$-containing pavements are highly sensitive to a variety of environmental and material variables. For some variables substantial investigation has been completed, although without development of a consensus on expected performance. In other areas, the published record of research is nearly void. These research gaps can be placed in three categories: fundamentals, deactivation, and field.

To provide fundamental knowledge, various researchers have published accounts of laboratory studies that evaluated photocatalytic pavement specimens within a photoreactor, an experimental apparatus that allows for the control of various environmental conditions (e.g., Ballari \& Brouwers, 2013; Ballari et al., 2009; Beeldens, 2008; Dylla et al., 2010; Hüsken et al., 2009; and Murata et al., 2000). Independent variables investigated have included NO concentration, irradiance, gas flow rate, and relative humidity. Results presented to date have not brought about a consensus in terms of the impact of environmental variables on the NO oxidation rate. Available literature is also vague in terms of the relationship between slab temperature and NO oxidation. Pervious concrete pavements, which are already employed in efforts to minimize the negative effects of stormwater, could also be used to address air pollution. Due to increased void content, pervious pavements have an increased specific surface area as compared to conventional concrete pavement mixes. This increased specific surface area could result in increased NO oxidation rate. 


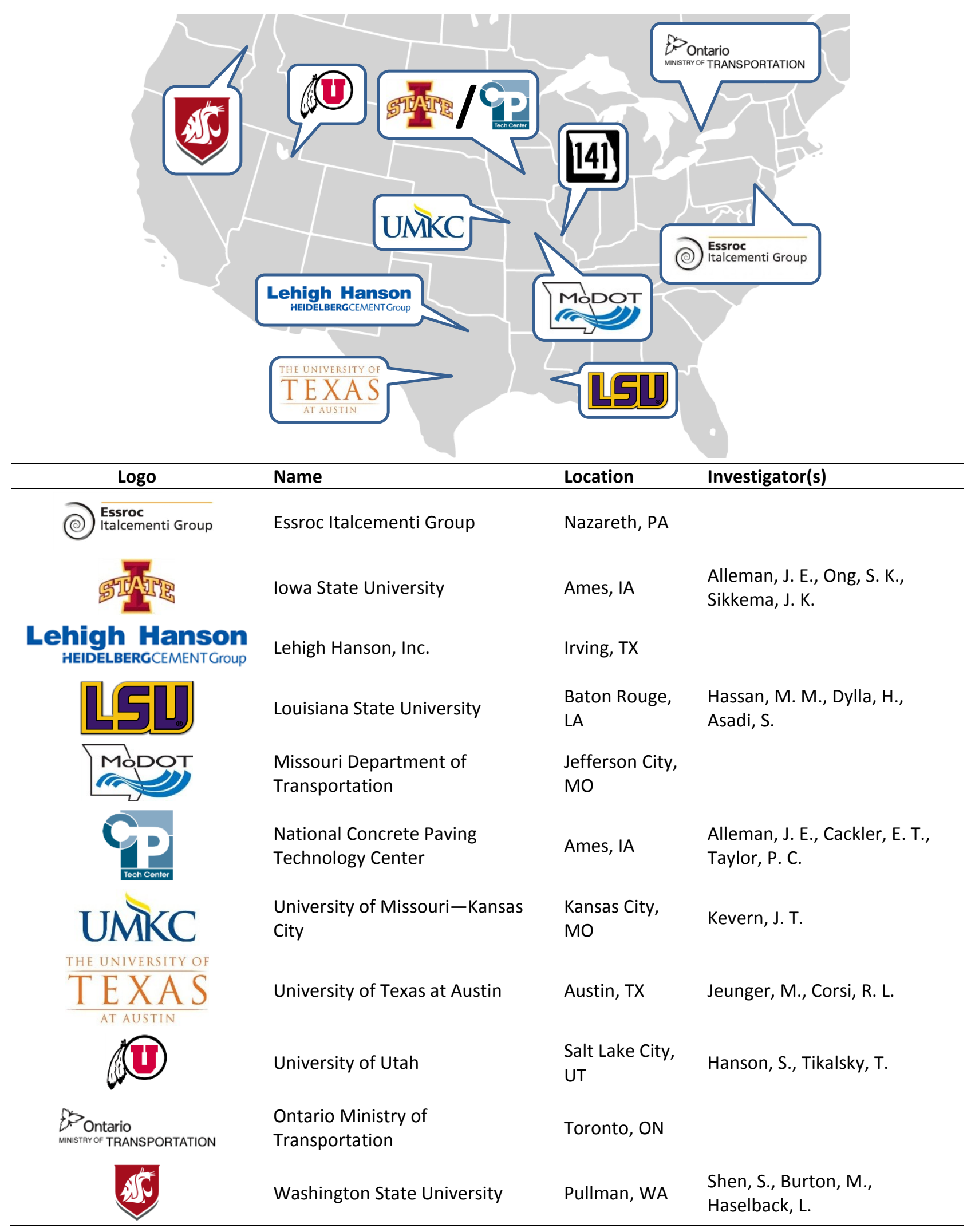

Figure 1.1. Photocatalytic pavement research activity within North America. 


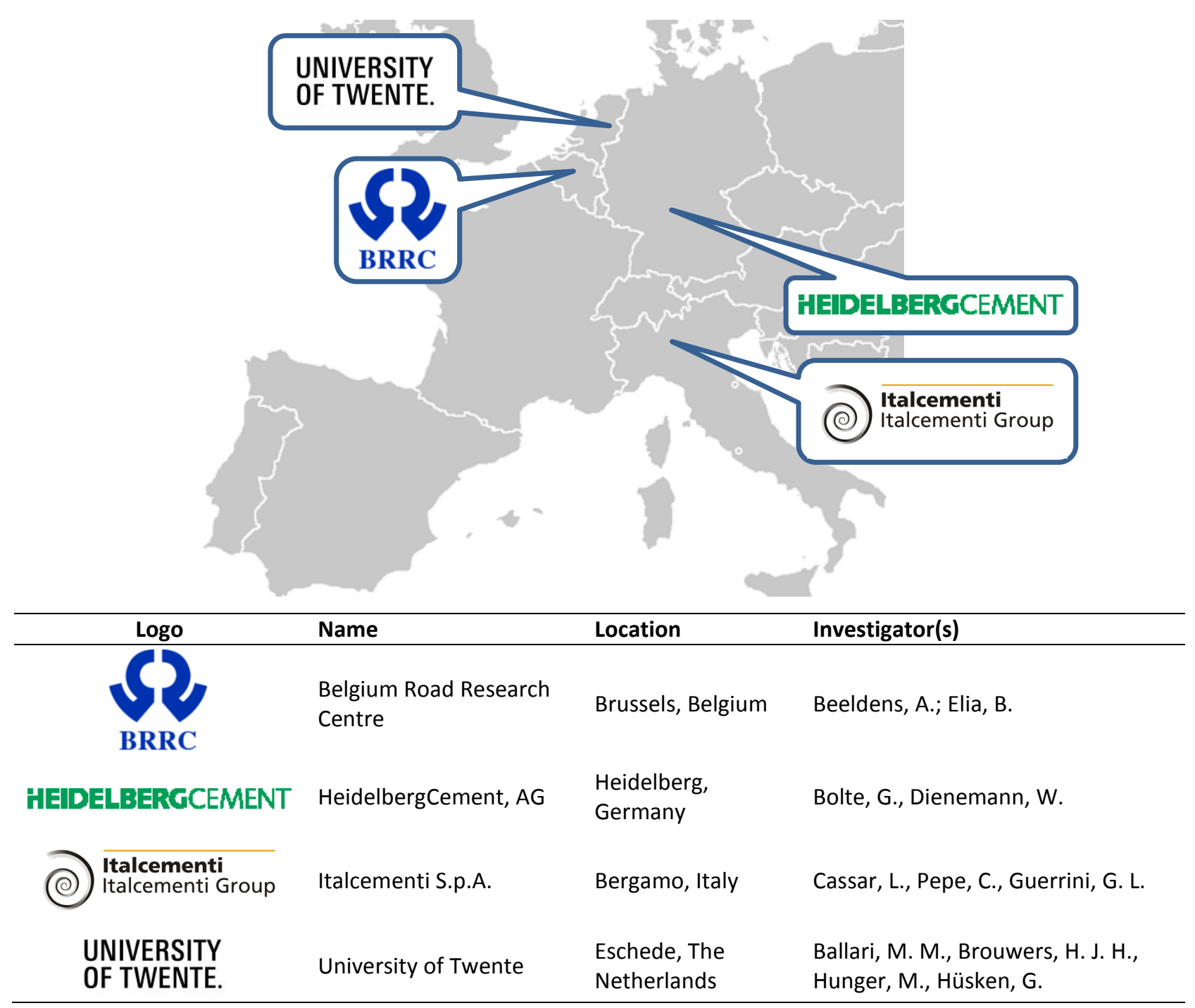

Figure 1.2. Photocatalytic pavement research activity within Europe.

When placed in the field environments, a variety of roadway pollutants or even reaction products may act to blind the pavement by preventing UV light from reaching $\mathrm{TiO}_{2}$ particles. Observed reductions in NO can be significant and in lab studies have been reported to range between 22 and $88 \%$ (Dylla et al., 2011; Murata \& Tobinai, 2002; Yu, 2003). In order to avoid an intolerable reduction in pollution removal performance, the pollutants that result in the greatest decrease in NO removal rate must be identified. For $\mathrm{TiO}_{2}$ pavements exposed to $\mathrm{NO}_{x}$, it is also possible that the accumulation of the reaction products-nitrate $\left(\mathrm{NO}_{3}{ }^{-}\right)$and nitrous acid $\left(\mathrm{HNO}_{2}\right)$-may cause a reduction in oxidation. Although it is expected that, under field conditions, these species will be less prevalent on the pavement than other substances that interfere with the pavement's photocatalytic properties, accumulation of these reaction 
products could have a disproportionately negative impact on $\mathrm{NO}_{\mathrm{x}}$ oxidation performance because they are generated at the locations of photocatalytic activity.

While available research record has provided valuable insights into photocatalytic degradation of $\mathrm{NO}_{\mathrm{x}}$ by concrete pavement containing $\mathrm{TiO}_{2}$, in order for this technology to be adopted by potential stakeholders and implemented as an air pollution mitigation strategy, research must advance and address prevalent knowledge gaps. This study makes an incremental step towards filling in known gaps by addressing the following objectives: (1) summarize the current photocatalytic pavement performance, as well as highlight data gaps and research needs, (2) provide fundamental knowledge of the performance of photocatalytic pavement in regards to changes in various environmental and material variables (3) identify and evaluate the impact of species that blind photocatalytic reactions, and (4) document performance of photocatalytic concrete pavement in field conditions.

\section{Dissertation Organization}

This dissertation focuses on photocatalytic degradation of $\mathrm{NO}_{\mathrm{x}}$ by concrete pavement containing $\mathrm{TiO}_{2}$. The dissertation is organized in paper format and Chapters 2, 4, 5, and 7 are written as journal articles. Chapter 2 delivers a literature review on the application of photocatalytic pavements for the mitigation of $\mathrm{NO}_{\mathrm{x}}$ pollution. In this review, the mass transfer and kinetic processes necessary for the overall photocatalytic reaction are only discussed briefly. These processes undergird both lab and field applications; therefore, Chapter 3 provides a review and application of appropriate literature to demonstrate that, at lab and field scales, oxidation of NO is limited by adsorption and reaction of the reactant; consequently mass transfer is not a rate-limiting step. With a historical context and scientific basis established, Chapter 4 investigates the NO oxidation under varied environmental conditions. This investigation includes analysis of previously studied variables (e.g., NO concentration, UV-A irradiance, and relative humidity) in order to determine whether significant differences exist in the behavior of different photocatalytic concrete pavement materials. In addition, the investigation of previously unstudied variables (i.e., temperature and slab water loss) provides expanded knowledge on the factors which will affect field performance. Chapter 5 evaluates pervious photocatalytic concrete in comparison with a photocatalytic mortar slab, both of which were manufactured with the same type of photocatalytic cement and water-to-cement ratios. Chapter 6, an investigation in the fouling category, analyzes the impact of roadway pollutants and reaction products on NO oxidation at loading rates that could be expected to occur at field sites. Chapter 7 delivers preliminary results of an in-progress field 
evaluation on Route 141 in Missouri. Chapter 8 concludes this dissertation, summarizes the findings from preceding chapters, and recommends future work.

\section{References}

Ballari, M. M., \& Brouwers, H. J. H. (2013). Full scale demonstration of air-purifying pavement. Journal of hazardous materials, 254-255, 406-414. doi: 10.1016/j.jhazmat.2013.02.012

Ballari, M. M., Hunger, M., Hüsken, G., \& Brouwers, H. J. H. (2009). Heterogeneous Photocatalysis Applied to Concrete Pavement for Air Remediation. Paper presented at the 3rd International Symposium on Nanotechnology in Construction (NICOM 3), Prague, Czech Republic.

Beeldens, A. (2008). Air purification by pavement blocks: final results of the research at the BRRC. Ljubljana, Slovenia.

Dylla, H., Hassan, M. M., Mohammad, L. N., Rupnow, T., \& Wright, E. (2010). Evaluation of Environmental Effectiveness of Titanium Dioxide Photocatalyst Coating for Concrete Pavement. Transportation Research Record: Journal of the Transportation Research Board, 2164(-1), 46-51. doi: 10.3141/2164-06

Dylla, H., Hassan, M. M., Schmitt, M., Rupnow, T., Mohammad, L. N., \& Wright, E. (2011). Effects of Roadway Contaminants on Titanium Dioxide Photodegradation of NOx. Paper presented at the Transportation Research Board 90th Annual Meeting, Washington, DC.

Hüsken, G., Hunger, M., \& Brouwers, H. J. H. (2009). Experimental study of photocatalytic concrete products for air purification. Building and Environment, 44(12), 2463-2474. doi: DOI 10.1016/j.buildenv.2009.04.010

Murata, Y., Kamitani, K., \& Takeuchi, K. (2000). Air Purifying Blocks Based on Photocatalysis. Paper presented at the Japan Interlocking BLock Pavement Engineering Association World Congress 2000, Tokyo, Japan.

Murata, Y., \& Tobinai, K. (2002). Influence of various factors on NOx removal performance of permeable interlocking block based on photocatalysis. Journal of Structural and Construction Engineering(Transactions of AIJ)(555), 9-15.

Primary National Ambient Air Quality Standards for Nitrogen Dioxide: Final Rule, 75 Fed. Reg. 6474 (2010) (to be codified at 40 C.F.R. pts. 50 and 58).

Primary National Ambient Air Quality Standards for Nitrogen Dioxide: Proposed Rule, 75 Fed. Reg. 34404 (2009) (to be codified at 40 C.F.R. pts. 50 and 58).

USEPA. (2001). National Air Quality and Emissions Trends Report, 1999. (EPA 454/R-01-004). Washington, D.C. 
USEPA. (2008). Integrated Science Assessment for Oxides of Nitrogen - Health Criteria (Final Report). (EPA/600/R-08/071, 2008). Washington, D.C.

USEPA. (2010). Final Regulatory Impact Analysis (RIA) for the $\mathrm{NO}_{2}$ National Ambient Air QUality Standards (NAAQS). Research Triangle Park, NC: Retrieved from http://www.epa.gov/ttnecas1/regdata/RIAs/FinalNO2RIAfulldocument.pdf.

Yu, J. C. (2003). Deactivation and Regeneration of Environmentally Exposed Titanium Dioxide (TiO2) Based Products Hong Kong. 


\title{
CHAPTER 2. PHOTOCATALYTIC OXIDATION OF NO BY PAVEMENT CONTAINING TIO $_{2}$ : REVIEW
}

A paper to be submitted to the Journal of the Air \& Waste Management Association

\author{
J.K. Sikkema ${ }^{1}$, J.E. Alleman ${ }^{2}$, and S.K. Ong ${ }^{2}$
}

\begin{abstract}
1. Abstract
Pavements containing the photocatalyst $\mathrm{TiO}_{2}$ exhibit unique properties, which result in the oxidation of both organic and inorganic pollutants, including $\mathrm{NO}_{\mathrm{x}}$. These pavements can serve as a new $\mathrm{NO}_{\mathrm{x}}$ pollution mitigation technology for U.S. stakeholders, thereby improving the sustainability of the transportation sector. Multiple lab-based photoreactor studies have demonstrated photo-induced oxidation of $\mathrm{NO}_{x}$ and found relationships between various environmental (e.g., UV irradiance, relative humidity, $\mathrm{NO}_{x}$ concentration, $\mathrm{NO}_{2} / \mathrm{NO}_{\mathrm{x}}$ ratio, and flow rate), materials (e.g., $\mathrm{TiO}_{2}$ content, $\mathrm{TiO}_{2}$ properties, and mix design), and operational (e.g., blinding by environmental contaminants and pavement age) factors. Limited field monitoring has provided data that supports laboratory research at a variety of locations and pavement types (e.g., concrete, paving blocks, and spray coatings). While the body of literature is substantial, future research must strengthen the link between photoreactor and field studies, determine the environmental variables with the greatest impact on the $\mathrm{NO}_{\mathrm{x}}$ oxidation rate, and develop models to facilitate selection of roadways for which the maximum abatement of $\mathrm{NO}_{\mathrm{x}}$ pollution can be achieved.
\end{abstract}

\section{Introduction}

Titania serves as the common name for titanium dioxide $\left(\mathrm{TiO}_{2}\right)$ and fictional literature's often-used name for the queen of the fairies. This dual meaning provides an uncanny allusion to the compound's nearly magical photocatalytic degradation of a broad set of organic and inorganic pollutants. The publication by Keidel (1929), which documented fading of $\mathrm{TiO}_{2}$-containing paints, represents the first known account of this compound's photo-induced capabilities. A subsequent study documented $\mathrm{TiO}_{2}{ }^{-}$ initiated bleaching of dyes (Goodeve \& Kitchener, 1938). In the 1960s, Fujishima and Honda (1972) carried out the first research yielding the potential for practical applications. Their study found that light (at a wavelength below $415 \mathrm{~nm}$ ) induced a photocurrent between $\mathrm{TiO}_{2}$ and platinum electrodes

\footnotetext{
${ }^{1}$ Instructor; Engineering, Dordt College, Sioux Center, lowa

${ }^{2}$ Professor; Civil, Construction, and Environmental Engineering, lowa State University, Ames, lowa
} 
immersed in an aqueous solution, resulting in oxygen and hydrogen evolution. Following this discovery, initial research was focused on enhancements to water decomposition and by 1977 researchers began studying environmental applications. Frank and Bard (1977) employed $\mathrm{TiO}_{2}$ as a photocatalyst to oxidize cyanide ions, which frequently occur as a by-product of industrial processes. In this study, a sample's cyanide concentration was reduced by up to $54 \%$ when illuminated by a xenon lamp for 30 min in the presence of $\mathrm{TiO}_{2}$. When samples were placed in sunlight for two days, in excess of $99 \%$ cyanide removal was observed. These new findings channeled interest towards environmental applications that address aqueous and airborne pollutants.

Photocatalytic degradation of nitrogen oxides $\left(\mathrm{NO}_{\mathrm{x}}\right)$ from on-road motor vehicles by pavement containing $\mathrm{TiO}_{2}$ has generated a substantial amount of research interest as an environmental application of this compound. $\mathrm{NO}_{\mathrm{x}}$ emissions result in a variety of detrimental effects to both respiratory systems and the natural ecosystem. For example, $\mathrm{NO}_{\mathrm{x}}$ contributes to the formation of tropospheric ozone when reacted with volatile organic compounds (VOCs) in the presence of sunlight (USEPA, 1999). Within the $\mathrm{NO}_{\mathrm{x}}$ group of compounds, nitrogen dioxide $\left(\mathrm{NO}_{2}\right)$ raises the most significant human health concerns. This compound is toxic when inhaled at high concentrations and can cause respiratory ailments (e.g., respiratory infections, bronchitis, and emphysema) at part-per-billion by volume (ppbv) levels of exposure (USEPA, 2008).

Although $\mathrm{NO}_{2}$ raises the greatest public health concerns, the United States Environmental Protection Agency (USEPA) has estimated that approximately 95\% of emissions in the $\mathrm{NO}_{\mathrm{x}}$ category are in the form of nitric oxide (NO) (USEPA, 2001). However, within the atmosphere $\mathrm{NO}_{x}$ compounds can readily be transformed into $\mathrm{NO}_{2}$; therefore, strategies to minimize $\mathrm{NO}_{2}$ pollution often focus on $\mathrm{NO}$ emissions. Furthermore, due to the reactivity of $\mathrm{NO}_{x}$ species, USEPA treats all $\mathrm{NO}_{x}$ emissions as $\mathrm{NO}_{2}$ (USEPA, 2001). Within the United States, on-road motor vehicles account for $34 \%$ of $\mathrm{NO}_{2}$ emissions (USEPA, 2001). An estimated 48 million people (i.e., more than $15 \%$ of the U.S. population) live within $90 \mathrm{~m}(300 \mathrm{ft}$ ) of fourlane (or larger) highway, railroad, or airport and are exposed to elevated concentrations of $\mathrm{NO}_{\mathrm{x}}$ (Primary National Ambient Air Quality Standards for Nitrogen Dioxide: Proposed Rule, 2009; Thoma et al., 2008). Furthermore, multiple health studies have linked an increase in the observation of negative health effects with the proximity of people to major roadways (Brauer et al., 2002; Brunekreef et al., 1997; Finkelstein et al., 2004; Garshick et al., 2003; Kim et al., 2004). 
Conventional efforts to mitigate transportation sector air pollution are focused on alternative vehicles and fuels, transportation policy, and emissions control technologies (Clean Air Act, 2008; USEPA, 2007). These strategies have reached a point where additional improvements in air quality will require novel approaches and significant expense. Advances in photocatalytic concrete pavements provide a new pathway to improve the sustainability of transportation by reducing the negative impacts associated with vehicle emissions. Photocatalytic reactions cause oxidation of a variety of organic and inorganic pollutants. Notably, the photocatalytic property of these pavements causes oxidation of $\mathrm{NO}_{\mathrm{x}}$. To foster research in photocatalytic degradation of motor vehicle pollution by pavement containing titanium dioxide, the following sections examine the field and identify research needs. While these pavements catalyze oxidation of a variety of organic and inorganic pollutants, this review places focus on reactions with $\mathrm{NO}_{\mathrm{x}}$.

\section{Regulatory Drivers and Conventional Mitigation Strategies}

Within the United States, efforts to minimize the atmospheric concentration of $\mathrm{NO}_{\mathrm{x}}$ from on-road motor vehicles are driven by the National Ambient Air Quality Standards (NAAQS) and vehicle emissions standards. Both of these regulatory classes receive their authority from the Clean Air Act (CAA) and subsequent amendments (Clean Air Act, 2008).

$\mathrm{NO}_{2}$ is one of six criteria pollutants regulated by National Ambient Air Quality Standards (NAAQS) because exposure can cause infections, bronchitis, and emphysema (USEPA, 2008). NOx also presents other environmental concerns; small particles formed by reaction of $\mathrm{NO}_{\mathrm{x}}$ with moisture and ammonia cause lung damage and $\mathrm{NO}_{x}$ represents a critical step in formation of tropospheric ozone, yet another NAAQS criteria pollutant due to detrimental effects to natural ecosystems and the respiratory system. VOC emissions, while not regulated by NAAQS, are also of similar concern because $\mathrm{NO}_{\mathrm{x}}$ and VOC reactions in the presence of sunlight generate ozone (USEPA, 1999).

USEPA NAAQS establish primary standards, which protect public health, and secondary standards, which protect public welfare (Clean Air Act, 2008, § 7409(b)). 2010 revisions strengthened the NAAQS for $\mathrm{NO}_{2}$ by supplementing the existing annually averaged $53 \mathrm{ppbv} \mathrm{NO}_{2}$ primary and secondary standards with a primary standard that designates an area as nonattainment if the 3-year average of the $98^{\text {th }}$ percentile of the annual distribution of the daily maximum 1-hour average $\mathrm{NO}_{2}$ concentrations exceeds 100 ppbv (Primary National Ambient Air Quality Standards for Nitrogen Dioxide: Final Rule, 2010). 
With use of data from an existing network of 409 area-wide $\mathrm{NO}_{2}$ monitors (i.e., monitors located to measure $\mathrm{NO}_{2}$ on a neighborhood or larger scale), USEPA found one location in nonattainment of the 100 ppb standard (USEPA, 2010a). However, the 2010 final rule also requires installation of near-road $\mathrm{NO}_{2}$ monitors by 2013. These monitor must be located within $50 \mathrm{~m}$ of a road segment that is selected on the basis of annual average daily traffic (AADT), but placement also requires consideration of "fleet mix, congestion patterns, terrain, geographic location, and meteorology" (USEPA, 2010b). In these near-road locations, $\mathrm{NO}_{2}$ concentrations are $30 \%$ to $100 \%$ higher than area-wide concentrations (USEPA, 2010c). When developing the regulation's impact assessment, USEPA did not have adequate data to predict which areas may violate the new 100 ppbv standard after these monitors are installed. The agency concluded "the possibility exists that there may be many more (emphasis added) potential nonattainment areas than have been analyzed" (Primary National Ambient Air Quality Standards for Nitrogen Dioxide: Final Rule, 2010).

A USEPA nonattainment designation has multiple and sometimes severe consequences. Within 18 months after an area within a state is designated nonattainment for $\mathrm{NO}_{2}$, the state must submit a state implementation plan (SIP). This plan must detail the control techniques that the state will employ in order to both attain and maintain the NAAQS (Clean Air Act, 2008, § 7510). To aid SIP preparation USEPA issues information on control technologies-including data on installation and operation cost and emissions reductions-to the States (Clean Air Act, 2008, § 7508(b)). Transportation often contributes substantially to criteria pollutant emissions. USEPA provides specific control measures to control these emissions including the following: improving public transportation, establishing lanes for high occupancy vehicles, and facilitating non-automobile travel (Clean Air Act, 2008, $\S 7508(e)$ ). If a state's implementation plan fails to meet the various requirements found in the CAA, the USEPA administrator can impose austere highway and offset sanctions. Highway sanctions allow the administrator to bar the Secretary of Transportation from awarding Title 23 projects or grants, with the exception of those for which safety improvement is the principal purpose (Clean Air Act, 2008, § 7509(b)). For areas that USEPA designates as nonattainment, construction and operation of facilities that will emit criteria pollutants requires either an emissions reduction-or offset-from existing sources or construction in a location that will not contribute to the emissions that exceed the applicable standard. For an area that fails to attain NAAQS, the administrator can increase this offset of emissions reduction to increased emissions to a ratio of 2 to 1 (Clean Air Act, 2008, § 7509(b)). 


\subsection{Motor Vehicle Emissions Standards}

As noted, within the United States, on-road motor vehicles account for $34 \%$ of $\mathrm{NO}_{2}$ emissions

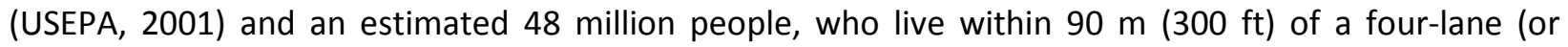
larger) highway, railroad, or airport, are exposed to elevated concentrations of $\mathrm{NO}_{\mathrm{x}}$ (Primary National Ambient Air Quality Standards for Nitrogen Dioxide: Proposed Rule, 2009; Thoma et al., 2008). The significance of these emissions, both in terms of the proportion of total $\mathrm{NO}_{\mathrm{x}}$ emissions and health impact, has resulted in promulgation of tailpipe $\mathrm{NO}_{\mathrm{x}}$ emissions standards by USEPA. Categories of onroad vehicles include light-duty vehicles, light-duty trucks, and medium-duty passenger vehicles, heavyduty highway compression-ignition engines and urban buses. For light-duty vehicles, light-duty trucks, and medium-duty passenger vehicles newer than model year 2004, USEPA has established 8 emissions categories (termed "bins"). $\mathrm{NO}_{\mathrm{x}}$ emissions limits [at full useful vehicle life, approximately 160,000$190,000 \mathrm{~km}(100,000-120,000 \mathrm{miles})]$ in these bins range from 0.00 to $0.12 \mathrm{~g} \cdot \mathrm{km}^{-1}\left(0.20 \mathrm{~g} \cdot \mathrm{mi}^{-1}\right)$ (USEPA, 2007). Auto manufacturers may sell vehicles that fall into any of the 8 bins, but the average emissions limit of all vehicles sold must fall below the bin $5 \mathrm{limit}, 0.04 \mathrm{~g} \cdot \mathrm{km}^{-1}\left(0.07 \mathrm{~g} \cdot \mathrm{mi}^{-1}\right)$ (USEPA, 2012a). Heavyduty highway compression-ignition engines and urban buses are regulated by a separate set of emissions standards. For model year 2010 and newer vehicles, $\mathrm{NO}_{\mathrm{x}}$ emissions are limited to $0.27 \mathrm{~g} \cdot \mathrm{kW}$ $\mathrm{h}^{-1}$ (0.2 grams per brake horsepower-hour) (Control of emissions from new and in-use highway vehicles and engines, 2008).

For vehicles in the light-duty category, the present bin 5 emissions limit represents a $98 \%$ reduction from emissions prior to implementation of standards (USEPA, 2007). For heavy-duty vehicles, the noted limits are a 98\% reduction from 1985 emissions limits (USEPA, 2012b). To achieve these levels of $\mathrm{NO}_{\mathrm{x}}$ emission control requires advanced and expensive tailpipe control equipment. For example, retrofit installation of a selective catalytic reduction device on a heavy-duty vehicle diesel engine costs between $\$ 12,000$ and $\$ 20,000$ when installed with an oxidation catalyst or costs between $\$ 15,000$ and $\$ 25,000$ when installed with a diesel particulate filter (MECA, 2007).

\section{Principles of $\mathrm{NO}_{x}$ Oxidation by Photocatalytic Pavement}

Similar to any other productive effort, the law of diminishing marginal returns governs the effectiveness of conventional $\mathrm{NO}_{x}$ mitigation strategies. In these efforts, each additional dollar spent is used less efficiently because the spending results in smaller and smaller marginal gains. In the case of conventional $\mathrm{NO}_{\mathrm{x}}$ mitigation strategies, each additional dollar spent results in diminishing marginal 
reductions in ambient $\mathrm{NO}_{x}$ concentrations. In the case of ambient $\mathrm{NO}_{x}$ pollution, documented negative health effects for those who live in near-road microenvironments indicate that further reductions in $\mathrm{NO}_{x}$ should be sought. However, if a point of low marginal returns has been reached, achieving this goal with conventional strategies will be expensive. In order to achieve desired health impacts in a manner that efficiently uses whatever funding is available, stakeholders should consider $\mathrm{NO}_{\mathrm{x}}$ mitigation strategies that fall outside of the current paradigm and are governed by a separate input-output curve (i.e., dollars spent vs. $\mathrm{NO}_{\mathrm{x}}$ reduction). Photocatalytic pavements are one of these new-paradigm strategies for motor-vehicle pollution abatement. This technology must be evaluated with further laboratory and field research.

Pavement-specific literature refers to $\mathrm{NO}_{x}$ degradation as the DeNOx-process. This process has one stage for $\mathrm{NO}_{2}$, two stages for $\mathrm{NO}$, and is illustrated in Figure 2.1. The process begins when $\mathrm{NO}_{\mathrm{x}}$ adsorbs on sites where ${ }^{\bullet} \mathrm{OH}$ is generated by exposed $\mathrm{TiO}_{2}$. Adsorbed $\mathrm{NO}$ is oxidized to $\mathrm{NO}_{2}$ by the ${ }^{\bullet} \mathrm{OH}$. $\mathrm{NO}_{2}$, both adsorbed from the air and formed by oxidation of $\mathrm{NO}$, then oxidized to nitrate $\left(\mathrm{NO}_{3}{ }^{-}\right)$. It is possible for $\mathrm{NO}_{3}{ }^{-}$to be bound to pavement surface by an alkali, but it is most probable that this product is flushed by water from the surface (Hüsken et al., 2009). The high probability that $\mathrm{NO}_{3}{ }^{-}$will be washed from the surface can be attributed to another unique photo-induced $\mathrm{TiO}_{2}$ property, superhydrophilicity. Under sunlight, water on the surface of a pavement containing $\mathrm{TiO}_{2}$ spreads into a thin film with a contact angle of nearly zero degrees. This low contact angle allows water to penetrate between the pavement's surface and adsorbed material such as particulates, oil, and organisms. This penetration lifts and flushes material from the surface (Fujishima \& Zhang, 2006). Concentration of reaction products (i.e., $\mathrm{NO}_{2}{ }^{-}$and $\mathrm{NO}_{3}{ }^{-}$) has not been measured in the field, but one report estimates a maximum concentration of 1.2 $\mathrm{mg} \cdot \mathrm{L}^{-1}-\mathrm{N}$, a value far below USEPA's $10 \mathrm{mg} \cdot \mathrm{L}^{-1}-\mathrm{N}$ standard for drinking water (City Concept, 2004; USEPA, 2009). 


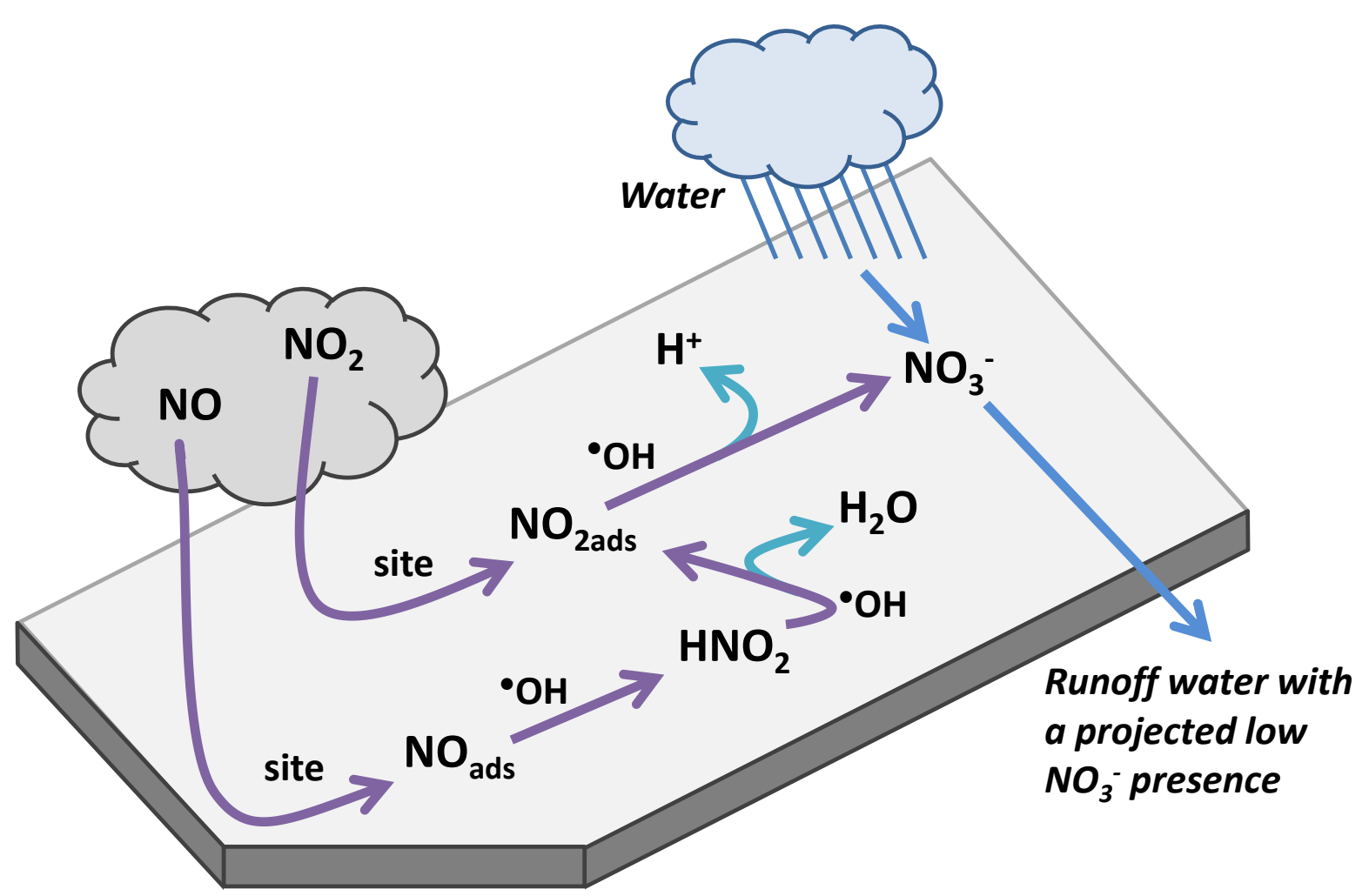

Figure 2.1. Photocatalytic oxidation of $\mathrm{NO}$ and $\mathrm{NO}_{2}$ by concrete pavement containing $\mathrm{TiO}_{2}$.

Photocatalytic pavements represent a novel approach that may serve as a means to effectively mitigate $\mathrm{NO}_{\mathrm{x}}$ pollution. Current research has not expanded beyond this pollution abatement effort. However, it should be noted that $\mathrm{TiO}_{2}$-based photocatalysts degrade an extensive range of both organic and inorganic pollutants, which may well result in additional pollution abatement benefits (Beeldens et al., 2011).

The wide range of pollutants degraded by $\mathrm{TiO}_{2}$-based photocatalysts is highly desirable considering that 1162 different air toxics are found on the USEPA's Master List of Compounds Emitted by Mobile Sources because these compounds are known or suspected to cause cancer or other serious health and environmental effects (USEPA, 1994, 2006). For the USEPA, monitoring all mobile source air toxics is impractical. In their case, the following six criteria pollutants have been selected as indicators of air quality: carbon monoxide, lead, nitrogen oxides, ozone, particulate matter, and sulfur oxides. Table 2.1 uses a similar approach to indicate the suitability of $\mathrm{TiO}_{2}$ photocatalysts as a means to mitigate mobile source pollution. Notably, this table replaces ozone with VOCs because ozone is not emitted directly and VOCs are a precursor to tropospheric ozone. With the exception of particulate matter, photocatalytic 
reactions have been reported for each pollutant. Furthermore, with the exception of lead, each reaction occurs in the gas phase.

Table 2.1. Emissions and $\mathrm{TiO}_{2}$-based photocatalytic reactions for mobile source pollutant indicators.

\begin{tabular}{|c|c|c|c|c|c|}
\hline Pollutant & $\begin{array}{l}\text { Estimated U.S. } \\
\text { emissions from } \\
\text { on-road vehicles } \\
\text { (10 }{ }^{3} \text { metric tons) } \\
\text { (USEPA, 2001) }\end{array}$ & $\begin{array}{l}\text { Percent of total } \\
\text { U.S. emissions } \\
\text { from on-road } \\
\text { vehicles (\%) } \\
\text { (USEPA, 2001) }\end{array}$ & $\begin{array}{l}\text { Selected } \\
\text { associated } \\
\text { species }\end{array}$ & $\begin{array}{l}\mathrm{TiO}_{2} \text {-based photocatalytic } \\
\text { reactions }\end{array}$ & $\begin{array}{l}\text { Reaction } \\
\text { references }\end{array}$ \\
\hline Carbon monoxide & 45,350 & 51 & $\mathrm{CO}$ & $\mathrm{CO}+\mathrm{O}^{*} \rightarrow \mathrm{CO}_{2}$ & $\begin{array}{l}\text { (Hwang et al., } \\
\text { 2003) }\end{array}$ \\
\hline Lead $^{\mathrm{iii}}$ & 0.02 & 0.52 & $\mathrm{~Pb}(\mathrm{II})$ & $\begin{array}{l}{ }^{\bullet} \mathrm{R}+\mathrm{Pb}(\mathrm{II}) \rightarrow \mathrm{R}_{\mathrm{Ox}}+\mathrm{Pb}(\mathrm{I}) \\
\text { (inhibited by oxygen, best } \\
\text { suited for aqueous } \\
\text { treatment) }\end{array}$ & $\begin{array}{l}\text { (Murruni et } \\
\text { al., 2008) }\end{array}$ \\
\hline Nitrogen dioxide & 7,793 & 34 & $\mathrm{NO}_{2}, \mathrm{NO}$ & $\begin{array}{l}\mathrm{NO}_{2}+{ }^{\bullet} \mathrm{OH} \rightarrow \mathrm{NO}_{3}^{-}+\mathrm{H}^{+}, \\
\mathrm{NO}+2^{\bullet} \mathrm{OH} \rightarrow \mathrm{NO}_{2}+\mathrm{H}_{2} \mathrm{O}\end{array}$ & $\begin{array}{l}\text { (Dalton et al., } \\
\text { 2002) }\end{array}$ \\
\hline $\begin{array}{l}\text { Volatile organic } \\
\text { compounds (VOCs) }\end{array}$ & 4,805 & 29 & $\begin{array}{l}\mathrm{C}_{4} \mathrm{H}_{6}, \mathrm{C}_{6} \mathrm{H}_{5} \mathrm{CH}_{3} \\
\mathrm{C}_{8} \mathrm{H}_{10}, \mathrm{CH}_{2} \mathrm{O} \\
\mathrm{C}_{4} \mathrm{H}_{9} \mathrm{OH} \\
\left(\mathrm{CH}_{3}\right)_{2} \mathrm{CO} \\
\mathrm{CH}_{3}\left(\mathrm{CH}_{2}\right)_{2} \mathrm{CHO}\end{array}$ & Multiple reactions possible & $\begin{array}{l}\text { (Obee \& } \\
\text { Brown, 1995; } \\
\text { Peral \& Ollis, } \\
\text { 1992) }\end{array}$ \\
\hline $\begin{array}{l}\text { Particulate matter } \\
{\text { (diameter }<10 \mu \mathrm{m})^{\mathrm{iv}}}\end{array}$ & 268 & 1.2 & N/A & N/A & \\
\hline $\begin{array}{l}\text { Particulate matter } \\
(\text { diameter }<2.5 \mu \mathrm{m})^{\text {iv }}\end{array}$ & 208 & 3.4 & N/A & N/A & \\
\hline Sulfur dioxide ${ }^{\mathrm{ii}}$ & 329 & 1.9 & $\mathrm{SO}_{2}, \mathrm{HOSO}_{2}$ & $\begin{array}{l}{ }^{\bullet} \mathrm{OH}+\mathrm{SO}_{2} \rightarrow \mathrm{HOSO}_{2}, \\
\mathrm{HOSO}_{2}+\mathrm{O}^{*} \rightarrow{ }^{\bullet} \mathrm{OH}+\mathrm{SO}_{3}\end{array}$ & $\begin{array}{l}\text { (Zhao et al., } \\
\text { 2009) }\end{array}$ \\
\hline \multicolumn{6}{|c|}{$\begin{array}{l}\text { 'List excludes ozone because this species is not emitted directly. VOCs are listed instead because reactions between VOCs and } \\
\text { NOx produce ozone. }\end{array}$} \\
\hline \multicolumn{6}{|c|}{ ii $\mathrm{O} *$ denotes an active oxygen species } \\
\hline \multicolumn{6}{|c|}{ iii $\mathrm{R}$ denotes a radical species } \\
\hline iv Total emissions incl & $s$ both natural ant & pogenic emissic & & & \\
\hline
\end{tabular}

\section{Overview of Heterogeneous Photocatalysis}

Photocatalytic pavements have unique properties, which result in the oxidation of both organic and inorganic pollutants (Beeldens et al., 2011). These properties arise because cements used in these pavements contain $\mathrm{TiO}_{2}$, a photocatalyst. While other photocatalytic materials exists, investigation has identified $\mathrm{TiO}_{2}$, with the anatase crystal structure, as the most effective (Ohama \& Van Gemert, 2011). The unique photocatalytic oxidation properties of $\mathrm{TiO}_{2}$ are chiefly due to generation of hydroxyl radicals $\left({ }^{\circ} \mathrm{OH}\right)$ under UV-A illumination (i.e., wavelength range of $300 \mathrm{~nm}$ to $400 \mathrm{~nm}$ ) (Fujishima \& Zhang, 2006). 
As illustrated in Figure 2.2, when nanoscale $\mathrm{TiO}_{2}$ particles absorb light with energy greater than the gap between valence and conduction bands (i.e., 1-3.3 electron volts), valence band electrons are excited and move to the conduction band (Tompkins et al., 2005). This electron movement produces electronhole pairs. $\mathrm{TiO}_{2}$ particles, which are n-type semiconductors, contain sufficient numbers of mobile electrons that generation of electron-hole pairs do not significantly upset thermodynamic equilibrium. Therefore, the energy from light can be stored without compromising $\mathrm{TiO}_{2}$ particle integrity. Once produced, electron holes tend to recombine with an electron, eliminating the hole-pair and releasing the stored energy as thermal energy or radiation. However, if the electron hole migrates to the particle surface, oxidative reactions are possible. In the typical photocatalytic oxidation process, an electron from a hydroxyl ion fills the $\mathrm{TiO}_{2}$ particle's electron hole, creating a $\left({ }^{\circ} \mathrm{OH}\right)$. This radical is highly reactive and can then oxidize various pollutant molecules (Fujishima et al., 2000).

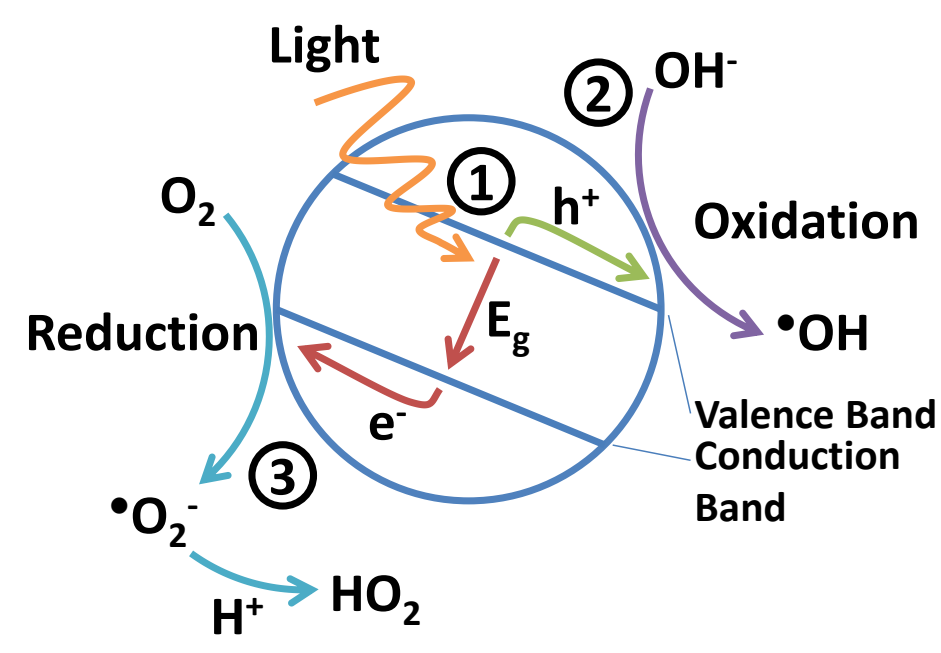

(1) Light with energy greater than band-gap energy $\left(E_{g}\right)$ excites an electron ( $\left.e^{-}\right)$from the valence to the conduction band creating a valence-band hole $\left(\mathrm{h}^{+}\right)$.

(2) $\mathrm{h}^{+}$migrates to surface and oxidizes a hydroxyl ion $\left(\mathrm{OH}^{-}\right)$to a hydroxyl radical $\left(\bullet^{\bullet} \mathrm{OH}\right)$.

(3) To maintain neutral charge the excited electron migrates to the surface and reduces molecular oxygen $\left(\mathrm{O}_{2}\right)$ to a molecular oxygen radical $\left(\bullet^{\circ} \mathrm{O}^{-}\right)$.

Figure 2.2. Photocatalytic oxidation steps (adapted from Tompkins et al., 2005).

Photocatalytic oxidation causes the $\mathrm{TiO}_{2}$ particle to gain electrons. A net gain of electrons threatens the continued usability of the particles for photocatalytic oxidation because a negative charge will develop if too many electrons are gained. This state has not been observed in practice. Research indicates that in many cases, a neutral charge is maintained when electrons leave $\mathrm{TiO}_{2}$ particles via reduction of molecular oxygen to radical oxygen (also illustrated in Figure 2.2). The electron holes have a greater oxidizing power than the reducing power of excited electrons; therefore, reduction of molecular oxygen does not cancel out the $\mathrm{TiO}_{2}$ 's oxidizing power. Of note, radical oxygen when reacted with 
hydrogen produces the hydroperoxyl radical, which also can oxidize certain molecules (Fujishima et al., 1999).

Optimization of $\mathrm{TiO}_{2}$ for use as a photocatalyst is the subject of ongoing research. Anatase has the highest photocatalytic activity levels of common TiO2 mineral forms due to comparatively higher surface area and surface density of sites available for photocatalysis (Herrmann, 1999). Although anatase $\mathrm{TiO}_{2}$ displays a comparatively high level of photo-activity, it only absorbs UV light (which represents approximately $5 \%$ of sunlight). Enhanced photocatalytic activity could be achieved if the spectrum of light that $\mathrm{TiO}_{2}$ absorbs is increased. Efforts to obtain this result have included coupling with semiconductors, doping with metal, preparing $\mathrm{TiO}_{2}$ that is oxygen deficient, and doping with non-metal anions (Fujishima et al., 2008). Non-metal anion doping shows the greatest potential to achieve development of visible-light photocatalysts. Publications have reported that doping with nitrogen, carbon, sulfur, boron, phosphorus, and fluorine increases the spectrum of light that $\mathrm{TiO}_{2}$ absorbs to the visible range (Fujishima et al., 2008). These developments increase photocatalytic generation of ${ }^{\bullet} \mathrm{OH}$, thereby increasing photocatalytic degradation of various pollutants. Undoubtedly, future developments will also enhance photo-degradation of $\mathrm{NO}_{\mathrm{x}}$ by pavement containing $\mathrm{TiO}_{2}$.

\section{Commercial Development and Patents}

Paz (2010) published a summary of patents relevant to air treatment by $\mathrm{TiO}_{2}$ photocatalysis. When comparing photocatalytic water and air treatment, the publication notes that scientific manuscripts published in the water treatment field far outnumber the manuscripts in the air treatment field. However, a review of patents finds the reverse situation. (Paz, 2010) provided a general review of various pavement-type applications and issues including the following uses: extruded block materials, spray-on applications, shear-resistant materials, bituminous void-filling with reactive cement mortar, and paint. Table 2.2 summarizes 11 patents believed to have been secured in direct relation to $\mathrm{TiO}_{2}$ bearing pavement (or similar, i.e., paver, brick, tile, etc.) materials. 
Table 2.2. Patent synopsis relative to $\mathrm{TiO}_{2}$-containing paving materials.

\begin{tabular}{|c|c|c|c|c|}
\hline \# & Patent number & Date & $\begin{array}{c}\text { Inventors \& } \\
\text { assignee }\end{array}$ & Topic \& notes \\
\hline 1 & EP $0,786,283$ & 1997 & $\begin{array}{l}\text { Murata et. al. } \\
\text { [Mitsubishi } \\
\text { Materials Corp.] }\end{array}$ & $\begin{array}{l}\mathrm{NO}_{\mathrm{X}} \text {-Cleaning Paving Block } \\
\text { (NOTE: involved a double-layer paving block having enhanced } \mathrm{NO}_{\mathrm{X}} \\
\text { cleaning capability) }\end{array}$ \\
\hline 2 & US 6,117,229 & 2000 & $\begin{array}{l}\text { Cassar and Pepe } \\
\text { [Italcementi] }\end{array}$ & $\begin{array}{l}\text { Use of Organic Additives for the Preparation of Cementitious } \\
\text { Compositions with Improved Properties of Constancy of Color } \\
\text { (NOTE: the use of photocatalytic anatase kept the 'white' luminance, } \\
\text { purity (intensity of hue) and tonality of hue intact over time) }\end{array}$ \\
\hline 3 & US 6,406,536 & 2002 & $\begin{array}{l}\text { Cassar and Pepe } \\
\text { [Italcementi] }\end{array}$ & $\begin{array}{l}\text { Organic Additives for the Preparation of Cementitous Compositions with } \\
\text { Improved Constancy of Color } \\
\text { (NOTE: Use of photocatalyst } \mathrm{TiO}_{2} \text { anatase "able to oxidize, in presence of } \\
\text { light, air, and ambient humidity, pollutant substances in the } \\
\text { environment"; "enables cementitious compositions to be obtained which } \\
\text { are particularly suitable for being applied by brush, sprayer, or roller"; } \\
\text { "the photocatalytic action need not necessarily be fast, in that the fouling } \\
\text { of the product by environmental pollutants takes place slowly over time } \\
\ldots \text { even extremely small percentages of photocatalysts may produce a } \\
\text { very high effect of conservation of colour"; "inorganic compounds, such } \\
\text { as oxides of nitrogen } \mathrm{NO}_{x} \text { which may be oxidized to nitrates.") }\end{array}$ \\
\hline 4 & US $6,409,821$ & 2002 & $\begin{array}{l}\text { Cassar and Pepe } \\
\text { [Italcementi] }\end{array}$ & $\begin{array}{l}\text { Hydraulic Binder and Cement Compositions Containing Photocatalyst } \\
\text { Particles } \\
\text { (NOTE: Covers hydraulic binder, dry premixes, and cement compositions } \\
\text {... where these "compositions contain, in bulk, particles of a photocatalyst } \\
\text { capable of oxidizing polluting substances ... in the presence of light, } \\
\text { oxygen, and water ... having improved property to maintain ... for longer } \\
\text { time periods the brilliance and the colour quantity." }\end{array}$ \\
\hline 5 & US 6,824,826 & 2004 & $\begin{array}{l}\text { Amadelli, Cassar, } \\
\text { and Pepe } \\
\text { [Italcementi] }\end{array}$ & $\begin{array}{l}\text { Use of Photocatalytic Preparations of Colloidal Titanium Dioxide for } \\
\text { Preserving Appearance of Cementitious, Stone, or Marble Products } \\
\text { (NOTE: } \mathrm{TiO}_{2} \text { being used to preserve surface characteristics) }\end{array}$ \\
\hline 6 & US 7,300,514 & 2007 & $\begin{array}{l}\text { Bonafous, } \\
\text { Cassar, Cassat, } \\
\text { Colombet, } \\
\text { Guillot } \\
\text { [Climents } \\
\text { Francais] }\end{array}$ & $\begin{array}{l}\text { Photocatalytic Granular Mixture for Mortar and Concrete and Its Use } \\
\text { (NOTE: Using "at least two granular classes with different B.E.T. specific } \\
\text { surfaces. It has a photocatalytic actvitity greater than that of a } \\
\text { monodisperse photocatalyst..." and by which the new material "whose } \\
\text { aptitude for self-cleaning, for the reduction of odors, and for the } \\
\text { depollution of ambient air, is considerably improved." }\end{array}$ \\
\hline 7 & EP $1,600,430$ & 2010 & $\begin{array}{l}\text { Cassar and Pepe } \\
\text { [Italcementi] }\end{array}$ & Paving Tile Comprising a Hydraulic Binder and Photocatalytic Particles \\
\hline 8 & US 7,960,042 & 2011 & $\begin{array}{l}\text { Cassar, Cucitore, } \\
\text { and Pepe } \\
\text { [Italcementi] }\end{array}$ & $\begin{array}{l}\text { Cement-Based Paving Blocks for Photocatalytic Paving for the Abatement } \\
\text { of Urban Pollutants } \\
\text { (NOTE: Cement-based paving block for photocatalytic paving for the } \\
\text { abatement of urban pollutants (PAH, aldehydes, benzene, carbon black } \\
\text { RE: PM10, oxides of nitrogen and sulfur, carbon monoxide...") }\end{array}$ \\
\hline 9 & US $8,039,100$ & 2011 & $\begin{array}{l}\text { Cucitore, } \\
\text { Cangiano, and } \\
\text { Cassar } \\
\text { [Italcementi] }\end{array}$ & $\begin{array}{l}\text { High Durability Photocatalytic Paving for Reducing Urban Polluting Agents } \\
\text { (NOTE: prolonged capability even in the face of high mechanical stress } \\
\text { caused by heavy traffic) }\end{array}$ \\
\hline 10 & US 8,092,586 & 2012 & $\begin{array}{l}\text { Ancora, Borsa, } \\
\text { and Cassar } \\
\text { [Italcementi] }\end{array}$ & $\begin{array}{l}\text { Titanium Dioxide Based Photocatalytic Composites and Derived Products } \\
\text { on a Metakaolin Support } \\
\text { (NOTE: “... possible to obtain binders and derived products with high } \\
\text { photocatalytic efficiency, even when using photocatalyst quantities which } \\
\text { are lesser than those present in products of prior technical art.") }\end{array}$ \\
\hline 11 & $\begin{array}{l}\text { US } \\
20,120,270,721\end{array}$ & 2012 & $\begin{array}{l}\text { Guerrini } \\
\text { [Italcementi] }\end{array}$ & $\begin{array}{l}\text { Cementitious Products and Articles of Manufacture Containing Carbon- } \\
\text { Doped Titanium Dioxide } \\
\text { (NOTE: An improvement to the prior art with } \mathrm{TiO}_{2} \text { in photocatalytic } \\
\text { cementitous products, where, "...product articles of manufacture } \\
\text { containing it have a high and efficient photocatalytic action." }\end{array}$ \\
\hline
\end{tabular}




\section{Laboratory Evaluation of Photocatalytic Pavements}

Evaluation of new technologies proceeds from laboratory to field stages. Photocatalytic pavements are no exception. Flow-through photoreactor lab studies, constitute a significant portion of this technology's published body of literature. The sections that follow provide an overview of the experimental apparatus and testing approaches used in this evaluation and summarize results while noting areas needing future study.

\subsection{Experimental Apparatus and Testing Approach}

Test methods to evaluate oxidation of nitric oxide by photocatalyic pavements are provided by international, Japanese, and Italian standards (ISO, 2007; JIS, 2010; UNI, 2007). Each standard provides a similar scope for a test method to determine removal of NO by photocatalytic ceramic materials. Although written to provide a standard testing approach for ceramics, the international standard has been similarly employed by a number of researchers for their evaluation of photocatalytic concrete. NO removal is determined by measuring the amount of pollutant removed from a test gas after it passes over a photocatalytic material housed within a flow-through photoreactor. The standard provides equations to determine the net number of moles of $\mathrm{NO}_{\mathrm{x}}$ removed from the test gas by the sample; however, the bulk of publications report percent $\mathrm{NO}$ or $\mathrm{NO}_{\mathrm{x}}$ removal.

The apparatus required to complete this determination are divided into the following groups: test gas supply, photoreactor, light source, and pollutant analyzer (see Figure 2.3 for schematic). The ISO standard proposes the following operating conditions: 1.0 ppmv NO input concentration, 50\% relative humidity, $3.0 \mathrm{~L} \cdot \mathrm{min}^{-1}$ flow rate, $50 \mathrm{~mm}$ photoreactor width, $5.0 \pm 0.5 \mathrm{~mm}$ air pathway height, and $5 \mathrm{~h}$ sample irradiation length. In order to test percent NO removal under various environments; however, these conditions are frequently modified by various research teams. 


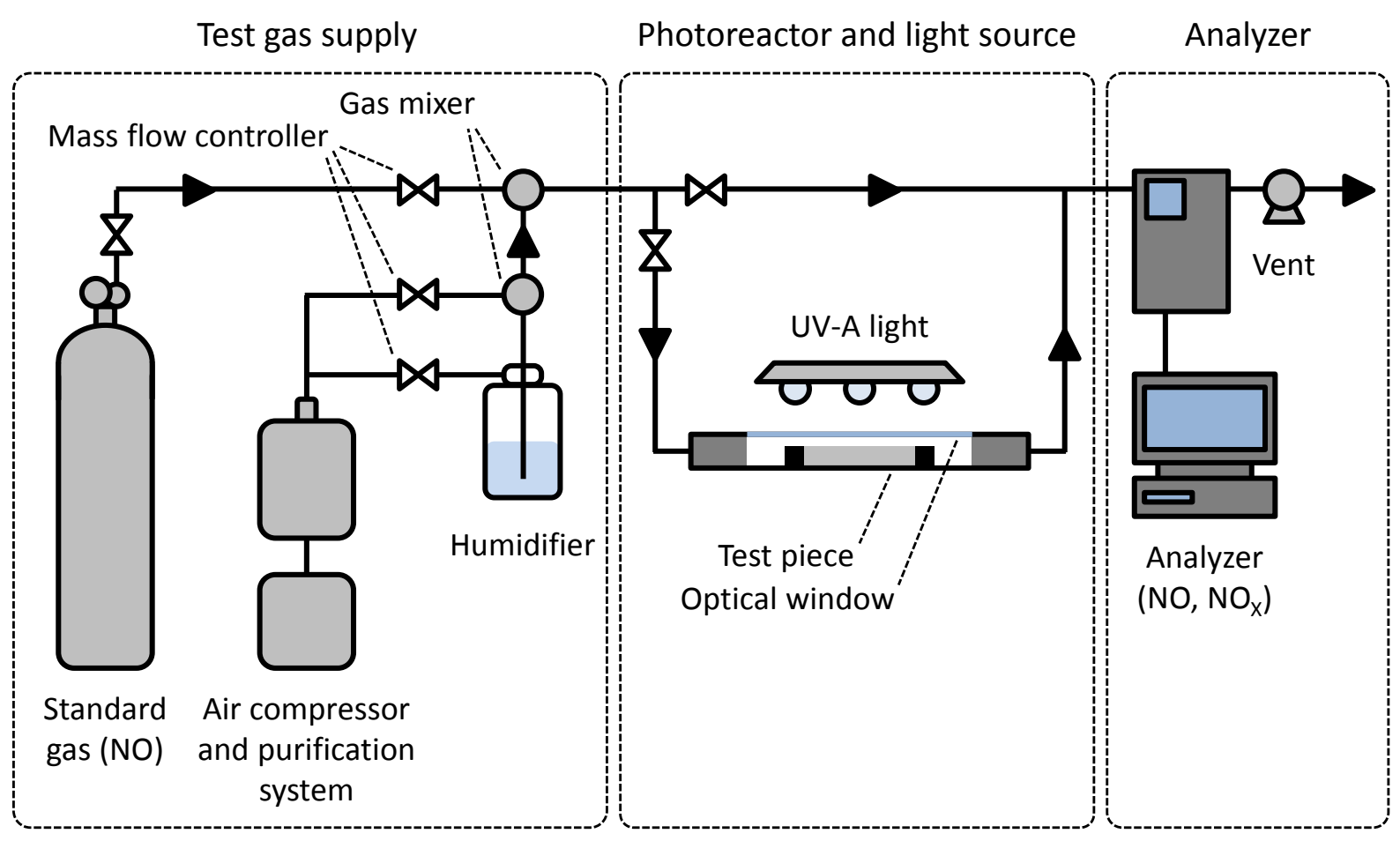

Figure 2.3. Schematic of experimental apparatus (adapted from ISO, 2007).

\subsection{Photoreactor Studies}

To predict the performance of photocatalytic pavements under field conditions, researchers use photoreactor tests to measure $\mathrm{NO}_{\mathrm{x}}$ removal under various environmental, material, and operation conditions. The earliest publications tracked the environmental variables of irradiance, relative humidity, $\mathrm{NO}_{\mathrm{x}}$ concentration, $\mathrm{NO}_{2} / \mathrm{NO}_{\mathrm{x}}$ fraction, and flow rate and the material variable, $\mathrm{TiO}_{2}$ content. Table 2.3 presents a summary of these evaluations and the relationship between each independent variable and the resulting $\mathrm{NO}_{x}$ removal. To achieve the maximum $\mathrm{NO}_{x}$ removal efficiency at minimum cost requires further investigation. The following sections describe environmental, material, and operation variables that impact $\mathrm{NO}_{\mathrm{x}}$ removal and identify areas that require additional study. 
Table 2.3. Summary of photoreactor tests for mortars containing $\mathrm{TiO}_{2}$ (unless noted, values are presented with the reported number of significant digits).

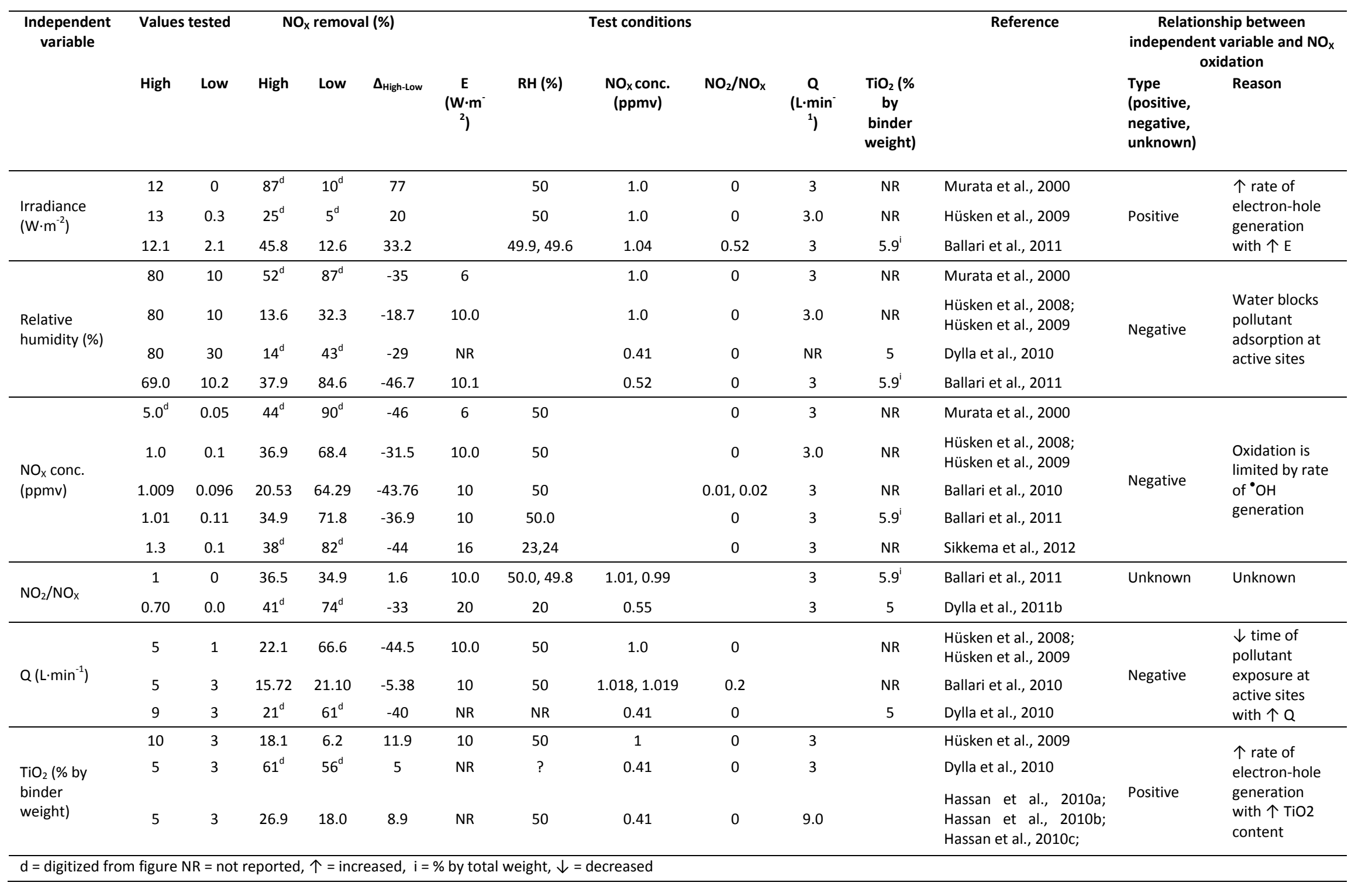




\subsubsection{Environmental Variables}

\subsubsection{UV Irradiance}

Increased UV irradiance on a photocatalytic surface would be expected to increase the rate at which electron holes are created. An increase in electron-hole generation results in increased production of hydroxyl radicals, which oxidize $\mathrm{NO}_{\mathrm{x}}$. Multiple publications report that the relationship between irradiance and pollutant oxidation can be divided into two regimes. These regimes are divided into a linear relationship below the regime division point and a non-linear relationship above this point (Herrmann et al., 2007; Jacoby et al., 1995; Kumar et al., 1995; Lim et al., 2000; Obee \& Brown, 1995). Jacoby et al. (1995) explains that under the linear regime, electron holes are filled by reactions with species on the photocatalytic surface (e.g., $\mathrm{OH}^{-}$) faster than by recombination with excited electrons; in contrast, under the non-linear regime, holes are filled by recombination at a faster rate than by reaction with other species. Although these publications are in consensus that this regime is identifiable, reports of the regime division point irradiance value range from 10 to $250 \mathrm{~W} \cdot \mathrm{m}^{-2}$ (Herrmann et al., 2007; Lim et al., 2000). Photocatalytic pavement studies, which investigated the relationship between irradiance and $\mathrm{NO}_{\mathrm{x}}$ removal, have not confirmed this linear regime at irradiance values ranging from 0.1-13.1 W. $\mathrm{m}^{-2}$ (Ballari et al., 2009; Hüsken et al., 2009; Murata et al., 2000). For each of these studies, the relationship can be described by a power law $\left(R^{2}>0.98\right.$ for each study). A linear relationship can only be assumed if measurements at low irradiance values are excluded; however, the number of points that must be excluded to obtain a $R^{2}>0.95$ differs between studies, with the greatest value being $5 \mathrm{~W} \cdot \mathrm{m}^{-2}$. As reported by Grant and Slusser (2005), mean daytime UV-A irradiance from the most northern (Fairbanks, Alaska, latitude $65.1^{\circ} \mathrm{N}$ ) and southern (Homestead, FL, latitude $25.4^{\circ} \mathrm{N}$ ) locations of a United States Department of Agriculture (USDA) climate monitoring network ranged from 10.5 to $22.3 \mathrm{~W} \cdot \mathrm{m}^{-2}$. These values all fall in the area where the linear or nonlinear regime applies. However, in urban areas $\mathrm{NO}_{\mathrm{x}}$ ambient concentration follows a diurnal pattern associated with traffic. Urban background monitoring in London, UK, found that $\mathrm{NO}_{2}$ peaks both in early morning and late afternoon and $\mathrm{NO}$, which oxidizes quickly to $\mathrm{NO}_{2}$ during daylight hours, peaks in early morning (Bigi \& Harrison, 2010). At these peaks, irradiance values are substantially lower than the mean daytime value. Improving the efficiency at which photocatalytic pavement mitigates atmospheric $\mathrm{NO}_{\mathrm{x}}$ pollution requires greater photoactivity and additional laboratory study at these low irradiance values. 


\subsubsection{Relative Humidity}

Photocatalytic degradation of $\mathrm{NO}_{\mathrm{x}}$ by pavement containing titanium dioxide occurs when $\mathrm{NO}_{\mathrm{x}}$ is oxidized by ${ }^{\bullet} \mathrm{OH}$ (Figure 2.1). These ${ }^{\circ} \mathrm{OH}$ are generated by oxidation of a hydroxyl ion $\left(\mathrm{OH}^{-}\right)$by an electron hole (see preceding Figure 2.2). Water vapor serves as the atmospheric source for $\mathrm{OH}^{-}$ions. Intuition would consequently suggest that increased humidity would result in increased $\mathrm{NO}_{\mathrm{x}}$ removal; the published literature suggests that the opposite is true. In addition to photocatalytic properties, materials containing $\mathrm{TiO}_{2}$ also exhibit photo-induced super-hydrophilicity (i.e., water on the surface has a contact angle of nearly $0^{\circ}$ ) (Fujishima et al., 2008). Due to this unique property, adsorbed water vapor disperses over the surface, blinding photocatalytically active sites from UV light (Beeldens, 2007). Data from photocatalytic pavement studies indicate a linear relationship with a negative slope (see Table 2.3). These studies all occurred at room temperature, allowing comparison of the results by relative humidity. In contrast, field applications could exhibit substantial variations in temperature, which results in significant changes in the amount of water that can be present in the atmosphere. For field studies, specific humidity (the ratio of water vapor mass to total air mass) provides a better comparison. At $20^{\circ} \mathrm{C}$, $10 \%$ and $80 \%$ relative humidity (the extremes of laboratory data) convert to specific humidity values of 1.44 and $11.6 \mathrm{~g}$ water per $\mathrm{kg}$ moist air respectively (at $101.1 \mathrm{kPa}$ ). As part of the rule making process, the USEPA used 2006-2008 data to determine ambient $\mathrm{NO}_{2}$ concentration in the form of the 2010promulgated $\mathrm{NO}_{2}$ standard for counties within the United States. The five counties with the highest $\mathrm{NO}_{2}$ concentration in this measurement form are as follows: Cook, IL, San Diego, CA, Los Angeles, CA, Erie, NY, and Denver, CO. With exception of Denver County, each of the listed counties frequently experiences high specific humidity conditions. Any field application of photocatalytic concrete to mitigate $\mathrm{NO}_{\mathrm{x}}$ pollution will need to be carefully tailored to the environmental conditions.

\subsubsection{3. $\mathrm{NO}_{\mathrm{X}}$ Concentration}

Photocatalytic pavement studies indicate that a clear negative correlation is evident between inlet $\mathrm{NO}_{\mathrm{x}}$ concentration and percent $\mathrm{NO}_{\mathrm{x}}$ removal (Ballari et al., 2010; Ballari et al., 2011; Hüsken \& Brouwers, 2008; Hüsken et al., 2009; Murata et al., 2000; Sikkema et al., 2012). Herrmann (1999) reports that $\mathrm{NO}_{x}$ reaction kinetics fall into a low-concentration first-order regime and a high-concentration zero-order regime. Under the zero-order regime, the reaction rate is controlled by reactions between adsorbed molecules. As applied to $\mathrm{NO}_{x}$ removal by photocatalytic pavements, the overall rate of $\mathrm{NO}_{x}$ removal will remain constant as input concentration increases, therefore the percent $\mathrm{NO}_{\mathrm{x}}$ removal will decrease. As compared to the zero-order regime, the decrease in percent $\mathrm{NO}_{x}$ removal is dramatic within the first- 
order regime because the availability of active sites for photo-oxidation decreases with increased concentration. Many photoreactor studies follow the ISO method and thereby assess $\mathrm{NO}_{\mathrm{x}}$ removal at 1 ppmv. This value is an order of magnitude greater than even the highest value of USEPA $\mathrm{NO}_{2}$ standard and cannot be considered representative of environments where this technology may see application. Although photoreactor studies do evaluate the relationship between input concentration and $\mathrm{NO}_{\mathrm{x}}$ removal, data points are often evenly distributed between high and low concentrations. As research moves to field application, it will need to be complemented by photoreactor studies that place focus on $\mathrm{NO}_{\mathrm{x}}$ removal at low-concentration values.

\subsubsection{4. $\mathrm{NO}_{2} / \mathrm{NO}_{x}$ Ratio}

USEPA emissions estimates used for national trends assume a $\mathrm{NO}_{2} / \mathrm{NO}_{\mathrm{x}}$ ratio of 1 because $\mathrm{NO}$ is freely oxidized in the atmosphere (USEPA, 2001). Within near-road environments assumed and measured $\mathrm{NO}_{2} / \mathrm{NO}_{\mathrm{x}}$ values for initial emissions in near-road environments fall between 0.05 and 0.31 (Wang et al., 2011). Photocatalytic pavement research has not established the relationship between $\mathrm{NO}_{2} / \mathrm{NO}_{\mathrm{x}}$ ratio and $\mathrm{NO}_{\mathrm{x}}$ removal. Dylla et al. (2011a) asserts a negative correlation. The data set from Ballari et al. (2011) does not support this claim, listing $\mathrm{NO}_{\mathrm{x}}$ removal of $34.9 \%$ and $36.5 \%$ at $\mathrm{NO}_{2} / \mathrm{NO}_{\mathrm{x}}$ ratios of 0 and 1 , respectively. Settling these conflicts within the literature will require additional photoreactor studies that focus on near-road $\mathrm{NO}_{2} / \mathrm{NO}_{\mathrm{x}}$ ratios, which were identified in Wang et al. (2011).

\subsubsection{Flow Rate}

$\mathrm{NO}_{x}$ removal within a specific volume of test gas increases proportionally to the residence time over a photocatalytic surface because greater time exists for pollutants to absorb and be oxidized at active sites. As a result, literature demonstrates a clear negative correlation between $\mathrm{NO}_{\mathrm{x}}$ removal and flow rate. In each case the relationship appears linear, but each publication supplies at most 3 data points (Ballari et al., 2010; Dylla et al., 2010; Hüsken \& Brouwers, 2008; Hüsken et al., 2009). Tested flow rates (1-9 L. $\left.\mathrm{min}^{-1}\right)$ do not vary substantially from the $3 \mathrm{~L} \cdot \mathrm{min}^{-1}$ specified in the ISO (2007) standard. If the standard's reactor dimensions are also used, air velocity over the photocatalytic surface would measure $0.2 \mathrm{~m} \mathrm{~s}^{-1}$. Although considerable variation in wind velocity occurs within the field, in a relatively unobstructed environment, a reasonable expectation would set wind velocities at least an order of magnitude greater than the value specified by the standard (approximately $7 \mathrm{~km} \cdot \mathrm{h}^{-1}$ ). Wind velocity of this magnitude would significantly reduce the effectiveness of field applications of photocatalytic 
pavements, especially if the wind carried pollutants in a direction perpendicular to the roadway. Street canyons may represent an optimal location for photocatalytic pavements. The structures that border each side of such streets reduce natural ventilation and in many cases air pollution rises well above background concentrations (Vardoulakis et al., 2003). While this reduced airflow provides suitable site conditions for photocatalytic pavement, application of this technology within a street canyon must take into account decreased irradiance during periods when buildings obstruct sunlight.

\subsubsection{Temperature}

Available literature is vague in regards to the impact of surface or air temperature changes on $\mathrm{NO}_{\mathrm{x}}$ oxidation performance. Assertions are general and in most cases state that $\mathrm{NO}_{\mathrm{x}}$ removal efficiency increases with higher temperature (Beeldens et al., 2011) and that only large differences in temperature (i.e., summer vs. winter) are significant (Dylla et al., 2011a). In addition to being vague, the literature also is contradictory and one source reports a decrease in oxidation rates with increased temperature (Chen \& Chu, 2011). Cold temperature climates, such as those that occur in northern and continental areas of the United Sates, may substantially reduce the pavement's air purification performance. To determine whether photocatalytic pavement can serve as a viable method to address air pollution in these climates, the influence of temperature on the rate of $\mathrm{NO}_{\mathrm{x}}$ oxidation must be researched.

\subsubsection{Material Variables}

\subsubsection{1. $\mathrm{TiO}_{2}$ Content}

Photocatalytically active sites occur on the surface of pavement where $\mathrm{TiO}_{2}$ is exposed. An increase in the amount of $\mathrm{TiO}_{2}$ contained in the photocatalytic material (often measured as a percentage of binder mass) results in greater $\mathrm{NO}_{x}$ removal (Dylla et al., 2010; Hassan et al., 2010a, 2010b, 2010c; Hüsken et al., 2009). Although this positive correlation is supported by literature, the relationship is nonlinear. Studies of VOC oxidation have found that gains in catalytic activity diminish with increases in $\mathrm{TiO}_{2}$ content and have proposed that optimal $\mathrm{TiO}_{2}$ content falls between 1 and 5\% (Strini et al., 2005; Watts \& Cooper, 2008). This diminished return was attributed to catalyst aggregation and segregation that resulted in a decrease in $\mathrm{TiO}_{2}$ concentration at the material's surface. Due to the nature of this relationship, it is not apparent whether this benefit is justified by the unit cost of $\mathrm{TiO}_{2}$ (Dylla et al., 2010). It should be noted, $\mathrm{TiO}_{2}$ content is not frequently reported in photocatalytic pavement studies. Within patents governing this technology $\mathrm{TiO}_{2}$ content as a percentage of binder ranges from 2-10\% (Paz, 2010). Specific values are not available, presumably to protect competitive advantage. Future 
stakeholders will need to rely on the research and development process of the patent holders and on available data verifying the product's performance.

\subsubsection{2. $\mathrm{TiO}_{2}$ Properties}

In addition to the content, the properties of $\mathrm{TiO}_{2}$ contained within a photocatalytic pavement also impact $\mathrm{NO}_{\mathrm{x}}$ removal. $\mathrm{TiO}_{2}$ occurs in a variety of mineral forms, including anatase, brookite, and rutile. Although each mineral form is photocatalytically active, direct comparison finds that anatase is bestsuited for photocatalytic oxidation applications because anatase is superior in both the rate at which electron-hole pairs are generated and in its better ability to adsorb reactants (Sclafani \& Herrmann, 1996). Although anatase is a superior photocatalyst, mixtures of rutile and anatase (e.g., Degussa P-25, which contains anatase and rutile at a 3:1 ratio) garner the greatest photoactivity due to interaction between the minerals (Ohno et al., 2001). In addition to an appropriate mixture of mineral forms, high specific surface area values have also been demonstrated to enhance photocatalytic activity (Hüsken et al., 2009). Further discussion of $\mathrm{TiO}_{2}$ properties, which enhance photocatalytic activity falls outside of the scope of this review. If of interest to the reader, the following publication would serve as a good starting point: Carp et al. (2004). As noted by the article, particular research needs include development of photocatalysts that can be activated by visible light and are selective in the pollutants that are oxidized. Stakeholders considering use of photocatalytic pavements would be wise to follow developments in $\mathrm{TiO}_{2}$ photocatalysts and if possible select a catalyst which incorporates worthwhile research developments.

\subsubsection{Mix Design and Surface Treatment}

Even if the most photocatalytically efficient photocatalyst is selected for use in a pavement application, substantial care needs to be taken in designing a mix and surface treatment in order to garner the maximum removal of ambient $\mathrm{NO}_{x}$. In cementitious systems some pavements can be made photocatalytic with the addition of a thin mortar placed on the surface of a non-photocatalytic component. $\mathrm{TiO}_{2}$ is added to either the cement or water components of the mortar mix. Lab research indicates that $\mathrm{TiO}_{2}$ is more homogeneously distributed, resulting in greater $\mathrm{NO}_{\mathrm{x}}$ removal, when $\mathrm{TiO}_{2}$ is mixed with water (Hüsken et al., 2009). The researchers' quality control may not be achievable in readymix plants. It is possible a more consistent distribution of $\mathrm{TiO}_{2}$ in a photocatalytic mortar may be realized by tasking cement suppliers with the supplying photocatalytic cement. A second method to produce a cementitious photocatalytic pavement is to simply substitute photocatalytic cement in place of Type I 
cement when pouring concrete. With present technology, this practice is expensive. The cost can be reduced to an extent by using a two-lift pavement construction. Using widely accepted construction practice, a top layer could be reduced to a $4 \mathrm{~cm}$ thickness (Hall et al., 2007). This technique does substantially increase costs (e.g., it requires two paving plants, two paving machines, and additional labor), but opens up new opportunities to use lower-quality less expensive concrete in the bottom lift. Reportedly, these savings may be sufficient to offset the additional costs (Cable \& Frentress, 2004).

Another option to produce photocatalytic pavement is to simply spray a water-based $\mathrm{TiO}_{2}$ coating on an existing concrete surface (a process developed by PURETi, New York, NY). This process may be economical and lab testing indicates that it produces similar levels of $\mathrm{NO}_{\mathrm{x}}$ removal as a $5 \% \mathrm{TiO}_{2}$ content (by binder weight) mortar coating (Hassan et al., 2010b). It would seem probable that a water-based spray coating would dissipate over time with exposure to roadway environments. Simulated weathering did not confirm this expectation (Hassan et al., 2010b). However given that coating pavement in this fashion is not common, additional lab research complemented by field testing is recommended.

Surface treatments also can enable greater $\mathrm{NO}_{\mathrm{x}}$ removal. Sand blasting and mixes in which aggregate sized less than $300 \mu \mathrm{m}$ in diameter were removed, treatments which increase the pavement specific surface area, both increase $\mathrm{NO}_{x}$ removal (Dylla et al., 2010; Hüsken et al., 2009; Poon \& Cheung, 2007). A rapidly developing advancement holding substantial promise is that of pervious photocatalytic concrete, which has approximately 6 times more surface area exposure to sunlight (Asadi et al., 2012). Under the same testing conditions, pervious concrete with a $\mathrm{TiO}_{2}$ depth of 2 inches or greater provided, at minimum, 11\% greater NO removal than non-pervious photocatalytic (Asadi et al., 2012).

\subsubsection{Operational Variables}

\subsubsection{Blinding}

The air-purifying effectiveness of photocatalytic pavements is hindered by reductions in $\mathrm{NO}_{\mathrm{x}}$ oxidation rate in comparison to the initial oxidation rate (i.e., the rate when the pavement was installed). Pavement-specific literature attributes observed reductions to a decrease in irradiance reaching $\mathrm{TiO}_{2}$ caused by fine dust and organism adhesion (Beeldens et al., 2011) and interference from roadway contaminants such as dirt, de-icing salt, and motor oil (Dylla et al., 2011b). Other $\mathrm{TiO}_{2}$ studies attributed reductions in photocatalytic activity to blinding by the accumulation of oxidation products and intermediates (Beeldens, 2008; Demeestere et al., 2008; Ibusuki \& Takeuchi, 1994; Zhao \& Yang, 
2003). These observed reductions in $\mathrm{NO}_{x}$ removal are significant. A study in which photocatalytic paving blocks set in an outdoor environment and then tested in a photoreactor at set intervals observed a $50 \%$ decrease in removal efficiency over a 5-month period (Murata \& Tobinai, 2002). This decrease was attributed to dust and organism adhesion. A similar test reported a $36 \%$ to $78 \%$ decrease in removal efficiency over 4 months and a $22 \%$ to $88 \%$ decrease with 12 months of exposure (Yu, 2003). After observing accumulation of particulate matter, oil, and chewing gum, and scratches on the pavement surface, the researchers credited a reduction in photocatalytic surface area as the cause for the decrease. To maximize the air-cleaning performance of photocatalytic concrete, the primary factors that cause reductions in $\mathrm{NO}_{\mathrm{x}}$ removal must be identified. Dylla et al. (2011b) used laboratory tests to determine the influence of dirt, de-icing salt, and motor oil on $\mathrm{NO}_{\mathrm{x}}$ removal. Each material significantly reduced oxidation efficiency, but the study did not compare the amount of material applied to test pieces to amounts observed on installed pavements. This study also did not assess whether the oxidized product, $\mathrm{NO}_{3}^{-}$, caused a reduction in oxidation efficiency. To ensure long-term performance of photocatalytic pavement, photoreactor studies must determine the primary factors that cause the field observed decrease in $\mathrm{NO}_{x}$ removal.

\subsubsection{Pavement Age}

As noted above, materials that interfere with catalytically active sites can cause decreases in $\mathrm{NO}_{\mathrm{x}}$ removal. Sufficient data does not exist to establish whether photocatalytic activity also decreases with pavement age. One report notes that activity lasts for a least one year, but acknowledges that longer duration tests are not complete (Cassar, 2004). Theoretically, the pavement should maintain photocatalytic activity because $\mathrm{TiO}_{2}$ is not consumed by the $\mathrm{NO}_{x}$ oxidation process. Furthermore, any abrasion that results from traffic should expose new $\mathrm{TiO}_{2}$ particles. Nevertheless, these assertions have not been verified with robust laboratory or field data. United States stakeholders will not progress with any large-scale projects unless research establishes that pavement age does not have a significant impact on activity (Berdahl \& Akbari, 2007).

\subsubsection{Wash-off/Regeneration}

Efficient use of photocatalytic pavement requires strategies to address the known decrease in $\mathrm{NO}_{\mathrm{x}}$ oxidation rate that occurs over time after the pavement is installed in a near-road environment. Researchers have suggested shearing airflow, burning chemisorbed carbon species, simulated rainfall, and road cleaning (Beeldens et al., 2011; Demeestere et al., 2008; Zhao \& Yang, 2003). Demeestere et al. 
(2008) found that airflow was a completely ineffective regeneration mechanism. In contrast, while surface burning may be economical for some small-scale applications, it is impractical for pavements. Some sources claim that rain or surface washing is sufficient to regenerate photocatalytic activity (Beeldens, 2008; Beeldens et al., 2011). One source noted the beneficial effect of rain, but still recommended surface washing at two-month intervals (Yu, 2002). However, another researcher found that washing with a brush and deionized water did not cause a statistically significant change (or increase) in the activity of photocatalytic paving blocks that had been partially deactivated by outdoor exposure in a near-road environment for a period of months ( $Y u, 2003)$. The conflicts that exist in published literature point to a need for research that determines effective washing mechanisms to regenerate the photocatalytic activity of these pavements. This research must tailor washing mechanisms to the factors that cause $\mathrm{NO}_{x}$ oxidation rate reductions and estimate the required washing frequency to maintain $\mathrm{NO}_{\mathrm{x}}$ oxidation performance.

\subsubsection{Ecological Impact}

Although the $\mathrm{NO}_{3}{ }^{-}$product that results from $\mathrm{NO}_{\mathrm{x}}$ oxidation can be used as a plant nutrient, within the United States, $\mathrm{NO}_{3}{ }^{-}$is a water pollutant where excessive concentrations in aquatic environments causes eutrophication (The Cadmus Group, 2009). Research on this possible unintended pollution is limited but appears to suggest that concentrations are at levels that do not warrant ecological concern. One example calculation yielded a concentration of $5.3 \mathrm{mg} / \mathrm{L} \mathrm{NO}_{3}{ }^{-}$(City Concept, 2004). A second publication asserts that $\mathrm{NO}_{3}{ }^{-}$becomes bound inside the concrete matrix as calcium nitrate $\left(\mathrm{CaNO}_{3}\right)$ and that dissolution into runoff water would be at a concentration 10 times less than the first pollution level (PICADA, 2011). Another publication seemingly acknowledges that a water pollution problem is possible by proposing that $\mathrm{NO}_{3}{ }^{-}$can be extracted from runoff by a standard sewage plant (Husken et al., 2009). This solution may be practical in the authors' country of residence (the Netherlands) but within the United States, the majority of road runoff travels directly to surface water. Potential stakeholders require laboratory and field data that confirms $\mathrm{NO}_{3}{ }^{-}$in runoff will not exacerbate current water pollution problems (Berdahl \& Akbari, 2007). 


\section{Field Evaluation of Photocatalytic Pavements}

Multiple field studies of photocatalytic pavements do exist (see Table 2.4), but documentation is comparatively less extensive than that of laboratory research. Available field studies can be categorized as those that compare photocatalytic and control sections, measure $\mathrm{NO}_{3}{ }^{-}$deposition as evidence of photocatalytic activity, and attempt to model observations. These categories of field research are summarized in the sub-sections that follow.

Table 2.4. Photocatalytic pavement field studies.

a. Field comparison of photocatalytic and control sections.

\begin{tabular}{|c|c|c|c|c|c|c|c|}
\hline Location & $\begin{array}{l}\text { Installation } \\
\text { type }\end{array}$ & Pavement type & $\begin{array}{c}\text { Surface } \\
\text { area }\left(\mathrm{m}^{2}\right)\end{array}$ & $\begin{array}{c}\text { Traffic } \\
\text { volume }\end{array}$ & $\begin{array}{c}\mathrm{NO}_{\mathrm{x}} \\
\text { conc. } \\
\text { change } \\
(\%)\end{array}$ & $\begin{array}{c}\text { Measurement } \\
\text { type }\end{array}$ & Reference \\
\hline $\begin{array}{l}\text { Antwerp, } \\
\text { Belgium }\end{array}$ & $\begin{array}{l}\text { Parking } \\
\text { lanes of } \\
\text { urban road }\end{array}$ & Paving blocks & 10,000 & -- & 20 & Avg. & Beeldens, 2007, 2008 \\
\hline \multirow{2}{*}{$\begin{array}{l}\text { Via } \\
\text { Morandi, } \\
\text { Segrate, } \\
\text { Italy }\end{array}$} & \multirow[t]{2}{*}{ Urban road } & \multirow[t]{2}{*}{ Thin mortar overlay } & \multirow[t]{2}{*}{7,000} & \multirow[t]{2}{*}{1000 veh $^{-1}$} & 60 & Max. & \multirow{2}{*}{$\begin{array}{l}\text { Italcementi, 2006; } \\
\text { Essroc, 2008; } \\
\text { Italcementi, 2009; }\end{array}$} \\
\hline & & & & & 50 & Avg. & \\
\hline $\begin{array}{l}\text { Calusco } \\
\text { d'Adda, } \\
\text { Bergamo, } \\
\text { Italy }\end{array}$ & $\begin{array}{l}\text { Industrial } \\
\text { site road }\end{array}$ & Paving blocks & 8,000 & -- & 45 & Avg. & $\begin{array}{l}\text { Italcementi, 2006; } \\
\text { Italcementi, } 2009\end{array}$ \\
\hline $\begin{array}{l}\text { Porpora } \\
\text { Street, } \\
\text { Milan, Italy }\end{array}$ & $\begin{array}{l}\text { Road within } \\
\text { tunnel }\end{array}$ & $\begin{array}{l}\text { Concrete, } \\
\text { photocatalytic ceiling } \\
\text { paint }\end{array}$ & $\begin{array}{c}728 \\
\text { (concrete) }\end{array}$ & 30,000 veh d $^{-1}$ & 23 & $\begin{array}{l}\text { Min. UV } \\
\text { irradiance }\end{array}$ & Italcementi, 2006 \\
\hline \multirow{4}{*}{$\begin{array}{l}\text { Borgo } \\
\text { Palazzo, } \\
\text { Bergamo, } \\
\text { Italy }\end{array}$} & \multirow[t]{4}{*}{ Urban } & \multirow[t]{4}{*}{ Paving blocks } & \multirow[t]{2}{*}{7,000} & \multirow[t]{4}{*}{400 cars h $^{-1}$} & 40 & Max. & \multirow[t]{2}{*}{ Italcementi, 2009} \\
\hline & & & & & 20 & Min & \\
\hline & & & \multirow[t]{2}{*}{12,000} & & 66 & Max. & \multirow{2}{*}{$\begin{array}{l}\text { Guerrini \& Peccati, } \\
2007\end{array}$} \\
\hline & & & & & 20 & Min. & \\
\hline $\begin{array}{l}\text { Rue Jean } \\
\text { Bleuzen, } \\
\text { Vanves, } \\
\text { France }\end{array}$ & Urban road & Concrete overlay & 6,000 & 13,000 cars d $^{-1}$ & 20 & Min. & Italcementi, 2009 \\
\hline \multirow{2}{*}{$\begin{array}{l}\text { Vanves, } \\
\text { France }\end{array}$} & \multirow[t]{2}{*}{ Urban road } & Paving blocks & \multirow{2}{*}{$\begin{array}{l}250 \mathrm{~m} \\
\text { length }\end{array}$} & \multirow[t]{2}{*}{14,000 cars d $^{-1}$} & \multirow[t]{2}{*}{$40-50$} & \multirow[t]{2}{*}{ Uncertain } & \multirow[t]{2}{*}{ Gignoux, et al., 2010} \\
\hline & & Concrete overlay & & & & & \\
\hline \multirow{2}{*}{$\begin{array}{l}\text { St-Denis, } \\
\text { France }\end{array}$} & \multirow[t]{2}{*}{ Urban road } & \multirow[t]{2}{*}{ Concrete overlay } & \multirow[t]{2}{*}{2,000} & \multirow[t]{2}{*}{--} & 30 & $2 \mathrm{~m}$ height & \multirow[t]{2}{*}{ Rousseau, et al., 2009} \\
\hline & & & & & 15 & $20 \mathrm{~m}$ height & \\
\hline
\end{tabular}


b. Locations of other photocatalytic pavement field studies.

\begin{tabular}{|c|c|c|c|c|}
\hline Location & Installation type & Pavement type & $\begin{array}{c}\text { Surface } \\
\text { area }\left(\mathrm{m}^{2}\right)\end{array}$ & Reference \\
\hline Hengelo, Netherlands & Urban road & Paving blocks & $750-1,200$ & Overman, 2009 \\
\hline Milan, Italy & Parking garage & Spray coating on asphalt & 4,000 & Crispino \& Vismara, 2010 \\
\hline Forli-Cesena, Italy & Highway & Spray coating on asphalt & 2,500 & Crispino \& Vismara, 2010 \\
\hline Cantù and Monza, Italy & Urban road & Spray coating on asphalt & -- & Crispino \& Vismara, 2010 \\
\hline Ferrara, Italy & Urban road & Spray coating on asphalt & 13,000 & Crispino \& Vismara, 2010 \\
\hline Milan, Italy & Road within tunnel & Spray coating on asphalt & 11,000 & Crispino \& Vismara, 2010 \\
\hline Multiple locations, Japan & $\begin{array}{l}\text { Sidewalks and urban } \\
\text { roads }\end{array}$ & Paving blocks & 25,000 & Beeldens \& Cassar, 2011 \\
\hline $\begin{array}{l}\text { Baton Rouge, LA, United } \\
\text { States }\end{array}$ & Urban road & $\begin{array}{l}\text { Spray coating on } \\
\text { concrete }\end{array}$ & -- & Hassan \& Okeil, 2011 \\
\hline $\begin{array}{l}\text { Den Hoek 3, Wijnegem, } \\
\text { Belgium }\end{array}$ & Industrial site road & $\begin{array}{l}\text { Concrete, two-lift } \\
\text { construction }\end{array}$ & -- & Beeldens \& Boonen, 2012 \\
\hline
\end{tabular}

\subsection{Field Comparison of Photocatalytic and Control Pavement Sections}

Table 2.4a summarizes the field studies that reported a percent change in $\mathrm{NO}_{\mathrm{x}}$ concentration between control and photocatalytic sections. For the studies listed, the Borgo Palazzo report provides the most detailed data. The proposed locations for the control and photocatalytic locations were monitored prior to the study, verifying that each section demonstrated similar characteristics for $\mathrm{NO}_{\mathrm{x}}$ pollution concentration and variation with time (Guerrini \& Peccati, 2007). During low irradiance hours, concentration at each section was not measurably different. For daylight hours, when both irradiance and traffic markedly increased, the change in concentration between the control and photocatalytic sections ranged from $20-66 \%$. The report also noted that soiling caused by construction traffic caused a decreased in photocatalytic activity.

In addition to general observations, which comport well with laboratory data, the report from Guerrini and Peccati (2007) also provided new insights specific to field applications. As evidenced by the 1-hour standard promulgated by the USEPA in 2010, short-term exposure to $\mathrm{NO}_{\mathrm{x}}$ is particularly damaging to human health. The control location data display peaks in $\mathrm{NO}_{\mathrm{x}}$ concentration that correspond with high traffic volumes. These peaks are substantially diminished in observations from the photocatalytic section. Furthermore values of percent difference for these instances are substantially above average reports, indicating that photocatalytic pavement is particularly effective as a tool to mitigate short-term spikes in air pollution. Laboratory data has established that photocatalytic pavements oxidize $\mathrm{NO}_{x}$ when a small volume of $\mathrm{NO}_{x}$ is passed over the pavement surface, but it is 
difficult to extrapolate this lab data to large areas. Observations by Guerrini and Peccati (2007) begin to provide this extrapolation by providing measurements at 0.3 and $1.8 \mathrm{~m}$. While measurements at the lower observation point indicate greater $\mathrm{NO}_{\mathrm{x}}$ oxidation, even at $1.8 \mathrm{~m}$ the photocatalytic section values are on average $20 \%$ lower than at the control location.

At the Baton Rouge site, $\mathrm{NO}_{\mathrm{x}}$ concentration was also measured simultaneously for a concrete section coated sprayed with a $\mathrm{TiO}_{2}$ aqueous solution and a control section (Hassan \& Okeil, 2011). To compare the two sections, in one figure the authors reported total daily $\mathrm{NO}_{\mathrm{x}}$ reduction in units of ppb. For each data point, the reported value was greater than $1000 \mathrm{ppb}$. The statistical approach used is difficult to understand and does not facilitate comparisons with other field or laboratory studies. Considering that this value is an order of magnitude greater than the USEPA 1-hour standard, it is highly improbable that the statistic is the difference between locations. Regardless, the report does provide evidence that the pavement oxidizes $\mathrm{NO}_{\mathrm{x}}$ in field applications. Hassan' and Okiel's work also draws correlations between environmental factors and $\mathrm{NO}_{x}$ reduction observed. In concert with lab data, the authors observed that $\mathrm{NO}_{x}$ reduction was negatively correlated to relative humidity and wind speed and positively correlated to irradiance.

The author's consideration of wind direction warrants additional discussion. It is anticipated that the majority field applications of photocatalytic pavement will occur in a street canyon where both natural ventilation is reduced and heavy traffic represents the major portion of $\mathrm{NO}_{\mathrm{x}}$ pollution. For the geometric configuration of a street canyon, longitudinal winds flush the area, preventing accumulation of $\mathrm{NO}_{\mathrm{x}}$. Under transverse winds, the residence time of the pollutant molecule is increased, permitting more time for photocatalytic oxidation and thereby resulting in increased percent $\mathrm{NO}_{\mathrm{x}}$ reduction. This study found that $\mathrm{NO}_{\mathrm{x}}$ reduction was higher when winds were in a longitudinal direction than when winds blew transversely. The result can be explained by the sites geometric conditions. Unlike anticipated applications, this study occurred in an area free from buildings which would prevent natural ventilation. Instead of flushing the surface and diminishing $\mathrm{NO}_{x}$ reduction, longitudinal winds are associated with the highest $\mathrm{NO}_{x}$ residence time at this particular location. Of particular interest, the authors found that transverse winds were especially negative. These winds carry the pollutant off of the pavement. Future stakeholders will need to take time to consider where they install pavements. As mentioned previously, a street canyon may be an especially good location. Due to a lack of natural ventilation, residence time of the pollutant above the photocatalytic surface is increased, enhancing photocatalytic oxidation. 
Available field studies that compare photocatalytic and control sections of pavement highlight multiple factors that influence photocatalytic oxidation and the difficulty in providing data that provides sufficient evidence that will persuade stakeholders to adopt this technology. The reported studies are worthwhile, but additional work must provide more detailed data and data that is collected for a longer duration than that of the present work.

\subsection{Field Measurement of $\mathrm{NO}_{3}^{-}$Deposition}

The comparative approach, which evaluates photocatalytic pavement with reference to a control section, requires significant expenses of both time and dollars. Furthermore, the data obtained can be difficult to evaluate because of multiple factors that influence both the concentration of $\mathrm{NO}_{\mathrm{x}}$ pollution in an area and the effectiveness of photocatalytic oxidation. An alternative approach measures $\mathrm{NO}_{3}{ }^{-}-$the final product of $\mathrm{NO}_{\mathrm{x}}$ photocatalytic oxidation-that accumulates on the surface of a pavement containing $\mathrm{TiO}_{2}$. For photoreactor tests, this approach is described by an international standard (ISO, 2007). Osborn et al. (2012) applied this approach in an effort to evaluate photocatalytic pavements in the field. A section of the pavement surface was isolated and soaked with water. This water was then analyzed for $\mathrm{NO}_{3}{ }^{-}$concentration. For a 7 day observation period, $\mathrm{NO}_{3}{ }^{-}$concentration on the photocatalytic section averaged $0.04 \mathrm{mg} \mathrm{l}^{-1}$ as $\mathrm{N}$ whereas the control section averaged $0.003 \mathrm{mg} \mathrm{l}^{-1}$ as $\mathrm{N}$. While the method holds promise, deficiencies must be addressed in order to use this approach to evaluate photocatalytic pavements. Foremost, the author does not provide evidence that the procedure removes all $\mathrm{NO}_{3}{ }^{-}$from the pavement surface or provide a factor to account for the amount of $\mathrm{NO}_{3}{ }^{-}$that remains on the surface following use of the washing technique. Additionally, the author assumes that all $\mathrm{NO}_{3}{ }^{-}$oxidized remains on the surface and that water is the only factor that can remove the compound. Without factors that account for these uncertainties, the application is quite limited.

\subsection{Modeling Efforts to Predict Field Observations}

Comparative field studies and studies that measure products of $\mathrm{NO}_{3}{ }^{-}$on the photocatalytic surface represent worthwhile steps to validate photocatalytic pavements in the field. However, it is probable that the most useful tool to persuade future stakeholders will be models that can accurately predict $\mathrm{NO}_{\mathrm{x}}$ concentration for photocatalytic and non-photocatalytic pavements. This type of model, would then serve as a tool by which a particular area could be evaluated as a candidate for photocatalytic pavement. After determining an expected decrease in $\mathrm{NO}_{\mathrm{x}}$ concentration for the area, the stakeholders 
could then determine whether the cost of constructing a photocatalytic roadway outweighs other pollution mitigation options.

Based on field data, Hassan and Okeil (2011) provide a nonlinear regression model governed by variables of traffic volume, relative humidity, wind speed, temperature, and irradiance factors. Considering the multiple factors involved, the model's reported $0.70 \mathrm{R}^{2}$ value appears quite high. However application to other test locations is severely limited because upper boundaries are set at values of 52 vehicle $\cdot h^{-1}, 2.7 \mathrm{~m} \cdot \mathrm{s}^{-1}$, and $20^{\circ} \mathrm{C}$ for traffic volume, wind speed, and temperature respectively. Furthermore, the model does not distinguish whether the output result is for the breathing height of an adult or directly at the pavement surface. Although a stakeholder will be regulated by the concentration recorded at a near-road or area-wide monitor, true concern is human welfare. Therefore, models should allow users to determine an estimate of concentration at the breathing heights of both children and adults.

Barmpass et al. (2006) provides a fluid dynamics-based model which can be used to predict the $\mathrm{NO}_{\mathrm{x}}$ abatement effectiveness of photocatalytic materials. Although the model was developed for photocatalytic coatings on buildings, it was also adapted for photocatalytic pavements. A reference scenario was developed with inputs of street and building dimensions, wind speed and direction, and average observed $\mathrm{NO}_{\mathrm{x}}$ concentration. The scenario was then adjusted for photocatalytic oxidation of $\mathrm{NO}_{\mathrm{x}}$ by inclusion of a deposition velocity variable. Incorporating all environmental factors that influence photocatalytic oxidation into a single variable severely limits the model. As noted by the authors this model should only be used as a "rough guide".

Overman's two-dimensional model is based on both fluid dynamics and kinetic equations for photocatalytic oxidation and atmospheric reactions (Overman, 2009). The fluid dynamics components are governed by building and street geometry along with wind speed and direction. The photocatalytic oxidation kinetics component is based upon data obtained by Ballari et al. (2010) and includes inputs to account for irradiance, relative humidity, and $\mathrm{NO}$ and $\mathrm{NO}_{2}$ concentration. In addition, with input of $\mathrm{O}_{3}$, the model accounts for atmospheric photolysis of $\mathrm{NO}_{2}$ by UV irradiance. This model was applied to a road in Hengelo, Netherlands, with predicted reduction ranging from 2-6\% and $10-19 \%$ for $\mathrm{NO}$ and $\mathrm{NO}_{2}$ respectively. The two-dimensional component of the model allows for predictions of concentration at varied heights; however, wind direction is always assumed to be transverse. To account for other wind directions, a three-dimensional model would be required. 


\section{Summary and Research Gaps}

Photocatalytic pavements have generated high interest from researchers and potential stakeholders. With an ever-increasingly stringent regulatory environment, it is highly probable that new approaches will be needed to mitigate $\mathrm{NO}_{\mathrm{x}}$ pollution. Furthermore, while this review places focus on photocatalytic reactions with $\mathrm{NO}_{x}$, benefits exist that cause oxidation of other pollutants detrimental to both the human welfare and the natural environment. At present, multiple areas exist in both laboratory and field research for which additional knowledge is needed. While the body of literature is substantial, future research must seek to strengthen the link between photoreactor and field studies, determine the environmental variables with the greatest impact on $\mathrm{NO}_{\mathrm{x}}$ oxidation rate, and develop models to facilitate selection of roadways for which maximum $\mathrm{NO}_{\mathrm{x}}$ oxidation can be achieved. While the field is novel and fascinating to study, the amount of work to be overcome is still significant. Multiple researchers are needed to address this problem and each will only be able to incrementally move the state of knowledge forward. However, it is the authors' hope that with collective efforts of researchers in this field, a technology that meaningfully abates $\mathrm{NO}_{x}$ pollution can be developed.

\section{Acknowledgements}

The authors wish to thank the National Concrete Pavement Technology Center, the United States Department of Transportation, Essroc Italcementi Group, and Lehigh Hanson, Inc. for providing funding to pursue this review. In addition, the authors are grateful for in-kind services provided by the Missouri Department of Transportation and Fred Weber, Inc.

\section{References}

Amadelli, R., Cassar, L., \& Pepe, C. (2004). U.S. Patent No. 6,824,826.

Ancora, R., Borsa, M., \& Cassar, L. (2012). U.S. Patent No. 8,092,586.

Asadi, S., Hassan, M. M., Kevern, J. T., \& Rupnow, T. (2012). Development of Photocatalytic Pervious Concrete Pavement for Air and Stormwater Improvements. Transportation Research Record.

Ballari, M. M., Hunger, M., Hüsken, G., \& Brouwers, H. J. H. (2009). Heterogeneous Photocatalysis Applied to Concrete Pavement for Air Remediation. Paper presented at the 3rd International Symposium on Nanotechnology in Construction (NICOM 3), Prague, Czech Republic.

Ballari, M. M., Hunger, M., Hüsken, G., \& Brouwers, H. J. H. (2010). NOx photocatalytic degradation employing concrete pavement containing titanium dioxide. Applied Catalysis B-Environmental, 95(3-4), 245-254. doi: 10.1016/j.apcatb.2010.01.002 
Ballari, M. M., Yu, Q. L., \& Brouwers, H. J. H. (2011). Experimental study of the NO and NO2 degradation by photocatalytically active concrete. Catalysis Today, 161(1), 175-180. doi: 10.1016/j.cattod.2010.09.028

Barmpass, P., Moussiopoulos, N., \& Vlahocostas, C. (2006). De-Pollution Prediction Tool \& Integrated Economic Assessment PICADA Project.

Beeldens, A. (2007, October 8-9). Air Purification by Road Materials: Results of the Test Project in Antwerp. Paper presented at the International RILEM Symposium on Photocatalysis, Environment and Construction Materials - TDP 2007, Florence, Italy.

Beeldens, A. (2008). Air purification by pavement blocks: final results of the research at the BRRC. Ljubljana, Slovenia.

Beeldens, A., \& Boonen, E. (2012). A double layered photocatalytic concrete pavement: a durable application with air-purifying properties. Paper presented at the 10th International Conference on Concrete Pavements, Quebec City, Canada.

Beeldens, A., Cassar, L., \& Murata, Y. (2011). Applications of TiO2 Photocatalysis for Air Purification In Y. Ohama \& D. Van Gemert (Eds.), Application of titanium Dioxide Photocatalysis to Construction Materials (1st ed.): Springer.

Berdahl, P., \& Akbari, H. (2007). Evaluation of Titanium Dioxide as a Photocatalyst for Removing Air Pollutants

Bigi, A., \& Harrison, R. M. (2010). Analysis of the air pollution climate at a central urban background site. Atmospheric Environment, 44(16), 2004-2012. doi: 10.1016/j.atmosenv.2010.02.028

Bonafous, L., Cassar, L., Cassat, P., \& Guillot, L. (2007). U.S. Patent No. 7,300,514.

Brauer, M., Hoek, G., Van Vliet, P., Meliefste, K., Fischer, P. H., Wijga, A., . . Brunekreef, B. (2002). Air pollution from traffic and the development of respiratory infections and asthmatic and allergic symptoms in children. American Journal of Respiratory and Critical Care Medicine, 166(8), 10921098. doi: DOI 10.1164/rccm.200108-0070C

Brunekreef, B., Janssen, N. A. H., deHartog, J., Harssema, H., Knape, M., \& vanVliet, P. (1997). Air pollution from truck traffic and lung function in children living near motorways. Epidemiology, 8(3), 298-303.

Cable, J. K., \& Frentress, D. P. (2004). Two-Lift Portland Cement Concrete Pavements to Meet Public Needs. Ames, IA: Center for Portland Cement Concrete Pavement Technology.

Carp, O., Huisman, C. L., \& Reller, A. (2004). Photoinduced reactivity of titanium dioxide. [Review]. Progress in Solid State Chemistry, 32(1-2), 33-177. doi: 10.1016/j.progsolidstchem.2004.08.001 
Casar, L., \& Pepe, C. (2002). U.S. Patent No. 6,406,536.

Cassar, L. (2004). Photocatalysis of cementitious materials: Clean buildings and clean air. [Article]. Mrs Bulletin, 29(5), 328-331.

Cassar, L., Cucitore, R., \& Pepe, C. (2011). U.S. Patent No. 7,960,042.

Cassar, L., \& Pepe, C. (2000). U.S. Patent No. 6,117,229.

Cassar, L., \& Pepe, C. (2002). U.S. Patent No. 6,409,821.

Cassar, L., \& Pepe, C. (2010). European Patent No. 1,600,430.

Chen, M., \& Chu, J. W. (2011). NO(x) photocatalytic degradation on active concrete road surface - from experiment to real-scale application. [Article]. Journal of Cleaner Production, 19(11), 1266-1272. doi: 10.1016/j.jclepro.2011.03.001

City Concept. (2004). D-NOx: The concrete paving block for atmospheric purification Tessenderlo, Belgium.

Clean Air Act, 42 U.S.C. § 7401 et seq. (2008).

Control of emissions from new and in-use highway vehicles and engines, 40 C.F.R. pt. 86.007-11 (2008).

Crispino, M., \& Vismara, S. (2010). Innovative Photocatalytic Pavements Presentation at International Sustainable Pavements Workshop. Airie, VA.

Cucitore, R., Cangiano, S., \& Cassar, L. (2011). U.S. Patent No. 8,039,100.

Dalton, J. S., Janes, P. A., Jones, N. G., Nicholson, J. A., Hallam, K. R., \& Allen, G. C. (2002). Photocatalytic oxidation of NOx gases using TiO2: a surface spectroscopic approach. Environmental Pollution, 120(2), 415-422. doi: 10.1016/s0269-7491(02)00107-0

Demeestere, K., Dewulf, J., De Witte, B., Beeldens, A., \& Van Langenhove, H. (2008). Heterogeneous photocatalytic removal of toluene from air on building materials enriched with TiO2. Building and Environment, 43(4), 406-414. doi: 10.1016/j.buildenv.2007.01.016

Dylla, H., Hassan, M. M., Mohammad, L. N., Rupnow, T., \& Wright, E. (2010). Evaluation of Environmental Effectiveness of Titanium Dioxide Photocatalyst Coating for Concrete Pavement. Transportation Research Record: Journal of the Transportation Research Board, 2164(-1), 46-51. doi: $10.3141 / 2164-06$

Dylla, H., Hassan, M. M., Schmitt, M., Rupnow, T., \& Mohammad, L. N. (2011a). Laboratory Investigation of the Effect of Mixed Nitrogen Dioxide and Nitrogen Oxide Gases on Titanium Dioxide 
Photocatalytic Efficiency in Concrete Pavements. Journal of Materials in Civil Engineering, 23(7), 1087-1093. doi: 10.1061/(asce)mt.1943-5533.0000248

Dylla, H., Hassan, M. M., Schmitt, M., Rupnow, T., Mohammad, L. N., \& Wright, E. (2011b). Effects of Roadway Contaminants on Titanium Dioxide Photodegradation of NOx. Paper presented at the Transportation Research Board 90th Annual Meeting, Washington, DC.

Essroc. (2008). LEED-NC ${ }^{\circledR} 2.2$ Guide:Using TX Arca ${ }^{\circledR}$ and TX Aria ${ }^{\circledR}$ Photocatalytic Cements for New Construction and Major Renovations Nazareth, PA.

Finkelstein, M. M., Jerrett, M., \& Sears, M. R. (2004). Traffic air pollution and mortality rate advancement periods. American Journal of Epidemiology, 160(2), 173-177. doi: Doi 10.1093/Aje/Kwh181

Frank, S. N., \& Bard, A. J. (1977). Heterogeneous Photocatalytic Oxidation of Cyanide Ion in AqueousSolutions at Tio2 Powder. Journal of the American Chemical Society, 99(1), 303-304.

Fujishima, A., Hashimoto, K., \& Watanabe, T. (1999). TiO2 photo catalysis: fundamentals and applications. Tokyo: BKC, Inc.

Fujishima, A., \& Honda, K. (1972). Electrochemical Photolysis of Water at a Semiconductor Electrode. [10.1038/238037a0]. Nature, 238(5358), 37-38.

Fujishima, A., Rao, T. N., \& Tryk, D. A. (2000). Titanium dioxide photocatalysis. Journal of Photochemistry and Photobiology C: Photochemistry Reviews, 1(1), 1-21. doi: 10.1016/s1389-5567(00)00002-2

Fujishima, A., \& Zhang, X. T. (2006). Titanium dioxide photocatalysis: present situation and future approaches. Comptes Rendus Chimie, 9(5-6), 750-760. doi: DOI 10.1016/j.crci.2005.02.055

Fujishima, A., Zhang, X. T., \& Tryk, D. A. (2008). TiO(2) photocatalysis and related surface phenomena. [Review]. Surface Science Reports, 63(12), 515-582. doi: 10.1016/j.surfrep.2008.10.001

Garshick, E., Laden, F., Hart, J. E., \& Caron, A. (2003). Residence near a major road and respiratory symptoms in US veterans. Epidemiology, 14(6), 728-736. doi: DOI 10.1097/01.ede.0000082045.50073.66

Gignoux, L., Christory, J. P., \& Petit, J. F. (2010). Concrete roadways and air quality -- Assessment of trials in Vanes in the hear of the Paris region. Paper presented at the 12th International Symposium on Concrete Raods, Sevilla Spain.

Goodeve, C. F., \& Kitchener, J. A. (1938). Photosensitisation by titanium dioxide. Transactions of the Faraday Society, 34, 570-579. 
Grant, R. H., \& Slusser, J. R. (2005). Estimation of ultraviolet-A irradiance from measurements of 368-nm spectral irradiance. Journal of Atmospheric and Oceanic Technology, 22(12), 1853-1863. doi: 10.1175/jtech1823.1

Guerrini, G. L. (2012). U.S. Patent No. 20,120,270,721.

Guerrini, G. L., \& Peccati, E. (2007, October 8-9). Photocatalytic Cementitious Roads for Depollution. Paper presented at the International RILEM Symposium on Photocatalysis, Environment and Construction Materials - TDP 2007, Florence, Italy.

Hall, K., Dawood, D., Vanikar, S., Tally, R., Cackler, T., Correa, A., . . Voigt, G. (2007). Long-Life Concrete PAvements in Europe and Canda: Federal Highway Administration.

Hassan, M. M., Dylla, H., Mohammad, L. N., \& Rupnow, T. (2010a, April). Durability of Titanium Dioxide Photocatalytic Layer for Pavement Surfaces. Paper presented at the 46th Annual Conference of the Associated Schools of Construction, Boston, Massachusetts.

Hassan, M. M., Dylla, H., Mohammad, L. N., \& Rupnow, T. (2010b). Effect of Application Methods on the Effectiveness of Titanium Dioxide as a Photocatalyst Compound to Concrete Pavement. Paper presented at the Transportation Research Board 89th Annual Meeting, Washington, D.C.

Hassan, M. M., Dylla, H., Mohammad, L. N., \& Rupnow, T. (2010c). Evaluation of the durability of titanium dioxide photocatalyst coating for concrete pavement. [Article]. Construction and Building Materials, 24(8), 1456-1461. doi: 10.1016/j.conbuildmat.2010.01.009

Hassan, M. M., \& Okeil, A. (2011). Field and Laboratory Investigation of Photocatalytic Pavements: Final Report. Baton Rouge, LA: Gulf Coast REsearch Center for Evacuation and Transportation Resiliency.

Herrmann, J. M. (1999). Heterogeneous photocatalysis: fundamentals and applications to the removal of various types of aqueous pollutants. Catalysis Today, 53(1), 115-129.

Herrmann, J. M., Péruchon, L., Puzenat, E., \& Guillard, C. (2007, October 8-9). Photocatalysis: from fundamentals to self-cleaning glass applications. Paper presented at the International RILEM Symposium on Photocatalysis, Environment and Construction Materials - TDP 2007, Florence, Italy.

Hüsken, G., \& Brouwers, H. J. H. (2008, June 16-20). Air purification by cementitious materials: Evaluation of air purifying properties. Paper presented at the International Conference on Construction and Building Technology, Kuala Lumpur, Malaysia.

Husken, G., Hunger, M., \& Brouwers, H. J. H. (2009). Experimental study of photocatalytic concrete products for air purification. Building and Environment, 44(12), 2463-2474. doi: 10.1016/j.buildenv.2009.04.010 
Hüsken, G., Hunger, M., \& Brouwers, H. J. H. (2009). Experimental study of photocatalytic concrete products for air purification. Building and Environment, 44(12), 2463-2474. doi: DOI 10.1016/j.buildenv.2009.04.010

Hwang, S., Lee, M. C., \& Choi, W. (2003). Highly enhanced photocatalytic oxidation of CO on titania deposited with Pt nanoparticles: kinetics and mechanism. Applied Catalysis B-Environmental, 46(1), 49-63. doi: 10.1016/s0926-3373(03)00162-0

Ibusuki, T., \& Takeuchi, K. (1994). REMOVAL OF LOW CONCENTRATION NITROGEN-OXIDES THROUGH PHOTOASSISTED HETEROGENEOUS CATALYSIS. Journal of Molecular Catalysis, 88(1), 93-102. doi: 10.1016/0304-5102(93)e0247-e

ISO. (2007). Fine ceramics (advanced ceramics, advanced technical ceramics) -- Test method for airpurification performance of semiconducting photocatalytic materials -- Part 1: Removal of nitric oxide (Vol. 22197-1:2007): ISO.

Italcementi. (2006). TX Active by Italcementi. Bergamo, Italy.

Italcementi. (2009). TX Active, The Photocatalytic Active Principle: Technical Report. Retrieved from http://www.italcementigroup.com/NR/rdonlyres/96036B14-4C6D-4E07-9854-

1B1CE1AD6593/0/TXactivetechnicalreport2009.pdf

Jacoby, W. A., Blake, D. M., Noble, R. D., \& Koval, C. A. (1995). KINETICS OF THE OXIDATION OF TRICHLOROETHYLENE IN AIR VIA HETEROGENEOUS PHOTOCATALYSIS. Journal of Catalysis, 157(1), 87-96. doi: 10.1006/jcat.1995.1270

JIS. (2010). Fine ceramics (advanced ceramics, advanced technical ceramics)--Test method for airpurification performance of semiconducting photocatalytic materials--Part 1: Removal of nitric oxide. (JIS R 1701-1:2010). Tokyo, Japan.

Keidel, E. (1929). Farben-zeitung, 34, 1242.

Kim, J. J., Smorodinsky, S., Lipsett, M., Singer, B. C., Hodgson, A. T., \& Ostro, B. (2004). Traffic-related air pollution near busy roads - The East Bay children's respiratory health study. American Journal of Respiratory and Critical Care Medicine, 170(5), 520-526. doi: DOI 10.1164/rccm.200403-2810C

Kumar, P., Dushenkov, V., Motto, H., \& Raskin, I. (1995). PHYTOEXTRACTION - THE USE OF PLANTS TO REMOVE HEAVY-METALS FROM SOILS. Environmental Science \& Technology, 29(5), 1232-1238. doi: $10.1021 /$ es00005a014

Lim, T. H., Jeong, S. M., Kim, S. D., \& Gyenis, J. (2000). Photocatalytic decomposition of NO by TiO2 particles. Journal of Photochemistry and Photobiology a-Chemistry, 134(3), 209-217. doi: 10.1016/s1010-6030(00)00265-3 
MECA. (2007). Frequently Asked Questions about the Installation of Emission Control Technology on Existing Diesel Engines Washington, D.C.: Manufacturers of Emission Controls Association Retrieved from http://www.meca.org/galleries/defaultfile/diesel\%20retrofit\%20FAQ\%200507.pdf.

Murata, Y., Kamitani, K., \& Takeuchi, K. (2000). Air Purifying Blocks Based on Photocatalysis. Paper presented at the Japan Interlocking BLock Pavement Engineering Association World Congress 2000, Tokyo, Japan.

Murata, Y., Tawara, H., Obata, H., \& Murata, K. (2003). European Patent No. 0,786,283.

Murata, Y., \& Tobinai, K. (2002). Influence of various factors on NOx removal performance of permeable interlocking block based on photocatalysis. Journal of Structural and Construction Engineering(Transactions of AIJ)(555), 9-15.

Murruni, L., Conde, F., Leyva, G., \& Litter, M. I. (2008). Photocatalytic reduction of $\mathrm{Pb}(\mathrm{II})$ over $\mathrm{TiO}(2)$ : New insights on the effect of different electron donors. [Article]. Applied Catalysis BEnvironmental, 84(3-4), 563-569. doi: 10.1016/j.apcatb.2008.05.012

Obee, T. N., \& Brown, R. T. (1995). TIO2 PHOTOCATALYSIS FOR INDOOR AIR APPLICATIONS - EFFECTS OF HUMIDITY AND TRACE CONTAMINANT LEVELS ON THE OXIDATION RATES OF FORMALDEHYDE, TOLUENE, AND 1,3-BUTADIENE. Environmental Science \& Technology, 29(5), 1223-1231. doi: 10.1021/es00005a013

Ohama, Y., \& Van Gemert, D. (2011). Introduction. In Y. Ohama \& D. Van Gemert (Eds.), Application of titanium Dioxide Photocatalysis to Construction Materials (1st ed.): Springer.

Ohno, T., Sarukawa, K., Tokieda, K., \& Matsumura, M. (2001). Morphology of a TiO2 photocatalyst (Degussa, P-25) consisting of anatase and rutile crystalline phases. [Article]. Journal of Catalysis, 203(1), 82-86. doi: 10.1006/jcat.2001.3316

Osborn, D., Hassan, M. M., \& Dylla, H. (2012). Quantification of NOX reduction via Nitrate Accumulation on a TiO2 Photocatalytic Concrete Pavement. Transportation Research Record(??), ??

Overman, H. T. J. (2009). Simulation model for NOX distributions in a street canyon with air purifying pavement. (Master: Civil Engineering \& Management), University of Twente, Eschede, Netherlands.

Paz, Y. (2010). Application of TiO2 photocatalysis for air treatment: Patents' overview. Applied Catalysis B-Environmental, 99(3-4), 448-460. doi: 10.1016/j.apcatb.2010.05.011

Peral, J., \& Ollis, D. F. (1992). HETEROGENEOUS PHOTOCATALYTIC OXIDATION OF GAS-PHASE ORGANICS FOR AIR PURIFICATION - ACETONE, 1-BUTANOL, BUTYRALDEHYDE, FORMALDEHYDE, AND META-XYLENE OXIDATION. Journal of Catalysis, 136(2), 554-565. doi: 10.1016/00219517(92)90085-v 
PICADA. (2011). Guideline for end-users, GROWTH Project GRD1-2001-40449.

Poon, C. S., \& Cheung, E. (2007). NO removal efficiency of photocatalytic paving blocks prepared with recycled materials. Construction and Building Materials, 21(8), 1746-1753. doi: 10.1016/j.conbuildmat.2006.05.018

Primary National Ambient Air Quality Standards for Nitrogen Dioxide: Final Rule, 75 Fed. Reg. 6474 (2010) (to be codified at 40 C.F.R. pts. 50 and 58).

Primary National Ambient Air Quality Standards for Nitrogen Dioxide: Proposed Rule, 75 Fed. Reg. 34404 (2009) (to be codified at 40 C.F.R. pts. 50 and 58).Rousseau, P., Drouadaine, I., \& Mazé, M. (2009, May-June). Le procédé NOxer ${ }^{\circledR}$ : du développement aux mesures de dépollution sur site. Revue générale des routes et de l'aménagement.

Sclafani, A., \& Herrmann, J. M. (1996). Comparison of the photoelectronic and photocatalytic activities of various anatase and rutile forms of titania in pure liquid organic phases and in aqueous solutions. Journal of Physical Chemistry, 100(32), 13655-13661. doi: 10.1021/jp9533584

Sikkema, J. K., Alleman, J. E., Ong, S. K., Koziel, J. A., Taylor, P. C., \& Bai, H. (2012, September 18-21). Photocatalytic Concrete Pavements: Decrease in NOX Oxidation due to Reaction Product Blinding. Paper presented at the International Conference on Long-Life Concrete Pavement2012, Seattle, Washington.

Strini, A., Cassese, S., \& Schiavi, L. (2005). Measurement of benzene, toluene, ethylbenzene and o-xylene gas phase photodegradation by titanium dioxide dispersed in cementitious materials using a mixed flow reactor. Applied Catalysis B-Environmental, 61(1-2), 90-97. doi: 10.1016/j.apcatb.2005.04.009

The Cadmus Group, I. (2009). Nutrient Control Design Manual: State of Technology Review Report.

Thoma, E. D., Shores, R. C., Isakov, V., \& Baldauf, R. W. (2008). Characterization of near-road pollutant gradients using path-integrated optical remote sensing. Journal of the Air \& Waste Management Association, 58(7), 879-890. doi: Doi 10.3155/1047-3289.58.7.879

Tompkins, D. T., Lawnicki, B. J., Zeltner, W. A., \& Anderson, M. A. (2005). Evaluation of photocatalysis for gas-phase air cleaning - Part 1: Process, technical, and sizing considerations. Ashrae Transactions 2005, Vol 111, Pt 2, 111, 60-84.

UNI. (2007). (UNI 1247:2007). Milan, Italy.

USEPA. (1994). Environmental Fact Sheet: Air Toxics from Motor Vehicles. (EPA400-F-92-004). Washington, D.C.

USEPA. (1999). Technical Bulletin: Nitrogen Oxides (NOx), Why and How They Are Controlled. (EPA456/F-99-006R). Research Triangle Park, NC. 
USEPA. (2001). National Air Quality and Emissions Trends Report, 1999. (EPA 454/R-01-004). Washington, D.C.

USEPA. (2006). The Master List of Compounds Emitted by Mobile Sources - 2006. (EPA420-B-06-002).

USEPA. (2007). Summary of Current and Historical Light-Duty Vehicle Emission Standards. Washington, D.C.: Retrieved from http://www.epa.gov/greenvehicles/detailedchart.pdf.

USEPA. (2008). Risk and Exposure Assessment to Support the Review of the NO2 Primary National Ambient Air Quality Standard (EPA-452/R-08-008a). Research Triangle Park, NC.

USEPA. (2009). National Primary Drinking Water Regulations. (EPA 816-F-09-004). Washington, D.C.

USEPA. (2010a). Design Values (Average 1-Hour 98th Percentiles over 3 Years) by County for Nitrogen Dioxide Research Triangle Park, NC: Retrieved from http://www.epa.gov/oaqps001/nitrogenoxides/pdfs/NO2_final_designvalues_0608_Jan22.pdf.

USEPA. (2010b). Fact Sheet: Final Revisions to the National Ambient Air Quality Standards for Nitrogen Dioxide. Research Triangle Park, NC: Retrieved from http://www.epa.gov/oaqps001/nitrogenoxides/pdfs/20100122fs.pdf.

USEPA. (2010c). Final Regulatory Impact Analysis (RIA) for the NO2 National Ambient Air QUality Standards (NAAQS). Research Triangle Park, NC: Retrieved from http://www.epa.gov/ttnecas1/regdata/RIAs/FinalNO2RIAfulldocument.pdf.

USEPA. (2012a, July 20). Green Vehicle Guide: Frequent Questions Retrieved July 20, 2012, from http://www.epa.gov/greenvehicles/Faq.do

USEPA. (2012b, July 5). Heavy-Duty Highway Compression-Ignition Engines And Urban Buses -- Exhaust Emission Standards Retrieved July 19, 2012, from http://epa.gov/oms/standards/heavyduty/hdci-exhaust.htm

Vardoulakis, S., Fisher, B. E. A., Pericleous, K., \& Gonzalez-Flesca, N. (2003). Modelling air quality in street canyons: a review. Atmospheric Environment, 37(2), 155-182. doi: 10.1016/s13522310(02)00857-9

Wang, Y. J., DenBleyker, A., McDonald-Buller, E., Allen, D., \& Zhang, K. M. (2011). Modeling the chemical evolution of nitrogen oxides near roadways. Atmospheric Environment, 45(1), 43-52. doi: 10.1016/j.atmosenv.2010.09.050

Watts, M. J., \& Cooper, A. T. (2008). Photocatalysis of 4-chlorophenol mediated by TiO(2) fixed to concrete surfaces. Solar Energy, 82(3), 206-211. doi: 10.1016/j.solener.2007.08.001

Yu, J. C. (2002). Ambient Air Treatment by Titanium Dioxide (TiO2 ) Based Photocatalyst in Hong Kong Hong Kong. 
Yu, J. C. (2003). Deactivation and Regeneration of Environmentally Exposed Titanium Dioxide (TiO2) Based Products Hong Kong.

Zhao, J., \& Yang, X. D. (2003). Photocatalytic oxidation for indoor air purification: a literature review. Building and Environment, 38(5), 645-654. doi: 10.1016/s0360-1323(02)00212-3

Zhao, Y., Han, J., Shao, Y., \& Feng, Y. (2009). Simultaneous SO(2) and NO removal from flue gas based on $\mathrm{TiO}(2)$ photocatalytic oxidation. Environmental Technology, 30(14), 1555-1563. doi: $10.1080 / 09593330903313786$ 


\title{
CHAPTER 3. MASS TRANSFER AND KINETICS OF NO MITIGATION BY PHOTOCATALYTIC PAVEMENT
}

\author{
J.K. Sikkema ${ }^{1}$, J.E. Alleman ${ }^{2}$, and S.K. Ong ${ }^{2}$
}

\section{Abstract}

Effective application of photocatalytic pavements for the mitigation of $\mathrm{NO}_{\mathrm{x}}$ pollution requires an understanding of relevant mass transfer and kinetic phenomena. In the overall process by which NO is oxidized into $\mathrm{HNO}_{3}$, the aerial $\mathrm{NO}$ mass must be transferred to, adsorbed on, and chemically reacted at photocatalytically active sites. Prior publications in the area of photocatalytic pavements have applied a Langmuir-Hinshelwood model to accurately predict the NO reaction rate $\left(r_{N O}\right)$ associated with adsorption and chemical reaction steps. For standard conditions in the flow-through photoreactor that will be used by the authors, application of the Langmuir-Hinshelwood model predicted that $r_{N O}=$ $33.8 \mathrm{nmol} \cdot \mathrm{m}^{-2} \cdot \mathrm{s}^{-1}$. This value is substantially lower than the molar flux for mass transport $\left(W_{N O, z}\right)$ of $283 \mathrm{nmol} \cdot \mathrm{m}^{-2} \cdot \mathrm{s}^{-1}$, which was determined by application of Fick's first law of diffusion. The calculation that $r_{N O}$ is much less than $W_{N O, Z}$ indicates that the overall process is limited by the adsorption and reaction steps. A conservative application to field environments, where the NO concentration was set at the NAAQS standard of $53 \mathrm{ppbv}$, found that $r_{N O}=4.0 \mathrm{nmol} \cdot \mathrm{m}^{-2} \cdot \mathrm{s}^{-1}$ and $W_{N O, z}=20.5 \mathrm{nmol} \cdot \mathrm{m}^{-2}$. $s^{-1}$. Evaluation of UV-A irradiance and relative humidity data found that this conclusion would also be reached in many regions of the United States. These findings allow simplification of future studies and modeling efforts because, for most cases, complex mass transport processes, which vary depending on geometry and flow regime, do not need to be considered.

\footnotetext{
${ }^{1}$ Instructor; Engineering, Dordt College, Sioux Center, lowa

${ }^{2}$ Professor; Civil, Construction, and Environmental Engineering, lowa State University, Ames, lowa
} 


\section{Notation List}

$$
\begin{aligned}
& B=\text { photoreactor width } \\
& k_{c}=\text { mass transfer coefficient } \\
& B_{N O}=\text { molar flux for NO resulting from bulk } \\
& \text { motion of the fluid } \\
& k_{N O}^{\prime}=\text { reaction rate constant for oxidation of NO } \\
& k_{t}=\text { thermal conductivity } \\
& C_{A, \text { bulk }}=\text { concentration of species } A \text { in the bulk } \\
& \text { fluid } \\
& L_{\text {char }}=\text { characteristic length } \\
& L_{d}=\text { length for development of a laminar } \\
& C_{A, \text { surface }}=\text { concentration of species } A \text { at the } \\
& \text { catalyst surface } \\
& \text { parabolic velocity profile } \\
& N u=\text { Nusselt number } \\
& C_{g}=\text { reactant concentration } \\
& C_{N O, b u l k}=\text { concentration of } \mathrm{NO} \text { in the air over } \\
& \text { photocatalytic surface } \\
& C_{\mathrm{NO}_{2}}=\text { concentration of } \mathrm{NO}_{2} \text { in the air over } \\
& \text { photocatalytic surface } \\
& C_{W}=\text { concentration of water in the air over } \\
& \text { photocatalytic surface } \\
& D_{A B}=\text { diffusivity of species } A \text { in species } B \\
& D_{N O, A i r}=\text { diffusivity of } \mathrm{NO} \text { in Air } \\
& \frac{d C_{N O}}{d z}=\text { derivative of the concentration of NO with } \\
& \text { respect to } z \\
& E=U \mathrm{U}-\mathrm{A} \text { irradiance } \\
& H=\text { photoreactor slit height } \\
& h=\text { heat transfer coefficient } \\
& J_{N O}=\text { molar flux for NO resulting from diffusion } \\
& K_{d}=\text { adsorption equilibrium constant } \\
& K_{N O}^{\prime}=\text { adsorption equilibrium constant for } \mathrm{NO} \\
& K_{\mathrm{NO}_{2}}^{\prime}=\text { adsorption equilibrium constant for } \mathrm{NO}_{2} \\
& K_{W}=\text { adsorption equilibrium constant for water } \\
& k=\text { reaction rate constant } \\
& \operatorname{Pr}=\text { Prandtl number } \\
& q=\text { heat flux } \\
& R e=\text { Reynolds number } \\
& R e_{L}=\text { Reynolds number for the characteristic } \\
& \text { length } \\
& R e_{t r}=\text { Reynolds number for the transition region } \\
& r=\text { superficial reaction rate } \\
& r_{N O}=\text { superficial reaction rate for NO } \\
& S c=\text { Schmidt number } \\
& S h=\text { Sherwood number } \\
& T_{0}=\text { temperature in bulk fluid } \\
& T_{S}=\text { temperature at surface } \\
& u=\text { molar average velocity } \\
& W_{N O, z}=\text { molar flux for } \mathrm{NO} \text { along z-axis } \\
& \alpha=\text { kinetic parameter for irradiance } \\
& \delta=\text { mean film thickness } \\
& v_{\text {air }}=\text { kinematic viscosity of air }
\end{aligned}
$$

\section{Introduction}

Chapter 2 provided a literature review that focused on research which applied titanium dioxide $\mathrm{TiO}_{2}$ based photocatalysts to various pavement systems in an effort to address air pollution problems 
associated with oxides of nitrogen $\left(\mathrm{NO}_{\mathrm{x}}\right)$. This applied research predominantly consisted of lab-based photoreactor studies and field studies that sought to determine the rate of nitric oxide (NO) removal for different combinations of materials and environments (e.g., Ballari \& Brouwers, 2013; Ballari et al., 2009; Beeldens, 2008; Dylla et al., 2010; Hüsken et al., 2009; and Murata et al., 2000). Evaluation of these various studies requires an understanding of the mass transport and kinetic phenomena that undergird the reported findings. $\mathrm{TiO}_{2}$-based photocatalytic reactions involving the adsorption of a reactant from a gas to a solid surface (e.g., such as the oxidation of $\mathrm{NO}$ by a $\mathrm{TiO}_{2}$-containing pavement) has been predominantly modeled as a heterogeneous catalytic reaction which follows a LangmuirHinshelwood rate model (e.g., Dong et al., 2007; Hunger \& Brouwers, 2009; Ollis, 1993; Yamazaki et al., 1999; and Zhao \& Yang, 2003). Although termed a reaction, the entire process includes the following steps: (1) mass transfer of reactants from bulk fluid to catalyst surface, (2) adsorption of gas-phase reactants onto solid catalyst surface, (3) chemical conversion of reactants into products, (4) desorption from catalyst, and (5) chemical binding of products or mass transfer to bulk fluid (Yamazaki et al., 1999). Figure 3.1 illustrates steps 1 through 3 for the oxidation of $\mathrm{NO}$ by a $\mathrm{TiO}_{2}$-containing pavement. With evaluation these 3 steps, this review will demonstrate that, at both lab and field scales, oxidation of NO is limited by adsorption and reaction of the reactant; consequently mass transfer is not a rate-limiting step. In this demonstration, the steps will be considered in reverse order (i.e., from 3 to 1). Working through the overall reaction steps in this order, permits the establishment of a rate of adsorption and chemical reaction for a given set of environmental parameters. This rate will then be used as a baseline from which to compare the rate of mass transfer at lab and field scales. 


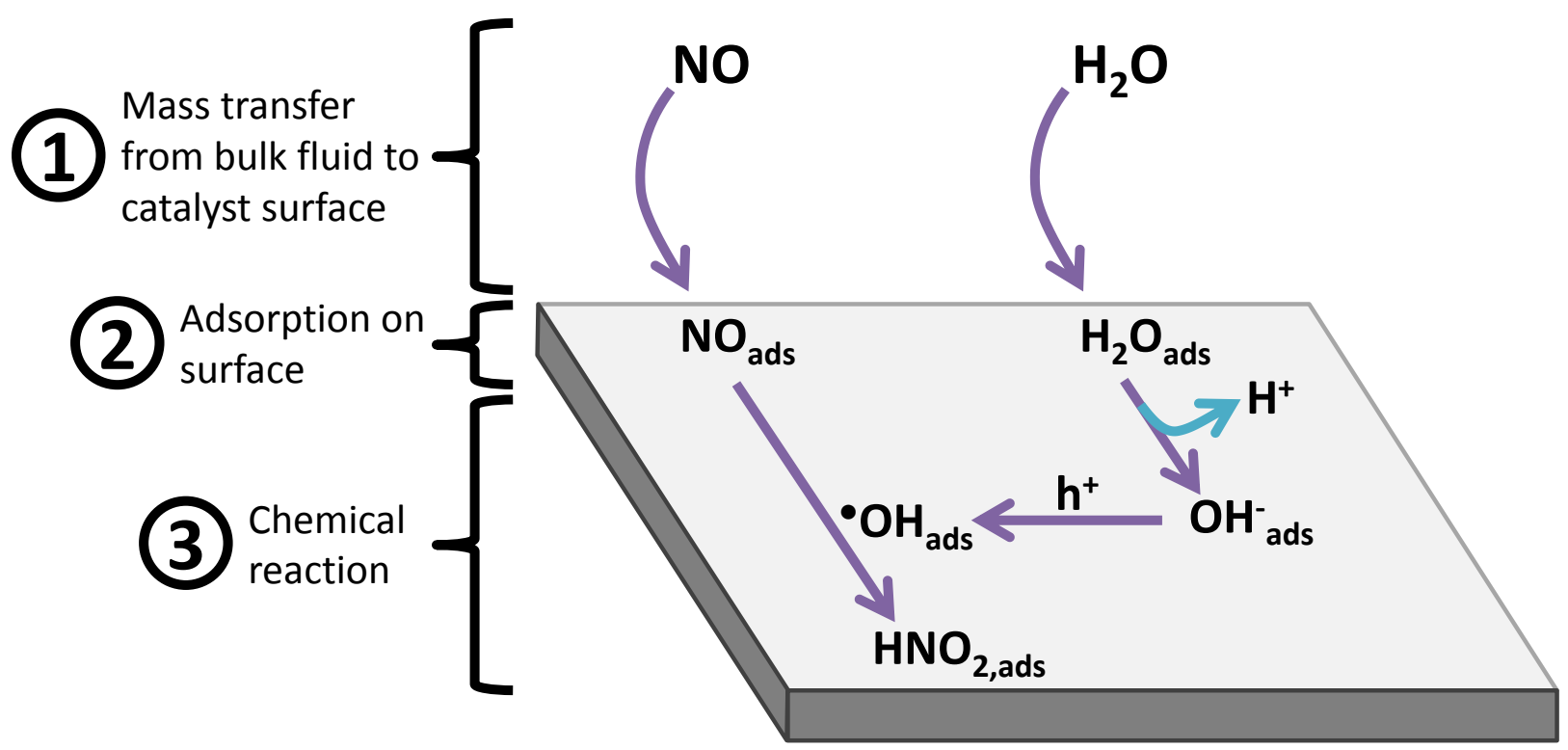

Figure 3.1. Mass transfer, adsorption, and reaction steps of a $\mathrm{TiO}_{2}$-based heterogeneous catalytic reaction that results in the oxidation of $\mathrm{NO}$ (subsequent reactions oxidize $\mathrm{HNO}_{2, \text { ads }}$ to $\mathrm{HNO}_{3, \mathrm{ads}}$ ).

\section{Kinetic Model for NO Adsorption and Oxidation}

As illustrated in Figure 3.1, the oxidation of $\mathrm{NO}$ occurs by hydroxyl radical $\left({ }^{\circ} \mathrm{OH}\right)$ attack following adsorption on a photocatalytically active site. This oxidation reaction also depends on a set of chemical reactions which generate ${ }^{\circ} \mathrm{OH}$; however, these steps can be incorporated into an overall model describing the rate of NO reaction $\left(r_{N O}\right)$ and do not need to be considered separately.

To describe the adsorption and chemical reaction steps for photocatalytic reactions involving $\mathrm{TiO}_{2}$ (i.e., steps 2 and 3 in Figure 3.1), researchers have employed the Langmuir-Hinshelwood model (Dong et al., 2007; Hunger \& Brouwers, 2009; Ollis, 1993; Yamazaki et al., 1999; Zhao \& Yang, 2003). In its general form, the disappearance of a reactant is given as,

$$
r=\frac{k K_{d} C_{g}}{1+K_{d} C_{g}}
$$

where $k$ is a reaction rate constant with primary dimensions of $[N] \cdot[L]^{-2} \cdot[T]^{-1}([N]$ denotes amount of substance, e.g., moles), $K_{d}$ is an adsorption equilibrium constant with dimensions of $[L]^{3} \cdot[N]^{-1}$, and $C_{g}$ is the reactant concentration with dimensions of $[N] \cdot[L]^{-3}$. In addition to NO concentration, published literature has established that the photocatalytic oxidation of $\mathrm{NO}$ is also affected by $\mathrm{NO}_{2}$ concentration, irradiance, and relative humidity (Dylla et al., 2010; Hüsken et al., 2009; Murata et al., 2000). Using data collected from photoreactor studies, Ballari et al. (2010) applied the Langmuir- 
Hinshelwood to account for these additional factors and established the following equation for NO oxidation:

$$
r_{N O}=\frac{k_{N O}^{\prime} K_{N O}^{\prime} C_{N O}}{1+K_{N O}^{\prime} C_{N O}+K_{N O_{2}}^{\prime} C_{N O_{2}}+K_{W} C_{W}}(-1+\sqrt{1+\alpha E}) .
$$

The values $^{1}$ (Ballari et al., 2010) and definitions (Overman, 2009) for these variables are as follows:

$r_{N O}=$ superficial reaction rate at the photocatalytic surface for $\mathrm{NO}\left(\mathrm{mol} \cdot \mathrm{m}^{-2} \cdot \mathrm{s}^{-1}\right)$,

$k_{N O}^{\prime}=4.93 \times 10^{-6} \mathrm{~mol} \cdot \mathrm{m}^{-2} \cdot \mathrm{s}^{-1}=$ reaction rate constant for oxidation of NO,

$K_{N O}^{\prime}=8.48 \times 10^{5} \mathrm{~m}^{3} \cdot \mathrm{mol}^{-1}=$ adsorption equilibrium constant for NO,

$C_{N O}=$ concentration of $\mathrm{NO}$ in the air over photocatalytic surface $\left(\mathrm{mol} \cdot \mathrm{m}^{-3}\right)$,

$K_{\mathrm{NO}_{2}}^{\prime}=3.02 \times 10^{5} \mathrm{~m}^{3} \cdot \mathrm{mol}^{-1}=$ adsorption equilibrium constant for $\mathrm{NO}_{2}$,

$\mathrm{C}_{\mathrm{NO}_{2}}=$ concentration of $\mathrm{NO}_{2}$ in the air over photocatalytic surface $\left(\mathrm{mol} \cdot \mathrm{m}^{-3}\right)$,

$K_{W}=50.7 \mathrm{~m}^{3} \cdot \mathrm{mol}^{-1}=$ adsorption equilibrium constant for water,

$C_{W}=$ concentration of water in the air over photocatalytic surface $\left(\mathrm{mol} \cdot \mathrm{m}^{-3}\right)$,

$\alpha=2.37 \times 10^{-3} \mathrm{~m}^{2} \cdot \mathrm{W}^{-1}=$ kinetic parameter for irradiance, and

$E=\mathrm{UV}-\mathrm{A}$ irradiance $\left(\mathrm{W} \cdot \mathrm{m}^{-2}\right)$.

Ballari et al. (2010) evaluated this model by plotting experimentally observed outlet NO concentration with the NO concentration predicted by the Langmuir-Hinshelwood model. A linear fit of this data had a slope of near unity $(0.988)$, intercept of $9.97 \times 10^{-10}$, and $R^{2}$ value of 0.992 , indicating agreement between the model and experimental results.

This model can be used in order to demonstrate that adsorption and reaction steps are limiting, rather than diffusion. When input variables are set to the standard conditions specified by ISO 221971:2007(E), an international standard frequently used to evaluate photocatalytic pavement materials in a photoreactor (ISO, 2007):

$$
\begin{aligned}
& C_{N O}=4.09 \times 10^{-5} \mathrm{~mol} \cdot \mathrm{m}^{-3}=1 \mathrm{ppmv}, \\
& C_{W}=0.472 \mathrm{~mol} \cdot \mathrm{m}^{-3}=50 \% \text { relative humidity, and } \\
& E=10 \mathrm{~W} \cdot \mathrm{m}^{-2} .
\end{aligned}
$$

Inserting these variables and the constants established by Ballari et al. (2010) into Equation (3.2) finds that $r_{N O}=33.8 \mathrm{nmol} \cdot \mathrm{m}^{-2} \cdot \mathrm{s}^{-1}$. This value will be used as a point of comparison in Section 5.2.1, which will establish the rate of NO diffusion from the bulk gas using the same input variables.

\footnotetext{
${ }^{1}$ Unit conversions have been applied for $[\mathrm{L}]$ and $[\mathrm{T}]$ dimensions.
} 


\section{Mass Transfer of NO}

\subsection{Mass Transfer Background}

Transport processes for environmental air pollutants are governed by advection and diffusion (Fogler, 2006). In flow-through photoreactor evaluations, transport must occur from the bulk fluid (also called the test gas) to the surface of the concrete. This transport process occurs by molecular diffusion, the random motion of particles. In the absence of other gradients (e.g., gravity, temperature) a species (for this discussion, NO) will diffuse from high concentration to low concentration. As a result of the concentration gradient a molar flux of NO $\left(U_{N O}\right)$ exists. This flux is measured with dimensions of $[N] \cdot[L]^{-2} \cdot[T]^{-1}$. In addition to the flux that results from molecular diffusion, the molar flux can also be influenced by the bulk motion of the fluid $\left(B_{N O}\right)$. As a result, the total molar flux is (Fogler, 2006),

$$
W_{N O}=J_{N O}+B_{N O} \text {. }
$$

The bulk motion of the fluid can be expressed in terms of the concentration of NO and the molar average velocity $(u)$, as follows:

$$
B_{N O}=C_{N O} u \text {. }
$$

However, in the present case, a photoreactor, the direction of $u$ is parallel to the pavement surface; therefore, the bulk motion of the fluid does not need to be considered in the flux term.

Fick's first law relates the concentration gradient to the molar diffusive flux of a species. Expressed in one dimension, this law states that,

$$
J_{N O, Z}=-D_{N O, A i r} \frac{d C_{N O}}{d z}
$$

where $J_{N O, z}$ is the diffusional flux of NO along the z-axis, $D_{N O, A i r}$ is the diffusivity of species NO in air, and $\frac{d C_{N O}}{d z}$ is the derivative of the concentration of NO with respect to $z$ (Fogler, 2006).

Fogler (2006) provides a detailed example, which demonstrates that, for diffusion through a stagnant film to a catalyst particle, the molar flux is,

$$
W_{A, Z}=J_{A, Z}=\frac{D_{A B}}{\delta}\left(C_{A, b u l k}-C_{A, \text { surface }}\right)
$$

where $D_{A B}$ is the diffusivity of species $A$ in species $B, \delta$ is the mean film thickness, $C_{A, b u l k}$ is the concentration of species $A$ in the bulk fluid, and $C_{A \text {,surface }}$ is the concentration of species $A$ at the catalyst surface. A mass transfer coefficient $k_{c}$ can be defined as the ratio of $D_{A B}$ to the characteristic length $\left(L_{\text {char }}\right.$ or in this case $\left.\delta\right)$ such that, 


$$
W_{A, Z}=k_{c}\left(C_{A, \text { bulk }}-C_{A, \text { surface }}\right) \text {. }
$$

To apply Equation (3.7) to other flow conditions and geometries requires use of correlations based on dimensionless groups. Due to the fact that heat and mass transfer are analogous, heat and mass transfer correlations are also analogous (Fogler, 2006). Therefore, when experimental data has found a correlation for the heat transfer coefficient $(h)$ based on the Nusselt number $(\mathrm{Nu})$ or Prandlt number $(\operatorname{Pr}), k_{c}$ can be estimated by simply replacing $N u$ and $\operatorname{Pr}$ with the Sherwood number $(S h)$ and Schmidt number $(S c)$, respectively (Fogler, 2006). For example, $h$ is related to the $N u$ as follows:

$$
h=\frac{N u k_{t}}{L_{\text {char }}}
$$

where $k_{t}$ is the thermal conductivity. Therefore, $k_{c}$ is related to $S h$ by the following equation:

$$
k_{c}=\frac{D_{A B} S h}{L_{c h a r}} \text {. }
$$

\subsection{NO Mass Transfer in Photoreactor}

It is the stated goal of this chapter section to establish that $W_{N O, Z}$ is not the rate-limiting step for the photoreactor studies reported in following chapters. Two examples will illustrate this point. The first example will calculate $W_{N O, z}$-under the assumption that diffusion is rate-limiting-using the same inputs applied to calculate $r_{N O}$ in Section 4 and then compare $W_{N O, z}$ to $r_{N O}$. The second will use the approach detailed by Hunger and Brouwers (2009) to estimate the percent removal that would be expected if diffusion was the rate-limiting step.

Prior to completing the two examples outlined above, Equations (3.7) and (3.9) must be used to determine an equation for the diffusional molar flux for the photoreactor used for this dissertation's studies. For the photoreactor geometry (a duct), the characteristic dimension is the hydraulic diameter, which is four times the cross-sectional area divided by the perimeter,

$$
L_{\text {char }}=\frac{4 H B}{2(H+B)^{\prime}}
$$

where $H$ is the reactor slit height and $B$ is the reactor width. When $H \ll B$, it is reasonable to approximate this relationship as,

$$
L_{\text {char }}=\frac{4 H B}{2 B}=2 H
$$

therefore,

$$
W_{N O, Z}=\frac{D_{N O, A i r}}{L_{c h a r}} \operatorname{Sh}\left(C_{N O, \text { bulk }}-C_{N O, \text { surface }}\right)=\frac{D_{N O, A i r}}{2 H} \operatorname{Sh}\left(C_{N O, \text { bulk }}-C_{N O, \text { surface }}\right) .
$$


This relationship is equivalent to the equation developed by Hunger and Brouwers (2009) when seeking to determine the diffusional molar flux for a photoreactor of similar dimensions.

\subsubsection{Determination of $W_{N O, Z}$ and comparison to $r_{N O}$ at standard lab conditions}

If diffusion were the rate limiting step, then NO concentration at the pavement sample's surface would be zero (because NO would be immediately adsorbed and oxidized); therefore, Equation (3.12) reduces to,

$$
W_{N O, Z}=\frac{D_{N O, A i r}}{2 H} \operatorname{Sh}\left(C_{N O, b u l k}\right) .
$$

The solution is dilute; therefore, the diffusion coefficient of NO in air $\left(D_{N O, A i r}\right)$ is approximately the kinematic viscosity $\left(v_{\text {air }}\right)$, which is $1.54 \times 10^{-5} \mathrm{~m}^{2} \cdot \mathrm{s}^{-1}$ (Overman, 2009). Sh (and $\mathrm{Nu}$ ) numbers vary depending on the type of flow and geometry of the system. Re provides information on the type of flow through the photoreactor. For the photoreactor used in this research effort, $H=6 \mathrm{~mm}, B=150 \mathrm{~mm}$, and $L=150 \mathrm{~mm}$. Based on these dimensions, at a flow rate of $3 \mathrm{~L} \cdot \mathrm{min}^{-1}, u_{\text {air }}=0.056 \mathrm{~m} \cdot \mathrm{s}^{-1}$; therefore,

$$
\operatorname{Re}=\frac{u_{\text {air }} 2 \mathrm{~h}}{v_{\text {air }}}=43 .
$$

As noted by Husken et al., 2009, the length $\left(L_{d}\right)$ for development of a laminar parabolic velocity profile in the photoreactor can be estimated with the following equation:

$$
L_{d}=0.1 \cdot R e \cdot H=26 \mathrm{~mm} \text {. }
$$

For the photoreactor setup used, $25 \mathrm{~mm}$ spacers secured the photocatalytic slab along the longitudinal axis. As estimated by Equation (3.19), the length for which entrance effects are present is only slightly longer than the spacer length; therefore, flow can be considered laminar over the slab. With $R e$ determined and the geometry known, $S h$ can be selected. For fully-developed laminar flow through a slit with one insulated side (the equivalent of inert for mass transfer) at constant flux, Mills (1995) lists $N u$ (and therefore $S h$ ) number as 5.385. Inserting these variables and the established constants to Equation (3.13) finds that $W_{N O, Z}=283 \mathrm{nmol} \cdot \mathrm{m}^{-2} \cdot \mathrm{s}^{-1}$. This rate of diffusion is more than $700 \%$ percent greater than $r_{N O}$ which was determined in Section 4; therefore, at standard conditions, adsorption and oxidation are rate limiting. This conclusion remains true for a wide mix of environmental conditions. For example, when NO concentration is reduced to $0.05 \mathrm{ppmv} W_{N O Z}$ is $270 \%$ greater than $r_{N O}$. There are some scenarios whereby these models can be manipulated such that $r_{N O}$ is greater than $W_{N O z}$. For example, if absolute humidity, irradiance, and NO concentration are set to $0.19 \mathrm{~mol} \cdot \mathrm{m}^{-3}$ (the equivalent of $20 \%$ relative humidity at $20^{\circ} \mathrm{C}$ ), $20 \mathrm{~W} \cdot \mathrm{m}^{-2}$, and $0.05 \mathrm{ppmv}, r_{N O}$ is approximately $15 \%$ 
greater than $W_{N O, z}$. However, as will be discussed in Section 5.3, these conditions are unlikely to prevail within the United States

\subsubsection{Determination of percent removal at standard lab conditions if diffusion were rate-limiting}

The conclusion reached in Section 5.2.1 can also be reached by estimating the percent NO removal that would occur if diffusion were the rate limiting step. In this case, percent removal can be determined by applying a mass balance, whereby the decrease in NO concentration that occurs as the test gas travels along the $\mathrm{x}$-axis is solely due to mass transfer to the photocatalytic surface. As was the case in Section 5.2.1, once transferred to the surface, adsorption and conversion of NO are assumed to occur instantaneously. This balance, as formulated by Hunger and Brouwers (2009), is,

$$
u_{\text {air }} h \frac{d C_{N O}}{d x}=-\frac{D_{N O, A i r}}{2 h} \operatorname{Sh} C_{N O} .
$$

With application of the boundary condition that $C_{N O}=C_{N O, \text { in }}$, this mass balance can be separated and integrated as follows:

$$
\begin{aligned}
& \int_{C_{N O, \text { in }}}^{C_{N O \text { out }}} \frac{d C_{N O}}{C_{N O}}=-\frac{D_{D_{N O, A i r}} S h}{2 h^{2} u_{\text {air }}} \int_{0}^{L} d x, \\
& \ln \left(\frac{C_{N O, \text { out }}}{C_{N O, \text { in }}}\right)=-\frac{D_{N O, \text { Air }} S h}{2 h^{2} u_{\text {air }}} L .
\end{aligned}
$$

Applying the exponential function property that $e^{\ln (x)}=x$, Equation (3.18) can be expressed as,

$$
\left(\frac{C_{N O, \text { out }}}{C_{N O, \text { in }}}\right)=e^{-\frac{D_{N O, A i r} S h}{2 h^{2} u_{\text {air }}} L} .
$$

For the photoreactor used in this research effort, $h=6 \mathrm{~mm}, L=150 \mathrm{~mm}$, and $u_{\text {air }}=0.056 \mathrm{~m} \cdot \mathrm{s}^{-1}$.

Substituting these values into Equation (3.19) finds that $\left(\frac{C_{N O, o u t}}{C_{N O, \text { in }}}\right)=0.045$. Therefore, if diffusion to the surface was the rate limiting step for the photoreactor considered, exit concentration would be about $4.5 \%$ of inlet concentration (i.e., 95\% removal). Measurements reported in Chapter 4 reveal that this near-complete level of conversion does not occur (the highest percent NO removal is $62 \%$ ). Therefore, the conclusion that diffusion is not the rate-limiting step in photoreactor studies is reasonable.

\subsection{Field Scale NO Mass Transfer}

Although diffusion of NO to the photocatalytic surface is not the rate limiting step in photoreactor setups, thus far this chapter has not addressed NO transport and adsorption and conversion at field scales. Intuition would suggest that turbulence caused by wind and traffic motion would result in higher rates of diffusion in the field than in the lab. This conclusion can be demonstrated to be correct by considering a conservative example case. For this case NO concentration $\left(C_{N O, b u l k}\right)$ will be set to 53 
ppbv, the primary $\mathrm{NO}_{2}$ national ambient air quality standard ppbv (Primary National Ambient Air Quality Standards for Nitrogen Dioxide: Final Rule, 2010). This is an exceedingly low value considering that in near-road locations, $\mathrm{NO}_{\mathrm{x}}$ concentrations are $30 \%$ to $100 \%$ higher than area-wide concentrations (USEPA, 2010). Air with this NO concentration will be carried by a $5 \mathrm{mi} \cdot \mathrm{hr}^{-1}$ wind $\left(u_{\text {air }}\right)$ that flows transversely across a 24 -ft wide $\left(L_{c h a r}\right)$ photocatalytic roadway. These values are also conservative considering that these pavements have been proposed to augment existing $\mathrm{NO}_{x}$ control strategies for locations where traditional $\mathrm{NO}_{\mathrm{x}}$ mitigation mechanisms (e.g., tailpipe emissions standards) are insufficient to maintain $\mathrm{NO}_{\mathrm{x}}$ at a concentration that does not negatively affect human health. These locations are heavilytrafficked roadways. Along these roadways, localized wind currents generated by vehicular traffic would most certainly be greater than $5 \mathrm{mi} \cdot \mathrm{hr}^{-1}$ at the times when traditional control mechanisms were insufficient.

For this example, the transversely-flowing air which contains NO creates a boundary layer above the pavement surface that NO must diffuse through before it comes into contact with the photocatalytically active sites. Unlike the calculations in Section 5.2.1, Sh cannot be selected based solely on geometry. Instead an appropriate correlation for this boundary layer must be selected. Mills (1995) provides $\mathrm{Nu}$ correlations for various values of $R e$ and $\operatorname{Pr}$ (for mass transfer $N u$ is equivalent to $S h$ and $\operatorname{Pr}$ is equivalent to $S c$ ). For the example given,

$$
\begin{aligned}
& R e=\frac{u_{\text {air }} L_{\text {char }}}{v_{\text {air }}}=1.06 \times 10^{6} \text { and } \\
& S c=\frac{v_{\text {air }}}{D_{N O \text {,air }}}=1 .
\end{aligned}
$$

For these values of $R e$ and $S c$, the correlation provided is,

$$
S h=0.664 R e_{t r}^{\frac{1}{2}} S c^{\frac{1}{3}}+0.036 R e_{L}^{0.8} S c^{0.43}\left[1-\left(\frac{R e_{t r}}{R e_{L}}\right)^{0.8}\right],
$$

where $R e_{L}$ is the Reynolds number for the characteristic length [the value reported in Equation (3.20)] and $R e_{t r}$ is the Reynolds number for the transition region. At the Reynolds number for this example case, the boundary layer can be considered to be turbulent from the leading edge of the pavement; therefore, $R e_{t r}=0$. Input of the values obtained from Equations (3.20) and (3.21) into Equation (3.22) finds that $S h=2.38 \times 10^{3}$. With $S h$ determined, application of Equation (3.12) finds that $W_{N O, z}=$ $20.5 \mathrm{nmol} \cdot \mathrm{m}^{-2} \cdot \mathrm{s}^{-1}$. Using the same input concentration (53 ppbv) and the standard values for relative humidity $(50 \%)$ and irradiance $\left(10 \mathrm{~W} \cdot \mathrm{m}^{-2}\right)$, application of Equation (3.2) finds that $r_{N O}=$ $4.0 \mathrm{nmol} \cdot \mathrm{m}^{-2} \cdot \mathrm{s}^{-1}$. This result indicates that even in this conservative example, the overall reaction by which NO is oxidized is limited by the adsorption and oxidation step. 
As was noted in Section 5.2.1, Equation (3.2) can be manipulated to produce a scenario in which $r_{N O}$ is greater than $W_{N O, z}$. However, diffusion-limited conditions are unlikely to prevail within the United States. For 6 regionally-distributed locations in the United States, Grant and Slusser (2005) provide average values for mean daytime UV-A irradiance and absolute humidity based on data collected over a period of years by the United States Department of Agriculture Ultraviolet Monitoring and Research Program. Input of these values into Equation (3.2) finds the maximum estimate of $r_{N O}$ for a photocatalytic pavement would occur in Nunn, Colorado (a community near Fort Collins), which provides a mix of low absolute humidity $\left(0.25 \mathrm{~mol} \cdot \mathrm{m}^{-3}, 26 \%\right.$ relative humidity at $\left.20^{\circ} \mathrm{C}\right)$ and high UV-A irradiance $\left(22.3 \mathrm{~W} \cdot \mathrm{m}^{2}\right)$. However, even in these ideal conditions, $r_{N O}=13.6 \mathrm{nmol} \cdot \mathrm{m}^{-2} \cdot \mathrm{s}^{-1}$; which is a value less than $W_{\mathrm{NOZ}}$ calculated above. This evaluation confirms that in field applications, it is probable that NO adsorption and oxidation will be the rate-limiting step in the overall photocatalytic reaction.

\section{Conclusions}

In order to effectively apply photocatalytic pavements to mitigate $\mathrm{NO}_{\mathrm{x}}$ pollution, an understanding of the relevant mass transfer and kinetic phenomena is required. The overall photocatalytic reaction, which results in the oxidation of NO, requires a number of steps, including NO mass transfer to the photocatalytic surface, NO adsorption on surface, and chemical reaction. A Langmuir-Hinshelwood rate model has been demonstrated to accurately predict the adsorption and chemical reaction steps and diffusion governs the mass transport that carries NO to the catalytic surface. Application of appropriate transport and kinetic equations found that, in nearly all reasonable cases, the overall rate of NO degradation is limited by the adsorption and oxidation step rather than the diffusion of the species to the surface. This conclusion was found to be true for both observations made in photoreactor-based studies (where $r_{N O}=33.8 \mathrm{nmol} \cdot \mathrm{m}^{-2} \cdot \mathrm{s}^{-1}$ and $W_{N O, Z}=283 \mathrm{nmol} \cdot \mathrm{m}^{-2} \cdot \mathrm{s}^{-1}$ ) and for reasonable field environments within the United States (where $r_{N O}=4 \mathrm{nmol} \cdot \mathrm{m}^{-2} \cdot \mathrm{s}^{-1}$ and $W_{N O, Z}=20.5 \mathrm{nmol}$. $\left.m^{-2} \cdot s^{-1}\right)$. With this understanding of relevant mass transfer and kinetic phenomena, future studies and modeling efforts are simplified because, for most cases, complex mass transport processes which vary depending on geometry and flow regime do not need to be considered.

\section{References}

Ballari, M. M., \& Brouwers, H. J. H. (2013). Full scale demonstration of air-purifying pavement. Journal of hazardous materials, 254-255, 406-414. doi: 10.1016/j.jhazmat.2013.02.012 
Ballari, M. M., Hunger, M., Husken, G., \& Brouwers, H. J. H. (2010). Modelling and experimental study of the NOx photocatalytic degradation employing concrete pavement with titanium dioxide. [Article; Proceedings Paper]. Catalysis Today, 151(1-2), 71-76. doi: 10.1016/j.cattod.2010.03.042

Ballari, M. M., Hunger, M., Hüsken, G., \& Brouwers, H. J. H. (2009). Heterogeneous Photocatalysis Applied to Concrete Pavement for Air Remediation. Paper presented at the 3rd International Symposium on Nanotechnology in Construction (NICOM 3), Prague, Czech Republic.

Beeldens, A. (2008). Air purification by pavement blocks: final results of the research at the BRRC. Ljubljana, Slovenia.

Dong, Y. C., Bai, Z. P., Liu, R. H., \& Zhu, T. (2007). Decomposition of indoor ammonia with TiO2-loaded cotton woven fabrics prepared by different textile finishing methods. [Article; Proceedings Paper]. Atmospheric Environment, 41(15), 3182-3192. doi: 10.1016/j.atmosenv.2006.08.056

Dylla, H., Hassan, M. M., Mohammad, L. N., Rupnow, T., \& Wright, E. (2010). Evaluation of Environmental Effectiveness of Titanium Dioxide Photocatalyst Coating for Concrete Pavement. Transportation Research Record: Journal of the Transportation Research Board, 2164(-1), 46-51. doi: $10.3141 / 2164-06$

Fogler, H. S. (2006). External Diffusion Effects on Heterogeneous Reactions. In H. S. Fogler (Ed.), Elements of Chemical Reaction Engineering (4th ed.). Upper Saddle Rivier, NJ: Pearson Education, Inc.

Grant, R. H., \& Slusser, J. R. (2005). Estimation of ultraviolet-A irradiance from measurements of 368-nm spectral irradiance. Journal of Atmospheric and Oceanic Technology, 22(12), 1853-1863. doi: 10.1175/jtech1823.1

Hunger, M., \& Brouwers, H. J. H. (2009). Self-cleaning surfaces as an innovative potential for sustainable concrete. Paper presented at the Excellence in Concrete Construction through Innovation, Boca Raton, FL.

Hüsken, G., Hunger, M., \& Brouwers, H. J. H. (2009). Experimental study of photocatalytic concrete products for air purification. Building and Environment, 44(12), 2463-2474. doi: DOI 10.1016/j.buildenv.2009.04.010

ISO. (2007). Fine ceramics (advanced ceramics, advanced technical ceramics) -- Test method for airpurification performance of semiconducting photocatalytic materials -- Part 1: Removal of nitric oxide (Vol. 22197-1:2007): ISO.

Mills, A. F. (1995). Basic Heat and Mass Transfer: Richard D. Irwin, Inc.

Murata, Y., Kamitani, K., \& Takeuchi, K. (2000). Air Purifying Blocks Based on Photocatalysis. Paper presented at the Japan Interlocking BLock Pavement Engineering Association World Congress 2000, Tokyo, Japan. 
Ollis, D. F. (1993). Photoreactors For Purification and Decontamination of Air (Vol. 3). Amsterdam: Elsevier Science Publ B V.

Overman, H. T. J. (2009). Simulation model for NOX distributions in a street canyon with air purifying pavement. (Master: Civil Engineering \& Management), University of Twente, Eschede, Netherlands.

Primary National Ambient Air Quality Standards for Nitrogen Dioxide: Final Rule, 75 Fed. Reg. 6474 (2010) (to be codified at 40 C.F.R. pts. 50 and 58).

USEPA. (2010). Final Regulatory Impact Analysis (RIA) for the $\mathrm{NO}_{2}$ National Ambient Air QUality Standards (NAAQS). Research Triangle Park, NC: Retrieved from http://www.epa.gov/ttnecas1/regdata/RIAs/FinalNO2RIAfulldocument.pdf.

Yamazaki, S., Tanaka, S., \& Tsukamoto, H. (1999). Kinetic studies of oxidation of ethylene over a TiO2 photocatalyst. [Article]. Journal of Photochemistry and Photobiology a-Chemistry, 121(1), 55-61. doi: 10.1016/s1010-6030(98)00448-1

Zhao, J., \& Yang, X. D. (2003). Photocatalytic oxidation for indoor air purification: a literature review. Building and Environment, 38(5), 645-654. doi: 10.1016/s0360-1323(02)00212-3 


\title{
CHAPTER 4. PHOTOCATALYTIC CONCRETE PAVEMENTS: LABORATORY INVESTIGATION OF NO OXIDATION RATE UNDER VARIED ENVIRONMENTAL CONDITIONS
}

\author{
A paper to be submitted to Building and Environment \\ J. K. Sikkema ${ }^{1}$, J. E. Alleman ${ }^{2}$, S. K. Ong ${ }^{2}$, and L. Y. Ong ${ }^{3}$
}

\begin{abstract}
1. Abstract
Photocatalytic concrete pavements have been proposed as a novel technology to mitigate $\mathrm{NO}_{\mathrm{x}}$ pollution in near-road environments. $\mathrm{TiO}_{2}$ contained in these pavements catalyzes the oxidation of $\mathrm{NO}_{\mathrm{x}}$ under the influence of UV light. This study employed a photoreactor to perform bench-scale evaluations of NO oxidation rates that occur with changes in NO concentration, irradiance, test gas flow rate, relative humidity, slab water loss and temperature. In accord with previous research, this study observed that NO oxidation rates were positively correlated with NO inlet concentration and irradiance and negatively correlated with relative humidity. On a percent removal basis, a negative correlation existed with flow rate. This correlation was not apparent when evaluated on an oxidation rate basis. Slab water loss - a previously unstudied variable-was found to positively correlate with NO oxidation rate at losses of $0-2 \%$ of saturated mass; however, at losses greater that $2 \%$ a negative correlation was observed. Analysis of collected temperature data indicated a positive correlation; this finding contrasts previous statements which considered this variable insignificant. For the tests conducted, removal rate ranged from 6.2-57 $\mathrm{nmole} \cdot \mathrm{m}^{-2} \cdot \mathrm{s}^{-1}\left(4.0-36 \mathrm{~g} \cdot\right.$ lane-mile $\left.{ }^{-1} \cdot \mathrm{hr}^{-1}\right)$, indicating that when siting field installations careful judgment must be exercised to ensure that environmental conditions promote a substantial level of $\mathrm{NO}_{\mathrm{x}}$ oxidation. $\mathrm{NO}$ emissions from a highway (10 twelve-foot-wide lanes, $\mathrm{AADT}=250,000$ ) were conservatively estimated to be $720 \mathrm{~g} \cdot \mid \mathrm{lane}-\mathrm{mile}^{-1} \cdot \mathrm{hr}^{-1}$. Convection and dispersion will quickly dilute these emissions; however, at the NO oxidation rate values reported in this study, it is not immediately clear that ambient $\mathrm{NO}_{x}$ concentration will be substantially diminished due to the effect of photocatalytic pavements.
\end{abstract}

\footnotetext{
${ }^{1}$ Instructor; Engineering, Dordt College, Sioux Center, lowa

${ }^{2}$ Professor; Civil, Construction, and Environmental Engineering, lowa State University, Ames, lowa

${ }^{3}$ Student; Civil, Construction, and Environmental Engineering, lowa State University, Ames, lowa
} 


\section{Introduction}

Within the United States, an estimated 48 million people live within $90 \mathrm{~m}$ a four-lane (or larger) highway, railroad, or airport (Primary National Ambient Air Quality Standards for Nitrogen Dioxide: Proposed Rule, 2009). This population segment is susceptible to negative health effects associated with $\mathrm{NO}_{2}$ exposure (Thoma et al., 2008; Brauer et al., 2002; Brunekreef et al., 1997; Finkelstein et al., 2004; Garshick et al., 2003; Kim et al., 2004). Nitrogen dioxide $\left(\mathrm{NO}_{2}\right)$, a motor vehicle air pollutant, is regulated by the United States Environmental Protection Agency (USEPA). The agency's justification for this regulation has recently been confirmed with evidence from multiple epidemiologic studies that indicated an association between short-term $\mathrm{NO}_{2}$ exposure and adverse respiratory symptoms, particularly in children and those affected with asthma (USEPA, 2008b).

$\mathrm{NO}_{2}$ falls within a group of highly reactive oxides of nitrogen commonly known as $\mathrm{NO}_{\mathrm{x}}$. Nitric oxide (NO) accounts for $95 \%$ of $\mathrm{NO}_{\mathrm{x}}$ emissions (USEPA, 2001). This pollutant is freely oxidized to $\mathrm{NO}_{2}$ in the atmosphere; hence, the efforts to abate $\mathrm{NO}_{2}$ pollution target $\mathrm{NO}$ emissions. In fact, due to the high reactivity of the various $\mathrm{NO}_{\mathrm{X}}$ species, USEPA assumes all $\mathrm{NO}_{\mathrm{x}}$ in emissions estimates to be in the form of $\mathrm{NO}_{2}$ (USEPA, 2001). USEPA employs various mechanisms in an effort to minimize $\mathrm{NO}_{x}$ exposure (e.g., improvements in public transportation, establishment of lanes for high occupancy vehicles, facilitating non-automobile travel, and promulgation of tailpipe $\mathrm{NO}_{x}$ emissions standards) (Clean Air Act, 2008; USEPA, 2007). $\mathrm{NO}_{\mathrm{x}}$ mitigation strategies are not exempt from the law of diminishing marginal returns; therefore, in addition to efficiently applying conventional mechanisms, novel technologies should be considered. These technologies may yield higher levels of pollution reduction per dollar spent. Photocatalytic pavements represent one of these novel approaches. When exposed to sunlight and in the presence of water molecules, titanium dioxide $\left(\mathrm{TiO}_{2}\right)$ contained within these pavements generates hydroxyl radicals $\left({ }^{\bullet} \mathrm{OH}\right)$, a powerful oxidizing agent. These radicals promote the oxidation of a variety of organic and inorganic pollutants. Notably, the photocatalytic property of these pavements results in oxidation of $\mathrm{NO}_{x}$ to $\mathrm{NO}_{3}^{-}$(Figure 4.1). 


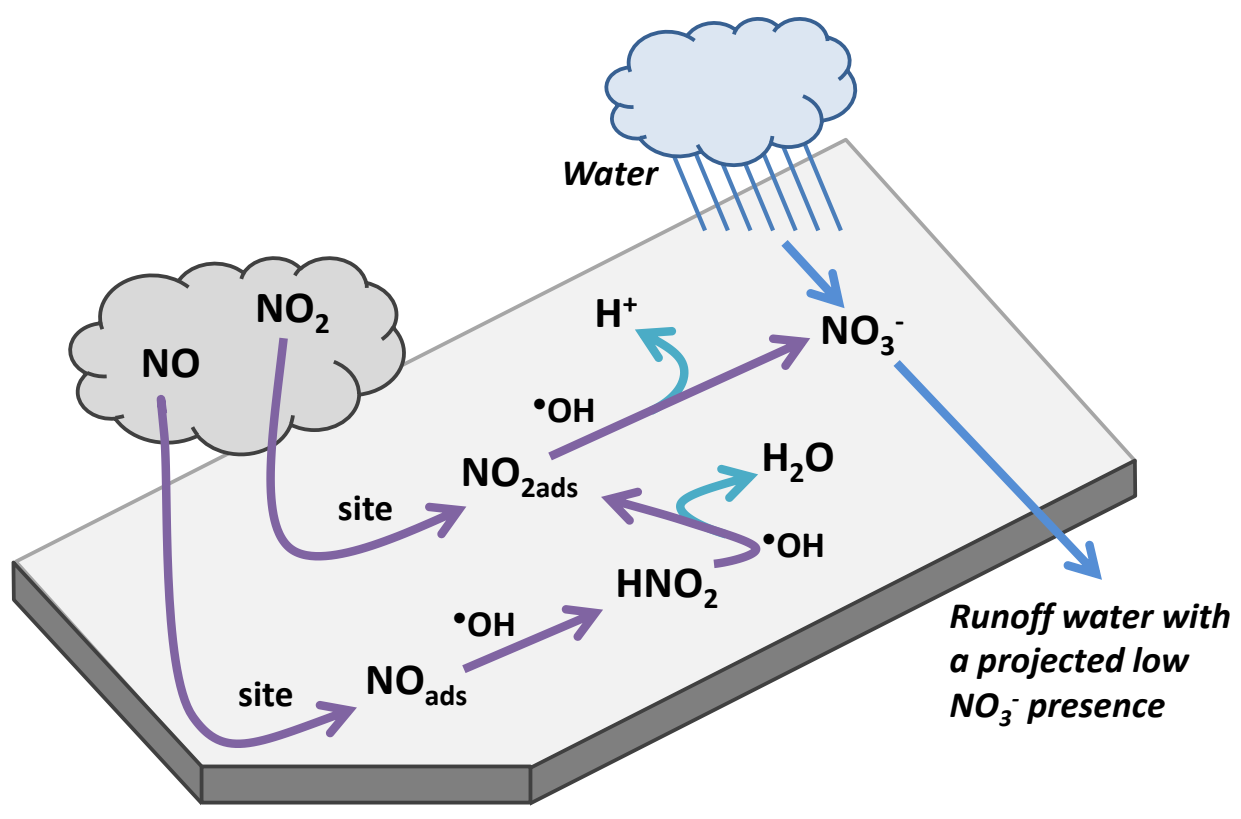

Figure 4.1. Photocatalytic oxidation of $\mathrm{NO}$ and $\mathrm{NO}_{2}$ by pavement containing $\mathrm{TiO}_{2}$ (partially adapted from Ballari et al., 2011).

Employment of these pavements as a mechanism to minimize the ambient concentration of $\mathrm{NO}$ in a targeted area will require an extensive development of what is known about NO oxidation rates under varied environmental conditions. In an effort to provide this new knowledge, various researchers have published accounts of laboratory studies that evaluated photocatalytic pavement specimens within a photoreactor, an experimental apparatus that allows for the control of various environmental conditions (Dylla et al., 2010; Hüsken et al., 2009; Murata \& Tobinai, 2002). Independent variables investigated have included NO concentration, irradiance, test gas flow rate, and relative humidity. Results presented to date have not brought about a consensus in terms of the NO oxidation rates that can be expected. Murata et al. (2000), Hüsken et al. (2009), and Ballari et al. (2011) each suggest that NO oxidation rates positively correlate with NO concentration; however, for tests conducted at the same environmental conditions ( $\left.1.0 \mathrm{ppmv}, 10 \mathrm{~W} \cdot \mathrm{m}^{-2}, 3 \mathrm{~L} \cdot \mathrm{min}^{-1}, 50 \% \mathrm{RH}\right)$ the range in oxidation rates was wide (from 38 to $84 \mathrm{nmole} \cdot \mathrm{m}^{-2} \cdot \mathrm{s}^{-1}$ ). Similarly, publications have noted a positive correlation between irradiance and oxidation rate, but at $10 \mathrm{~W} \cdot \mathrm{m}^{-2}$ calculated oxidation rates were $87 \mathrm{nmole} \cdot \mathrm{m}^{-2} \cdot \mathrm{s}^{-1}$ for Murata et al. (2000) and $24 \mathrm{nmole} \cdot \mathrm{m}^{-2} \cdot \mathrm{s}^{-1}$ for Hüsken et al. (2009). Both Murata et al. (2000) and Hüsken et al. (2009) observed a negative correlation between relative humidity and oxidation rate; however, at $50 \%$ relative humidity oxidation rates differed by $22 \mathrm{nmole} \cdot \mathrm{m}^{-2} \cdot \mathrm{s}^{-1}$. These prior studies have all assumed that the source of ${ }^{\bullet} \mathrm{OH}$ required for photocatalytic oxidation is water vapor from the atmosphere. Yet, given the porous nature of cementitious mixtures, water contained within a pavement could also serve 
as a ${ }^{\bullet} \mathrm{OH}$ source. At the time of placement, these pores can become filled with water. As hydration occurs and pores become filled with air, water that is available as a ${ }^{\bullet} \mathrm{OH}$ source decreases. This decrease in water content could lead to a decrease in the NO oxidation rate of the slab; however, no lab investigation has tested this hypothesis. Hüsken et al. (2009) observed a positive correlation between percent NO removal (as opposed to NO oxidation rate) and flow rate (slope of a linear fit was less than 10). This finding was also reported in Ballari et al. (2010), however in this case slope was only slightly less than -1. Finally, available literature is both vague and contradictory in terms of the relationship between slab temperature and NO oxidation, with one source asserting that oxidation rate increases with an increase in temperature (Beeldens et al., 2011) and another reporting a decrease in oxidation rate with increased temperature (Chen \& Chu, 2011).

Consequently, this study employed TX Active mortar slabs and a photoreactor to evaluate the change in NO oxidation rate that occurs with changes in NO concentration, irradiance, test gas flow rate, relative humidity, slab water content, or temperature. In instances when published data existed, the data collected in this study was compared with data published by other researchers in order to draw conclusions in regards to the NO oxidation rate that can be expected and the variation that occurs between specimens.

\section{Materials and Methods}

\subsection{Photocatalytic Mortar Slab Preparation and Cleaning}

Three photocatalytic mortar slabs were used to evaluate this study's objectives. These slabs measured $152 \mathrm{~mm}(6 \mathrm{in}) \times 152 \mathrm{~mm}(6 \mathrm{in}) \times 25 \mathrm{~mm}(1 \mathrm{in})$. Multiple mechanisms have been used to manufacture photocatalytic slabs (e.g., mixing $\mathrm{TiO}_{2}$ with water or cement, spraying an aqueous $\mathrm{TiO}_{2}$ mixture, or applying a $\mathrm{TiO}_{2}$-enriched slurry). For this study, the researchers used a commerciallyavailable cement that contains $\mathrm{TiO}_{2}$ ( $\mathrm{TX}$ Active, Essroc Italcementi Group, Nazareth, PA). Of note, the $\mathrm{TiO}_{2}$ content in this cement was not provided by the manufacturer. The proportions of the cement (TX Active or Type I), water, and fine aggregate (ASTM C778 standard sand, U.S. Silica Co., Frederick, MD) were recorded as $624 \mathrm{~kg} \cdot \mathrm{m}^{-3}\left(1052 \mathrm{lb} \cdot \mathrm{yd}^{-3}\right), 262 \mathrm{~kg} \cdot \mathrm{m}^{-3}\left(442 \mathrm{lb} \cdot \mathrm{yd}^{-3}\right)$, and $1412 \mathrm{~kg} \cdot \mathrm{m}^{-3}\left(2380 \mathrm{lb} \cdot \mathrm{yd} \mathrm{d}^{-3}\right)$ respectively. Given the small volume of the slabs constructed, the mix did not include coarse aggregate. Except for the coarse aggregate, the relative proportions of materials used to manufacture the laboratory mortar slabs were similar to that of a pavement section poured at a field site, which will be evaluated in future research efforts (Cackler et al., 2012). The slab pour used a two-lift procedure with 
equal volumes of a Type I cement bottom lift followed by a TX Active photocatalytic cement top lift. Following the pour, a damp cloth and plastic sheet were laid over the slab surface for a 24-h curing period. Following this initial curing period, the slabs were removed from the forms and placed in a $100 \%$ relative humidity room for the duration of a $14-d$ curing period.

Prior to evaluating NO oxidation rates (described in Section 3.3), slabs were cleaned by immersion in water (Type I reagent grade) for $2 \mathrm{~h}$ and oven-dried at $60^{\circ} \mathrm{C}\left(140^{\circ} \mathrm{F}\right)$ for $20 \mathrm{~h}$. This procedure was similar to that specified by the International Organization for Standardization (ISO) standard 22197-1:2007(E); this standard governs evaluation of NO removal by photocatalytic materials (ISO, 2007).

\subsection{Experimental Apparatus}

A flow-through poly(methyl methacrylate) (PMMA, i.e., plexiglass) photoreactor served as the primary component of the experimental apparatus. Figure 4.2 provides a schematic of the photoreactor, along with the NO test gas supply system, UV-A light source, and $\mathrm{NO} / \mathrm{NO}_{\mathrm{x}}$ monitor. The international standard, ISO 22197-1:2007(E), provided information on the construction and operation of the setup (ISO, 2007). In addition, the findings from Chapter 3 were used to ensure that for all tests completed in the study, the overall rate of NO degradation was limited by the adsorption and oxidation steps (rather than the diffusion of the species to the photocatalytic surface). The test gas supplied to the photoreactor was a mixture of breathing air (Grade D, Airgas USA, LLC, North Central Region, West Chicago, IL) and $51.6 \pm 1 \%$ ppmv NO balanced in nitrogen (EPA protocol gas, Praxair, Inc., Danbury, CT) adjusted to a NO concentration of $0.11-1.0$ ppmv, relative humidity of $10-70 \%$, and flow rate of 1.5 $5.0 \mathrm{~L} \cdot \mathrm{min}^{-1}$. A UV-A light (XX-15BLB, Ultra-Violet Products, LLC, Upland, CA), directed at the UV-Atransparent optical window located at the top of the photoreactor, activated the photocatalytic properties of the mortar slab. The primary emissions spectrum peak from the light was $365 \mathrm{~nm}$. At the location of the slab surface, the irradiance at $365 \mathrm{~nm}$ was measured to be $0.22-1.5 \times 10^{1} \mathrm{~W} \cdot \mathrm{m}^{-2}$ using 365 nm UV sensor and radiometer (CX-365 and VLX-3W, Vilber Lourmat, Marne-la-Vallée, France). Except for instances when temperature was investigated as an independent variable, slab temperature was room temperature (approximately $25^{\circ} \mathrm{C}$ ).

Within the reactor, $25 \mathrm{~mm}$ ( 1 in) wide PMMA spacers secured the slab's position and were set at a height that was either flush with or less than $2 \mathrm{~mm}$ below the slab surface. The gas flowed over the slab through a cross section with a width of $150 \mathrm{~mm}(6 \mathrm{in})$ and a height $(\mathrm{H})$ of approximately $6 \mathrm{~mm}(0.25 \mathrm{in})$. Turbulent airflow over the slab would introduce additional variability in the test. Using the approach 
detailed in Husken et al., 2009, Reynolds number (Re) was calculated to be 42.6 using an air kinematic viscosity of $1.54 \times 10^{-5} \mathrm{~m}^{2} \cdot \mathrm{s}^{-1}\left(1.66 \times 10^{-5} \mathrm{ft}^{2} \cdot \mathrm{s}^{-1}\right)$ and an air flow rate of $3 \mathrm{~L} \cdot \mathrm{min}^{-1}\left(0.8 \mathrm{gal} \cdot \mathrm{min}^{-1}\right)$. The length $\left(L_{d}\right)$ for a parabolic velocity profile in the photoreactor was estimated to be approximately $27.1 \mathrm{~mm}(1.1$ in) by the following equation: $L_{d}=0.1 \cdot R e \cdot H$. The estimated length was slightly longer than the length of the PMMA spacers, which indicates that approximately $1.1 \%$ of the slab surface did not have a fully developed parabolic velocity profile. At $3 \mathrm{~L} \cdot \mathrm{min}^{-1}$, theoretical retention time of the test gas within the photoreactor was estimated to be $38 \mathrm{~s}$. Theoretical retention time of the test gas in the volume above the slab at $3 \mathrm{~L} \cdot \mathrm{min}^{-1}$ was estimated to be $2.7 \mathrm{~s}$.

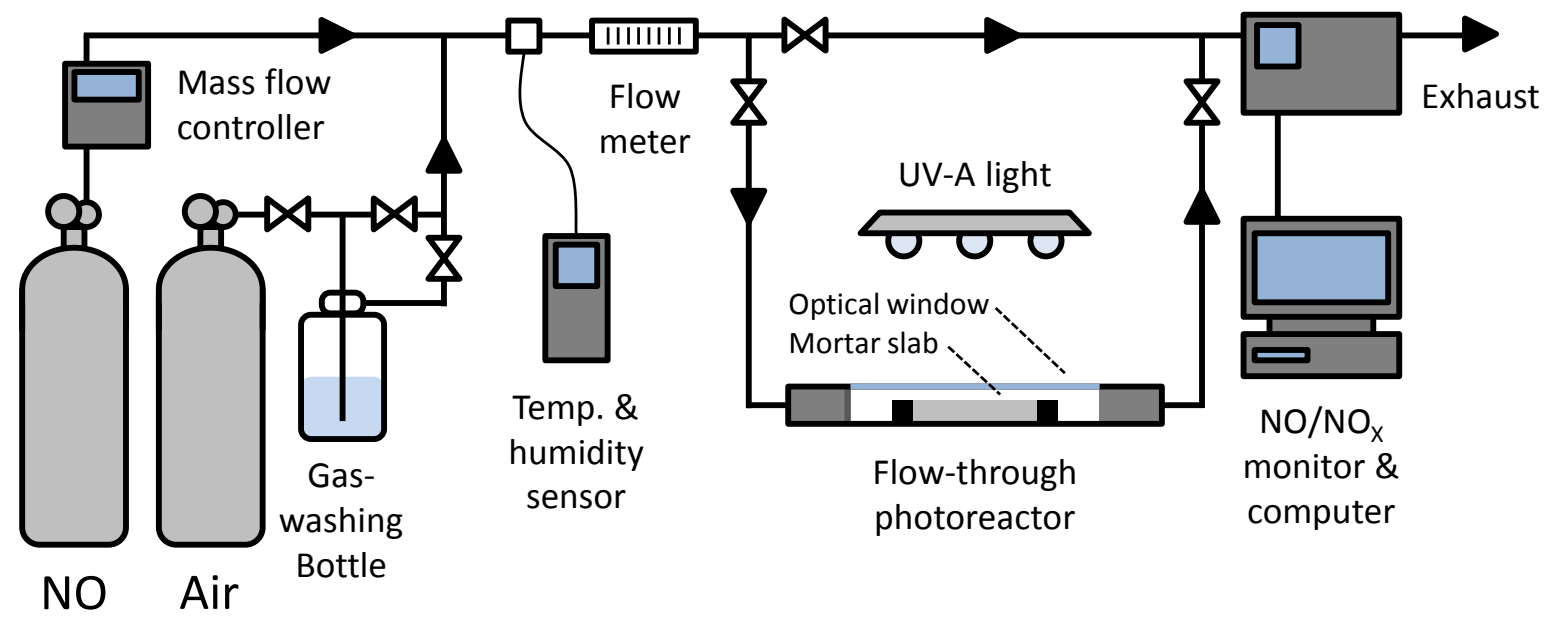

Figure 4.2. Diagram of experimental apparatus (partially adapted from Ballari et al., 2011).

A NO/NO $\mathrm{x}$ monitor, (Model 410 Nitric Oxide Monitor and Model $401 \mathrm{NO}_{2}$ Converter, 2B Technologies, Inc., Boulder, CO), completed the experimental apparatus. The monitor recorded the gas concentrations at $10 \mathrm{~s}$ intervals and was set to measure either $\mathrm{NO}$ or $\mathrm{NO}_{\mathrm{x}}$. Unlike chemiluminescence instruments, which detect the light produced when NO reacts with ozone $\left(\mathrm{O}_{3}\right)$, the Model 410 measures the change in UV absorbance at $254 \mathrm{~nm}$ when $\mathrm{O}_{3}$ is consumed upon reaction with NO. UV absorbance is an absolute method; therefore, the analyzer requires calibration annually to correct for non-linearity that exists in the photodiode response and associated electronics.

\subsection{Operational Procedure}

Operation of the experimental apparatus was divided into two phases: parameter setting and testing. While in the parameter setting phase, the test gas flowed through the photoreactor; however, the slab was not irradiated by UV light. This phase was used to set airflow rate, relative humidity, and 
pollutant concentration. After adjusting parameters to desired values, gas flow was maintained through the photoreactor for a period sufficient to reach steady-state conditions.

The testing period comprised two steps during which the UV light was turned off and on and concentrations of $\mathrm{NO}$ and $\mathrm{NO}_{\mathrm{x}}$ were measured. Figure 4.3 illustrates the UV on and off measurement cycle. Of note, a gap occurred between measurement of UV light on and off segments. The change in concentration that occurred when the light was turned on or off was not instantaneous. The period between measurements permitted time for concentration stabilization after each parameter change. In some instances, the time gap was not sufficient for concentration stabilization. When analyzing the data strings, these values were identified and removed.

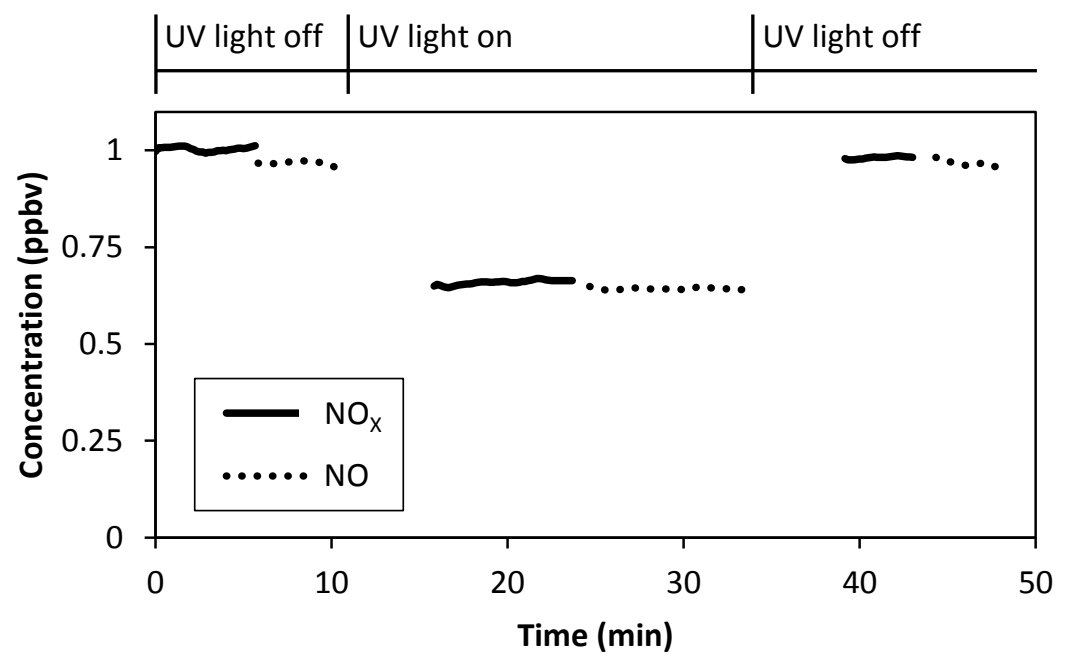

Figure 4.3. Typical $\mathrm{NO} / \mathrm{NO}_{\mathrm{x}}$ monitor data from testing procedure.

An alternative approach to test for photocatalytic oxidation measures NO concentration as the test gas first flows through a bypass line and then is diverted to flow through the photoreactor. With this approach a portion of the decrease in concentration that occurs as the gas flows through the photoreactor could be due to adsorption on the slab and dilution by air leakage. Measuring the difference in concentration between UV off and on periods avoids these error sources and limits the source for a change concentration to photo-oxidation and photo-dissociation. To evaluate whether photo-dissociation occurred within the photoreactor, the researchers also evaluated a slab that was not manufactured with photocatalytic cement (see Control in Table 4.1). A two-tailed $t$-test, assuming unequal variances, did not find evidence of a significant difference between average UV-off and UV-on NO concentration at $90 \%$ confidence $(t=3.019, \mathrm{df}=4, p=0.039)$. 


\subsection{Variable Control and Measurement for Completed Tests}

To evaluate the objectives listed above, the study collected data on the NO oxidation rates of photocatalytic mortar slabs under varied environmental regimes. In some cases, $\mathrm{NO}_{\mathrm{x}}$ oxidation rates were also collected. The following environmental variables were considered: NO concentration ( $\mathrm{C}$ uv off), irradiance (Irrad), test gas flow rate $(\mathrm{Q})$, relative humidity $(\mathrm{RH})$, slab water loss, and slab temperature (temp).Table 4.1 presents values of these variables for the tests of NO concentration irradiance, test gas flow rate, relative humidity, and slab temperature. For these tests, at the initial measurement (Test ID 0), all variables were set at the values specified by ISO 22197-1:2007(E) (i.e., $C_{U V}$ off $=1.0$ ppmv, Irrad. = $\left.10 \mathrm{~W} \cdot \mathrm{m}^{-2}, \mathrm{Q}=3.0 \mathrm{~L} \cdot \mathrm{min}^{-1}, \mathrm{RH}=50 \%\right)$. In subsequent tests, each independent variable was decreased or increased from the ISO-specified values in order to evaluate the change in $\mathrm{NO}$ and $\mathrm{NO}_{\mathrm{x}}$ oxidation. To facilitate comparison to other published work, selected values of these variables were similar to values reported in said studies. 
Table 4.1. Environmental conditions and results of tests completed.

\begin{tabular}{|c|c|c|c|c|c|c|c|c|c|c|c|c|c|c|c|c|c|c|}
\hline \multirow{5}{*}{ Test \# } & \multirow{5}{*}{ Slab ID } & \multicolumn{9}{|c|}{ Environmental conditions } & \multicolumn{8}{|c|}{ Results } \\
\hline & & \multirow[t]{4}{*}{ Description } & \multirow{2}{*}{\multicolumn{4}{|c|}{$\begin{array}{c}\mathrm{Cuv} \mathrm{off} \\
\text { (ppmv) }\end{array}$}} & \multirow{4}{*}{$\begin{array}{c}\text { Irrad. } \\
\left(W \cdot m^{-2} \times 10^{1}\right) \\
\end{array}$} & \multirow{4}{*}{$\begin{array}{c}Q \\
\left(L \cdot \min ^{-1}\right)\end{array}$} & \multirow{4}{*}{$\begin{array}{l}\mathrm{RH} \\
(\%) \\
\end{array}$} & \multirow{4}{*}{$\begin{array}{c}\text { Temp. } \\
\left({ }^{\circ} \mathrm{C}\right) \\
\end{array}$} & \multirow{2}{*}{\multicolumn{4}{|c|}{$\begin{array}{c}\mathrm{C}_{\mathrm{UV} \text { on }} \\
\text { (ppmv) }\end{array}$}} & \multicolumn{4}{|c|}{ Oxidation rate } \\
\hline & & & & & & & & & & & & & & & \multicolumn{2}{|c|}{ (nmole $\left.\cdot \mathrm{m}^{-2} \cdot \mathrm{s}^{-1}\right)$} & \multicolumn{2}{|c|}{$\left(g \cdot \text { lane-mile }{ }^{-1} \cdot \mathrm{hr}^{-1}\right)^{\mathrm{i}}$} \\
\hline & & & \multicolumn{2}{|c|}{$\mathrm{NO}_{\mathrm{x}}$} & \multicolumn{2}{|c|}{ NO } & & & & & \multicolumn{2}{|c|}{$\mathrm{NO}_{\mathrm{x}}$} & \multicolumn{2}{|r|}{ NO } & \multirow[t]{2}{*}{$\mathrm{NO}_{\mathrm{x}}$} & \multirow[t]{2}{*}{ NO } & \multirow[t]{2}{*}{$\mathrm{NO}_{\mathrm{x}}$} & \multirow[t]{2}{*}{ NO } \\
\hline & & & $\overline{\mathbf{x}}$ & s & $\overline{\mathbf{x}}$ & s & & & & & $\overline{\mathbf{x}}$ & s & $\overline{\mathbf{x}}$ & s & & & & \\
\hline 0 & & Control & & & 1.1 & 0.00067 & 1.0 & 3.0 & 50 & $22^{\mathrm{ii}}$ & & & 1.1 & 0.0033 & & 0.36 & & 0.23 \\
\hline 0 & 1 & Initial & 1.0 & 0.0039 & 1.0 & 0.0046 & 1.0 & 3.0 & 50 & $22^{\mathrm{ii}}$ & 0.71 & 0.0022 & 0.64 & 0.00054 & 28 & 33 & 18 & 21 \\
\hline 1 & 1 & $\Delta$ conc. & 0.12 & 0.014 & 0.11 & 0.011 & 1.0 & 3.0 & 50 & $22^{\mathrm{ii}}$ & 0.068 & 0.00062 & 0.043 & 0.0019 & 4.8 & 6.2 & 3.1 & 4.0 \\
\hline 2 & 1 & $\Delta$ conc. & 0.31 & 0.013 & 0.30 & 0.010 & 1.0 & 3.0 & 50 & $22^{i i}$ & 0.19 & 0.00055 & 0.15 & 0.00063 & 11 & 13 & 7.2 & 8.6 \\
\hline 3 & 2 & $\Delta$ irrad. & 1.0 & 0.0030 & 1.0 & 0.0036 & 0.22 & 3.0 & 50 & $22^{i i}$ & 0.93 & 0.00035 & 0.89 & 0.00030 & 7.1 & 10 & 4.5 & 6.1 \\
\hline 4 & 2 & $\Delta$ irrad. & 1.0 & 0.0054 & 1.0 & 0.012 & 0.40 & 3.0 & 50 & $22^{i i}$ & 0.88 & 0.00030 & 0.83 & 0.00031 & 10 & 14 & 6.5 & 8.7 \\
\hline 5 & 2 & $\Delta$ irrad. & 1.0 & 0.0015 & 1.0 & 0.0029 & 0.70 & 3.0 & 50 & $22^{\mathrm{ii}}$ & 0.88 & 0.0011 & 0.82 & 0.0015 & 13 & 18 & 8.5 & 11 \\
\hline 6 & 2 & $\Delta$ irrad. & 1.0 & 0.0060 & 1.0 & 0.0034 & 1.0 & 3.0 & 50 & $22^{i i}$ & 0.86 & 0.0012 & 0.79 & 0.00041 & 16 & 22 & 10 & 14 \\
\hline 7 & 1 & $\Delta$ irrad. & 1.0 & 0.0049 & 1.0 & 0.0051 & 1.5 & 3.0 & 50 & $22^{\mathrm{ii}}$ & 0.76 & 0.0013 & 0.69 & 0.0012 & 23 & 28 & 15 & 18 \\
\hline 8 & 1 & $\Delta Q$ & 1.0 & 0.020 & 1.0 & 0.016 & 1.0 & 1.5 & 50 & $22^{\mathrm{ii}}$ & 0.58 & 0.0018 & 0.51 & 0.00055 & 21 & 23 & 13 & 15 \\
\hline 9 & 1 & $\Delta Q$ & 1.0 & 0.0075 & 1.0 & 0.0068 & 1.0 & 5.0 & 50 & $22^{i i}$ & 0.84 & 0.0036 & 0.79 & 0.00055 & 25 & 31 & 16 & 19 \\
\hline 10 & 1 & $\Delta R H$ & 1.0 & 0.0054 & 1.0 & 0.011 & 1.0 & 3.0 & 10 & $22^{i i}$ & 0.55 & 0.0021 & 0.50 & 0.0017 & 44 & 46 & 28 & 29 \\
\hline 11 & 1 & $\Delta R H$ & 1.0 & 0.0037 & 1.0 & 0.0041 & 1.0 & 3.0 & 20 & $22^{\mathrm{ii}}$ & 0.59 & 0.0024 & 0.52 & 0.00083 & 39 & 44 & 25 & 28 \\
\hline 12 & 1 & $\Delta \mathrm{RH}$ & 1.0 & 0.0034 & 1.0 & 0.0044 & 1.0 & 3.0 & 70 & $22^{\mathrm{ii}}$ & 0.80 & 0.0025 & 0.73 & 0.00069 & 20 & 24 & 13 & 15 \\
\hline 13 & 3 & $\Delta$ temp. & & & 1.0 & 0.0003 & 1.0 & 3.0 & 20 & 55 & & & 0.72 & 0.0041 & & 28 & & 18 \\
\hline 14 & 3 & $\Delta$ temp. & & & 1.0 & 0.0024 & 1.0 & 3.0 & 20 & 49 & & & 0.72 & 0.0049 & & 28 & & 18 \\
\hline 15 & 3 & $\Delta$ temp. & & & 1.0 & 0.0005 & 1.0 & 3.0 & 20 & 44 & & & 0.78 & 0.0060 & & 24 & & 15 \\
\hline 16 & 3 & $\Delta$ temp. & & & 1.0 & 0.0010 & 1.0 & 3.0 & 20 & 39 & & & 0.70 & 0.0022 & & 23 & & 14 \\
\hline 17 & 3 & $\Delta$ temp. & & & 1.0 & 0.00073 & 1.0 & 3.0 & 20 & 36 & & & 0.69 & 0.0029 & & 24 & & 15 \\
\hline 18 & 3 & $\Delta$ temp. & & & 0.92 & 0.0017 & 1.0 & 3.0 & 20 & 34 & & & 0.70 & 0.0016 & & 20 & & 12 \\
\hline 19 & 3 & $\Delta$ temp. & & & 0.92 & 0.0013 & 1.0 & 3.0 & 20 & 32 & & & 0.73 & 0.0054 & & 17 & & 11 \\
\hline 20 & 3 & $\Delta$ temp. & & & 0.92 & 0.0077 & 1.0 & 3.0 & 20 & 19 & & & 0.73 & 0.0079 & & 17 & & 11 \\
\hline 21 & 3 & $\Delta$ temp. & & & 0.88 & 0.0019 & 1.0 & 3.0 & 20 & 21 & & & 0.71 & 0.0013 & & 15 & & 10 \\
\hline 22 & 3 & $\Delta$ temp. & & & 0.94 & 0.0018 & 1.0 & 3.0 & 20 & 22 & & & 0.78 & 0.0022 & & 14 & & 9 \\
\hline 23 & 3 & $\Delta$ temp. & & & 1.0 & 0.0018 & 1.0 & 3.0 & 20 & 7.1 & & & 0.85 & 0.0041 & & 11 & & 7 \\
\hline 24 & 3 & $\Delta$ temp. & & & 1.0 & 0.0013 & 1.0 & 3.0 & 20 & 13 & & & 0.81 & 0.0021 & & 14 & & 9 \\
\hline 25 & 3 & $\Delta$ temp. & & & 1.0 & 0.0011 & 1.0 & 3.0 & 20 & 15 & & & 0.81 & 0.0042 & & 13 & & 8 \\
\hline
\end{tabular}

i 1 lane-mile $=5280 \mathrm{ft} \cdot 12 \mathrm{ft}=5886 \mathrm{~m}^{2}$
is slab temperature not measured during test; oven temperature assumed 


\subsubsection{NO concentration, irradiance, test gas flow rate, and relative humidity}

Needle valves and a mass flow controller permitted control of NO concentration, test gas flow rate, and relative humidity. To control irradiance the distance between the UV light and photoreactor optical window was varied until the target value was observed on the radiometer.

\subsubsection{Slab temperature}

Prior to evaluation in the photoreactor, the slab was placed in an oven $\left(60^{\circ} \mathrm{C}\right)$ or refrigerator $\left(2-4^{\circ} \mathrm{C}\right)$. After removal from this environment, this slab was promptly loaded into the photoreactor. An infrared thermometer (15-077-966, Thermo Fisher Scientific, Waltham, MA) recorded temperature at 5 points on the slab surface (the slab center and the center of each quadrant) immediately prior to and after photoreactor evaluation. If slab temperature was greater than room temperature, photocatalytic evaluation began after temperature recording. At a slab temperature less than test gas temperature $\left(22^{\circ} \mathrm{C}\right)$, water could condense and blind photocatalytically active sites. This condensation would falsely indicate reduced photo-activity. To avoid this error, the researchers attempted to evaporate condensed water by using valves to reduce the test gas relative humidity to $0 \%$ for a 10 minute period. Following this period, the UV light was turned on, relative humidity was increased to the target value (20\%), and photocatalytic evaluation began. The possibility exists that the effort to avoid error by water condensation was unsuccessful. This possibility can be evaluated by comparing the slope of the NO oxidation rate versus temperature line for observations below and above $22^{\circ} \mathrm{C}$.

Additional NO oxidation rate evaluations were completed in succession as the slab temperature increased or decreased. Three sets of successive tests were recorded at the following temperature regimes: hot $\left(32-55^{\circ} \mathrm{C}\right.$, Test IDs $\left.13-19\right)$, warm $\left(19-22^{\circ} \mathrm{C}\right.$, Test IDs $\left.20-22\right)$, and cool $\left(7.1-15^{\circ} \mathrm{C}\right.$, Test IDs 23 25) as shown in Table 4.1.

Slab temperature was not measured at the midpoint of each test; instead, this value was estimated. The temperature and time data collected during the hot $(n=40)$, warm $(n=20)$, and cold $(n=20)$ sets of successive tests fit power law curves when adjusted for asymptotic values $\left(R^{2}>0.95\right.$ for each set). These curves were used to estimate slab temperature at the midpoint of the photoreactor test.

\subsubsection{Slab water loss}

To evaluate the effect of slab water loss, NO oxidation was periodically evaluated as water content decreased after starting at a saturated state. For these tests, NO concentration was set to $1.0 \mathrm{ppmv}$, 
flow rate to $3 \mathrm{~L} \cdot \mathrm{min}^{-1}$, relative humidity to $20 \%$, and UV-A irradiance to $10 \mathrm{~W} \cdot \mathrm{m}^{-2}$ at $365 \mathrm{~nm}$. To achieve saturation, a slab was immersed in water for $24 \mathrm{~h}$. To promote water loss, the slab was placed in a $60^{\circ} \mathrm{C}$ oven. The slab was periodically removed from this oven in order to measure slab mass and NO oxidation rate. Testing continued for the duration of $48 \mathrm{~h}$. Slab water loss was determined by the use of mass measurements at the saturated point and at the point of photoreactor evaluation.

\subsection{Presentation of Results}

It has been the tendency of other published work to present NO removal as a percentage based on the difference between UV-off and -on concentrations of NO. Percent removal data is in part a function of lab conditions (e.g., slab dimensions), which makes extrapolation to the field impossible. In this publication, the authors chose instead to present results as the NO oxidation rate. This value was calculated using the following equation:

$$
\text { NO oxidation rate }=\frac{P}{R \cdot T} \cdot \frac{Q}{A} \cdot\left(C_{U V \text { off }}-C_{U V \text { on }}\right)
$$

where,

$$
\begin{aligned}
& P=1 \mathrm{~atm}=\text { atmospheric pressure, } \\
& R=8.314 \mathrm{~J} \cdot \mathrm{mol}^{-1} \cdot \mathrm{K}^{-1}=\text { ideal gas constant, } \\
& T=298 \mathrm{~K}=\text { temperature, } \\
& Q=\text { volumetric flow rate } \\
& A=230 \mathrm{~cm}^{2}=\text { slab surface area, } \\
& C_{U V \text { off }}=N O \text { concentration with } U V \text { light off }, \text { and } \\
& C_{U V \text { on }}=N O \text { concentration with } U V \text { light on. }
\end{aligned}
$$

\section{Results and Discussion}

\subsection{NO Oxidation Rate for Tests Completed}

Table 4.1 documents the environmental parameters and oxidation rate results of the tests completed for this study. Of note, in each instance the value of NO oxidation rate is greater than that of $\mathrm{NO}_{\mathrm{X}}$ oxidation rate. It could be expected that since the test gas supply to the reactor was nearly entirely comprised of $\mathrm{NO}$, then the $\mathrm{NO}$ and $\mathrm{NO}_{\mathrm{x}}$ removal values would be the same value. The discrepancy arises because $\mathrm{NO}$ is not oxidized completely to $\mathrm{HNO}_{3}$. Rather, a portion of the gas is transformed to $\mathrm{NO}_{2}$. $\mathrm{NO}_{2}$ that remains in the gas stream is counted as part of the outlet $\mathrm{NO}_{\mathrm{x}}$ concentration. As a result, $\mathrm{NO}_{\mathrm{x}}$ removal measures lower than NO removal. 
Figures 3.4-3.8 plot each independent variable versus NO oxidation rate. Overlaid on these plots is the data reported from previous research that investigated NO oxidation rates under differing environmental regimes (Ballari et al., 2010; Ballari et al., 2011; Hüsken \& Brouwers, 2008; Hüsken et al., 2009; Murata et al., 2000). Through analysis of these figures, this section assessed whether the trends exhibited in the collected data are consistent with that of previous research and whether this data helps to reduce the discord that exists in the research record.

\subsubsection{Influent NO Concentration}

Figure 4.4 indicates a correlation between inlet NO concentration and NO oxidation rate $\left(R^{2}=0.997\right)$ This correlation is also evident in the data from Murata et al. (2000) $\left(R^{2}=0.999\right.$ for presented data, $R^{2}=$ 0.944 for published data), Hüsken and Brouwers (2008) and Hüsken et al. (2009) $\left(R^{2}=0.997\right)$, and Ballari et al. (2010) $\left(R^{2}=0.95\right)$.

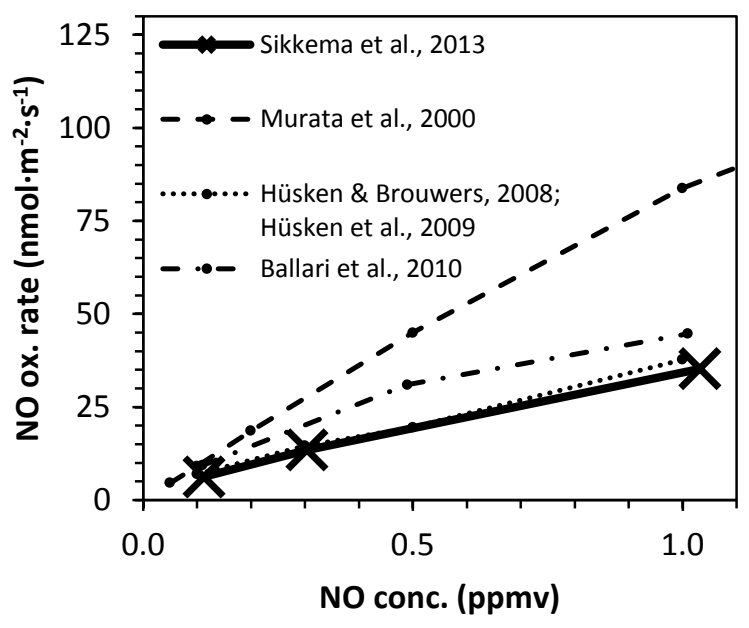

Figure 4.4. Effect of influent NO concentration on NO oxidation rate.

A correlation between inlet concentration and NO oxidation rate was previously reported by Herrmann (1999). This publication indicated that kinetics follow a Langmuir-Hinshelwood mechanism, under which both reactants adsorb (e.g., $\mathrm{NO}$ and ${ }^{\bullet} \mathrm{OH}$ ) on the surface before a new molecule is formed. For these type of reactions, kinetics typically fall into low-concentration and high-concentration classifications. In the low-concentration classification, kinetics are first-order; whereas in the highconcentration classification, kinetics are zero-order. As applied to NO degradation by photocatalytic pavements, this framework would indicate that, at high concentration, the rate of NO oxidation would remain constant. A constant oxidation rate occurs because a finite number of active sites are available 
for photocatalytic degradation. Once these sites are occupied, the rate of oxidation does not increase. In contrast, while within the low-concentration regime, the active sites have not yet been filled.

For reactants adsorbed from aqueous phases, Herrmann (1999) indicated that first-order regimes apply when concentration is less than $10^{-3} \mathrm{M}$ and zero-order regimes apply at a concentration greater than $5 \times 10^{-3} \mathrm{M}$. These divisions have not been established for reactants adsorbed from a gas phase. Except for Ballari et al. (2010), which only had 3 observations, $t$-tests of the data presented in Figure 4.4 rejected a null hypothesis that slope equaled $0 \mathrm{nmole} \mathrm{m}^{-2} \cdot \mathrm{s}^{-1} \cdot \mathrm{ppmv}^{-1}(p=<0.028)$. Based on this analysis, it is evident that this data falls into first-order regimes, indicating that active sites have not been filled. For applications of photocatalytic pavement, a determination of where the breakpoint between firstand zero-order regimes occurs is not necessary. Locations where these pavements may be installed can be assumed to have $\mathrm{NO}_{\mathrm{x}}$ concentrations near the National Ambient Air Quality Standards (NAAQSs) for $\mathrm{NO}_{2}$ (i.e., 53 and 100 ppbv) (Primary National Ambient Air Quality Standards for Nitrogen Dioxide: Final Rule, 2010). These values are substantially below the 1.0 ppmv upper limit of the data analyzed; therefore, field applications can also be assumed to fall in a first-order regime.

In addition to finding evidence that influent NO concentration effects NO oxidation rates, a $t$-test which compared the slope of linear regression lines for the presented data sets found no significant difference between this study's data and the data from Hüsken and Brouwers (2008) and Hüsken et al. (2009) ( $t=-1.377, \mathrm{df}=3, p=0.262)$, and Ballari et al. (2010) $(t=-0.861, \mathrm{df}=2, p=0.480)$. A similar $t$-test did find that the slope was significantly different than the data from Murata et al. (2000) $(t=-23.037$, df $=4, p=0.000$ ). Review of Murata et al. (2000)'s writing found that the reactor setup was not markedly different that that of the authors'; therefore, an explanation for this difference is not readily available and any hypothesis would be speculative. It can be concluded, though, that because these slopes are significantly different, a generalized assumption of the effect of NO concentration on NO oxidation rate cannot be made. Instead, if a photocatalytic material is going to be used in the field, it would be wise to complete lab evaluations in order to project levels of oxidation that will be observed in the field.

When considered at the scale of field application, the data presented in Figure 4.4 does not provide clear evidence that photocatalytic pavements will have a substantial impact on ambient $\mathrm{NO}_{\mathrm{x}}$ concentration. This conclusion can be demonstrated with a pragmatic example. The logical target location for a photocatalytic pavement is a near-road environment in which vehicular traffic causes $\mathrm{NO}_{\mathrm{x}}$ concentration to rise above NAAQS values despite the use of traditional $\mathrm{NO}_{\mathrm{x}}$ control mechanisms (e.g., 
tailpipe emissions controls). In this example case, the purpose of placing photocatalytic pavement immediately next to the vehicular emission source would be to oxidize a portion of the mass of $\mathrm{NO}_{\mathrm{x}}$ in the atmosphere in the immediate vicinity of the roadway. With a reduced mass of $\mathrm{NO}_{\mathrm{x}}$ in the atmosphere, once convection and diffusion transport the pollutant $\mathrm{NO}_{\mathrm{x}}$ from the roadway to an exposed population, the concentration would be sufficiently lowered so that health is not negatively impacted. Due to the fact that the $\mathrm{NO}_{2}$ concentration in near-road areas is $30 \%$ to $100 \%$ higher than area-wide concentrations (USEPA, 2010b), the 2010 revisions to $\mathrm{NO}_{2}$ NAAQS required installation of a near-road monitor in certain urban centers along roadways with an Annual Average Daily Traffic (AADT) greater than or equal to $250,000\left(10,400\right.$ vehicles $\cdot h^{-1}$ ) (Primary National Ambient Air Quality Standards for Nitrogen Dioxide: Final Rule, 2010). As reported in USEPA (2008a) the average $\mathrm{NO}_{\mathrm{x}}$ emissions for the entire in-use passenger car fleet was $0.693 \mathrm{~g} \cdot \mathrm{mile}^{-1}$ as of July 2008. If this traffic was spread over 10 twelve-foot-wide lanes, $\mathrm{NO}_{\mathrm{x}}$ emissions would be $720 \mathrm{~g} \cdot$ lane-mile ${ }^{-1} \cdot \mathrm{hr}^{-1}$. Although convection and dispersion will quickly dilute these emissions, oxidation rate values reported in Figure 4.4 measured only 4.0-21 $\mathrm{g}$.lane-mile ${ }^{-1} \cdot \mathrm{hr}^{-1}$. At these low rates of oxidation, it is not immediately clear that ambient $\mathrm{NO}_{\mathrm{x}}$ concentration will be substantially diminished due to the effect of photocatalytic pavements.

\subsubsection{UV-A Irradiance}

Figure 4.5 indicates a positive correlation between UV-A irradiance and NO oxidation $\left(R^{2}=0.991\right)$. This correlation is also evident in the data from Murata et al. (2000) $\left(R^{2}=0.788\right)$ and Hüsken et al. (2009) $\left(R^{2}=0.923\right)$. This positive correlation exists because increased UV-A irradiance on a photocatalytic surface increases the rate at which electron holes are created. An increase in the rate of electron-hole generation results in the increased production rate of hydroxyl radicals, which oxidize NO. Multiple publications report that the relationship between irradiance and pollutant oxidation can be divided into two regimes. Although disagreement exists on the value of the division point between regimes (10-250

$\left.\mathrm{W} \cdot \mathrm{m}^{-2}\right)$, the publications note a linear relationship below the division point and a non-linear relationship above this point (Herrmann et al., 2007; Jacoby et al., 1995; Kumar et al., 1995; Lim et al., 2000; Obee \& Brown, 1995). Jacoby et al. (1995) explains that under the linear regime, electron holes are filled by reactions with species on the photocatalytic surface (e.g., $\mathrm{OH}^{-}$) faster than by recombination with excited electrons; in contrast, under the non-linear regime, holes are filled by recombination at a faster rate than by reaction with other species. 


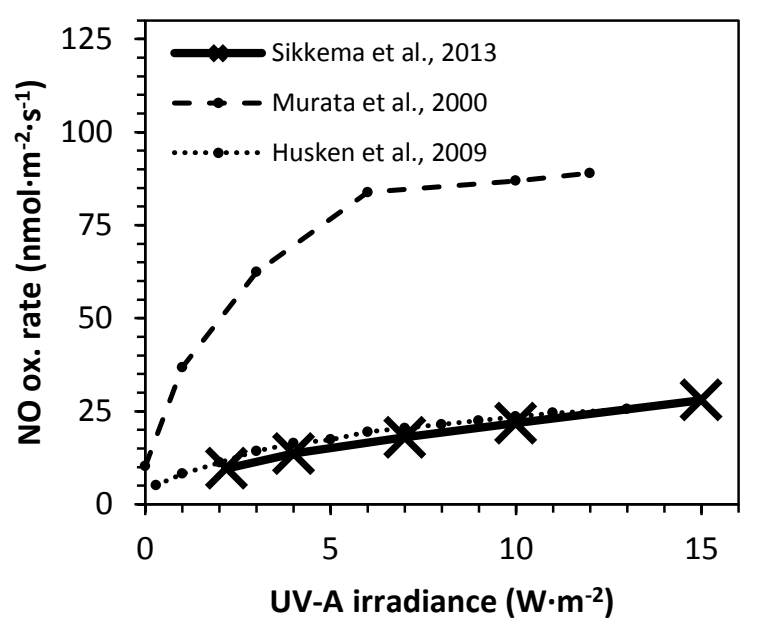

Figure 4.5. Effect of UV-A irradiance on NO oxidation rate.

As noted above, a linear relationship is apparent when reviewing the data collected in this study $\left(R^{2}\right.$ $=0.991$ ). Comparison of this data with Hüsken et al. (2009) did not find a significant difference in the slope of each data set's linear regression lines $(t=-0.931, \mathrm{df}=14, p=0.368)$. However, it should be noted that Hüsken et al. (2009) asserted power law relationship between percent NO removal and irradiance $\left(y=8.583 x^{0.431}, R^{2}=0.998\right)$ and concluded that linear behavior was limited to observations above $4 \mathrm{~W} \cdot \mathrm{m}^{-2}$. In contrast, the data from Murata et al. (2000) appears non-linear $\left(R^{2}=0.788\right.$ for linear regression). Furthermore, a $t$-test comparing the slope of linear regression lines between this data set and the authors' found a significant difference $(t=-2.922, \mathrm{df}=7, p=0.022$ ). In similarity with the conclusion reached in Section 4.1.1, this difference indicates that lab evaluation of a specific material selected for field application is warranted in order to assess its NO oxidation potential.

As reported by Grant and Slusser (2005), mean daytime UV-A irradiance from the most northern (Fairbanks, Alaska, latitude $65.1^{\circ} \mathrm{N}$ ) and southern (Homestead, FL, latitude $25.4^{\circ} \mathrm{N}$ ) locations of a United States Department of Agriculture (USDA) climate monitoring network ranged from 10.5 to $22.3 \mathrm{~W} \cdot \mathrm{m}^{-2}$. In addition to knowledge of the mean UV-A irradiance, application of photocatalytic pavement also requires knowledge on the change in irradiance during daylight hours.. This knowledge is needed because in urban areas $\mathrm{NO}_{\mathrm{x}}$ ambient concentration reportedly follows a diurnal pattern associated with traffic. Urban background monitoring in London, UK, found that $\mathrm{NO}_{2}$ peaks both in early morning and late afternoon and $\mathrm{NO}$, which oxidizes quickly to $\mathrm{NO}_{2}$ during daylight hours, peaks in early morning (Bigi \& Harrison, 2010). At these peaks, irradiance values are substantially lower than the mean daytime value. For example, at the $40^{\text {th }}$ parallel north, which roughly runs through the center of the United 
States, the difference between the typical mid-summer peak UV radiation and the radiation 4 hours earlier in the day is more than $70 \%$ (Long et al., 1996). At present, oxidation rates at these low irradiance values are quite low. To be effective at peak pollution hours, the ongoing efforts by other researchers to enhance $\mathrm{TiO}_{2}$ 's photo-induced reactivity must be incorporated into new formulations of photocatalytic pavements.

\subsubsection{Flow Rate}

A model utility test on the data collected in this study (presented in Figure 4.6) did not reject a null hypothesis that slope equaled $0 \mathrm{nmole} \cdot \mathrm{m}^{-2} \cdot \mathrm{s}^{-1} \cdot{ }^{\circ} \mathrm{C}^{-1}(t=0.830, \mathrm{df}=2, p=0.559)$, and therefore does not provide evidence of a correlation between flow rate and NO oxidation rate. The same conclusion was found with analysis of data from Hüsken and Brouwers (2008) and Hüsken et al. (2009) $(t=1.732$, df = 2, $p=0.333)$.

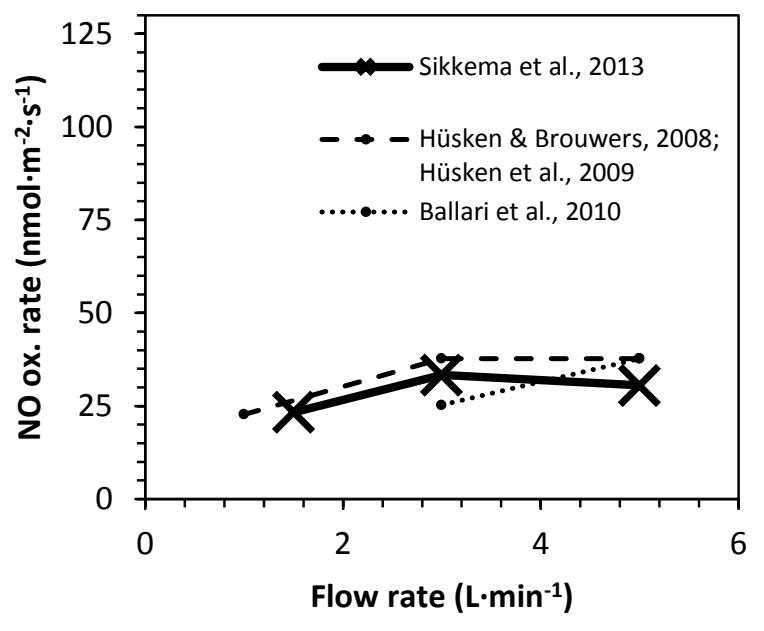

Figure 4.6. Effect of flow rate on NO oxidation rate.

Results, presented in the form of percent NO removal, were determined to be 45,31 , and $17 \%$ for flow rates of $1.5,3$, and $5 \mathrm{~L} \cdot \mathrm{min}^{-1}$ respectively. In these units, a negative relationship between flow rate is evident between flow rate and percent removal, although confidence is low $(t=-12.124, \mathrm{df}=2, p=$ 0.052). This relationship was also documented by other publications (Ballari et al., 2010; Dylla et al., 2010; Hüsken \& Brouwers, 2008; Hüsken et al., 2009). These studies suggested that percent NO removal from a specific volume of test gas increases proportionally to the residence time over a photocatalytic surface because greater time exists for pollutants to absorb and be oxidized at active sites. The lack of a correlation between flow rate and NO oxidation rate provides evidence that factors such as wind speed 
will impact the pavement's air cleaning efficiency; however, higher flow rates should be evaluated. This evaluation was not possible given specifications of the researcher's photoreactor.

\subsubsection{Relative Humidity}

Figure 4.7 indicates a negative correlation between relative humidity and NO oxidation rate $\left(R^{2}=\right.$ 0.990, $t=-13.788, \mathrm{df}=3, p=0.005$ ). This correlation is also found in the data from Murata et al. (2000) $(t=-3.001, \mathrm{df}=5, p=0.040)$ and Hüsken and Brouwers (2008) and Hüsken et al. (2009) $(t=-24.556, \mathrm{df}=$ $7, p=0.000$ ). Photocatalytic degradation of NO by pavement containing titanium dioxide occurs when $\mathrm{NO}$ is oxidized by ${ }^{\bullet} \mathrm{OH}$ (Figure 4.1). These ${ }^{\bullet} \mathrm{OH}$ are generated by oxidation of an $\mathrm{OH}^{-}$by an electron hole. Water adsorbed on the slab serves as the source for $\mathrm{OH}^{-}$. Intuition would thereby suggest that increased humidity would result in an increased rate of NO oxidation. By observation, the opposite has been found to be true. In addition to photocatalytic properties, materials containing $\mathrm{TiO}_{2}$ also exhibit photo-induced superhydrophilicity (i.e., water on the surface has a contact angle of nearly $0^{\circ}$ ) (Fujishima et al., 2008). Adsorbed water vapor disperses over the surface, blinding photocatalytically active sites (Beeldens, 2007).

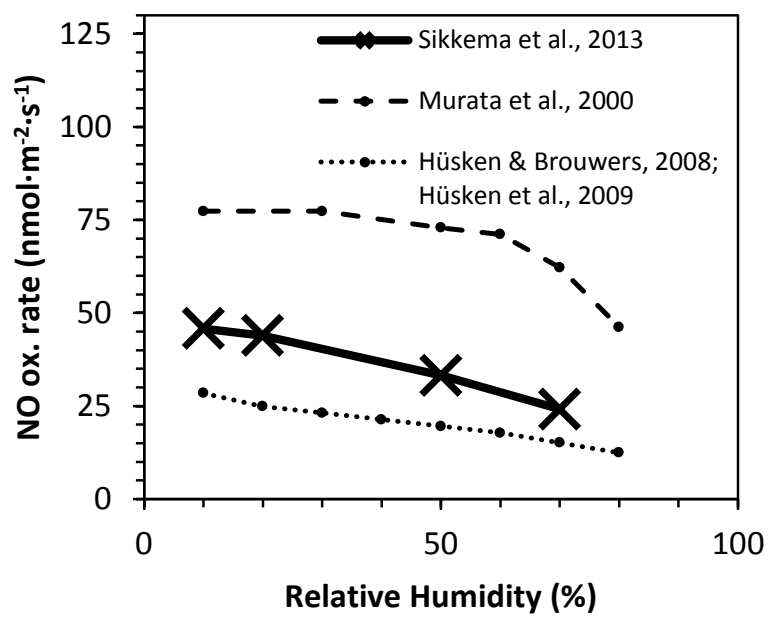

Figure 4.7. Effect of relative humidity on NO oxidation rate.

Although a negative correlation was found in each data set displayed in Figure 4.7, both data values and relationships differed. A null hypothesis that the difference in slopes of regression lines was 0 (i.e., $H_{0}: B_{1}-B_{2}=0$ ) was used to compare this study's data to the other displayed data sets. This evaluation found no significant difference between this study and Murata et al. (2000) ( $t=0.134, \mathrm{df}=6, p=0.898)$. However, a significant difference in slope was observed between this study and Hüsken and Brouwers 
(2008) and Hüsken et al. (2009) $(t=-5.451, \mathrm{df}=8, p=0.001)$. Evaluation of the y-intercept found a significant difference between this study and both Murata et al. (2000) $(t=-281.105, \mathrm{df}=6, p=0.000)$ and Hüsken and Brouwers (2008) and Hüsken et al. (2009) ( $t=738.024$, $\mathrm{df}=8, p=0.000)$. This evaluation provides further evidence of the complexity of photocatalytic pavement materials. As concluded in previous sections, the researchers recommend that individual materials undergo a thorough evaluation prior to field evaluation.

The observed negative correlation that occurs as a result of water's blinding effect could limit the effectiveness of photocatalytic pavement in humid regions. Based on 2006-2008 data, the five counties with the highest ambient $\mathrm{NO}_{2}$ concentration in the form of the 2010-promulgated $\mathrm{NO}_{2}$ standard for counties within the United States are as follows: Cook, IL, San Diego, CA, Los Angeles, CA, Erie, NY, and Denver, CO (USEPA, 2010a). With the exception of Denver County, each of the listed counties frequently experiences high humidity conditions. As displayed in Figure 4.7, the NO oxidation rate at high humidity is substantially diminished. Unless photocatalytic pavements can be modified to lessen their sensitivity to changes in relative humidity, effective application in these polluted areas will be difficult.

\subsubsection{Slab Water Loss}

Figure 4.8 documents variation in NO oxidation rate as water evaporated from the slab. For water losses of $0-2 \%$ of saturated mass, a positive correlation is apparent $\left(R^{2}=0.850\right)$ and a 0 slope null hypothesis was rejected ( $t=4.760, \mathrm{df}=5, p=0.009$ ). Conversely, for water losses greater than $2 \%$ of saturated mass, a negative correlation is apparent $\left(R^{2}=0.991\right)$ and a 0 slope null hypothesis was rejected $(t=-18.779, \mathrm{df}=5, p=0.000)$. These observations can be explained as follows: between 0 and $2 \%$ water loss, as water is evaporated from the slab it no longer blinds active sites and the NO oxidation rate increases. This explanation is similar to the explanation for the correlation between relative humidity and NO oxidation rates. For water losses above $2 \%$ the rate of NO oxidation appears to be limited because water contained within the slab is not available as a source for ${ }^{\bullet} \mathrm{OH}$. In this study, the peak NO oxidation rate was observed at $2 \%$ slab water loss. Under field condition a different peak would be observed. This difference would arise because water content varies throughout the depth of a concrete pavement; therefore, the water loss at the pavement surface would differ from the water loss of the entire slab. 


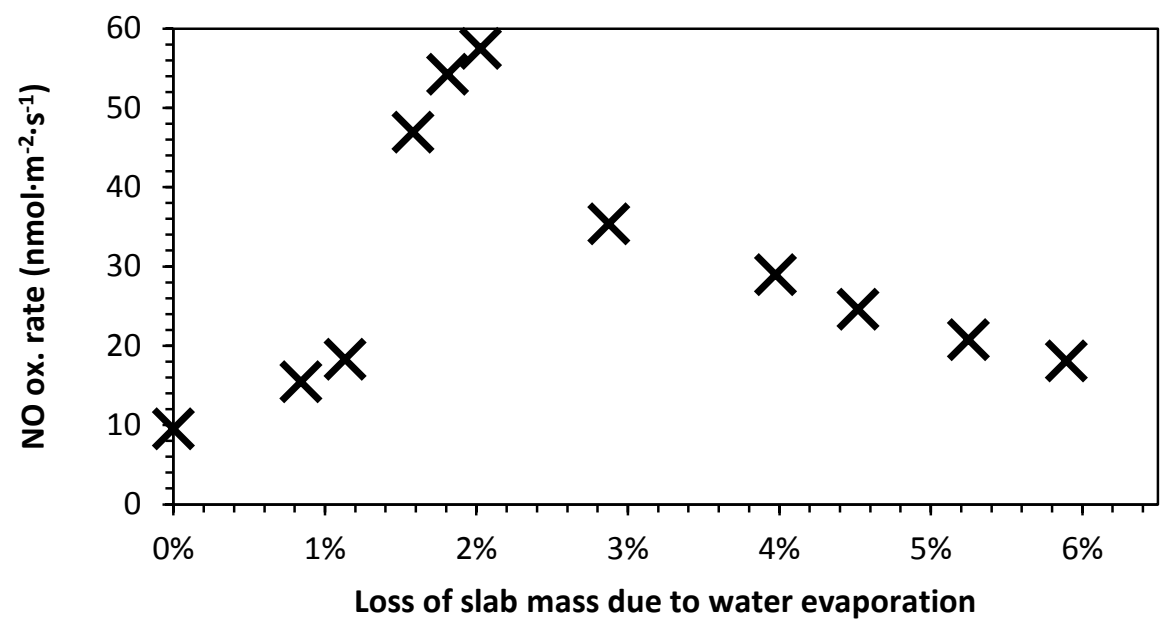

Figure 4.8 Effect of slab water loss due to water evaporation on NO oxidation rate.

The findings presented in Figure 4.8 complicate recommendations for field application of $\mathrm{TiO}_{2}$ containing pavements. On the basis of relative humidity, areas with sustained periods of low humidity would be recommended for application. It would be assumed that mitigation of NO pollution would continue as long as relative humidity remained low. However, sustained low humidity would also cause evaporation of water contained in the pores of the slab. Based on the data presented, a photocatalytic concrete pavement could be expected to remove NO initially; however, over time NO oxidation would decrease and the benefits would be lost. If $\mathrm{TiO}_{2}$-containing pavement is to be applied in the field to mitigate NO pollution, methods to maintain slab water content must be developed.

\subsubsection{Slab Temperature}

Figure 4.9 displays the effect of temperature on NO oxidation rate. Linear regression of this data found a $R^{2}$ value of 0.910 . A model utility test rejected a null hypothesis that slope equaled $0 \mathrm{nmole} \cdot \mathrm{m}^{-}$ ${ }^{2} \cdot \mathrm{s}^{-1} \cdot{ }^{\circ} \mathrm{C}^{-1}$ with confidence in excess of $99.99 \%(t=10.516, \mathrm{df}=12)$. As noted in Section 3.4.2, tests which occurred at slab temperatures below $22^{\circ} \mathrm{C}$ presented the possibility of error due to water condensation. Linear regression of data points above $22^{\circ} \mathrm{C}$ found a slope of $0.442 \mathrm{nmole} \cdot{ }^{-2} \cdot \mathrm{s}^{-1} \cdot{ }^{\circ} \mathrm{C}^{-1}\left(\mathrm{R}^{2}=0.799, \mathrm{n}=7\right)$; for data points below $22^{\circ} \mathrm{C}$ the slope was $0.232 \mathrm{nmole} \cdot \mathrm{m}^{-2} \cdot \mathrm{s}^{-1}{ }^{\circ} \mathrm{C}^{-1}\left(\mathrm{R}^{2}=0.485, \mathrm{n}=6\right)$. A pooled-variance $t$-test of a null hypothesis that the difference between these two slopes was 0 (i.e., $H_{0}: B_{1}-B_{2}=0$ ) indicated that the slopes were not significantly different $(t=1.245, \mathrm{df}=9, p=0.244)$. Although the values of the slopes differ, the data collected does not support a claim that this difference is significant. 


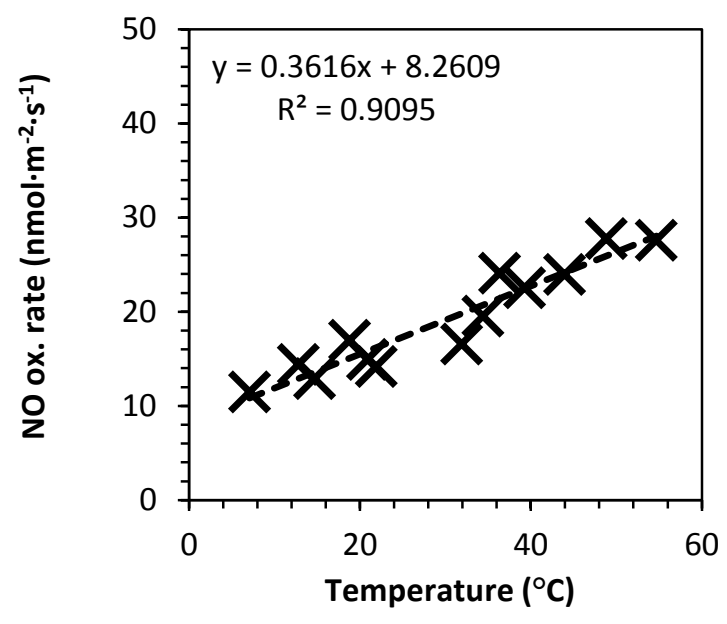

Figure 4.9. Effect of temperature on NO oxidation rate.

The effect of temperature on NO oxidation rates has not been studied in previous photoreactor studies; therefore, comparison with other data sets was not possible. Photocatayltic pavement publications that do make statements in regard to the impact of temperature on oxidation rates are often vague. In most instances publications assert that the oxidation rate increases with an increase in temperature (Beeldens et al., 2011) and that only large differences in temperature (i.e., summer vs. winter) are significant (Dylla et al., 2011). In addition to being vague, the literature also is contradictory and one source reported a decrease in oxidation rate with increased temperature (Chen \& Chu, 2011).

Under the generalization of the Arrhenius' equation, the rate of a chemical reaction is expected to double for every $10^{\circ} \mathrm{C}$ increase in temperature. The change in reaction rate displayed in Figure 4.9 does not follow this generalization. Although Herrmann (1999) dealt with aqueous photocatalysis, this publication provides useful insight. It states that in the range of $20-80^{\circ} \mathrm{C}$, activation energy is negligible and is not a rate limiting step. Furthermore, at temperatures below $0^{\circ} \mathrm{C}$, the apparent activation energy of the photocatalyst increases leading to a decrease in oxidation rate. This information partially explains the observations; however, it would appear that other factors also influence the reported observations.

\section{Conclusions}

Photocatalytic pavements offer a novel technological option to mitigate $\mathrm{NO}_{\mathrm{x}}$ pollution. In order for these pavements to be adopted by potential stakeholders, information is needed that documents the NO oxidation rate under varied environmental conditions. A positive correlation was observed between NO oxidation rate and influent NO concentration. Comparison of this study with Hüsken and Brouwers 
(2008), Hüsken et al. (2009) and Ballari et al. (2010) found no significant difference in the slope of regression lines through this data. However, a significant difference in slope was observed in comparison with Murata et al. (2000). A positive correlation was also observed between NO oxidation rates and UV-A irradiance $\left(R^{2}=0.991\right)$. Comparison of this study with Hüsken et al. (2009) found no significant difference in the slope of regression lines through this data. A significant difference in slope was observed in comparison with Murata et al. (2000). A correlation was not observed between NO oxidation rates and flow rate. This same conclusion was reached with analysis of data from Hüsken and Brouwers (2008) and Hüsken et al. (2009). A negative correlation was observed between NO oxidation rate and relative humidity. In contrast with evaluations for UV-A irradiance and NO concentration, no significant difference was found with comparison of this study to Murata et al. (2000). A significant difference in slope was observed between this study and Hüsken and Brouwers (2008) and Hüsken et al. (2009). Slab water loss, a variable not investigated in prior work, was found to affect NO oxidation rates. At losses of $0-2 \%$ of saturated mass, a positive correlation was observed; whereas, at losses greater that $2 \%$ a negative correlation was observed. A positive correlation was documented for slab temperature. This finding contrasts previous assertions which considered this variable insignificant; however, the rates did not double for every $10^{\circ} \mathrm{C}$ increase in temperature as would be suggested by the Arrhenius equation.

Overall, it can be concluded that photocatalytic mortar slabs manufactured with TX Active pavement are highly sensitive to changes in environmental variables. NO oxidation rates observed in this study ranged from 6.2-57 nmole $\cdot \mathrm{m}^{-2} \cdot \mathrm{s}^{-1}\left(4.0-36 \mathrm{~g} \cdot\right.$ lane-mile $\left.\mathrm{e}^{-1} \cdot \mathrm{hr}^{-1}\right)$. Furthermore, significant differences were found by comparison to other studies. Therefore, if a potential stakeholder is considering use of this technology to mitigate $\mathrm{NO}_{\mathrm{x}}$ emissions, careful preliminary work should be undertaken to both evaluate the environmental conditions of the test site and the properties of the selected photocatalytic material. Finally, in a conservative example NO emissions from a highway (10 twelve-foot-wide lanes, AADT = $250,000)$ were estimated to be $720 \mathrm{~g} \cdot l a n e-m_{i l e}{ }^{-1} \cdot \mathrm{hr}^{-1}$. Although convection and dispersion will quickly dilute these emissions, at the low NO oxidation rate values reported in this study, it is not immediately clear that ambient $\mathrm{NO}_{x}$ concentration will be substantially diminished due to the effect of photocatalytic pavements. 


\section{Acknowledgments}

The authors wish to thank the National Concrete Pavement Technology Center, the United States Department of Transportation, Essroc Italcementi Group, and Lehigh Hanson, Inc. for providing funding to pursue this study.

\section{References}

Ballari, M. M., Hunger, M., Hüsken, G., \& Brouwers, H. J. H. (2010). NOx photocatalytic degradation employing concrete pavement containing titanium dioxide. Applied Catalysis B-Environmental, 95(3-4), 245-254. doi: 10.1016/j.apcatb.2010.01.002

Ballari, M. M., Yu, Q. L., \& Brouwers, H. J. H. (2011). Experimental study of the NO and NO2 degradation by photocatalytically active concrete. Catalysis Today, 161(1), 175-180. doi: 10.1016/j.cattod.2010.09.028

Beeldens, A. (2007, October 8-9). Air Purification by Road Materials: Results of the Test Project in Antwerp. Paper presented at the International RILEM Symposium on Photocatalysis, Environment and Construction Materials - TDP 2007, Florence, Italy.

Beeldens, A., Cassar, L., \& Murata, Y. (2011). Applications of TiO2 Photocatalysis for Air Purification In Y. Ohama \& D. Van Gemert (Eds.), Application of titanium Dioxide Photocatalysis to Construction Materials (1st ed.): Springer.

Bigi, A., \& Harrison, R. M. (2010). Analysis of the air pollution climate at a central urban background site. Atmospheric Environment, 44(16), 2004-2012. doi: 10.1016/j.atmosenv.2010.02.028

Brauer, M., Hoek, G., Van Vliet, P., Meliefste, K., Fischer, P. H., Wijga, A., . . Brunekreef, B. (2002). Air pollution from traffic and the development of respiratory infections and asthmatic and allergic symptoms in children. American Journal of Respiratory and Critical Care Medicine, 166(8), 10921098. doi: DOI 10.1164/rccm.200108-0070C

Brunekreef, B., Janssen, N. A. H., deHartog, J., Harssema, H., Knape, M., \& vanVliet, P. (1997). Air pollution from truck traffic and lung function in children living near motorways. Epidemiology, 8(3), 298-303.

Cackler, E. T., Alleman, J. E., Kevern, J. T., \& Sikkema, J. K. (2012). Technology Demonstrations Project: Environmental Impact Benefits with "TX Active" Concrete Pavement in Missouri DOT Two-Lift Highway Construction Demonstration. (DTFH61-06-H-00011 Work Plan 22). Ames, IA: National Concrete Pavement Technology Center.

Chen, M., \& Chu, J. W. (2011). NO(x) photocatalytic degradation on active concrete road surface - from experiment to real-scale application. [Article]. Journal of Cleaner Production, 19(11), 1266-1272. doi: 10.1016/j.jclepro.2011.03.001 
Clean Air Act, 42 U.S.C. § 7401 et seq. (2008).

Dylla, H., Hassan, M. M., Mohammad, L. N., Rupnow, T., \& Wright, E. (2010). Evaluation of Environmental Effectiveness of Titanium Dioxide Photocatalyst Coating for Concrete Pavement. Transportation Research Record: Journal of the Transportation Research Board, 2164(-1), 46-51. doi: 10.3141/2164-06

Dylla, H., Hassan, M. M., Schmitt, M., Rupnow, T., \& Mohammad, L. N. (2011). Laboratory Investigation of the Effect of Mixed Nitrogen Dioxide and Nitrogen Oxide Gases on Titanium Dioxide Photocatalytic Efficiency in Concrete Pavements. Journal of Materials in Civil Engineering, 23(7), 1087-1093. doi: 10.1061/(asce)mt.1943-5533.0000248

Finkelstein, M. M., Jerrett, M., \& Sears, M. R. (2004). Traffic air pollution and mortality rate advancement periods. American Journal of Epidemiology, 160(2), 173-177. doi: Doi 10.1093/Aje/Kwh181

Fujishima, A., Zhang, X. T., \& Tryk, D. A. (2008). TiO(2) photocatalysis and related surface phenomena. [Review]. Surface Science Reports, 63(12), 515-582. doi: 10.1016/j.surfrep.2008.10.001

Garshick, E., Laden, F., Hart, J. E., \& Caron, A. (2003). Residence near a major road and respiratory symptoms in US veterans. Epidemiology, 14(6), 728-736. doi: DOI 10.1097/01.ede.0000082045.50073.66

Grant, R. H., \& Slusser, J. R. (2005). Estimation of ultraviolet-A irradiance from measurements of 368-nm spectral irradiance. Journal of Atmospheric and Oceanic Technology, 22(12), 1853-1863. doi: 10.1175/jtech1823.1

Herrmann, J. M. (1999). Heterogeneous photocatalysis: fundamentals and applications to the removal of various types of aqueous pollutants. Catalysis Today, 53(1), 115-129.

Herrmann, J. M., Péruchon, L., Puzenat, E., \& Guillard, C. (2007, October 8-9). Photocatalysis: from fundamentals to self-cleaning glass applications. Paper presented at the International RILEM Symposium on Photocatalysis, Environment and Construction Materials - TDP 2007, Florence, Italy.

Hüsken, G., \& Brouwers, H. J. H. (2008, June 16-20). Air purification by cementitious materials: Evaluation of air purifying properties. Paper presented at the International Conference on Construction and Building Technology, Kuala Lumpur, Malaysia.

Hüsken, G., Hunger, M., \& Brouwers, H. J. H. (2009). Experimental study of photocatalytic concrete products for air purification. Building and Environment, 44(12), 2463-2474. doi: DOI 10.1016/j.buildenv.2009.04.010 
ISO. (2007). Fine ceramics (advanced ceramics, advanced technical ceramics) -- Test method for airpurification performance of semiconducting photocatalytic materials -- Part 1: Removal of nitric oxide (Vol. 22197-1:2007): ISO.

Jacoby, W. A., Blake, D. M., Noble, R. D., \& Koval, C. A. (1995). KINETICS OF THE OXIDATION OF TRICHLOROETHYLENE IN AIR VIA HETEROGENEOUS PHOTOCATALYSIS. Journal of Catalysis, 157(1), 87-96. doi: 10.1006/jcat.1995.1270

Kim, J. J., Smorodinsky, S., Lipsett, M., Singer, B. C., Hodgson, A. T., \& Ostro, B. (2004). Traffic-related air pollution near busy roads - The East Bay children's respiratory health study. American Journal of Respiratory and Critical Care Medicine, 170(5), 520-526. doi: DOI 10.1164/rccm.200403-2810C

Kumar, P., Dushenkov, V., Motto, H., \& Raskin, I. (1995). PHYTOEXTRACTION - THE USE OF PLANTS TO REMOVE HEAVY-METALS FROM SOILS. Environmental Science \& Technology, 29(5), 1232-1238. doi: 10.1021/es00005a014

Kundu, P. K., \& Cohen, I. M. (2010). Fluid Mechanics: Elsevier Science.

Lim, T. H., Jeong, S. M., Kim, S. D., \& Gyenis, J. (2000). Photocatalytic decomposition of NO by TiO2 particles. Journal of Photochemistry and Photobiology a-Chemistry, 134(3), 209-217. doi: 10.1016/s1010-6030(00)00265-3

Long, C. S., Miller, A. J., Lee, H. T., Wild, J. D., Przywarty, R. C., \& Hufford, D. (1996). Ultraviolet Index Forecasts Issued by the National Weather Service. Bulletin of the American Meteorological Society, 77(4), 729-748.

Murata, Y., Kamitani, K., \& Takeuchi, K. (2000). Air Purifying Blocks Based on Photocatalysis. Paper presented at the Japan Interlocking BLock Pavement Engineering Association World Congress 2000, Tokyo, Japan.

Murata, Y., \& Tobinai, K. (2002). Influence of various factors on NOx removal performance of permeable interlocking block based on photocatalysis. Journal of Structural and Construction Engineering(Transactions of AIJ)(555), 9-15.

Obee, T. N., \& Brown, R. T. (1995). TIO2 PHOTOCATALYSIS FOR INDOOR AIR APPLICATIONS - EFFECTS OF HUMIDITY AND TRACE CONTAMINANT LEVELS ON THE OXIDATION RATES OF FORMALDEHYDE, TOLUENE, AND 1,3-BUTADIENE. Environmental Science \& Technology, 29(5), 1223-1231. doi: 10.1021/es00005a013

Primary National Ambient Air Quality Standards for Nitrogen Dioxide: Final Rule, 75 Fed. Reg. 6474 (2010) (to be codified at 40 C.F.R. pts. 50 and 58).

Primary National Ambient Air Quality Standards for Nitrogen Dioxide: Proposed Rule, 75 Fed. Reg. 34404 (2009) (to be codified at 40 C.F.R. pts. 50 and 58). 
Thoma, E. D., Shores, R. C., Isakov, V., \& Baldauf, R. W. (2008). Characterization of near-road pollutant gradients using path-integrated optical remote sensing. Journal of the Air \& Waste Management Association, 58(7), 879-890. doi: Doi 10.3155/1047-3289.58.7.879

USEPA. (2001). National Air Quality and Emissions Trends Report, 1999. (EPA 454/R-01-004). Washington, D.C.

USEPA. (2007). Summary of Current and Historical Light-Duty Vehicle Emission Standards. Washington, D.C.: Retrieved from http://www.epa.gov/greenvehicles/detailedchart.pdf.

USEPA. (2008a). Average Annual Emissions and Fuel Consumption for Gasoline-Fueled Passenger Cars and Light Trucks. (EPA420-F-08-024). Washington, D.C.: Retrieved from http://www.epa.gov/otaq/consumer/420f08024.pdf.

USEPA. (2008b). Integrated Science Assessment for Oxides of Nitrogen - Health Criteria (Final Report). (EPA/600/R-08/071, 2008). Washington, D.C.

USEPA. (2010a). Design Values (Average 1-Hour 98th Percentiles over 3 Years) by County for Nitrogen Dioxide Research Triangle Park, NC: Retrieved from http://www.epa.gov/oaqps001/nitrogenoxides/pdfs/NO2 final designvalues 0608 Jan22.pdf.

USEPA. (2010b). Final Regulatory Impact Analysis (RIA) for the $\mathrm{NO}_{2}$ National Ambient Air QUality Standards (NAAQS). Research Triangle Park, NC: Retrieved from http://www.epa.gov/ttnecas1/regdata/RIAs/FinalNO2RIAfulldocument.pdf.

USEPA. (2011, July 6). Nitrogen Dioxide: Health Retrieved September 27, 2011, from http://www.epa.gov/air/nitrogenoxides/health.html 


\title{
CHAPTER 5. PERVIOUS PHOTOCATALYTIC CONCRETE PAVEMENT: LABORATORY INVESTIGATION OF THE EFFECT OF PHOTOCATALYTIC LAYER DEPTH ON NO OXIDATION RATE AND COMPARISON WITH PHOTOCATALYTIC MORTARS
}

\author{
A paper to be submitted to Catalysis Today \\ J. K. Sikkema ${ }^{1}$, J. T. Kevern' ${ }^{2}$, J. E. Alleman ${ }^{3}$, and S. K. Ong ${ }^{3}$
}

\begin{abstract}
1. Abstract
Photocatalytic concrete pavements hold potential to minimize the effects of substantial $\mathrm{NO}_{\mathrm{x}}$ pollution in near-road environments. NO oxidation rates for conventional mixtures have been evaluated in multiple research efforts. Pervious concrete pavements, which are already employed in efforts to minimize the negative effects of stormwater, could also be used to address air pollution. Due to increased air voids, it has been reported that pervious concrete exposes approximately 6 times more surface area to sunlight than conventional mixtures. This increased specific surface area could result in increased NO oxidation rate. In this study, the NO oxidation rate was measured from a set of photocatalytic pervious concrete slabs and a set of photocatalytic mortar slabs that were each manufactured with the same type of photocatalytic cement and water-to-cement ratios. At a confidence level of $90 \%$, the average NO oxidation rate for pervious and mortar slabs were $44.2 \pm 4.18$ and $40.9 \pm$ $6.04 \mathrm{nmol} \cdot \mathrm{m}^{-2} \cdot \mathrm{s}^{-1}$, respectively. This difference was not found to be significant. The study also evaluated whether there is a significant correlation between NO oxidation rate and the photocatalytic layer depth in pervious concrete slabs manufactured using a two-lift technique. Data collected did no provide evidence for this correlation. For each objective, the NO oxidation rate was determined based on measurements from a bench-scale flow-through photoreactor. This reactor permitted control of environmental conditions.
\end{abstract}

\section{Introduction}

Photocatalytic concrete pavements hold the potential to serve as an air pollution mitigation technology. Under sunlight and in the presence of water, these pavements generate hydroxyl radicals

\footnotetext{
${ }^{1}$ Instructor; Engineering, Dordt College, Sioux Center, lowa

${ }^{2}$ Assistant Professor; Civil and Mechanical Engineering, University of Missouri Kansas City, Kansas City, MO

${ }^{3}$ Professor; Civil, Construction, and Environmental Engineering, lowa State University, Ames, lowa
} 
$\left({ }^{\bullet} \mathrm{OH}\right)$, which oxidize a variety of organic and inorganic atmospheric air pollutants (e.g., see oxidation of $\mathrm{NO}$ and $\mathrm{NO}_{2}$ in Figure 4.1). Extensive bench-scale laboratory testing has determined the influence of a variety of environmental parameters on the removal of nitric oxide (NO) (Ballari et al., 2011; Dylla et al., 2010; Hüsken et al., 2009; Murata \& Tobinai, 2002). For these studies NO was selected as a surrogate for oxidizable atmospheric air pollutants. In addition to serving as a surrogate, NO is one compound that makes up the group of air pollutant species termed $\mathrm{NO}_{\mathrm{x}}$. Within the $\mathrm{NO}$. group, nitrogen dioxide $\left(\mathrm{NO}_{2}\right)$ raises the greatest concerns from the perspective of health and environmental impairment. However, due to the ease and rapidity at which species within the $\mathrm{NO}_{\mathrm{x}}$ group can be oxidized to $\mathrm{NO}_{2}$, in pollution estimates USEPA treats all emissions within the $\mathrm{NO}_{x}$ category as $\mathrm{NO}_{2}$ (USEPA, 2001). USEPA (2001) has estimated that $\mathrm{NO}$ accounts for $95 \%$ of atmospheric emissions in the $\mathrm{NO}_{\mathrm{x}}$ category; therefore, any effort that seeks to mitigate the negative impacts of $\mathrm{NO}_{2}$ should target $\mathrm{NO}$ emissions.

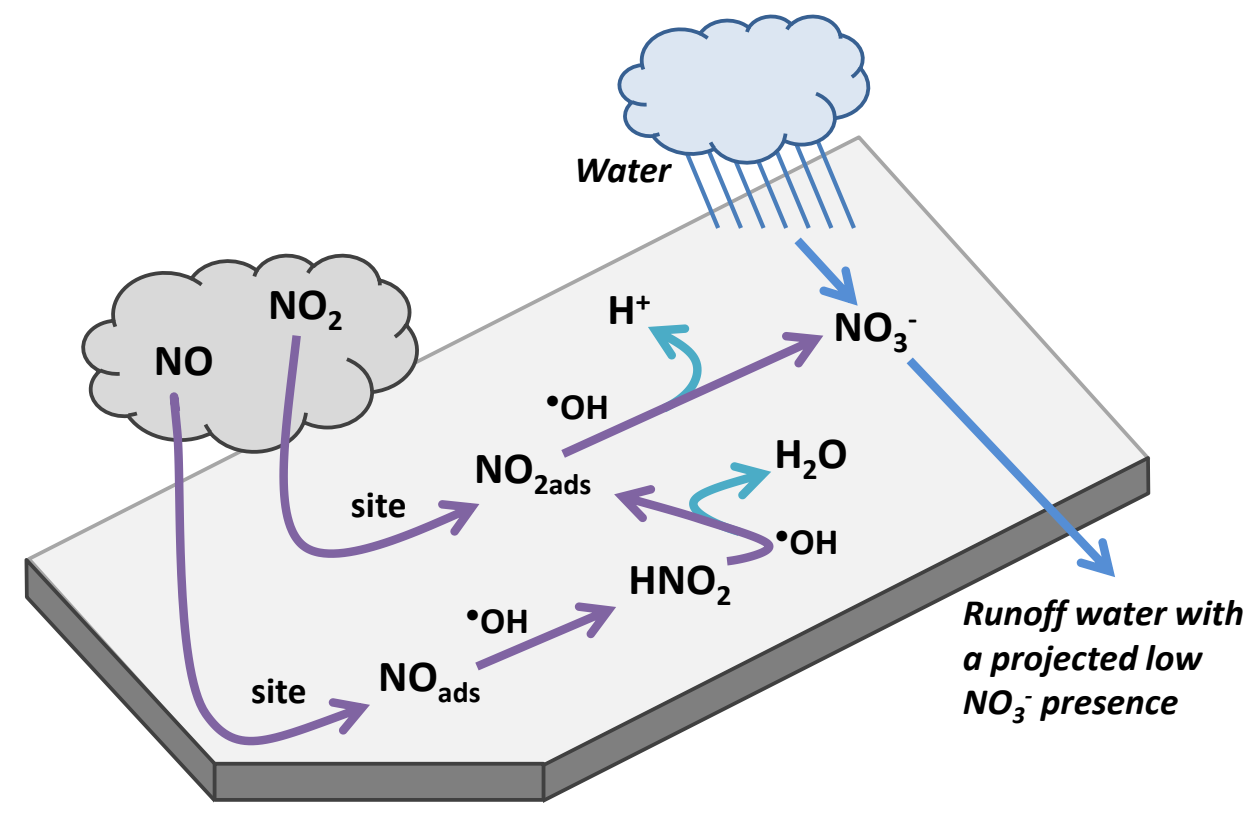

Figure 5.1. Photocatalytic oxidation of $\mathrm{NO}$ and $\mathrm{NO}_{2}$ by pavement containing $\mathrm{TiO}_{2}$ (partially adapted from Ballari et al., 2011 from).

At $34 \%$ of all $\mathrm{NO}_{\mathrm{x}}$ emissions, pollution from on-road motor vehicles represents one of the major sources of this pollutant that must be targeted in overall $\mathrm{NO}_{\mathrm{x}}$ abatement efforts (USEPA, 2001). If effective, photocatalytic pavements could be an attractive approach to mitigating $\mathrm{NO}_{\mathrm{x}}$ pollution that arises from vehicles because the pavement could be placed in a near-road location, where $\mathrm{NO}_{2}$ concentrations are elevated by 30 to $100 \%$ in comparison to area-wide concentrations (USEPA, 2010). 
In addition to the elevation in air pollution caused by tailpipe emissions, motor vehicles also contribute to water pollution. Kayhanian et al. (2003) found that annual average daily traffic (AADT) was one of the factors that had a significant effect on the concentration of most highway pollutants in runoff. Pervious (also called permeable or porous) pavement has been demonstrated to improve the quality of stormwater discharges (Drake et al., 2013); therefore, it has been proposed for use in applications such as highway shoulders (Alam et al., 2012). By addition of $\mathrm{TiO}_{2}$ to pervious concrete mixtures, the environmental benefits of pervious pavements could be augmented to enhance air quality in addition to water quality. Asadi et al. (2012) noted that in comparison to conventional concrete mixtures, 6 times more surface area is exposed to sunlight in pervious concrete. Due to this increased specific surface area pervious concrete pavements could exhibit higher rates of NO oxidation than conventional photocatalytic concrete.

A second noteworthy speculation relates to the optimal photocatalytic layer thickness in two-lift concrete pavements. Two-lift construction of concrete pavements bonds a high-quality top layer to a low-quality bottom layer. The top layer is thin and is designed for qualities such as freeze-thaw durability, increased friction, noise minimization, and-in this case of $\mathrm{TiO}_{2}$-containing mixturesphotoactivity, whereas the bottom layer is thick and permits use of recycled or low-quality aggregates (Van Dam, 2012). The addition of $\mathrm{TiO}_{2}$ to a concrete mixture increases expense; therefore, for conventional photocatalytic two-lift concretes the top lift thickness should be minimized. In contrast, in pervious mixtures UV-A light may be able to reach photocatalytically active sites below the surface (Asadi et al., 2012); therefore, an optimal top-layer thickness max exist.

Asadi et al. (2012) used a lab-scale photoreactor to in an initial effort to evaluate NO removal for various photocatalytic pervious concrete samples. Calculated oxidation rates ranged from 2 to 11 $\mathrm{nmole} \cdot \mathrm{m}^{-2} \cdot \mathrm{s}^{-1}$. These values are lower than the oxidation rates that can be calculated from other publications (Ballari et al., 2011; Hüsken et al., 2009; Murata \& Tobinai, 2002); however, Asadi et al. (2012) conducted tests at an inlet concentration of $430 \mathrm{ppb}$, which is substantially lower than the 1000 ppb used in many of the other evaluations. The authors did report that photocatalytic layer depth increased NO removal; however, the statistical significance of this conclusion was not evaluated. Asadi et al. (2012) also compared their data to data reported by Dylla et al. (2010). At the same environmental conditions (i.e., $30 \%$ relative humidity, $24 \mathrm{~W} \cdot \mathrm{m}^{-2}$, and $3 \mathrm{~L} \cdot \mathrm{m}^{-2}$ ) NO oxidation rates calculated from Dylla et al. (2010) were 5.1 and $5.6 \mathrm{nmole} \cdot \mathrm{m}^{-2} \cdot \mathrm{s}^{-1}$ for samples with 3 and $5 \% \mathrm{TiO}_{2}$ respectively. In comparison, for 
pervious samples with photocatalytic layer thickness of 0.5 in $(15 \mathrm{~mm}), 1$ in $(25 \mathrm{~mm}), 2$ in $(50 \mathrm{~mm})$, and

3 in $(75 \mathrm{~mm})$ the NO oxidation rates were $4.5,5.3,6.0$ and $7.1 \mathrm{nmole} \cdot \mathrm{m}^{-2} \cdot \mathrm{s}^{-1}$ respectively. This result lead Asadi et al. (2012) to state that pervious samples were superior to impervious samples at layer thicknesses of at least 2 in. However the comparison was made was between pervious slabs made with a commercially-available photocatalytic cement and slabs manufactured by applying a photocatalytic surface coating to a concrete base.

To incrementally advance knowledge on the NO oxidation performance of pervious photocatalytic pavement, this study featured two objectives. The first objective sought to determine if a significant correlation exists between NO oxidation rate and photocatalytic layer depth for a wider range of thicknesses than previously evaluated. The second objective sought to determine if a there was a significant difference in the average NO oxidation rate measured from a set of photocatalytic pervious concrete slabs and a set of photocatalytic mortar slabs, which were both manufactured using the same type of photocatalytic cement and water-to-cement ratios.

\section{Materials and methods}

\subsection{Photocatalytic Slab Preparation}

\subsubsection{Photocatalytic Mortar Slabs}

Mortar slabs selected for this study measured $150 \mathrm{~mm}(6 \mathrm{in}) \times 150 \mathrm{~mm}(6 \mathrm{in}) \times 25 \mathrm{~mm}$ (1 in). To introduce $\mathrm{TiO}_{2}$ into the mixture, the researchers used a cement that contained $\mathrm{TiO}_{2}$ ( $\mathrm{TX}$ Active, Essroc Italcementi Group, Nazareth, PA). The proportions of the cement (TX Active or Type I), water, and fine aggregate (ASTM C778 standard sand, U.S. Silica Co., Frederick, MD) were recorded as $624 \mathrm{~kg} \mathrm{~m}^{-3}$ (1052 $\left.\mathrm{lb} \mathrm{yd}^{-3}\right), 262 \mathrm{~kg} \mathrm{~m}^{-3}\left(442 \mathrm{lb} \mathrm{yd}^{-3}\right)$, and $1412 \mathrm{~kg} \mathrm{~m}^{-3}\left(2380 \mathrm{lb} \mathrm{yd}^{-3}\right)$ respectively. Given the small size of the slabs constructed, the mix did not include coarse aggregate. Except for the coarse aggregate, the relative proportions of materials used to manufacture the laboratory mortar slabs were similar to that of a highway pavement. The slab pour used a two-lift procedure with equal volumes of a Type I cement bottom lift followed by a TX Active photocatalytic cement top lift.

\subsubsection{Photocatalytic Pervious Concrete Slabs}

To provide a basis for comparison with the mortar slabs, the photocatalytic pervious concrete slabs manufactured for this study used the same type of photocatalytic cement (TX Active) and water-tocement ratio (0.4). These slabs measured $150 \mathrm{~mm}(6$ in) $\times 150 \mathrm{~mm}(6 \mathrm{in}) \times 150 \mathrm{~mm}(6 \mathrm{in})$. The 
proportions of cement (TX Active or Type I), water, coarse aggregate (crushed limestone, 50\% passing $9.5 \mathrm{~mm}$ sieve, 7\% passing $4.75 \mathrm{~mm}$ sieve), fine aggregate (ASTM C33 river sand), and polypropylene fiber (Fibermesh 300, Propex, Chattanooga, TN) were recorded as $300 \mathrm{~kg} \mathrm{~m}^{-3}\left(510 \mathrm{lb} \mathrm{yd}^{-3}\right), 120 \mathrm{~kg} \mathrm{~m}^{-3}(200 \mathrm{lb}$ $\left.\mathrm{yd}^{-3}\right), 1200 \mathrm{~kg} \mathrm{~m}^{-3}\left(2030 \mathrm{lb} \mathrm{yd}^{-3}\right), 360 \mathrm{~kg} \mathrm{~m}^{-3}\left(213 \mathrm{lb} \mathrm{yd}^{-3}\right)$, and $0.9 \mathrm{~kg} \mathrm{~m}^{-3}\left(1.5 \mathrm{lb} \mathrm{yd}^{-3}\right)$ respectively. The mixture was designed for $24 \%$ void content. The following admixtures included in the mix: super absorbent polymer [a partial sodium salt of cross-linked polypromancic acid, described in Fisher (2010)], polycarboxylate high range water reducer (Glenium 7500, BASF, Florham Park, NJ), hydration stabilizer (Delvo, BASF), and air entraining agent (VR Standard, BASF). Respective dosage rates for these admixtures were as follows: $1.3 \mathrm{~mL}$ (kg cement) $)^{-1}\left(2 \mathrm{oz} \mathrm{cwt}^{-1}\right), 2.6 \mathrm{~mL}(\mathrm{~kg} \text { cement})^{-1}\left(4 \mathrm{oz} \mathrm{cwt}^{-1}\right), 2.6 \mathrm{~mL}$ (kg cement) $)^{-1}\left(4 \mathrm{oz} \mathrm{cwt}^{-1}\right)$, and $0.65 \mathrm{~mL}(\mathrm{~kg} \text { cement })^{-1}\left(1 \mathrm{oz} \mathrm{cwt}^{-1}\right)$. The pour of pervious slabs also used a two-lift procedure. Instead of using equal volumes of a Type I and TX Active mixes, the volumes were varied in order to manufacture slabs with photocatalytic (i.e., TX Active) pervious pavement depths of 15 $\mathrm{mm}$ (0.5 in), $75 \mathrm{~mm}$ (3 in), and $150 \mathrm{~mm}$ (6 in).

\subsubsection{Slab Curing and Cleaning}

Following the pours, the researchers covered the slab surface with a damp cloth and plastic sheet for a 24-h period while the slab cured. After this initial curing period, forms were removed and the slabs were transferred into a $100 \%$ humidity room for a minimum of $14 \mathrm{~d}$.

Before the NO oxidation rate was evaluated, the slabs were cleaned using a two-step process by which the slabs were first immersed in water (Type I reagent grade) for $2 \mathrm{~h}$ and then dried in an oven at $60^{\circ} \mathrm{C}\left(140^{\circ} \mathrm{F}\right)$ for $20 \mathrm{~h}$. This procedure was similar to that employed by an applicable standard for the evaluation of photocatalytic materials (ISO, 2007).

\subsection{Experimental Apparatus}

A flow-through photoreactor, made of poly(methyl methacrylate) (PMMA, i.e., plexiglass), was the main component in the experimental apparatus (displayed in Figure 4.2). Additional components included a NO test gas supply system, UV-A light source, and NO/NO $\mathrm{N}_{\mathrm{x}}$ analyzer. Guidance on construction and operation of the apparatus was provided by the international standard, ISO 221971:2007(E) (ISO, 2007). The test gas supplied to the photoreactor was a mixture of $51.6 \pm 1 \%$ ppmv NO balanced in nitrogen (EPA protocol gas, Praxair, Inc., Danbury, CT) and breathing air (Grade D, Airgas USA, LLC, North Central Region, West Chicago, IL) adjusted to NO concentrations that ranged between 0.94 and 1.1 ppmv. Photocatalytic properties of the slabs were activated by directing a UV-A light (XX- 
15BLB, Ultra-Violet Products, LLC, Upland, CA) at the UV-A-transparent optical window located at the top of the photoreactor. The emissions spectrum from this light features a primary peak at $365 \mathrm{~nm}$. As measured by a $365 \mathrm{~nm}$ UV sensor and radiometer (CX-365 and VLX-3W, Vilber Lourmat, Marne-laVallée, France), the measured irradiance at the location of the slab surface was $1.0 \times 10^{1} \mathrm{~W} \cdot \mathrm{m}^{-2}$. As determined in Chapter 3, use of these environmental conditions ensured that for the tests completed, the rate of NO degradation was limited by the adsorption and oxidation steps, not mass transfer to the slab surface.

For mortar slabs, 25 mm (1 in) wide PMMA spacers were used to secure the slab's position and rose to an elevation that was either flush with or less than $2 \mathrm{~mm}$ below the slab surface. Tape was wrapped around pervious concrete slabs and used to ensure that the test gas flowed over the photocatalytic surface. In each case, the test gas flowed through a cross section with a width of $150 \mathrm{~mm}(6 \mathrm{in})$ and a height of approximately $6 \mathrm{~mm}$ (0.25 in).

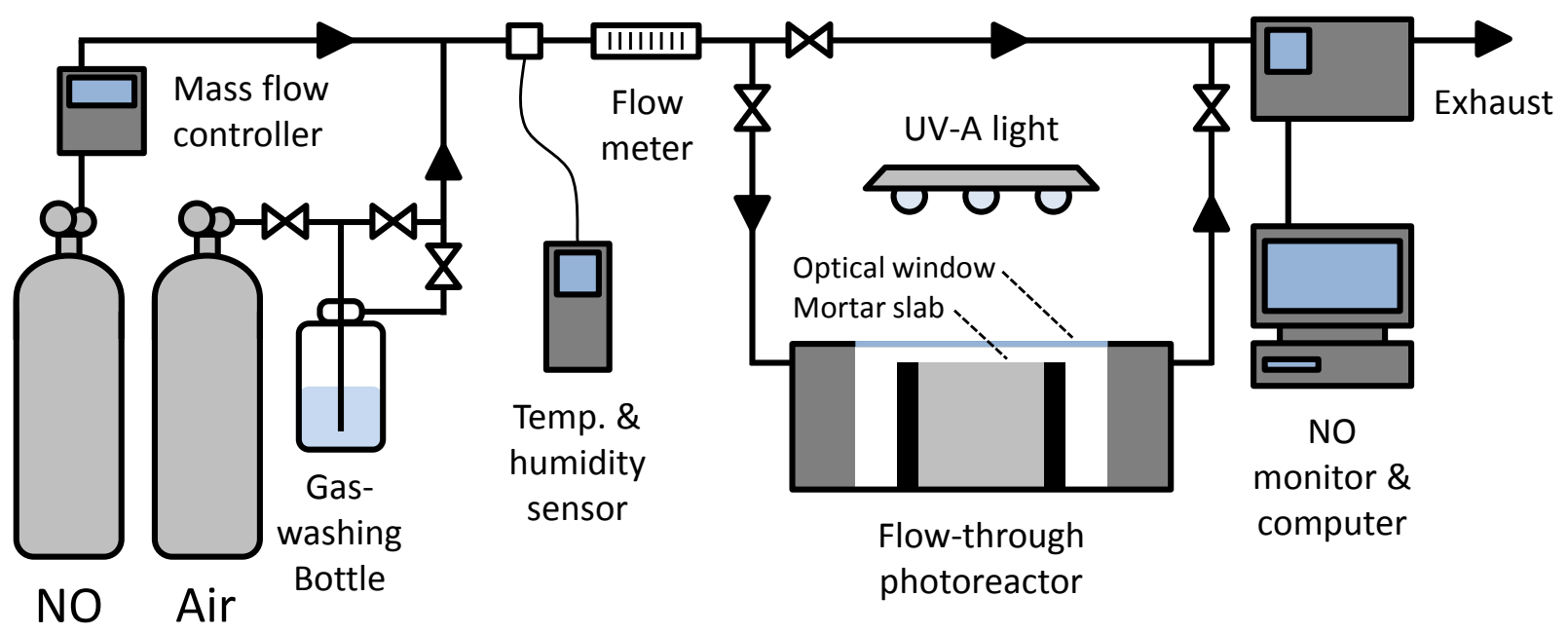

Figure 5.2. Diagram of experimental apparatus (adapted from Ballari et al., 2011).

The apparatus was completed with a NO monitor (Model 410 Nitric Oxide Monitor, 2B Technologies, Inc., Boulder, CO). The monitor recorded the gas concentrations at $10 \mathrm{~s}$ intervals. Chemiluminescence instruments detect the light produced when NO reacts with ozone $\left(\mathrm{O}_{3}\right)$ and require frequent calibration. In contrast, the Model 410 measures the change in UV absorbance at $254 \mathrm{~nm}$ when $\mathrm{O}_{3}$ is consumed upon reaction with NO. This is an absolute method; therefore, the manufacturer reports that the analyzer requires calibration annually to correct for non-linearity that exists in the photodiode response and associated electronics. 


\subsection{Operational Procedure}

The researchers used two phases to guide operation of the experimental apparatus: parameter setting and testing. The parameter setting phase was used to set airflow rate, relative humidity, and pollutant concentration. These variables were set by adjustment of needle valves and a mass flow controller. Operation within this phase continued until steady-state conditions were reached.

The second phase, the testing period, comprised two steps during which UV-light off and UV-light on concentrations of NO (illustrated in Figure 5.3). Due to the fact that the change in concentration that occurred upon turning on the UV-A light was not instantaneous, a gap occurred between measurements of these segments.

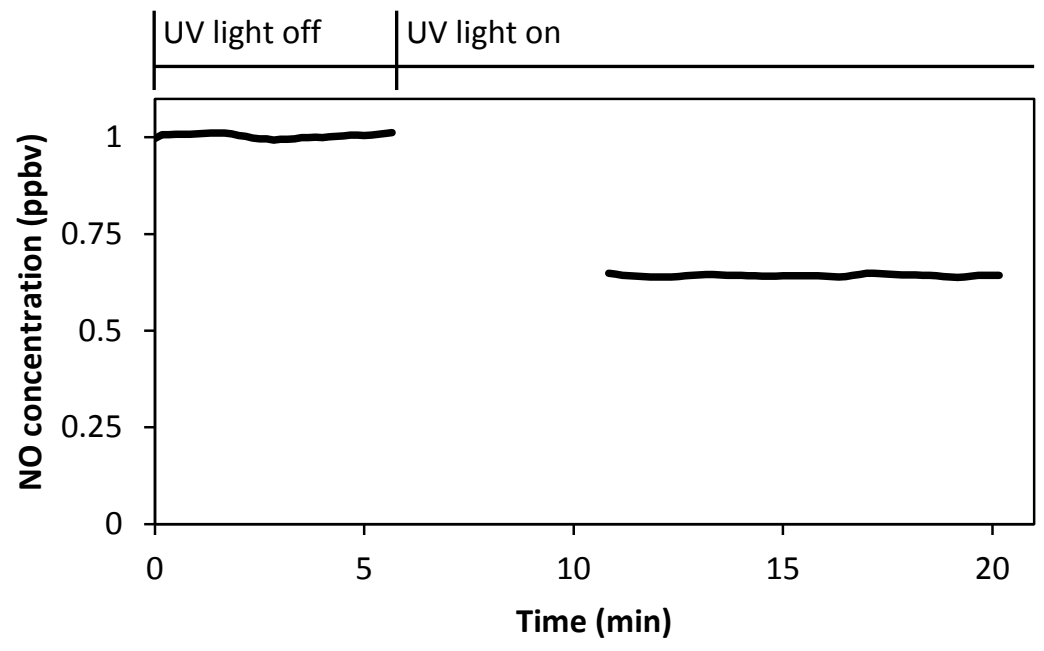

Figure 5.3. Typical NO monitor data from testing procedure.

\subsection{Presentation of Results}

In this publication, the authors chose to present results as the NO oxidation rate. This value was calculated using the following equation:

$$
\text { NO oxidation rate }=\frac{P}{R \cdot T} \cdot \frac{Q}{A} \cdot\left(C_{U V \text { off }}-C_{U V \text { on }}\right)
$$

where,

$$
\begin{aligned}
& P=1 \mathrm{~atm}=\text { atmospheric pressure, } \\
& R=8.314 \frac{\mathrm{J}}{\mathrm{mol} \cdot \mathrm{K}}=\text { ideal gas constant }, \\
& T=298 \mathrm{~K}=\text { temperature, } \\
& Q=\text { volumetric flow rate, }
\end{aligned}
$$


$A=230 \mathrm{~cm}^{2}=$ slab surface area,

$C_{U V \text { off }}=N O$ concentration with UV light off , and

$C_{U V \text { on }}=N O$ concentration with UV light on.

\section{Results and Discussion}

\subsection{NO removal rate of photocatalytic pervious concrete cubes and mortar slabs}

Table 5.1 provides NO removal data collected. In addition to presenting NO oxidation rate in terms of moles removed, Table 5.1 also lists oxidation in units of $\mathrm{g} \cdot$ lane-mile $\mathrm{e}^{-1} \cdot \mathrm{hr}^{-1}$ in the column furthest to the right. These units were included in order to facilitate comparison with emissions from on-road motor vehicles, which can be expressed in the same units. 
Table 5.1. Environmental conditions of and results for tests completed.

\begin{tabular}{|c|c|c|c|c|c|c|c|c|c|c|}
\hline \multirow{4}{*}{ Test \# } & \multirow{4}{*}{ Test description } & \multicolumn{5}{|c|}{ Environmental conditions } & \multicolumn{4}{|c|}{ Results } \\
\hline & & \multirow{3}{*}{$\begin{array}{c}\text { Irrad } \\
\left(\mathrm{W} \cdot \mathrm{m}^{-2} \times 10^{1}\right)\end{array}$} & \multirow{3}{*}{$\begin{array}{c}Q \\
\left(L \cdot \mathrm{min}^{-1}\right)\end{array}$} & \multirow{3}{*}{$\begin{array}{l}\text { RH } \\
\text { (\%) }\end{array}$} & \multirow{2}{*}{\multicolumn{2}{|c|}{$\begin{array}{l}C_{\text {Nouv on }} \\
\text { (ppmv) }\end{array}$}} & \multirow{2}{*}{\multicolumn{2}{|c|}{$\begin{array}{l}C_{\text {NO UV off }} \\
\text { (ppmv) }\end{array}$}} & \multicolumn{2}{|c|}{ NO oxidation rate } \\
\hline & & & & & & & & & \multirow{2}{*}{$\begin{array}{c}\text { (nmole } \cdot \mathrm{m}^{-} \\
\left.2 \cdot \mathrm{s}^{-1}\right)\end{array}$} & \multirow{2}{*}{$\begin{array}{c}\text { (g.lane- } \\
\text { mile }^{-1} \cdot \mathrm{hr}^{-1} \text { ) }\end{array}$} \\
\hline & & & & & $\overline{\mathbf{x}}$ & $\mathbf{S}$ & $\overline{\mathbf{x}}$ & $\mathbf{S}$ & & \\
\hline 1 & Pervious, Type I cement & 1.0 & 3.0 & 20 & 0.95 & 0.00015 & 0.93 & 0.00037 & 2.3 & 1.5 \\
\hline 2 & Pervious, $15 \mathrm{~mm} \mathrm{TiO}_{2}$-containing & 1.0 & 3.0 & 20 & 0.99 & 0.00065 & 0.48 & 0.00079 & 45 & 29 \\
\hline 3 & Pervious, 50 mm TiO ${ }_{2}$-containing & 1.0 & 3.0 & 20 & 0.99 & 0.0013 & 0.52 & 0.00079 & 41 & 26 \\
\hline 4 & Pervious, 50 mm $\mathrm{TiO}_{2}$-containing, rep 2 & 1.0 & 3.0 & 20 & 0.95 & 0.00082 & 0.46 & 0.0020 & 44 & 28 \\
\hline 5 & Pervious, 75 mm $\mathrm{TiO}_{2}$-containing & 1.0 & 3.0 & 20 & 0.98 & 0.0010 & 0.47 & 0.0017 & 46 & 29 \\
\hline 6 & Pervious, 75 mm TiO ${ }_{2}$-containing, rep 2 & 1.0 & 3.0 & 20 & 0.95 & 0.0008 & 0.47 & 0.00037 & 43 & 27 \\
\hline 7 & Pervious, $75 \mathrm{~mm} \mathrm{TiO}{ }_{2}$-containing, rep 3 & 1.0 & 3.0 & 20 & 0.97 & 0.0014 & 0.49 & 0.00076 & 42 & 27 \\
\hline 8 & Mortar, Type I cement & 1.0 & 3.0 & 50 & 1.1 & 0.00067 & 1.06 & 0.0033 & 0.36 & 0.23 \\
\hline 9 & Mortar, slab 1 & 1.0 & 3.0 & 20 & 1.0 & 0.0088 & 0.52 & 0.0051 & 44 & 28 \\
\hline 10 & Mortar, slab 2 & 1.0 & 3.0 & 20 & 1.0 & 0.0094 & 0.63 & 0.0053 & 36 & 23 \\
\hline 11 & Mortar, slab 3 & 1.0 & 3.0 & 20 & 0.98 & 0.0085 & 0.42 & 0.0052 & 50 & 32 \\
\hline 12 & Mortar, slab 4 & 1.0 & 3.0 & 20 & 0.94 & 0.0061 & 0.55 & 0.0020 & 35 & 22 \\
\hline 13 & Mortar, slab 5 & 1.0 & 3.0 & 20 & 0.98 & 0.0077 & 0.44 & 0.0063 & 48 & 31 \\
\hline 14 & Mortar, slab 6 & 1.0 & 3.0 & 20 & 0.98 & 0.0059 & 0.62 & 0.0023 & 32 & 21 \\
\hline
\end{tabular}

${ }^{\mathrm{i}} 1$ lane-mile $=5280 \mathrm{ft} \times 12 \mathrm{ft}=5886 \mathrm{~m}^{2}$ 


\section{Existence of Correlation Between Photocatalytic Layer Depth and NO Oxidation Rate}

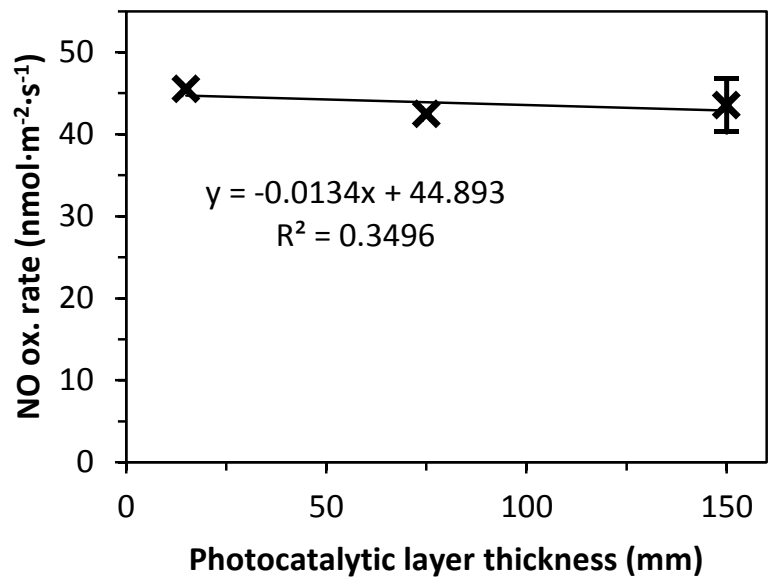

Figure 5.4 plots the effect of photocatalytic layer thickness on NO oxidation rate. A correlation is not evident based on linear regression $\left(R^{2}=0.3496\right)$. Furthermore, a model utility test did not reject a null hypothesis of $0 \mathrm{nmole} \cdot \mathrm{m}^{-2} \cdot \mathrm{s}^{-1} \cdot \mathrm{mm}^{-1}$ slope at any reasonable confidence level $(t=-0.751, \mathrm{df}=2, p=$ 0.590).

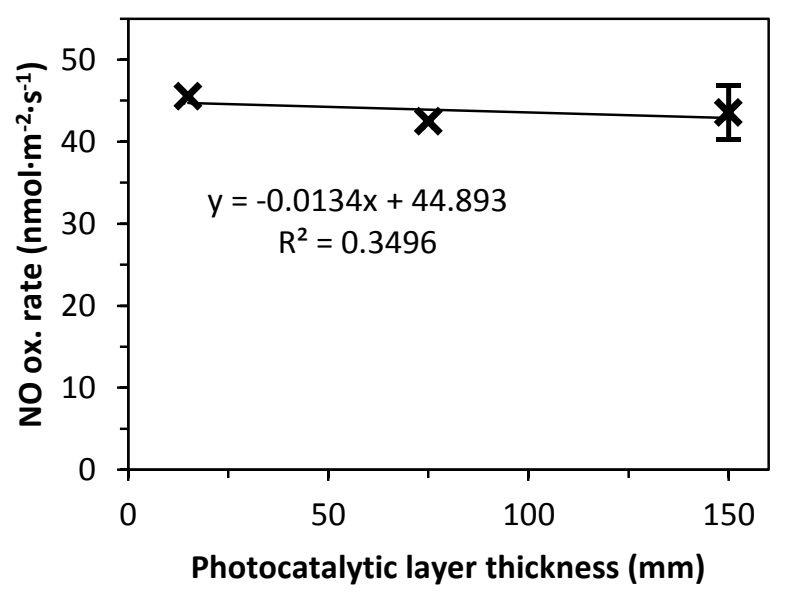

Figure 5.4. Effect of photocatalytic layer thickness on NO oxidation rate (average of observations plotted for 75 and $150 \mathrm{~mm}$ data points; error bars on $150 \mathrm{~mm}$ data point provide $90 \%$ confidence interval).

In contrast with this study, Asadi et al. (2012) concluded that a positive relationship existed between the depth of the pervious photocatalytic layer and NO removal. For the test presented as evidence of a correlation, the average NO oxidation rate was calculated to be $4.5,5.3,6.0$, and $7.1 \mathrm{nmole} \cdot \mathrm{m}^{-2} \cdot \mathrm{s}^{-1}$ for 
slabs with photocatalytic layers of $0.5,1,2$, and 3 inches, respectively. Linear regression of this data found a $R^{2}$ value of 0.984 . A model utility test rejected a null hypothesis that slope equaled $0 \mathrm{nmole} \cdot \mathrm{m}^{-}$ ${ }^{2} \cdot \mathrm{s}^{-1} \cdot \mathrm{mm}^{-1}$ at $90 \%$ confidence $(t=10.998, \mathrm{df}=2, p=0.008)$.

To explain the observed correlation, Asadi et al. (2012) postulated that UV light penetrated beneath the pervious slabs' surface and reached photocatalytically active sites throughout the depth of the $\mathrm{TiO}_{2}$ containing layer. The authors evaluated this conclusion with use of UV-sensitive paper (SunArt Paper, Tedco Toys, Hagerstown, IN), which darkens with exposure to UV-light. After placing the paper beneath a 150-mm thick pervious slab, the UV-A light was used to irradiate the slab surface at a level of $10 \mathrm{~W} \cdot \mathrm{m}^{-2}$ for a period of $10 \mathrm{~min}$. The paper was then processed according to the manufacture's guidelines and reviewed for evidence of UV penetration. Slicing the pervious sample permitted evaluations for thicknesses of 100, 75, 50, and $25 \mathrm{~mm}$. Figure 5.5 displays a section of processed UV-sensitive paper for the 25- and 50-mm slab thicknesses. In each image, an outline of the pervious slab is evident. In Figure $5.5 \mathrm{a}$, which displays the paper used to evaluate the $50-\mathrm{mm}$ slab, area within the slab footprint is white, indicating that UV did not penetrate through the sample. The paper used to evaluate the 25-mm pervious slab, is markedly different (Figure 5.5b). Although the slab outline is evident, the area within the slab footprint shows colorization that resulted from UV-exposure. Although the concrete samples were pervious, the connected voids did not permit penetration of UV-A light to a depth of $50 \mathrm{~mm}$. Without excitation of electrons by UV-light photocatalytic oxidation of NO will not occur. Therefore, for the pervious concrete mixture evaluated in this study, there is no evidence that additional benefit is derived with photocatalytic layer thicknesses in excess of $15 \mathrm{~mm}$. 


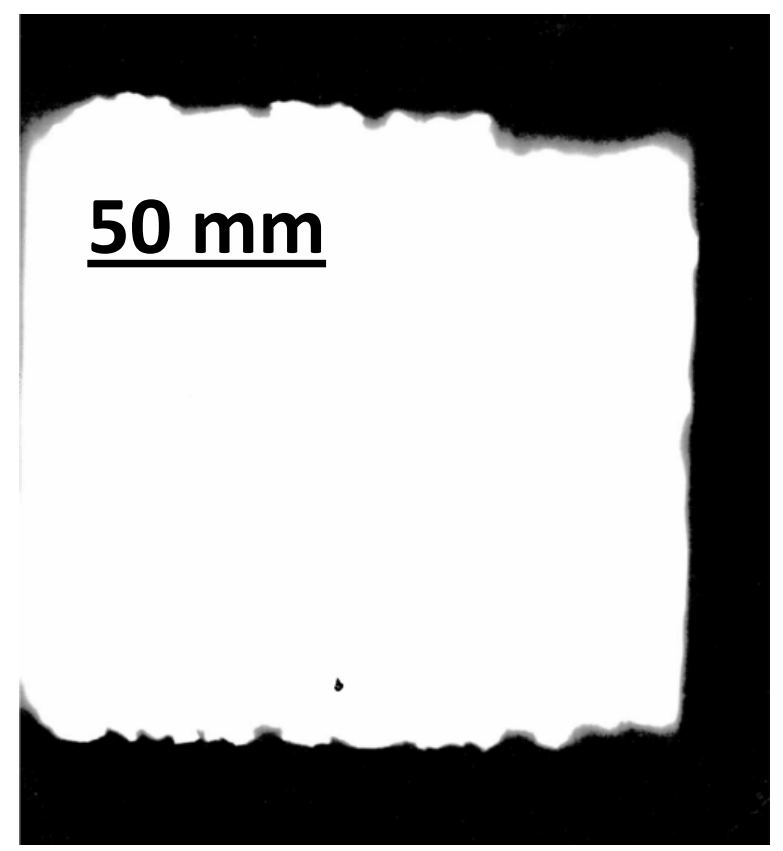

a. 50-mm thick slab.

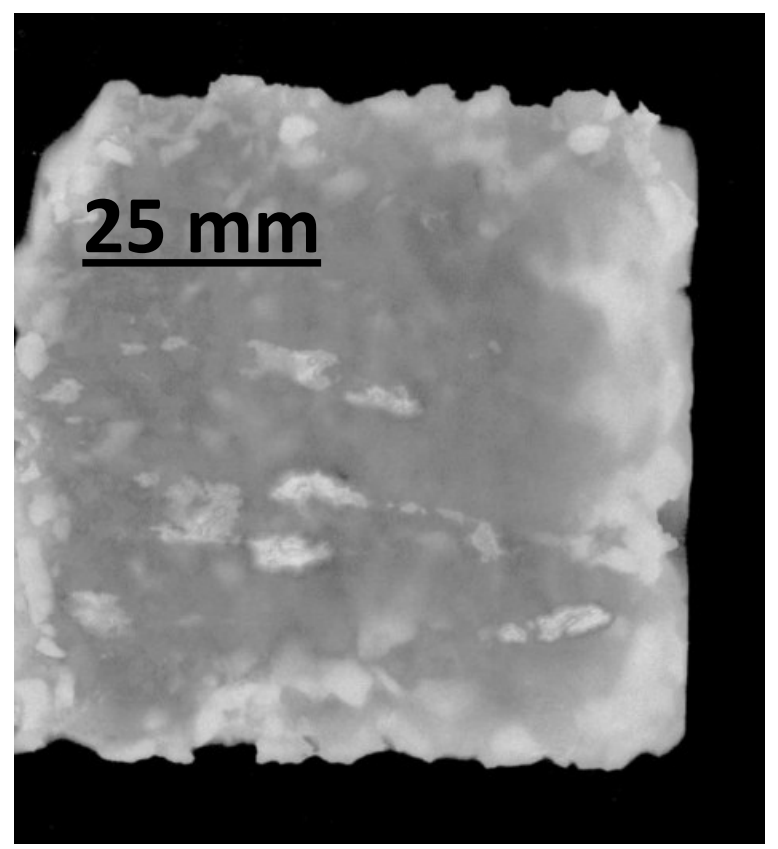

b. 25-mm thick slab.

Figure 5.5. Images of UV-sensitive paper placed beneath $150 \mathrm{~mm} \times 150 \mathrm{~mm}$ pervious slabs of varying thicknesses, which were irradiated with UV-A light at $10 \mathrm{~W} \cdot \mathrm{m}^{-2}$ (colorization within the slab footprint indicates UV penetration).

It is evident that the oxidation rates reported by Asadi et al. (2012) are lower than those reported in this study. For the tests reviewed above, the oxidation rate ranged between 4.5 and $7.1 \mathrm{nmole} \cdot \mathrm{m}^{-2} \cdot \mathrm{s}^{-1}$ for relative humidity, irradiance, flow rate, and NO concentration values of $30 \%, 24 \mathrm{~W} \cdot \mathrm{m}^{-2}, 3 \mathrm{~L} \cdot \mathrm{min}^{-1}$, and $430 \mathrm{ppb}$, respectively. In comparison, in this study, oxidation rates for pervious photocatalytic samples ranged from 41-46 nmole $\cdot \mathrm{m}^{-2} \cdot \mathrm{s}^{-1}$. The observed differences cannot be explained by applying the relationships between influent NO concentration, UV-A irradiance, and relative humidity on NO oxidation rate, which were established in Chapter 3. The slopes of the relationship between NO oxidation rate and NO concentration, UV-A irradiance, and relative humidity were determined to be 31 $\mathrm{nmole} \cdot \mathrm{m}^{-2} \cdot \mathrm{s}^{-1} \cdot \mathrm{ppm}^{-1}, 1.4 \mathrm{nmole} \mathrm{m}^{-2} \cdot \mathrm{s}^{-1} \cdot\left(\mathrm{W} \cdot \mathrm{m}^{-2}\right)^{-1}$ and $0.36 \mathrm{nmole} \cdot \mathrm{m}^{-2} \cdot \mathrm{s}^{-1} \cdot \% \mathrm{RH}^{-1}$, respectively. When these values are applied to transform the data from Asadi et al. (2012), the effect of running tests at a comparatively lower influent concentration are in large part cancelled out by the comparatively higher irradiance level. The lack of an explanation based on environmental variables reinforces the conclusion made in Chapter 3 that significant differences exist when comparison is made between studies and that if potential stakeholders are considering this technology, they would be wise to carefully evaluate both environmental conditions of the proposed site and material properties of the proposed pavement. 


\subsection{Existence of Difference in NO Removal by Pervious Cubes Versus Mortar Slabs}

Section 0 found no evidence of a correlation between photocatalytic layer depth and NO oxidation rate. Having reached this conclusion, the 3 pervious slabs evaluated were considered to be samples from the same population. Comparison of this pervious sample set with the set of mortar slabs evaluated permitted an analysis of whether a significant difference exists in the NO oxidation rate for the pervious and mortar samples. As noted previously, this is a valid basis for comparison because both the pervious and mortar slabs were manufactured using the same type of photocatalytic cement and water-to-cement ratios.

Figure 5.6 plots the mean value and $90 \%$ confidence interval for the pervious and mortar samples. Overlap of the $90 \%$ confidence interval suggests that the populations are not significantly different. This conclusion was confirmed with a $t$-test (two-tailed, unequal variances), which did not reject a null hypothesis of $0 \mathrm{nmol} \cdot \mathrm{m}^{-2} \cdot \mathrm{s}^{-1}$ difference between the average NO oxidation rate for pervious and mortar $\operatorname{slabs}(t=0.978, \mathrm{df}=7, p=0.360)$.

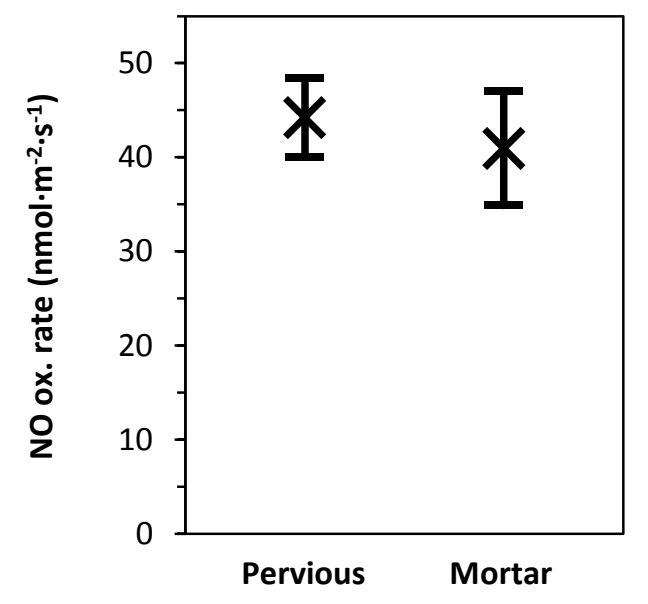

Figure 5.6. Comparison of mean value and $90 \%$ confidence intervals for pervious $(n=3)$ and mortar ( $n$ =6) samples.

Asadi et al. (2012) concluded that pervious samples, with photocatalytic layer thicknesses of at least 2 in, had greater rates of NO oxidation than impervious concrete samples. This study did not find the same conclusion. One explanation for the different conclusion reached is that Asadi et al. (2012) compared pervious concrete slabs manufactured with photocatalytic cement to with a conventional concrete mixture with a photocatalytic surface coating. Hüsken et al. (2009) found that different types 
of $\mathrm{TiO}_{2}$ and different techniques to apply $\mathrm{TiO}_{2}$ application to a mortar product (e.g., by mixing $\mathrm{TiO}_{2}$ with cement or mixing $\mathrm{TiO}_{2}$ with water) did affect $\mathrm{NO}$ removal. Realizing the conclusions from Hüsken et al. (2009), it should not be expected that similar rates of NO oxidation will be observed when evaluating pervious concrete slabs manufactured with photocatalytic cement and slabs manufactured by applying a photocatalytic surface coating to a conventional concrete mixture.

These findings do not provide evidence that pervious concrete pavements will oxidize NO at a greater rate than conventional concrete mixtures. However, these findings should not be interpreted as a conclusion that the use photocatalytic pervious concrete pavements should not be pursued. Although not addressed by this study, research efforts have begun an investigation to determine if a difference exists in the quality of stormwater discharges when comparing photocatalytic and conventional pervious concrete pavements (El-Ghussein, 2013).

\section{Conclusions}

Pervious photocatalytic concrete pavements have been proposed as a novel air pollution mitigation mechanism. Speculation had existed that due to the increased specific surface are of this type of pavement, it may exhibit higher rates of NO oxidation than conventional photocatalytic concrete mixtures. A laboratory evaluation of photocatalytic mortar and pervious slabs, which were manufactured with the same type of photocatalytic cement and water-to-cement ratios in order to provide a valid basis for comparison, found no significant difference between these two cementitious mixtures at a confidence level greater than $90 \%$. It had also been hypothesized that due penetration of UV-A light beneath the surface, a correlation between NO oxidation rate and photocatalytic layer depth may exist in slabs manufactured with a two-lift technique. Evaluation of slabs with photocatalytic layers of 15,75 , and $150 \mathrm{~mm}$ found no evidence of this correlation at a confidence level greater than $90 \%$. This finding indicates that potential users would be wise to minimize the thickness of the $\mathrm{TiO}_{2}$-containing layer in order to minimize pavement cost. Although this study did not provide evidence that photocatalytic pavements will achieve higher rates of NO oxidation than conventional mixtures, their development as an additional mechanism to employ photocatalytic pavements should continue to be pursued. In particular, as is the goal of other researchers, efforts should be made to determine if a difference exists in the quality of stormwater discharges when comparing photocatalytic and conventional pervious concrete pavements. 


\section{Acknowledgments}

The authors wish to thank the National Concrete Pavement Technology Center, the United States Department of Transportation, Essroc Italcementi Group, and Lehigh Hanson, Inc. for providing funding to pursue this study.

\section{References}

Alam, M. A., Haselbach, L., \& Cofer, W. F. (2012). Validation of the performance of pervious concrete in a field application with finite element analysis, Tampa, FL.

Asadi, S., Hassan, M. M., Kevern, J. T., \& Rupnow, T. D. (2012). Development of Photocatalytic Pervious Concrete Pavement for Air and Storm Water Improvements. Transportation Research Record: Journal of the Transportation Research Board, 2290(-1), 161-167.

Ballari, M. M., Yu, Q. L., \& Brouwers, H. J. H. (2011). Experimental study of the NO and NO2 degradation by photocatalytically active concrete. Catalysis Today, 161(1), 175-180. doi: 10.1016/j.cattod.2010.09.028

Drake, J. A. P., Bradford, A., \& Marsalek, J. (2013). Review of environmental performance of permeable pavement systems: State of the knowledge. Water Quality Research Journal of Canada, 48(3), 203-222.

Dylla, H., Hassan, M. M., Mohammad, L. N., Rupnow, T., \& Wright, E. (2010). Evaluation of Environmental Effectiveness of Titanium Dioxide Photocatalyst Coating for Concrete Pavement. Transportation Research Record: Journal of the Transportation Research Board, 2164(-1), 46-51. doi: $10.3141 / 2164-06$

El-Ghussein, F. (2013). Improving urban air and stormwater quality using photocatalytic highway pavement and photocatalytic pervious concrete shoulders. (Master's thesis), University of Missouri-Kansas City, Kansas City, MO.

Fisher, D. (2010). U.S. Patent Application Pub. No. US 2010/0285224 A1.

Hüsken, G., Hunger, M., \& Brouwers, H. J. H. (2009). Experimental study of photocatalytic concrete products for air purification. Building and Environment, 44(12), 2463-2474. doi: DOI 10.1016/j.buildenv.2009.04.010

ISO. (2007). Fine ceramics (advanced ceramics, advanced technical ceramics) -- Test method for airpurification performance of semiconducting photocatalytic materials -- Part 1: Removal of nitric oxide (Vol. 22197-1:2007): ISO.

Kayhanian, M., Singh, A., Suverkropp, C., \& Borroum, S. (2003). Impact of annual average daily traffic on highway runoff pollutant concentrations. Journal of Environmental Engineering, 129(11), 975990. 
Murata, Y., \& Tobinai, K. (2002). Influence of various factors on NOx removal performance of permeable interlocking block based on photocatalysis. Journal of Structural and Construction Engineering(Transactions of AIJ)(555), 9-15.

USEPA. (2001). National Air Quality and Emissions Trends Report, 1999. (EPA 454/R-01-004). Washington, D.C.

USEPA. (2010). Final Regulatory Impact Analysis (RIA) for the $\mathrm{NO}_{2}$ National Ambient Air QUality Standards (NAAQS). Research Triangle Park, NC: Retrieved from http://www.epa.gov/ttnecas1/regdata/RIAs/FinalNO2RIAfulldocument.pdf.

Van Dam, T. (2012). Designing Sustainable Concrete Pavements. In P. C. Taylor \& T. Van Dam (Eds.), Sustainable Concrete Pavements: A Manual of Practice. Ames, IA: National Concrete Pavement Technology Center. 


\title{
CHAPTER 6. PHOTOCATALYTIC CONCRETE PAVEMENTS: LABORATORY EVALUATION OF BLINDING BY OXIDATION PRODUCTS AND ROADWAY POLLUTANTS
}

\author{
A paper to be submitted to American Society of Civil Engineers Journal of Materials in Civil \\ Engineering
}

J. K. Sikkema ${ }^{1}$, J. E. Alleman ${ }^{2}$, and S. K. Ong ${ }^{2}$

\begin{abstract}
1. Abstract
On-road motor vehicles account for approximately $34 \%$ of nitrogen oxides $\left(\mathrm{NO}_{\mathrm{x}}\right)$ emitted in the

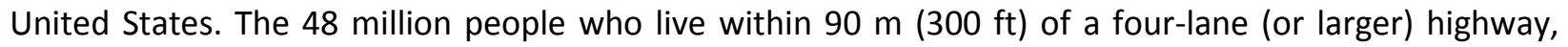
railroad, or airport are exposed to higher than average concentrations of $\mathrm{NO}_{\mathrm{x}}$ and experience multiple adverse health effects. Recent changes to air quality regulations for nitrogen dioxide $\left(\mathrm{NO}_{2}\right)$ may identify new areas of nonattainment, which in turn would intensify efforts to mitigate pollution from the transportation sector. The recent development of photocatalytic concrete pavements presents a novel option to abate $\mathrm{NO}_{\mathrm{x}}$ emissions from motor vehicles. However, over time these pavements are blinded because interfering substances (e.g., reaction products, roadway contaminants, fine dust, and organisms) foul the pavement surface. To determine the effect of reaction products, the NO oxidation rate of photocatalytic mortar slabs was tracked over 5 -hour and 20 -hour periods in a bench-scale photoreactor within which environmental conditions could be controlled. Although percent removal initially decreased in comparison to a reference measurement, as time progressed oxidation rate stabilized asymptotically. Hence, it is probable that reaction product formation on the surface of the concrete will not result in the complete loss of the pavement's air-cleaning property. NO oxidation rates of photocatalytic mortar slabs blinded by multiple soils, motor oil, and sodium chloride were also measured. Blinding was evident in comparison with baseline measurements. However, the magnitude of this decrease was not as large as reported in previous studies. Preliminary testing of regeneration methods did not find that full regeneration could easily be achieved. Therefore, methods to regenerate photocatalytic activity of blinded slabs must be developed.
\end{abstract}

\footnotetext{
${ }^{1}$ Instructor; Engineering, Dordt College, Sioux Center, lowa

${ }^{2}$ Professor; Civil, Construction, and Environmental Engineering, lowa State University, Ames, lowa
} 


\section{Introduction}

Nitrogen oxides $\left(\mathrm{NO}_{\mathrm{x}}\right)$-the sum of nitric oxide (NO), nitrogen dioxide $\left(\mathrm{NO}_{2}\right)$, and other oxides of nitrogen-are produced by high-temperature combustion processes. Exposure to elevated concentrations of these compounds has been linked with a variety of detrimental effects to both respiratory systems and the natural ecosystem (USEPA, 2008b).

Near-road environments represent an area of particular concern. This concern arises from the fact that approximately $34 \%$ of $\mathrm{NO}_{\mathrm{x}}$ emissions are from on-road motor vehicles (USEPA, 2001) and that an estimated 48 million people (i.e., more than $15 \%$ of the U.S. population) live within $90 \mathrm{~m}$ (300 ft) of major mobile sources of $\mathrm{NO}_{\mathrm{x}}$ (i.e., a four-lane or larger highway, railroad, or airport) (Primary National Ambient Air Quality Standards for Nitrogen Dioxide: Proposed Rule, 2009). Furthermore, multiple health studies have linked an increase in the observation of negative health effects with the proximity of populations to major roadways (Thoma et al., 2008; Brauer et al., 2002; Brunekreef et al., 1997; Finkelstein et al., 2004; Garshick et al., 2003; Kim et al., 2004).

In an effort to mitigate the negative health and public welfare effects that result from $\mathrm{NO}_{\mathrm{x}}$ emissions, in 1971 the USEPA listed $\mathrm{NO}_{2}$ as one of six principal pollutants regulated by National Ambient Air Quality Standards (NAAQS) (Bachmann, 2007). This $\mathrm{NO}_{x}$ species is closely linked to various respiratory ailments (e.g., respiratory infections, bronchitis, and emphysema) at part-per-billion by volume (ppbv) levels of exposure (USEPA, 2008b). It should be noted that although $\mathrm{NO}_{2}$ is regulated by NAAQS, NO accounts for approximately $95 \%$ of $\mathrm{NO}_{x}$ emissions (USEPA, 2001). However, NO is freely oxidized to $\mathrm{NO}_{2}$ in the atmosphere; therefore, efforts to abate $\mathrm{NO}_{2}$ pollution target $\mathrm{NO}$ emissions. In fact, due to the ease at which $\mathrm{NO}$ can be oxidized to $\mathrm{NO}_{2}$, emissions estimates used by the United States Environmental Protection Agency (USEPA) to develop air quality standards assume all $\mathrm{NO}_{\mathrm{x}}$ to be in the form of $\mathrm{NO}_{2}$ (USEPA, 2001).

In recognition of the detrimental human health effects associated with $\mathrm{NO}_{2}, 2010$ revisions strengthened $\mathrm{NO}_{2}$ NAAQS. In addition to retaining a annually averaged 53 ppbv $\mathrm{NO}_{2}$ standard, the revisions designate an area as nonattainment if the 3-year average of the $98^{\text {th }}$ percentile of the annual distribution of the daily maximum 1-hour average $\mathrm{NO}_{2}$ concentrations exceeds 100 ppbv (Primary National Ambient Air Quality Standards for Nitrogen Dioxide: Final Rule, 2010). Having identified that elevated exposure occurs in near-road environments, the 2010 final rule also required the installation of near-road $\mathrm{NO}_{2}$ monitors that must be located within 50 meters of a road segment, selected on the basis 
of annual average daily traffic (AADT), "fleet mix, congestion patterns, terrain, geographic location, and meteorology" (Primary National Ambient Air Quality Standards for Nitrogen Dioxide: Final Rule, 2010). When developing the regulation's impact assessment, USEPA did not have adequate data to predict which areas may violate the new 100 ppbv standard after these monitors are installed. However, the agency concluded "the possibility exists that there may be many more (emphasis added) potential nonattainment areas than have been analyzed" (USEPA, 2010).

Recent and past efforts to make the transportation sector more sustainable have been focused on the use of recycled and renewable materials and improving vehicle emissions controls to address air pollution problems (USEPA, 2008a). Many of these technologies have reached a point where additional reductions in tailpipe emissions will require new and innovative materials and significant expense (e.g., urea-based selective catalytic reduction).

Advances in photocatalytic concrete pavements have provided a new pathway to improve the sustainability of transportation by reducing the negative impacts associated with vehicle emissions. Titanium dioxide added to the cement utilized in these pavements (e.g., Essroc's TX Active cement) generates hydroxyl radicals $\left({ }^{\circ} \mathrm{OH}\right)$, a powerful oxidizing agent when exposed to sunlight (Figure 6.1). These radicals react with both organic and inorganic pollutants (Beeldens et al., 2011). Notably, hydroxyl radicals can oxidize $\mathrm{NO}_{\mathrm{x}}$ to compounds such as nitrous acid and nitrate (see Figure 6.2 for oxidation steps).

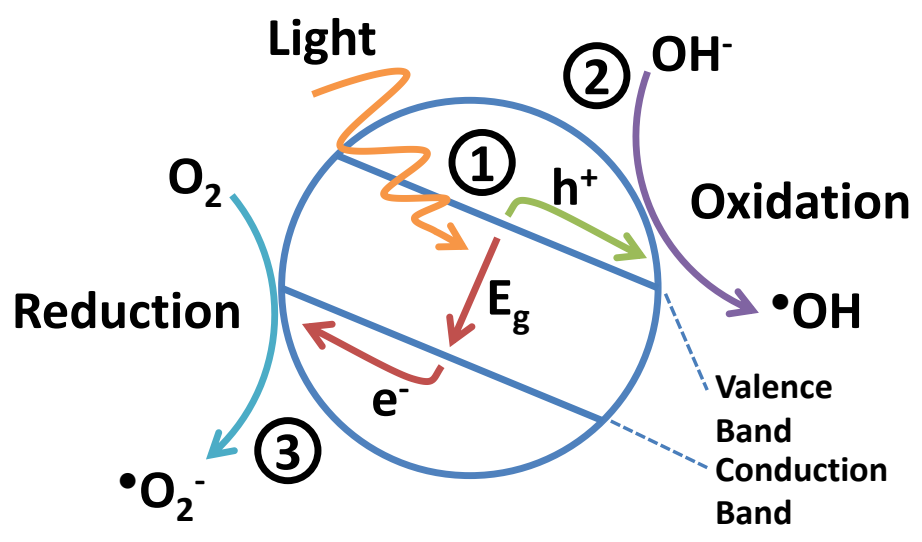

(1) Light with energy greater than band-gap energy $\left(E_{g}\right)$ excites an electron ( $\left.\mathrm{e}^{-}\right)$from the valence to the conduction band creating a valence-band hole $\left(\mathrm{h}^{+}\right)$.

(2) $\mathrm{h}^{+}$migrates to surface and oxidizes a hydroxyl ion $\left(\mathrm{OH}^{-}\right)$to a hydroxyl radical $\left(\bullet^{\circ} \mathrm{OH}\right)$.

(3) To maintain neutral charge the excited electron migrates to the surface and reduces molecular oxygen $\left(\mathrm{O}_{2}\right)$ to a molecular oxygen radical $\left(\bullet^{\circ} \mathrm{O}_{2}{ }^{-}\right)$.

Figure 6.1. Photocatalytic generation of ${ }^{\circ} \mathrm{OH}$ (adapted from Tompkins et al., 2005). 


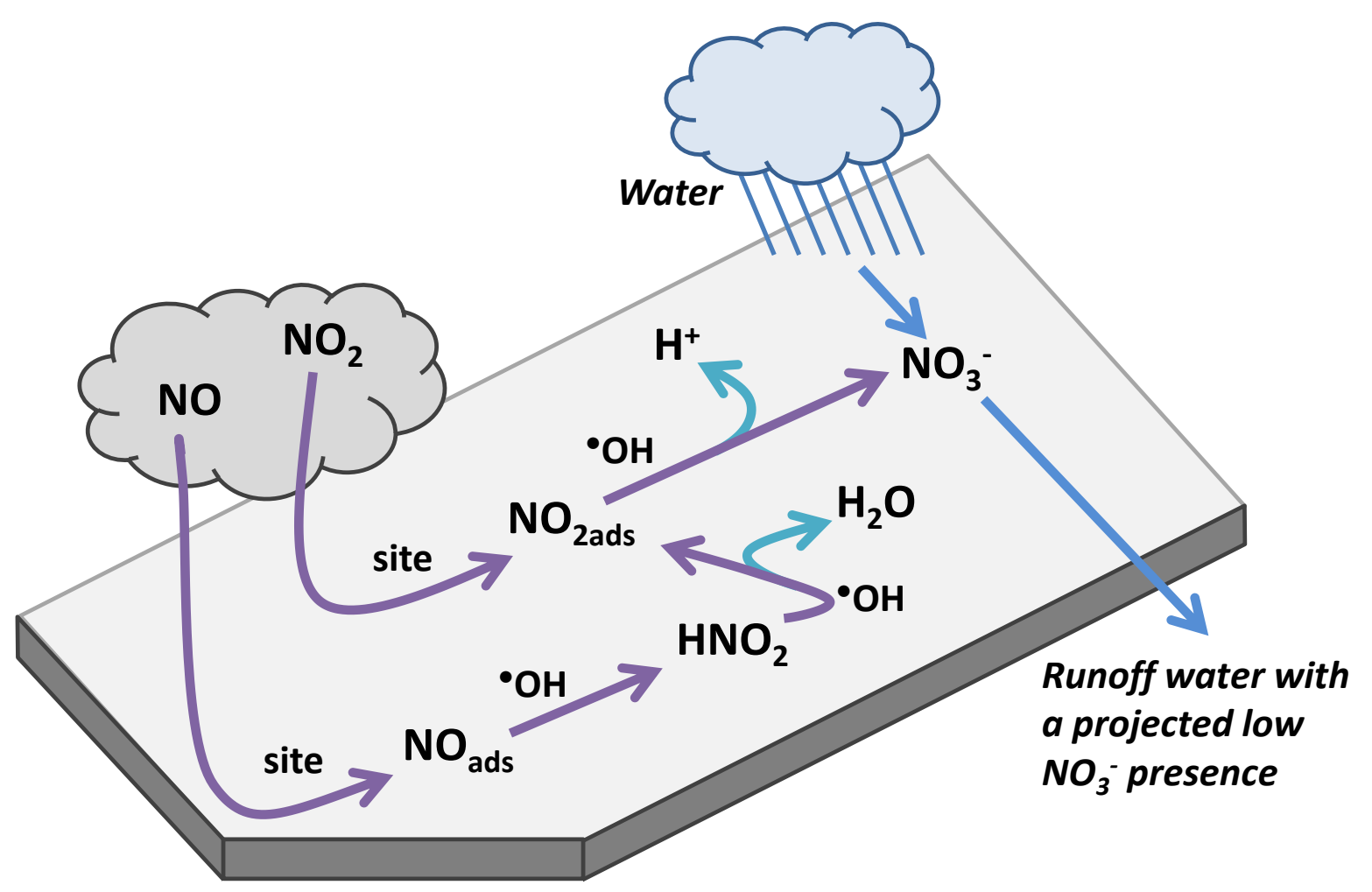

Figure 6.2. Photocatalytic oxidation of $\mathrm{NO}$ and $\mathrm{NO}_{2}$ by pavement containing $\mathrm{TiO}_{2}$ (oxidation steps from Ballari et al., 2011).

The air-purifying effectiveness of photocatalytic pavements is hindered by reductions in the rate of NO oxidation in comparison to the initial oxidation rate (i.e., the rate when the pavement was installed). Pavement-specific literature attributes such observed reductions to a decrease in irradiance reaching $\mathrm{TiO}_{2}$ due to fine dust and organism adhesion (Beeldens et al., 2011) and interference from roadway pollutants such as soil, de-icing salt, and motor oil (Dylla et al., 2011b). Other $\mathrm{TiO}_{2}$ studies attribute reductions in photocatalytic activity to the accumulation of oxidation products and intermediates (Beeldens, 2008; Demeestere et al., 2008; Ibusuki \& Takeuchi, 1994; Zhao \& Yang, 2003). These observed reductions in NO oxidation rate are significant. A study in which photocatalytic paving blocks were set in an outdoor environment and then tested in a photoreactor at set intervals observed a $50 \%$ decrease in the NO oxidation rate over a 5-month period (Murata \& Tobinai, 2002). This decrease was attributed to dust and organism adhesion. A similar test, involving a paving block with a thin $\mathrm{TiO}_{2}$ coating, reported a $36 \%$ to $78 \%$ decrease in NO removal over 4 months and a $22 \%$ to $88 \%$ decrease with 12 months of exposure (Yu, 2003). After observation of particulate matter, oil, chewing gum, and scratches on the pavement surface, the researchers credited a reduction in photocatalytic surface area as the cause for the decrease. 
For $\mathrm{TiO}_{2}$ pavements exposed to $\mathrm{NO}_{x}$, it is also possible that the accumulation of the reaction products-nitrate $\left(\mathrm{NO}_{3}{ }^{-}\right)$and nitrous acid $\left(\mathrm{HNO}_{2}\right)$-may cause a reduction in oxidation. Although it is expected that under field conditions these species will be less prevalent on the pavement than other substances that interfere with the pavement's photocatalytic properties, accumulation of these reaction products could have a disproportionately negative impact on $\mathrm{NO}_{\mathrm{x}}$ oxidation performance because they are generated at the locations of photocatalytic activity.

The studies noted above provide evidence that the rate of $\mathrm{NO}_{\mathrm{x}}$ oxidation correlates to exposure of the photocatalytic material to an outdoor environment. These studies, however, did not identify the contaminants that resulted in the greatest decrease in the $\mathrm{NO}_{\mathrm{x}}$ oxidation rate; rather, assumptions were made as to probable pollutants that might cause the observed decrease. In order to avoid regions in which contaminants would cause an intolerable reduction in pollution removal performance, the species of pollutants that results in the greatest decrease in NO removal performance must be identified. Dylla et al. (2011b) began to provide this information. This publication reported the influence of soil, de-icing salt, and motor oil on NO removal by a photocatalytic concrete slab housed within a flow-through photoreactor. Each material tested significantly reduced NO oxidation (9 to 52\%); with oil reportedly causing the greatest negative impact. Dylla et al. (2011b) provided the first study that differentiated between various pollutants; however, the study did not compare the mass of polluting material applied to test pieces to the mass of pollutants most likely be observed at field installations of photocatalytic pavement.

Efficient use of photocatalytic pavement will also require strategies that address the known decrease in the NO oxidation rate over time. Researchers have suggested shearing airflow, burning chemisorbed carbon species, rainfall, and road cleaning (Beeldens et al., 2011; Demeestere et al., 2008; Zhao \& Yang, 2003). Demeestere et al. (2008) found that airflow was a completely ineffective regeneration mechanism. While surface burning may be economical for some small-scale applications, it is impractical for pavements. Some sources claim that rain or surface washing is sufficient to regenerate photocatalytic activity (Beeldens, 2008; Beeldens et al., 2011). One source noted the beneficial effect of rain, but still recommended surface washing at two month intervals (Yu, 2002). However, this researcher also found that washing with a brush and deionized water did not cause a statistically significant change (or increase) in the activity of photocatalytic paving blocks that had been partially blinded by outdoor exposure in a near-road environment for a period of months (Yu, 2003). The 
conflicts that exist in this published literature subsequently suggest a need for research that determines effective washing techniques to regenerate the photocatalytic activity of these pavements.

In summary, previous related research generated the following noteworthy findings:

(1) various species blind photocatalytic pavements and reduce the rate of NO removal,

(2) different contaminants result in different levels of NO removal reduction, and

(3) that there was not agreement on the strategies which must be employed to regenerate photocatalytic activity.

To build upon this body of knowledge, this laboratory study used a bench-scale photoreactor to evaluate the decrease in NO oxidation rate attributable to reaction products and roadway pollutants. Investigation of reaction product blinding occurred by tracking changes in the NO oxidation rate over time. Roadway pollutant blinding was evaluated by loading pollutants species onto photocatalytic mortar slabs at masses likely to be observed in field installations. In addition, to provide preliminary information on strategies that could be used to clean photocatalytic pavements, this study also evaluated the efficiency of two methods of removing the tested roadway pollutants: power washing and power brushing.

\section{Materials and Methods}

\subsection{Photocatalytic Mortar Slab Preparation and Cleaning}

Mortar slabs measuring $152 \mathrm{~mm}(6 \mathrm{in}) \times 152 \mathrm{~mm}(6 \mathrm{in}) \times 25 \mathrm{~mm}$ (1 in) were constructed. The proportions of cement (TX Active, Essroc Italcementi Group, Nazareth, PA or Type I), water, and fine aggregate (ASTM C778 standard sand, U.S. Silica Co., Frederick, MD) were recorded as $624 \mathrm{~kg} \cdot \mathrm{m}^{-3}(1052$ $\left.\mathrm{lb} \cdot \mathrm{yd}^{-3}\right), 262 \mathrm{~kg} \cdot \mathrm{m}^{-3}\left(442 \mathrm{lb} \cdot \mathrm{yd}^{-3}\right)$, and $1412 \mathrm{~kg} \cdot \mathrm{m}^{-3}\left(2380 \mathrm{lb} \cdot \mathrm{yd}^{-3}\right)$ respectively. Due to the small volume of the constructed slabs, the mix did not include coarse aggregate. Except for the coarse aggregate, the proportions used for the laboratory mortar slabs were similar to a concrete pavement poured at a field test site (Cackler et al., 2012). The slab pour used a two-lift procedure with equal volumes of a Type I cement bottom lift followed by a TX Active photocatalytic cement top lift. Following the pour, a damp cloth and plastic sheet were laid over the slab surface for a 24-h period while the slab cured. Following this initial curing period, the slabs were removed from forms and placed in a $100 \%$ humidity room for the duration of a 14-d curing period.

Prior to carrying out the blinding procedure described in Section 3.4, slabs were cleaned by immersion in water (Type I reagent grade) for $2 \mathrm{~h}$ and oven-dried at $60^{\circ} \mathrm{C}\left(140^{\circ} \mathrm{F}\right)$ for $20 \mathrm{~h}$. This 
procedure is similar to that employed by the ISO standard. The surface of the slabs that were reused in the study were sprayed with high pressure water (i.e., a power washer) for $10 \mathrm{~s}$. These slabs were then cleaned using the same cleaning procedure described above. To document NO removal performance following pre-cleaning, these slabs were evaluated with the photoreactor.

\subsection{Tests Completed for Reaction Products Blinding Study}

To evaluate the decrease in NO oxidation rate that is attributable to blinding by reaction products, four prepared slabs were exposed to NO and UV irradiation as detailed in Table 6.5. Tests 1 and 2 were completed at concentrations similar to those of other photocatalytic pavement literature (e.g., (Dylla et al., 2011a and Dylla et al., 2011b) and Tests 3 and 4 were set at the USEPA standard for $\mathrm{NO}_{2}$ of 100 ppbv, which the authors consider characteristic of a highly polluted area. A 20-h test was selected to permit reaction product accumulation on the slab surface. Of note, because the experimental apparatus was constructed using high-precision valves (as opposed to a gas calibrator or mass flow controllers) inlet NO concentration increased with time during each test but this gradual increase did not interfere with evaluation of the decrease in NO oxidation rate.

Table 6.1. Reaction products blinding testing program parameters.

\begin{tabular}{|c|c|c|c|c|c|}
\hline Test \# & $\mathrm{t}$ & $\mathrm{C}_{\text {NO UV off }}$ & $Q^{1}$ & $\mathrm{RH}^{\mathrm{i}}$ & $\mathrm{T}^{1}$ \\
\hline Units & $\mathrm{h}$ & ppbv & $\mathrm{L} \cdot \mathrm{min}^{-1}\left(\mathrm{gal} \cdot \mathrm{min}^{-1}\right)$ & $\%$ & ${ }^{\circ} \mathrm{C}\left({ }^{\circ} \mathrm{F}\right)$ \\
\hline 1 & 5 & 1300 & $3(0.8)$ & 23 & $22(72)$ \\
\hline 2 & 20 & 1500 & $3(0.8)$ & 21 & $22(72)$ \\
\hline 3 & 5 & 100 & $3(0.8)$ & 24 & $23(73)$ \\
\hline 4 & 20 & 100 & $3(0.8)$ & 24 & $22(72)$ \\
\hline t & \multicolumn{5}{|c|}{ = duration of UV-A irradiance } \\
\hline$C_{\text {NO uv Off }}$ & \multicolumn{5}{|c|}{$=$ mean NO inlet concentration } \\
\hline Q & \multicolumn{5}{|c|}{$=$ flow rate } \\
\hline RH & \multicolumn{5}{|c|}{$=$ relative humidity } \\
\hline $\mathrm{T}$ & \multicolumn{5}{|c|}{$=$ temperature } \\
\hline
\end{tabular}

\subsection{Background for Roadway Pollutant Blinding Study}

The approach presented in the sections that follow was developed to provide a general estimate of the impact that blinding by roadway pollutants could have on a pavement within the United States. The mass of a particular pollutant loaded onto a test slab was based on documented pollution yields for highways; this area type is considered the most probable field installation of photocatalytic pavements. 
An alternative approach could be used to develop an estimate of pollutant blinding at a specific location. This method, which would be based on stormwater event mean concentration and climatic data, is outlined in Section 7.

\subsubsection{Pollutant Species Selection and Annual Yield}

The approach used to select pollutants and determine their loading rates on a per area basis began with general data readily available to the researchers and then used specific assumptions in order to arrive at rational selections for pollutant species and loading masses. Identification of the primary categories of pollutants that would blind a photocatalytic pavement represented the first step in the pollutant selection effort. The prevalence of pollutant categories is dependent upon the type of environment a pavement is installed within. A photocatalytic pavement could be selected for any area; however, it is reasonable that, due to the expense of the technology, the pavement will only be considered for roadways with comparatively high levels of vehicular pollution output. For roadways, pollution output is closely related to annual average daily traffic (AADT) values. Therefore, it was assumed that the predominant use of photocatalytic pavements will be in highway installations. It is foreseeable that the pavement could also be used in commercial and high-density residential areas. Pollutant loadings in these types of environments were not considered in this study; however, these environments could be analyzed in future work.

Burton and Pitt (2002) listed typical pollutant yields, which were estimated from stormwater data, for various types of urban areas (Table 6.2). This list includes freeways, a synonym for highways. For this urban area type, primary pollutant categories, in order of greatest to least, are as follows: total solids, suspended solids, and chloride. All other pollutant categories, listed in the freeway urban area type, were more than an order of magnitude smaller than the chloride yield. For the freeway area type, data on chemical oxygen demand (COD), a measurement that typically indicates presence of organic compounds, was not available. Reviews of yields from other area types found that the yield of COD frequently is similar in value to that of the primary pollutant categories listed above. This study assumed

the COD yield for highways was $265 \mathrm{lb} \cdot \mathrm{acre}^{-1} \cdot$ year $^{-1}$, which is the average of COD yields from commercial, parking lot, high-density residential, and industrial area types as reported by Burton and Pitt (2002). 
Table 6.2. Highway pollution yields (values and categories from Burton and Pitt, 2002).

\begin{tabular}{lclc}
\hline Pollutant category & $\begin{array}{c}\text { Yield } \\
\left(\mathbf{l b} \cdot \mathbf{a c r e}^{-1} \cdot \mathbf{y e a r}^{-1}\right)^{\mathbf{i}}\end{array}$ & Pollutant category & $\begin{array}{c}\text { Yield } \\
\left(\mathbf{l b} \cdot \mathbf{a c r e}^{-1} \cdot \mathbf{y e a r}^{-1}\right)^{\mathbf{i}}\end{array}$ \\
\hline Total solids & 1700 & Chemical oxygen demand & NA \\
Suspended solids & 880 & Lead & 4.5 \\
Chloride & 470 & Zinc & 2.1 \\
Total phospohorus & 0.9 & Chromium & 0.09 \\
Total Kjehldahl nitrogen & 7.9 & Copper & 0.37 \\
Ammonia & 1.5 & Cadmium & 0.02 \\
Nitrate plus nitrite & 4.2 & Arsenic & 0.02 \\
Biological oxygen demand $(5$ days) & NA & & \\
\hline
\end{tabular}

${ }^{i} 1.0 \mathrm{lb} \cdot$ acre $^{-1} \cdot \mathrm{year}^{-1}=0.11 \mathrm{~g} \cdot \mathrm{m}^{-2} \cdot \mathrm{yr}^{-1}$

Suspended solids and chloride (a dissolved solid) account for $1350 \mathrm{lb} \cdot \mathrm{ac}^{-1} \cdot \mathrm{yr}^{-1}$ of the $1700 \mathrm{lb} \cdot \mathrm{ac}^{-1} \cdot \mathrm{yr}^{-1}$ reported total solids yield. To account for the entirety of the total solids yield required an additional pollutant category with a yield of $350 \mathrm{lb} \cdot \mathrm{ac}^{-1} \cdot \mathrm{yr}^{-1}$. Burton and Pitt (2002) reported that chloride yields were linked to cold weather and in all probability resulted from road salt applications. It was assumed that when the chloride anion $\left(35.45 \mathrm{~g} \cdot \mathrm{mol}^{-1}\right)$ was loaded onto the highway it was bonded with sodium $\left(23 \mathrm{~g} \cdot \mathrm{mol}^{-1}\right)$. As a result of this assumption, a $300 \mathrm{lb} \cdot \mathrm{ac}^{-1} \cdot \mathrm{yr}^{-1}$ sodium yield was determined. Inclusion of this additional pollutant category accounted for $97 \%$ of the total solids yield; therefore, additional solids were not selected for this study. With the discrepancy in solids yields resolved, the researchers selected the following pollutant categories for their study: suspended solids, sodium chloride, and COD.

Within the identified pollutant categories the researchers selected pollutants they viewed as representative of a highway environment. Based on the data from Burton and Pitt (2002) suspended solids represented the principal substance that blind photocatalytic pavements. It was assumed that these solids are soils from the area upon which the pavement was placed. USDA classification based on particle diameter separates soils into categories of clay, silt and sand. The respective diameter ranges of these categories are less than $0.002 \mathrm{~mm}, 0.002-0.05 \mathrm{~mm}$, and greater than $0.05 \mathrm{~mm}$. In nearly every instance, natural soils are a mixture of these soil categories, rather than a pure sample of one category. Rather than analyze natural soils from various locations in the United States, the researchers chose to analyze separately the impact of blinding by samples of silica sand, silt, and bentonite clay. As obtained, the silt sample contained $6 \%$ impurities in the form of clay. To create a nearly-pure silt sample, the researchers mixed the sample with water, allowed time for the silt fraction to settle, and then poured off mixing water, which included a suspended clay fraction. To provide a preliminary basis of comparison 
to natural soils, the researchers also created a soil composite, which consisted of $1 / 3$ of each of the pure soils that were analyzed and procured a sample of street sweeper debris from the City of Ames, IA.

The researchers selected laboratory-grade sodium chloride (Thermo Fisher Scientific, Waltham, MA) for the category of the same name. Although a road salt could have been used instead, it is probable that this product contains unknown quantities of other compounds. To account for these compounds would have required an adjustment of the loading rate by an unknown amount.

Identifying a specific species for the COD yield was a challenge. Although hybrid and electrical vehicles are becoming more common, the majority of on-road motor vehicles both combust and are lubricated by hydrocarbons. Lubricating oils and fuels-not to mention other fluids within vehiclescontain a multitude of organic compounds. While other assumptions are reasonable, for their study the researchers selected heavy-duty motor oil (Fleet Supreme EC SAE 15W-40, ConocoPhillips, Houston, TX) used by transport trucks. COD data for this oil was not readily available. As a result this value was approximated as follows. Lubricating oils are generally chains of carbon with lengths of 15-30 atoms. With assumption of an average length of 22 carbons and a saturated hydrocarbon classification, the researchers estimated that the oil's molar mass was $310 \mathrm{~g} \mathrm{~mol}^{-1}$. The researchers also assumed that oxidation of this oil followed the equation displayed below:

$$
\mathrm{C}_{22} \mathrm{H}_{46}+33.5 \mathrm{O}_{2} \rightarrow 22 \mathrm{CO}_{2}+23 \mathrm{H}_{2} \mathrm{O}
$$

Based on these assumptions, the motor oil yield was determined to be $77 \mathrm{lb} \cdot \mathrm{ac}^{-1} \cdot \mathrm{yr}^{-1}$.

\subsubsection{Pollutant Species Loading Mass}

Rounded to one significant digit, the pollutant species yields presented in the previous section served as the basis for calculation of the mass of pollutant species to be applied to each slab. Three levels of loading mass were considered: severe, moderate, and minimal. The severe case was the rounded annual yield for each pollutant species. In the moderate case, pollutant species were loaded at $50 \%$ of the masses of the severe case. To arrive at masses for the minimal case, the severe case masses were divided by 100 . This value is the average number, rounded to one significant digit, of days annually with precipitation 0.01 inches or more for 285 cities reported by NOAA (2008). By multiplying the loading rate by the slab surface area $\left(36 \mathrm{in}^{2}, 230 \mathrm{~cm}^{2}\right)$, the mass of pollutant species for each loading level was determined. The loading masses at each level are presented in Table 6.3. 
Table 6.3. Pollutant species loading mass.

\begin{tabular}{|c|c|c|c|c|c|c|}
\hline \multicolumn{2}{|l|}{ Pollutant } & \multicolumn{2}{|c|}{ Yield } & \multicolumn{3}{|c|}{ Slab loading mass } \\
\hline Species & Category ${ }^{\mathrm{i}}$ & $\left(\right.$ lb·acre $\left.{ }^{-1} y^{-1}\right)$ & $\left(g \cdot m^{-2} y^{-1}\right)$ & $\begin{array}{c}\text { Severe } \\
\text { (mg) }\end{array}$ & $\begin{array}{l}\text { Moderate } \\
\text { (mg) }\end{array}$ & $\begin{array}{c}\text { Minimal } \\
(\mathrm{mg})\end{array}$ \\
\hline Sand & SS & 900 & 100 & 2000 & 1000 & 20 \\
\hline Silt & SS & 900 & 100 & 2000 & 1000 & 20 \\
\hline Clay & SS & 900 & 100 & 2000 & 1000 & 20 \\
\hline Soil composite & SS & 900 & 100 & 2000 & 1000 & 20 \\
\hline Street sweeper debris & SS & 900 & 100 & 2000 & 1000 & 20 \\
\hline Sodium chloride & DS & 800 & 90 & 2000 & 1000 & 20 \\
\hline Motor oil (15W-40) & COD & 80 & 9 & 200 & 100 & 2 \\
\hline $\begin{array}{l}\text { SS = suspended solids } \\
\text { ii Yield multiplied by sla } \\
\text { iii } 50 \% \text { of the severe lev } \\
\text { iv Severe level divided } \\
\text { United States cities rou }\end{array}$ & $\begin{array}{l}\text { solved solid } \\
30 \mathrm{~cm}^{2} \\
\text { vhich is the } \\
1 \text { significan }\end{array}$ & $\begin{array}{l}\text { se number of da } \\
\text { (NOAA, 2008) }\end{array}$ & nnually with & oitation 0. & 1 inches or $m$ & ore for 285 \\
\hline
\end{tabular}

\subsection{Roadway Pollutant Blinding Procedure}

To promote results that are repeatable and simulate conditions observed in the field, distribution of pollutant species should be homogenous over the slab surface. To achieve this distribution, the researchers mixed the pollutants with a liquid, poured this liquid on the slab, and evaporated the liquid, which left behind a pollutant residue that appeared homogenous by observation. Suspended and dissolved solids were mixed with $50 \mathrm{ml}$ of water (deionized or Type I reagent grade, Barnstead Nanopure II, Thermo Fisher Scientific, Waltham, MA). Motor oil is hydrophobic; therefore, water does not serve as a suitable mixing liquid. Instead motor oil was mixed with $50 \mathrm{~mL}$ of isopropyl alcohol. To prevent the mixture from flowing over the slab edge required a boundary. To create this boundary, the researchers constructed a poly(methyl methacrylate) (PPMA) container with interior length and width dimensions marginally larger than those of the slab and a height of $38 \mathrm{~mm}$ (1.5 in). The slab was set inside this container and the interface of the slab and the container sidewalls was sealed with silicone caulking. After pouring the pollutant mixture on the slab, the slab was placed in an oven at $60^{\circ} \mathrm{C}$ in order to accelerate the rate of liquid evaporation. The slabs remained within the oven for $8 \mathrm{~h}$. To provide a basis for comparison, control slabs were also created. Creation of these slabs followed the procedure above, except for the fact that a pollutant species was not mixed with the $50 \mathrm{~mL}$ of water (or alcohol) poured onto the slab.

\subsection{Tests Attempted in Roadway Pollutant Blinding Study}

The Table 6.4 below presents the tests attempted for the roadway pollutant blinding study. Test ID 1 was repeated 3 times and Test ID 5 was repeated 6 times to allow calculation of procedure uncertainty. 
In addition to testing each pollutant species separately, the tests completed also included pollutant composites at each mass loading level.

Table 6.4. Tests attempted in roadway pollutant blinding study.

\begin{tabular}{|c|c|c|c|c|c|}
\hline Test ID & Pollutant Species & $\begin{array}{c}\text { Slab loading } \\
\text { mass (mg) }\end{array}$ & Test ID & Pollutant Species & $\begin{array}{c}\text { Slab loading } \\
\text { mass (mg) }\end{array}$ \\
\hline 1 & Control & & 18 & Sodium chloride & 1000 \\
\hline 2 & Sand & 2000 & 19 & Sodium chloride & 20 \\
\hline 3 & Sand & 1000 & 20 & Motor oil (15W-40) & 200 \\
\hline 4 & Sand & 20 & 21 & Motor oil (15W-40) & 100 \\
\hline 5 & Silt & 2000 & 22 & Motor oil (15W-40) & 2 \\
\hline 6 & Silt & 1000 & 23 & Pollutant composite & \\
\hline 7 & Silt & 20 & & Soil composite & 2000 \\
\hline 8 & Clay & 2000 & & Sodium chloride & 2000 \\
\hline 9 & Clay & 1000 & & Motor oil (15W-40) & 200 \\
\hline 10 & Clay & 20 & 24 & Pollutant composite & \\
\hline 11 & Soil composite & 2000 & & Soil composite & 1000 \\
\hline 12 & Soil composite & 1000 & & Sodium chloride & 100 \\
\hline 13 & Soil composite & 20 & & Motor oil (15W-40) & 20 \\
\hline 14 & Street sweeper debris & 2000 & 25 & Pollutant composite & \\
\hline 15 & Street sweeper debris & 1000 & & Soil composite & 20 \\
\hline 16 & Street sweeper debris & 20 & & Sodium chloride & 20 \\
\hline 17 & Sodium chloride & 2000 & & Motor oil (15W-40) & 2 \\
\hline
\end{tabular}

\subsection{Tests Completed for Reaction Products Blinding Study}

Unlike roadway pollutants, reaction products cannot be obtained and loaded onto a slab. Instead, to evaluate the decrease in NO oxidation rate that is attributable to blinding by reaction products, four prepared slabs were exposed to NO and UV irradiation as detailed in Table 6.5. Tests 1 and 2 were completed at concentrations similar to those of other photocatalytic pavement literature (Dylla et al., 2011a; Dylla et al., 2011b) and Tests 3 and 4 were set at the USEPA standard for $\mathrm{NO}_{2}$ of 100 ppbv, which the authors consider characteristic of a highly polluted area. A 20-h test was selected to permit reaction product accumulation on the slab surface. Of note, because the experimental apparatus was constructed using high-precision valves (as opposed to a gas calibrator or mass flow controllers) inlet NO concentration increased with time during each test but this gradual increase did not interfere with evaluation of the decrease in NO oxidation rate. 
Table 6.5. Reaction products blinding testing program parameters.

\begin{tabular}{|c|c|c|c|c|c|}
\hline Test \# & $\mathrm{t}$ & $C_{\text {NO UV off }}$ & $\mathrm{Q}^{1}$ & $\mathrm{RH}^{\mathrm{i}}$ & $\mathrm{T}^{1}$ \\
\hline Units & $\mathrm{h}$ & ppbv & $\mathrm{L} \cdot \mathrm{min}^{-1}\left(\mathrm{gal} \cdot \mathrm{min}^{-1}\right)$ & $\%$ & ${ }^{\circ} \mathrm{C}\left({ }^{\circ} \mathrm{F}\right)$ \\
\hline 1 & 5 & 1300 & $3(0.8)$ & 23 & $22(72)$ \\
\hline 2 & 20 & 1500 & $3(0.8)$ & 21 & $22(72)$ \\
\hline 3 & 5 & 100 & $3(0.8)$ & 24 & $23(73)$ \\
\hline 4 & 20 & 100 & $3(0.8)$ & 24 & $22(72)$ \\
\hline $\mathrm{t}$ & \multicolumn{5}{|c|}{ = duration of UV-A irradiance } \\
\hline$C_{\text {NO uv off }}$ & \multicolumn{5}{|c|}{$=$ mean NO inlet concentration } \\
\hline Q & \multicolumn{5}{|c|}{$=$ flow rate } \\
\hline $\mathrm{RH}$ & \multicolumn{5}{|c|}{$=$ relative humidity } \\
\hline $\mathrm{T}$ & \multicolumn{5}{|c|}{$=$ temperature } \\
\hline
\end{tabular}

\subsection{Regeneration Approach and Procedure}

The regeneration of slabs for which the photocatalytic activity was inhibited due to blinding by various pollutants was attempted in order to provide preliminary data on the strategies that would need to be employed in order to maintain the pollution removal performance of a photocatalytic pavement. For this portion of the study, two cleaning mechanisms were selected: power brushing and power washing. Respectively, the researchers viewed mechanisms as the least and most intense cleaning mechanisms that would conceivably be employed. To approximate power brushing on a laboratory scale, the researchers selected a $4.4 \mathrm{~cm}$ diameter cylindrical brush. This brush featured plastic bristles that extended in all directions from the brush center to the perimeter of the brush radius. For controlled rotation, the brush was connected to a power drill, which rotated at a rate of 850 rounds per minute. Velocity at the tips of the brush was approximately $2 \mathrm{~m} \mathrm{~s}^{-1}$. The rotating brush was then applied to the surface of a slab pre-loaded with a specific contaminant. A Task Force TF2000 (Active Products, Toronto, ON) was employed for the power washing portion of the regeneration study. The nozzle of the power washer was held at a distance of $50 \mathrm{~cm}$ from the slab surface. The researchers sprayed the entirety of the slab using a top-to-bottom and side-to-side pattern for $5 \mathrm{~s}$ each respectively.

\subsection{Tests Completed in Regeneration Study}

The Table 6.2 presents the tests completed for the regeneration study. Test IDs 3 and 4 were repeated 3 times to allow calculation of a confidence interval for the procedure. In addition to testing each pollutant species separately, the tests completed also included pollutant composites at each mass loading level. 
Table 6.6. Tests completed in regeneration study.

\begin{tabular}{lccc}
\hline & & \multicolumn{2}{c}{ Powered regeneration test ID } \\
\cline { 3 - 4 } Pollutant species & Slab loading mass $(\mathbf{m g})$ & Brush & Wash \\
\hline Sand & 2000 & 1 & 2 \\
Silt & 2000 & 3 & 4 \\
Clay & 2000 & 5 & 6 \\
Soil composite & 2000 & 7 & 8 \\
Street sweeper debris & 2000 & 9 & 10 \\
Sodium chloride & 2000 & 11 & 12 \\
Motor oil (15W-40) & 200 & 13 & 14 \\
Pollutant composite & & 15 & 16 \\
$\quad$ Soil composite & 2000 & & \\
Sodium chloride & 2000 & & \\
Motor oil (15W-40) & 200 & & \\
\hline
\end{tabular}

\subsection{Experimental Apparatus}

The experimental apparatus consisted of a flow-through photoreactor, NO test gas supply system, UV-A light source, and NO monitor. Specific details regarding these components are described in Chapter 4. For the tests completed in this chapter, environmental parameters were to values which ensured that the rate of NO degradation was limited by the adsorption and oxidation steps, not mass transfer to the slab surface. These values were as follows: 1000 ppbv NO concentration, $20 \%$ relative humidity, $3 \mathrm{~L} \cdot \mathrm{min}^{-1}$ flow rate, and $10 \mathrm{~W} \cdot \mathrm{m}^{-2}$ irradiance at the slab surface at $365 \mathrm{~nm}$.

\subsection{Operational Procedure}

Operation of the experimental apparatus followed the procedure established in Chapter 4. This operation included two phases: parameter setting and testing. While in the parameter setting phase, the test gas flowed through the photoreactor, but the UV-A light remained off. This phase was used to set airflow rate, relative humidity, and pollutant concentration to the values noted in Section 3.9. After adjusting parameters to desired values, flow was maintained through the photoreactor for a period sufficient to reach steady-state conditions.

The testing period comprised two steps during which UV-light off and UV-light on concentrations of NO were measured. In similarity with the procedure established in Chapter 3, when transitioning between these two steps, the researchers waited until concentration had stabilized after this parameter change. 
Based on data collected, NO oxidation rate was calculated using the following equation:

$$
\text { NO oxidation rate }=\frac{P}{R \cdot T} \cdot \frac{Q}{A} \cdot\left(C_{U V \text { off }}-C_{U V \text { on }}\right)
$$

where,

$$
\begin{aligned}
& P=1 \mathrm{~atm}=\text { atmospheric pressure } \\
& R=8.314 \frac{\mathrm{J}}{\mathrm{mol} \cdot \mathrm{K}}=\text { ideal gas constant } \\
& T=298 \mathrm{~K}=\text { temperature }, \text { and } \\
& A=230 \mathrm{~cm}^{2}=\text { slab surface area } .
\end{aligned}
$$

Comparison of the oxidation rate following blinding to a baseline measurement of a particular slab permitted determination of percent change in the oxidation rate attributable to the blinding species.

\section{Results and Discussion}

\subsection{Reaction Products Blinding}

Figure 6.3 provides plots of NO oxidation rate versus time for the four photoreactor tests. The NO oxidation rate for the high concentration tests (Test 1 and Test 2) ranged between 38 and $64 \mathrm{nmole} \cdot \mathrm{m}^{-}$ ${ }^{2} \cdot \mathrm{s}^{-1}$ and decreased with time. Conversely, for the $100 \mathrm{ppbv}$ tests (Test 3 and Test 4 ), the NO oxidation rate remained relatively consistent over time and ranged between 6.5 and $10 \mathrm{nmole} \cdot \mathrm{m}^{-2} \cdot \mathrm{s}^{-1}$.

Data presented in these plots was obtained from 4 different slabs. Substantial variability can exist between slabs; therefore the 4 slabs used for this portion of the study were also evaluated at identical conditions $\left(\mathrm{C}_{\mathrm{NO}}\right.$ uv off $\left.=1030 \mathrm{ppbv}, \mathrm{Q}=3 \mathrm{~L} \cdot \mathrm{min}^{-1}, \mathrm{RH}=20 \%, 10 \mathrm{~W} \cdot \mathrm{m}^{-2}\right)$. The standard deviation of these tests was $1.8 \mathrm{nmole} \cdot \mathrm{m}^{-2} \cdot \mathrm{s}^{-1}$; indicating that comparisons can be made between the 4 slabs. 

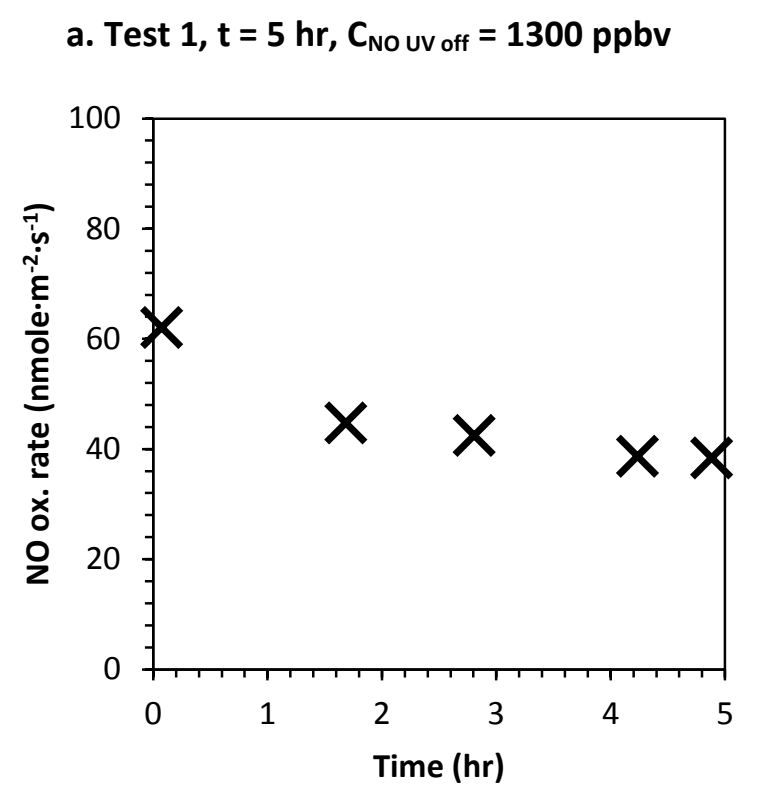

c. Test $3, t=5 \mathrm{hr}, \mathrm{C}_{\mathrm{NO} \text { uv off }}=100 \mathrm{ppbv}$

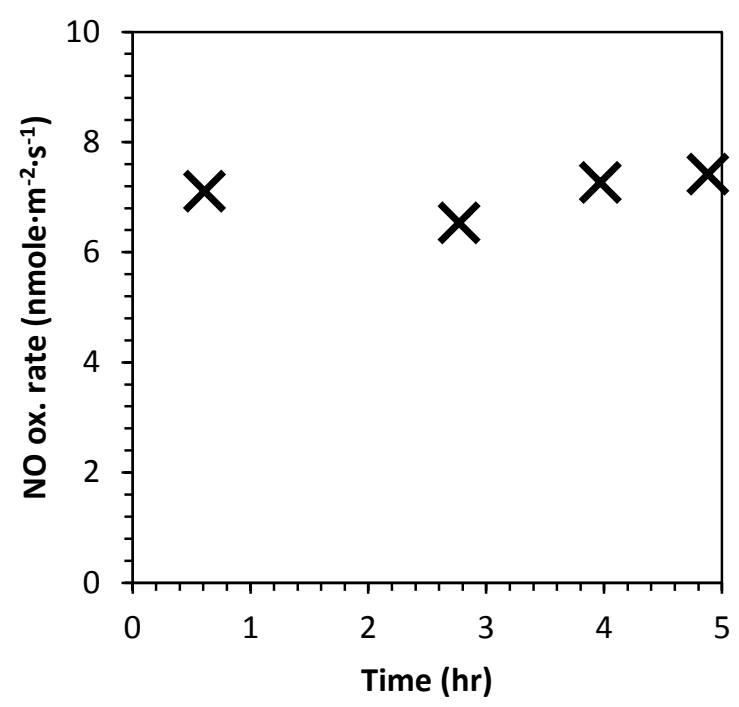

b. Test $2, \mathrm{t}=20 \mathrm{hr}, \mathrm{C}_{\mathrm{NO} \text { uv off }}=1500 \mathrm{ppbv}$

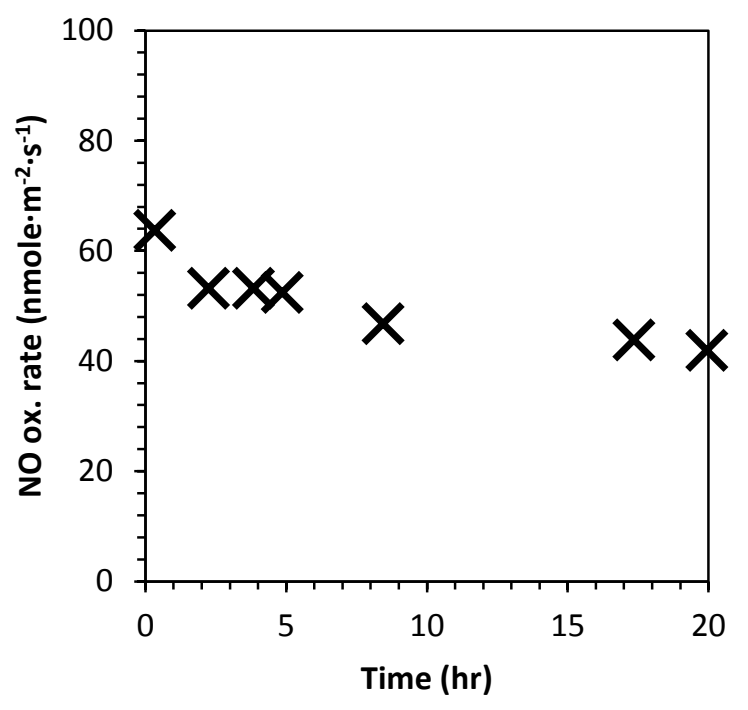

d. Test $4, \mathrm{t}=20 \mathrm{hr}, \mathrm{C}_{\mathrm{NO} \text { uv off }}=100 \mathrm{ppbv}$

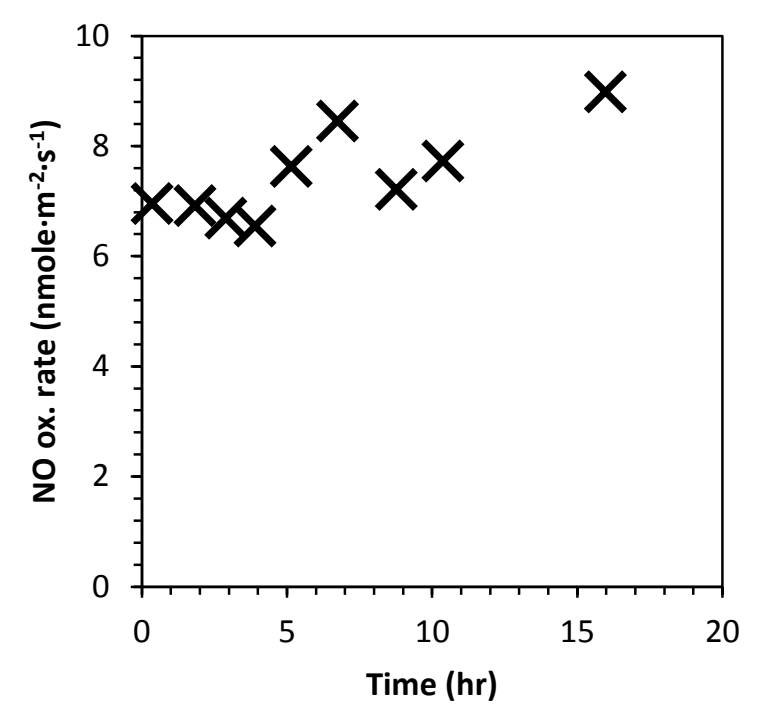

Figure 6.3. $\mathrm{NO}_{\mathrm{x}}$ oxidation rate versus time for photoreactor tests.

Figure 6.3.c and Figure 6.3.d do not provide evidence that reaction product accumulation results in a decrease in NO oxidation rate. A model utility test on the data collected in Test 3 did not reject a null hypothesis that slope equaled $0 \mathrm{nmole} \cdot \mathrm{m}^{-2} \cdot \mathrm{s}^{-1} \cdot \mathrm{hr}^{-1}(t=1.032 \mathrm{df}=4, p=0.378)$. The null hypothesis was rejected for Test $4(t=0.830, \mathrm{df}=9, p=0.000)$; however, regression indicated a positive slope. In contrast, Figure 6.3.a and Figure 6.3.b both document a decrease in NO oxidation rate over the measurement period; $39 \%$ and $34 \%$, respectively. In both cases, model utility tests indicated that the 
slope of a regression line through the data was not zero (Test 1: $t=-3.832, \mathrm{df}=4, p=0.031$; Test 2: $t=-$ 4.266, $\mathrm{df}=7, p=0.005)$.

Comparison with other blinding studies finds that the percent decrease that occurred in Test 1 and Test 2 substantially lower than the maximum value reported by other studies (i.e., 88\% reported by Yu, 2003). This result should be expected because this portion of the blinding study sought to determine the effect of reaction product accumulation; whereas, other studies (i.e., Dylla et. al, 2011b, Murata \& Tobinai, 2002, and Yu, 2003) sought to determine the blinding effect of various roadway pollutants. These pollutants accumulate on the photocatalytic surface at masses that are orders of magnitude greater that the expected reaction product mass.

Although the decrease is substantial, the results presented indicate that the pavement will maintain its photocatalytic properties over a long period for typical NO concentrations in ambient air. Consider that the 20-hr 1500 ppbv test exposed the mortar slab to roughly the same amount of NO as a 100-ppbv test over a 300-hr period or $25 \mathrm{~d}$ assuming $12 \mathrm{~h}$ of light per day. Within this time period, it is probable that the reaction products will be removed from the photocatalytically active sites by factors such as rainfall or street cleaning; therefore, it is improbable that the accumulation of these products will result in the decrease in performance observed in this study. Review of Figure 6.3.a and Figure 6.3.b also finds that as time progressed removal stabilized at an asymptotic value. Although a photocatalytic concrete pavement should not be expected to continue to exhibit the NO oxidation rate present at the time of pavement installation, the data collected suggests that reaction products will not cause the complete loss of the concrete's air-cleaning property.

\subsection{Roadway Pollutant Blinding}

\subsubsection{Results}

Unlike reaction product blinding, which was tracked over time, determining the extent of blinding by roadway pollutants required creation of a baseline measurement. For each slab to be tested, this baseline was obtained by determining the NO oxidation rate at standard conditions (noted in Section 3.9). The baseline analysis found that NO oxidation rate for the slabs ranged from 2.2 to $44.2 \mathrm{nmole} \cdot \mathrm{m}^{-}$ ${ }^{2} \cdot s^{-1}$. The wide variation in oxidation rates did not permit comparison between slabs on an oxidation rate basis. Instead, the extent of blinding was evaluated by computing the percent change in NO oxidation rate observed following a blinding procedure in comparison to the baseline observation. 
When calculating the percent change associated with blinding, data from the control measurements was used to eliminate the portion of change attributable to the blinding procedure. For the first instance in which a slab was blinded, this value was determined to be $-44 \%(s=11.1 \%, n=3)$. Control measurements for subsequent uses of a slab for a blinding effort did not exhibit as large a decrease attributable to the blinding procedure. The control change in oxidation rate was set at $-6 \%$. The difference between initial $(-44 \%)$ and subsequent control measurements $(-6 \%)$ was attributed to an initial reduction in surface area caused by application of silicone to seal the edges of the pavement slab. All silicone, especially silicone immediately next to the pavement surface, was not removed by the regeneration and pre-cleaning procedure; therefore, this initial decrease was carried forward to subsequent measurements.

Taking the observed change in NO oxidation rate and the data from control measurements into account, the change in NO oxidation rate attributable to blinding by roadway pollutants was calculated as follows:

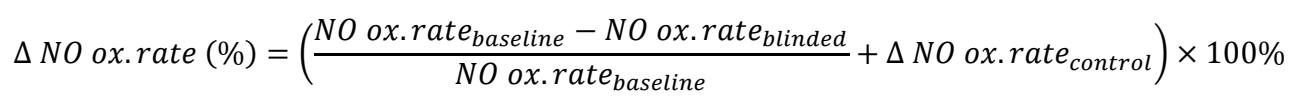

where,

$$
\begin{aligned}
& \text { NO ox.rate } \text { baseline }=\text { NO ox.rate prior to blinding treatment, } \\
& \text { NO ox.rate } \text { blinded }=\text { NO ox.rate following blinding treatment } \text {, and } \\
& \Delta N O \text { ox.rate } \text { control }=\text { change in NO ox. rate attributed to blinding procedure } \text {. }
\end{aligned}
$$

Figure 6.4 presents the results of the roadway pollutant blinding study for sand, silt, clay, and soil composite. Figure 6.5 presents results for street sweeper debris, sodium chloride, motor oil, and the pollutant composite. Efforts were made to minimize error when completing the blinding procedure; however, 6 repetitions of Test 6 (silt, $1000 \mathrm{mg}$ ) found that the $90 \%$ confidence interval was $\pm 4.84 \%$. To provide indication of whether one of the reported blinding tests significantly differed from the $0 \%$ baseline, horizontal dashed lines at $+4.84 \%$ and $-4.84 \%$ were plotted on Figure 6.4 and Figure 6.5. In addition, this confidence interval was illustrated with error bars attached to the provided data points. Overlap of a baseline and data point $90 \%$ confidence intervals suggests that the populations are not significantly different. Of note, data was not obtained for all tests attempted in Section 3.5. This data is absent from the plots that follow. 
a. Sand $(n=4)$.

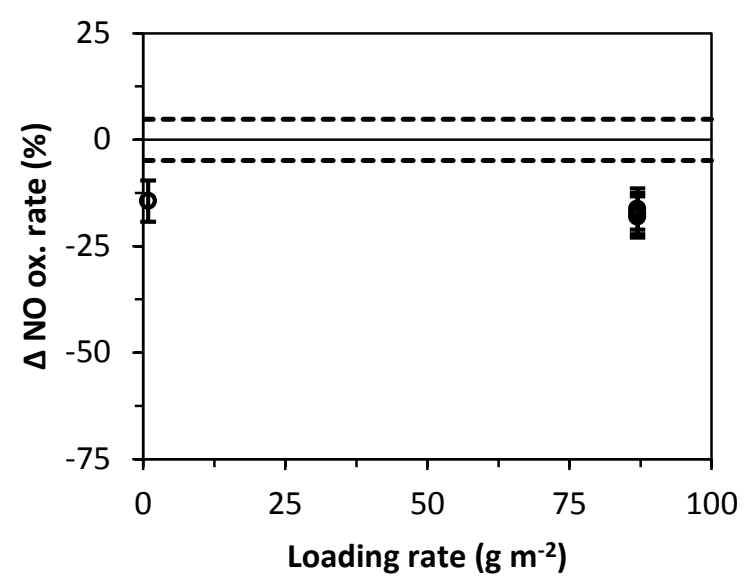

c. Clay ( $n=3)$.

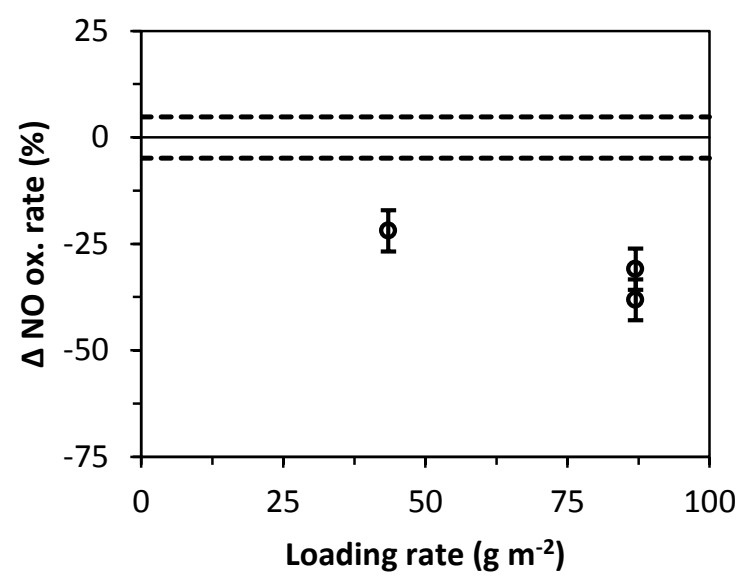

b. Silt $(n=8)$.

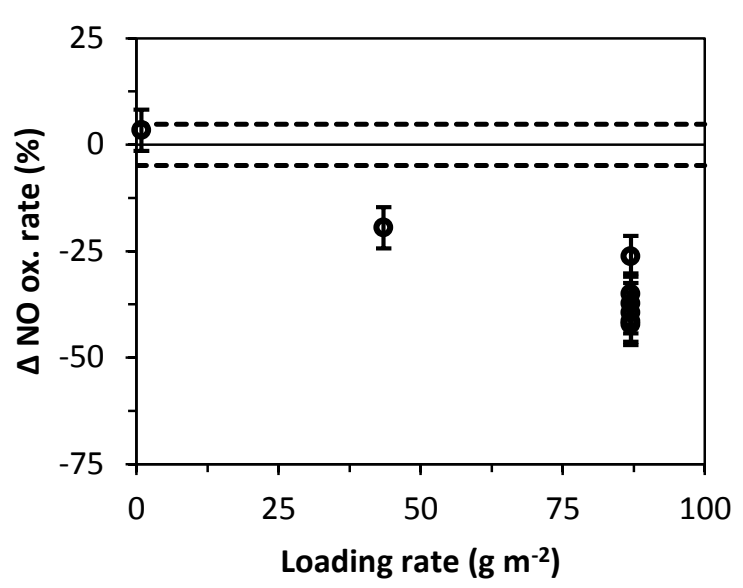

d. Soil composite $(n=3)$.

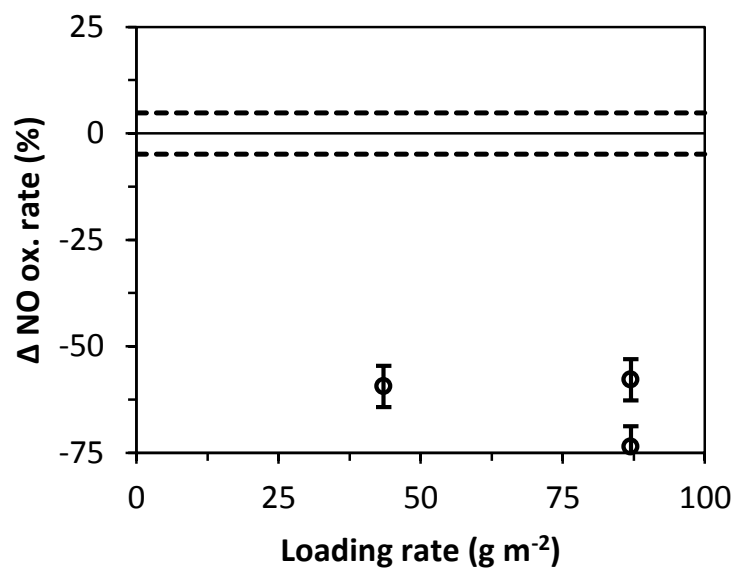

Figure 6.4. Change in NO oxidation rate due to blinding by roadway pollutants vs. loading rate. Dashed horizontal lines plot $90 \%$ confidence interval for the $0 \%$ baseline; error bars provide $90 \%$ confidence interval for blinded observations. 
a. Street sweeper debris $(n=3)$.

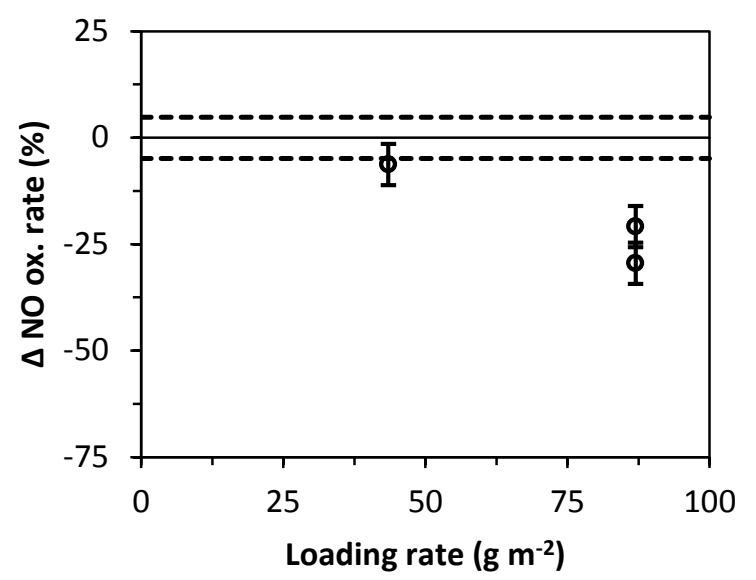

c. Motor oil $(n=4)$.

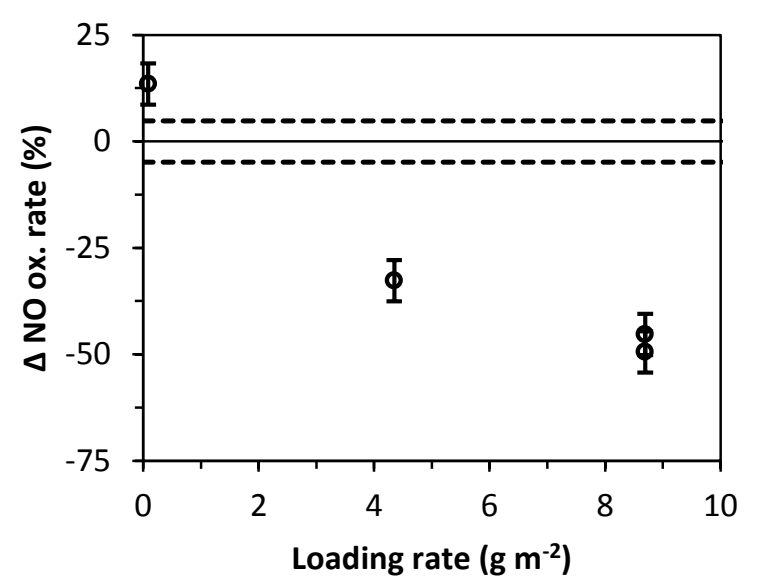

b. Sodium chloride $(n=4)$.

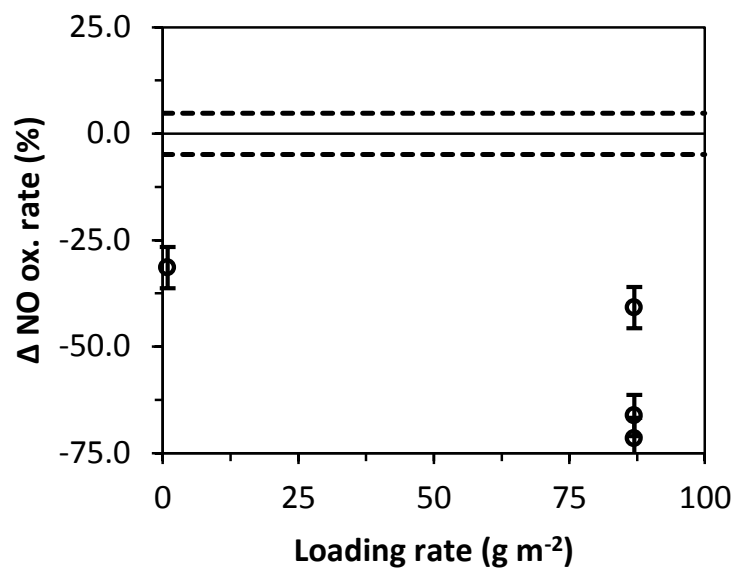

d. Pollutant composite ( $n=4$, note change in $y-$ axis scale).

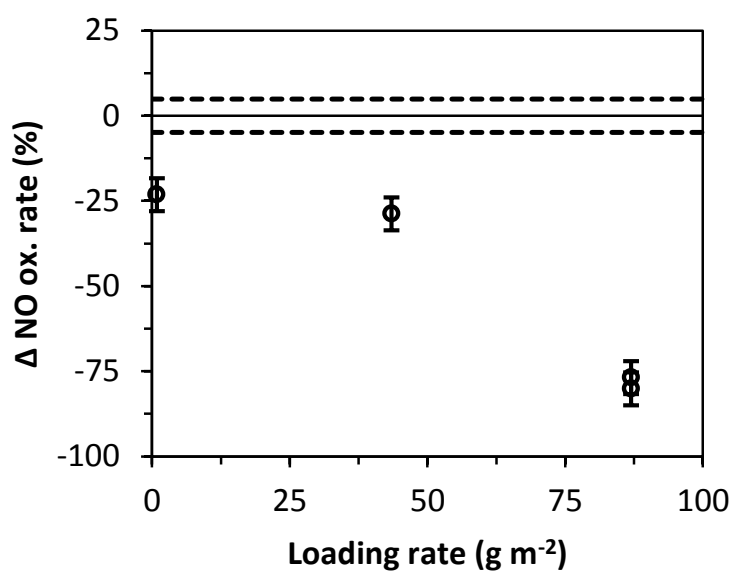

Figure 6.5. Change in NO oxidation rate due to blinding by roadway pollutants vs. loading rate. Dashed horizontal lines plot $90 \%$ confidence interval for the $0 \%$ baseline; error bars provide $90 \%$ confidence interval for blinded observations.

\subsubsection{Discussion}

Two types of observations can be made based on the data collected, one concerning the change in performance observed and the second in terms of the variability present in the experiment. For the measurements collected at $9 \mathrm{~g} \cdot \mathrm{m}^{-2}$ for oil and $100 \mathrm{~g} \cdot \mathrm{m}^{-2}$ for all other pollutant species, change in NO removal attributable to blinding averaged $-42 \%$ and ranged from $-16 \%$ to $-80 \%$. The range reported in this study is similar to the $22 \%$ to $88 \%$ decrease reported in Yu (2003)'s study, which placed paving blocks outdoors for 12 months. In both cases, the range is quite wide; however, it indicates that different roadway pollutants have markedly different effects on the NO oxidation rate of a photocatalytic pavement. 
Of all pollutant species tested, the impact of blinding by sand was of the least significance. As is evident in Figure 6.4(a), all measurements at $100 \mathrm{~g} \cdot \mathrm{m}^{-2}$ were below $20 \%$. This result appears reasonable. Sand, having the largest particle size of all species tested, will cover the least surface area of a slab, thereby causing the least amount of blinding. Applying the same logic, it would be reasonable to predict that clay (Figure 6.4.c) would have the greatest impact of all pollutant species. Furthermore, as noted in Section 3.3.1, bentonite clay was selected for this study. The dominant mineral within bentonite is montmorillonite, which is part of the smectite group. This mineral has a high capacity to absorb water. As a result, when water is absorbed a montmorillionite sample's volume will increase by several times and it will behave as a plastic material (Klein \& Dutrow, 2007). As described, these properties are ideal characteristics of a species that would coat a pavement surface and block UV-A light. However, review of the presented data finds that blinding by silt (Figure 6.4.b) resulted in the greater decrease in NO removal than blinding by clay (Figure 6.4.c). Observation found that silt tended to adhere to the slab surface following completion of the blinding procedure. In contrast, the bentonite clay began to flake away from the surface. It is probable that this flaking occurred as absorbed was evaporated within the $60^{\circ} \mathrm{C}$-temperature oven. Without absorbed water, the clay's plastic properties were lost. As the flakes cracked, a portion of UV-A light was able to penetrate to the surface, permitting photocatalytic oxidation. The conditions which caused evaporation of water from the interlayer between bentonite particles are not likely to persist in the field. Therefore, in full-scale demonstrations this species cause the greatest impact on blinding.

The soil composite sample (Figure 6.4.d) also substantially reduced photocatalytic activity. In this case, the mixture of silt and clay resulted in a substance that adhered to the surface. The impact of street sweeper debris (Figure 6.5.a) appeared similar to that of sand. This is due to the fact that the predominant soil found in this debris can be classified as sand, which has the largest particle size of all soil species.

Substantial variability occurred in the tests involving sodium chloride (Figure 6.5.b). Due to the fact that this pollutant dissolves in water, it is possible that during the evaporation procedure, it adheres as an extremely thin layer on the slab surface. This layer could cause substantial blinding. It should be noted, that sodium chloride is primarily applied to pavements during winter months. During these months, the photocatalytic ability of the pavement is already impaired due to both shortened hours at 
which the sun irradiates the slab surface and low temperature. Although a major impact on NO removal, environmental factors may play a larger role during these periods.

The impact of motor oil (Figure 6.5.c) was immense when considered on a per mass basis. Like sodium chloride, this pollutant also spreads in a thin layer across the slab surface. Therefore, it appears especially effective at causing a reduction in photocatalytic activity. Furthermore, as a readily oxidizable species, oil competes with NO for photocatalytic oxidation. Oil, being already adsorbed on the slab surface, likely has an advantage over NO in terms of photocatalytic oxidation.

\subsection{Regeneration Study}

In similarity with the approach detailed in Section 4.2.1, evaluation of regeneration procedures also occurred by computing the percent change in NO oxidation rate observed following regeneration of a blinded sample in comparison to a baseline observation. This change was calculated as follows:

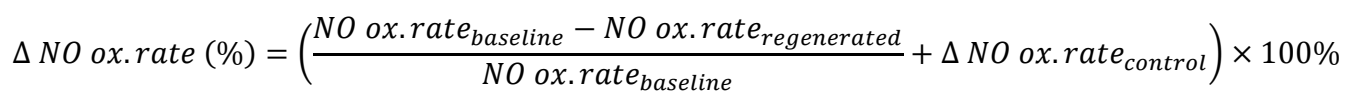
where,

NO ox. rate baseline $=$ NO ox.rate prior to blinding or regeneration treatment,

NO ox.rate regenerated $=$ NO ox.rate following regeneration treatment, and

$\triangle N O$ ox.rate control $=$ change in $N O$ ox. rate attributed to blinding procedure .

If the regeneration procedure was effective, the change in NO oxidation rate would be near zero because both the baseline (NO ox.rate baseline) and regenerated (NO ox.rate regenerated $_{\text {) }}$ measurements would be similar in value. Figure 6.6 does not display these result. Instead, the change is negative in nearly all cases, indicating that the regenerated oxidation rate is similar to the blinded oxidation rate. The only exceptions are sand, silt, and street sweeper derbies, which are all particulates large enough that they both did not result in substantial levels of blinding and can be visibly removed with a brush. 


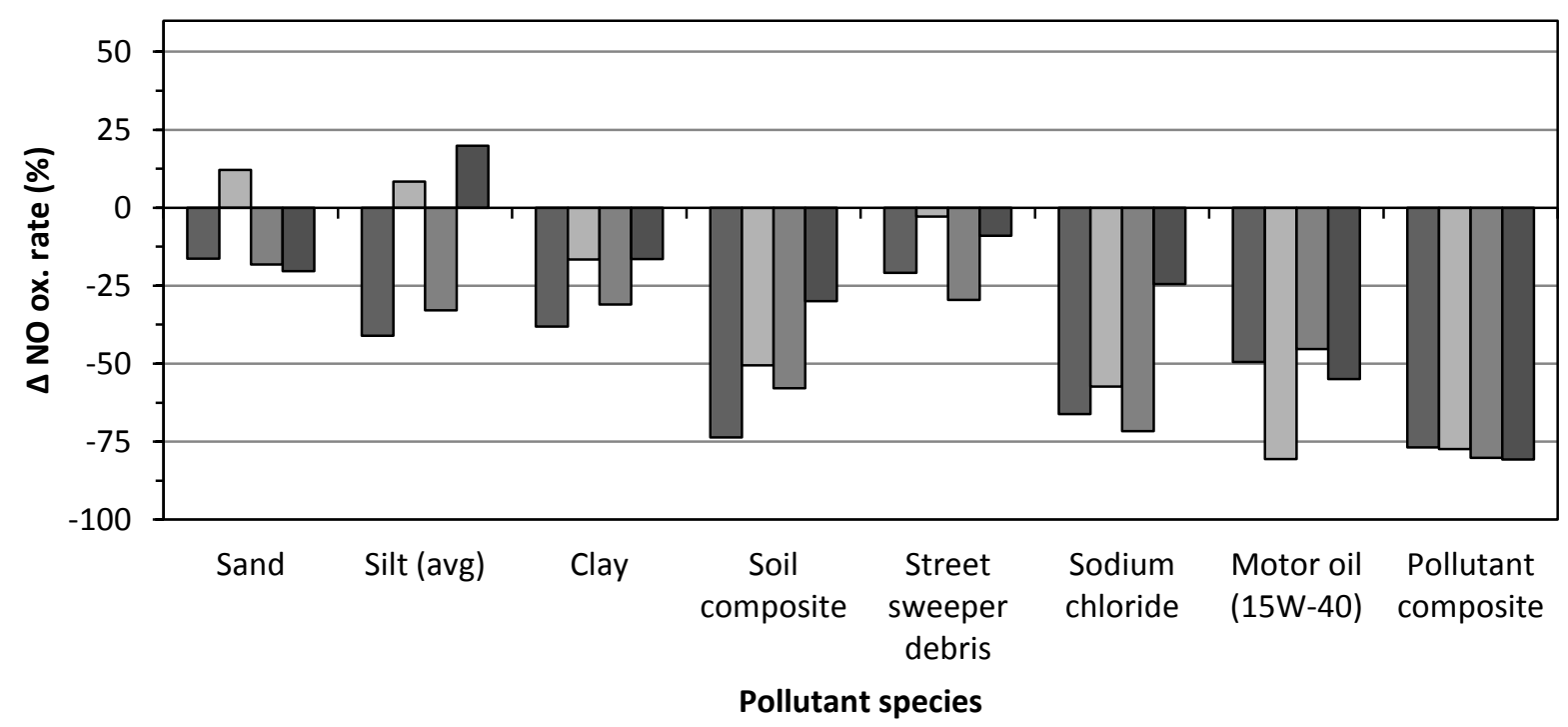

Blinded Pwr Brush $\quad \square$ Regen Pwr Brush $\quad \square$ Blinded Pwr Wash $\quad \square$ Regen Pwr Wash

Figure 6.6. Change in percent removal between blinded and regenerated mortar slab.

The results of this preliminary investigation should be considered inconclusive; however, obtaining inconclusive results is by no means insignificant. Literature had claimed that rain or surface washing is sufficient to regenerate photocatalytic activity (Beeldens, 2008; Beeldens et al., 2011). The observations of this study question the confidence with which this statement was made

\section{Conclusions}

The presented data provided new insights into the blinding and regeneration of photocatalytic concrete pavements. Reaction products have been hypothesized to have a disproportionately negative impact on a pavement's NO oxidation rate due to proximity of their location of formation to the location of active sites. Observations over 5 - and 20 -hour periods did find that over time the oxidation rates decreased by $39 \%$ and $34 \%$, respectively. However, the decrease approached an asymptotic value; indicating that the formation of reaction products will not cause the complete loss of a concrete's aircleaning properties. Investigation of blinding by roadway pollutants included the following species: sand, silt, clay, motor oil, and sodium chloride. Unlike previous work, this investigation studied the individual impact of these prevailing specific roadway pollutants at loadings that are likely to be observed in the field. Previous work had predicted that blinding by roadway pollutants would result in up to an $88 \%$ decrease in NO oxidation. The data provided by this article disputes these claims. With exception of sodium chloride, at normally observed levels of pollutant loading, the decrease in NO oxidation rate was 
less than $25 \%$. However, at a worst case scenario, the total annual loading, reduction was near $75 \%$. To validate this study's conclusions, the researchers recommend future work that compares this study's data with field data of similar pavement. Although this study would suggest that the impact of roadway pollutants is not as severe as previously thought, the authors also recommend that future work determine the effectiveness of a variety of cleaning methods, both in the field and in the laboratory. Work to evaluate regeneration methods was inconclusive. This result in itself is significant because previous reports had indicated that photoactivity can easily be regenerated.

\section{Acknowledgments}

The authors thank the National Concrete Pavement Technology Center, the United States Department of Transportation, Essroc Italcementi Group, and Lehigh Hanson, Inc. for providing funding to pursue this study. In addition, the authors are grateful for in-kind services provided by the Missouri Department of Transportation and Fred Weber, Inc.

\section{Appendix: Alternative Approach for Pollutant Loading Rate Determination}

Section 3.3 presented an approach to determine pollutant loading rates which was based on typical pollutant yields estimated from stormwater data for various types of urban areas. This approach provided general conclusions on levels of blinding that could be expected in field applications. These general conclusions will not be sufficient if stakeholders seek to develop effective management strategies for photocatalytic pavements. An accurate estimate of the load of pollutants on a pavement could easily be developed by documenting the event mean concentration (EMC) of pollutants in stormwater runoff. With known EMC values, loading rates can be determined with what is referred to as the simple method (Scheuler, 1987). This method has proven to be quite effective and continues to be included in stormwater manuals published by the state departments responsible for managing natural resources (e.g., lowa, New Hampshire, North Carolina, Virginia, and Wyoming). By this simple method, annual loading is calculated as follows:

$$
L=0.226 \cdot R \cdot C \cdot A
$$

where $L=$ annual load (lbs), $R=$ annual runoff (inches), $C=$ pollutant concentration $(\mathrm{mg} / \mathrm{L}), A=$ area (acres), and $0.226=$ unit conversion factor. This method requires knowledge of annual runoff which can be calculated as,

$$
R=P * P_{j} * R v
$$


where $R=$ annual runoff (inches), $P=$ annual rainfall (inches), $P_{j}=$ fraction of annual rainfall events that produce runoff (usually 0.9), and $\mathrm{Rv}=$ runoff coefficient. Runoff coefficient is calculated based on impervious cover in the subwatershed,

$$
R_{v}=0.05+0.9 * I_{a}
$$

where $I_{a}$ is the percent impervious area draining to the structure in decimal form.

Using this alternative approach, future research could be tailored to a specific site where photocatalytic pavement was installed. This research could determine whether or not a photocatalytic pavement would provide sufficient pollution mitigation or if various contaminants would be likely to foul the pavement.

\section{References}

Bachmann, J. (2007). Will the circle be unbroken: A history of the U.S. national ambient air quality standards. Journal of the Air and Waste Management Association, 57(6), 652-697.

Ballari, M. M., Yu, Q. L., \& Brouwers, H. J. H. (2011). Experimental study of the NO and NO2 degradation by photocatalytically active concrete. Catalysis Today, 161(1), 175-180. doi: 10.1016/j.cattod.2010.09.028

Beeldens, A. (2008). Air purification by pavement blocks: final results of the research at the BRRC. Ljubljana, Slovenia.

Beeldens, A., Cassar, L., \& Murata, Y. (2011). Applications of TiO2 Photocatalysis for Air Purification In Y. Ohama \& D. Van Gemert (Eds.), Application of titanium Dioxide Photocatalysis to Construction Materials (1st ed.): Springer.

Brauer, M., Hoek, G., Van Vliet, P., Meliefste, K., Fischer, P. H., Wijga, A., . . Brunekreef, B. (2002). Air pollution from traffic and the development of respiratory infections and asthmatic and allergic symptoms in children. American Journal of Respiratory and Critical Care Medicine, 166(8), 10921098. doi: DOI 10.1164/rccm.200108-0070C

Brunekreef, B., Janssen, N. A. H., deHartog, J., Harssema, H., Knape, M., \& vanVliet, P. (1997). Air pollution from truck traffic and lung function in children living near motorways. Epidemiology, 8(3), 298-303.

Burton, G. A., \& Pitt, R. E. (2002). Stormwater Effects Handbook: A Toolbox for Watershed Managers, Scientists, and Engineers. Boca Raton, FL: CRC Press, LLC.

Cackler, E. T., Alleman, J. E., Kevern, J. T., \& Sikkema, J. K. (2012). Technology Demonstrations Project: Environmental Impact Benefits with "TX Active" Concrete Pavement in Missouri DOT Two-Lift 
Highway Construction Demonstration. (DTFH61-06-H-00011 Work Plan 22). Ames, IA: National Concrete Pavement Technology Center.

Demeestere, K., Dewulf, J., De Witte, B., Beeldens, A., \& Van Langenhove, H. (2008). Heterogeneous photocatalytic removal of toluene from air on building materials enriched with TiO2. Building and Environment, 43(4), 406-414. doi: 10.1016/j.buildenv.2007.01.016

Dylla, H., Hassan, M. M., Schmitt, M., Rupnow, T., \& Mohammad, L. N. (2011a). Laboratory Investigation of the Effect of Mixed Nitrogen Dioxide and Nitrogen Oxide Gases on Titanium Dioxide Photocatalytic Efficiency in Concrete Pavements. Journal of Materials in Civil Engineering, 23(7), 1087-1093. doi: 10.1061/(asce)mt.1943-5533.0000248

Dylla, H., Hassan, M. M., Schmitt, M., Rupnow, T., Mohammad, L. N., \& Wright, E. (2011b). Effects of Roadway Contaminants on Titanium Dioxide Photodegradation of NOx. Paper presented at the Transportation Research Board 90th Annual Meeting, Washington, DC.

Finkelstein, M. M., Jerrett, M., \& Sears, M. R. (2004). Traffic air pollution and mortality rate advancement periods. American Journal of Epidemiology, 160(2), 173-177. doi: Doi 10.1093/Aje/Kwh181

Garshick, E., Laden, F., Hart, J. E., \& Caron, A. (2003). Residence near a major road and respiratory symptoms in US veterans. Epidemiology, 14(6), 728-736. doi: DOI 10.1097/01.ede.0000082045.50073.66

Ibusuki, T., \& Takeuchi, K. (1994). REMOVAL OF LOW CONCENTRATION NITROGEN-OXIDES THROUGH PHOTOASSISTED HETEROGENEOUS CATALYSIS. Journal of Molecular Catalysis, 88(1), 93-102. doi: 10.1016/0304-5102(93)e0247-e

Klein, C. \& Dutrow, B. (2007). Manual of Mineral Science (23rd Ed.): John Wiley \& Sons, Inc.

Kim, J. J., Smorodinsky, S., Lipsett, M., Singer, B. C., Hodgson, A. T., \& Ostro, B. (2004). Traffic-related air pollution near busy roads - The East Bay children's respiratory health study. American Journal of Respiratory and Critical Care Medicine, 170(5), 520-526. doi: DOI 10.1164/rccm.200403-2810C

Murata, Y., \& Tobinai, K. (2002). Influence of various factors on NOx removal performance of permeable interlocking block based on photocatalysis. Journal of Structural and Construction Engineering(Transactions of AIJ)(555), 9-15.

NOAA. (2008). Mean Number of Days with Precipitation .01 inch or More Retrieved 4 October 2012, from http://lwf.ncdc.noaa.gov/oa/climate/online/ccd/prcpdays.html

Primary National Ambient Air Quality Standards for Nitrogen Dioxide: Final Rule, 75 Fed. Reg. 6474 (2010) (to be codified at 40 C.F.R. pts. 50 and 58). 
Primary National Ambient Air Quality Standards for Nitrogen Dioxide: Proposed Rule, 75 Fed. Reg. 34404 (2009) (to be codified at 40 C.F.R. pts. 50 and 58).

Scheuler, T. (1987). Controlling Urban Runoff: A Practical Manual for Planning and Designing Urban Best Management Practices. Washington, D.C.: Metropolitan Washington Council of Governments

Thoma, E. D., Shores, R. C., Isakov, V., \& Baldauf, R. W. (2008). Characterization of near-road pollutant gradients using path-integrated optical remote sensing. Journal of the Air \& Waste Management Association, 58(7), 879-890. doi: 10.3155/1047-3289.58.7.879

Tompkins, D. T., Lawnicki, B. J., Zeltner, W. A., \& Anderson, M. A. (2005). Evaluation of photocatalysis for gas-phase air cleaning - Part 1: Process, technical, and sizing considerations. In M. Geshwiler (Ed.), Ashrae Transactions 2005, Vol 111, Pt 2 (Vol. 111, pp. 60-84). Atlanta: Amer Soc Heating, Refrigerating and Air-Conditioning Engs.

USEPA. (2001). National Air Quality and Emissions Trends Report, 1999. (EPA 454/R-01-004). Washington, D.C.

USEPA. (2008a). Progress Report: Vehicle and Engine Compliance Activities. (EPA-420-R-08-011). Washington, D.C.

USEPA. (2008b). Risk and Exposure Assessment to Support the Review of the NO2 Primary National Ambient Air Quality Standard (EPA-452/R-08-008a). Research Triangle Park, NC.

USEPA. (2010). Final Regulatory Impact Analysis (RIA) for the $\mathrm{NO}_{2}$ National Ambient Air QUality Standards (NAAQS). Research Triangle Park, NC: Retrieved from http://www.epa.gov/ttnecas1/regdata/RIAs/FinalNO2RIAfulldocument.pdf.

Yu, J. C. (2002). Ambient Air Treatment by Titanium Dioxide (TiO2 ) Based Photocatalyst in Hong Kong Hong Kong.

Yu, J. C. (2003). Deactivation and Regeneration of Environmentally Exposed Titanium Dioxide (TiO2 ) Based Products Hong Kong.

Zhao, J., \& Yang, X. D. (2003). Photocatalytic oxidation for indoor air purification: a literature review. Building and Environment, 38(5), 645-654. doi: 10.1016/s0360-1323(02)00212-3 


\title{
CHAPTER 7. PHOTOCATALYTIC CONCRETE PAVEMENTS: PRELIMINARY RESULTS OF FIELD EVALUATION AT MISSOURI ROUTE 141
}

\author{
J.K. Sikkema ${ }^{1}$, J.E. Alleman ${ }^{2}$, and S.K. Ong ${ }^{2}$
}

\section{Abstract}

The Missouri Rte. 141 field study sought to provide evidence that photocatalytic concrete pavement constructed using TX Active cement could mitigate pollution generated by on-road motor vehicles in near-road environments. The selected field site was part of a newly constructed alignment of Rte. 141 in the western St. Louis metropolitan region. Within this site, $1500 \mathrm{ft}$ test sections of photocatalytic concrete pavement and conventional concrete pavement were situated on the southbound lanes. Four monitoring methods were used to assess $\mathrm{NO}_{x}$ mitigation: passive ambient air quality monitoring, active ambient air quality monitoring, laboratory evaluation of photocatalytic mortar coupons placed in and subsequently removed from the roadway, and laboratory evaluation of fresh and aged samples. Following the highway's opening, Ogawa-based passive observations of $\mathrm{NO}_{\mathrm{x}}$ documented no instance in which average $\mathrm{NO}_{\mathrm{x}}$ concentration was significantly lower (90\% confidence) in the photocatalytic pavement test section when compared to the control pavement section. Active observations conducted over a 20 -hr period found that $\mathrm{NO}_{\mathrm{x}}$ photocatalytic and control pavement test sections averaged $33 \pm 2.5$ and $25 \pm 2.9$ ppbv (90\% confidence), respectively. Laboratory-based evaluation found a $48 \%$ decrease in NO oxidation rate when comparing fresh and aged photocatalytic mortar slabs, indicating that factors such as the formation of calcium carbonate on the pavement surface and the loss of slab water content could provide explanation for the field observations. Lab evaluation of photocatalytic mortar coupons placed in the roadway found evidence of blinding by roadway pollutants. Considered as a whole, the data collected did not supply evidence of photocatalytic oxidation of $\mathrm{NO}_{x}$ by TX Active pavement.

\section{Introduction}

Photocatalytic concrete pavements have been proposed as a novel $\mathrm{NO}_{\mathrm{x}}$ pollution abatement technology. Multiple field studies of photocatalytic pavements do exist, but documentation is comparatively less extensive than that of laboratory research. The majority of available field research assessed the effectiveness of photocatalytic pavements by comparing photocatalytic pavement test

\footnotetext{
${ }^{1}$ Instructor; Engineering, Dordt College, Sioux Center, lowa

${ }^{2}$ Professor; Civil, Construction, and Environmental Engineering, lowa State University, Ames, lowa
} 
section with a control test section made of conventional pavement materials. These studies are summarized in Table 7.1. Additional field sites have been constructed (see Table 7.2); however, published data to assess $\mathrm{NO}_{\mathrm{x}}$ mitigation at these locations was not available to the authors.

Table 7.1. Photocatalytic pavement field studies that compared a photocatalytic pavement test section with a control test section made of conventional pavement materials.

\begin{tabular}{|c|c|c|c|c|c|c|c|c|}
\hline \multirow[b]{2}{*}{ Location } & \multirow{2}{*}{$\begin{array}{l}\text { Installation } \\
\text { type }\end{array}$} & \multirow{2}{*}{$\begin{array}{l}\text { Pavement } \\
\text { type }\end{array}$} & \multicolumn{2}{|c|}{ Surface area } & \multirow[b]{2}{*}{$\begin{array}{l}\text { Traffic } \\
\text { volume }\end{array}$} & \multirow{2}{*}{$\begin{array}{l}\Delta \mathrm{NO}_{\mathrm{X}} \\
\text { conc. } \\
(\%)\end{array}$} & \multirow{2}{*}{$\begin{array}{l}\text { Measure- } \\
\text { ment type }\end{array}$} & \multirow[b]{2}{*}{ Reference } \\
\hline & & & $\left(\mathrm{ft}^{2}\right)$ & $\left(m^{2}\right)$ & & & & \\
\hline $\begin{array}{l}\text { Antwerp, } \\
\text { Belgium }\end{array}$ & $\begin{array}{l}\text { Parking } \\
\text { lanes of } \\
\text { urban road } \\
\end{array}$ & $\begin{array}{l}\text { Paving } \\
\text { blocks }\end{array}$ & 110,000 & 10,000 & -- & 20 & -- & Beeldens, 2007, 2008 \\
\hline \multirow[t]{2}{*}{$\begin{array}{l}\text { Via Morandi, } \\
\text { Segrate, Italy }\end{array}$} & \multirow[t]{2}{*}{ Urban road } & \multirow{2}{*}{$\begin{array}{l}\text { Thin } \\
\text { mortar } \\
\text { overlay }\end{array}$} & \multirow[t]{2}{*}{75,000} & \multirow[t]{2}{*}{7,000} & \multirow[t]{2}{*}{1000 veh $\mathrm{h}^{-1}$} & 60 & Max. & \multirow{2}{*}{$\begin{array}{l}\text { Essroc, 2008; } \\
\text { Italcementi, 2006, } \\
\text { 2009; }\end{array}$} \\
\hline & & & & & & 50 & Avg. & \\
\hline $\begin{array}{l}\text { Calusco } \\
\text { d'Adda, } \\
\text { Bergamo, } \\
\text { Italy }\end{array}$ & $\begin{array}{l}\text { Industrial } \\
\text { site road }\end{array}$ & $\begin{array}{l}\text { Paving } \\
\text { blocks }\end{array}$ & 86,000 & 8,000 & -- & 45 & Avg. & $\begin{array}{l}\text { Italcementi, 2006; } \\
\text { Italcementi, } 2009\end{array}$ \\
\hline $\begin{array}{l}\text { Porpora } \\
\text { Street, Milan, } \\
\text { Italy }\end{array}$ & $\begin{array}{l}\text { Road } \\
\text { within } \\
\text { tunnel }\end{array}$ & $\begin{array}{l}\text { Concrete, } \\
\text { photo- } \\
\text { catalytic } \\
\text { ceiling } \\
\text { paint }\end{array}$ & 7,840 & $\begin{array}{c}728 \\
\text { (concrete) }\end{array}$ & 30,000 veh $^{-1}$ & 23 & $\begin{array}{l}\text { At min. UV } \\
\text { irradiance }\end{array}$ & Italcementi, 2006 \\
\hline \multirow{4}{*}{$\begin{array}{l}\text { Borgo } \\
\text { Palazzo, } \\
\text { Bergamo, } \\
\text { Italy }\end{array}$} & \multirow{4}{*}{ Urban } & \multirow{4}{*}{$\begin{array}{l}\text { Paving } \\
\text { blocks }\end{array}$} & \multirow{2}{*}{75,000} & \multirow{2}{*}{7,000} & \multirow{4}{*}{400 cars $^{-1}$} & 40 & Max. & \multirow{2}{*}{ Italcementi, 2009} \\
\hline & & & & & & 20 & Min. & \\
\hline & & & \multirow{2}{*}{130,000} & \multirow{2}{*}{12,000} & & 66 & Max. & \multirow{2}{*}{$\begin{array}{l}\text { Guerrini \& Peccati, } \\
2007\end{array}$} \\
\hline & & & & & & 20 & Min. & \\
\hline $\begin{array}{l}\text { Rue Jean } \\
\text { Bleuzen, } \\
\text { Vanves, } \\
\text { France }\end{array}$ & Urban road & $\begin{array}{l}\text { Concrete } \\
\text { overlay }\end{array}$ & 65,000 & 6,000 & $\underset{1}{13,000 \text { cars }^{-}}$ & 20 & Min. & Italcementi, 2009 \\
\hline \multirow[t]{2}{*}{$\begin{array}{l}\text { Vanves, } \\
\text { France }\end{array}$} & \multirow[t]{2}{*}{ Urban road } & $\begin{array}{l}\text { Paving } \\
\text { blocks }\end{array}$ & \multirow[t]{2}{*}{$\begin{array}{l}820 \mathrm{ft} \\
\text { length }\end{array}$} & \multirow[t]{2}{*}{$\begin{array}{l}250 \mathrm{~m} \\
\text { length }\end{array}$} & \multirow[t]{2}{*}{$14,000{\text { cars } d^{-1}}^{-1}$} & \multirow[t]{2}{*}{$40-50$} & \multirow[t]{2}{*}{ Uncertain } & \multirow[t]{2}{*}{ Gignoux, et al., 2010} \\
\hline & & $\begin{array}{l}\text { Concrete } \\
\text { overlay }\end{array}$ & & & & & & \\
\hline \multirow{2}{*}{$\begin{array}{l}\text { St-Denis, } \\
\text { France }\end{array}$} & \multirow[t]{2}{*}{ Urban road } & Concrete & 22,000 & 2,000 & -- & 30 & $2 \mathrm{~m}$ height & Rousseau, et al., 2009 \\
\hline & & & & & & 15 & $20 \mathrm{~m}$ height & \\
\hline & & Paving & & & & $19^{i}$ & Avg. & \\
\hline $\begin{array}{l}\text { Hengelo, The } \\
\text { Netherlands }\end{array}$ & Urban road & $\begin{array}{l}\text { blocks and } \\
\text { spray }\end{array}$ & 8,100 & 750 & 110 veh $\mathrm{hr}^{-1}$ & $28^{\mathrm{ii}}$ & Afternoon & $\begin{array}{l}\text { Ballari \& Brouwers, } \\
2013\end{array}$ \\
\hline 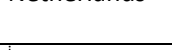 & & coating & & & & 45 & Max. & \\
\hline
\end{tabular}


Table 7.2. Other photocatalytic pavement field sites.

\begin{tabular}{|c|c|c|c|c|c|}
\hline \multirow[b]{2}{*}{ Location } & \multirow{2}{*}{$\begin{array}{l}\text { Installation } \\
\text { type }\end{array}$} & \multirow[b]{2}{*}{ Pavement type } & \multicolumn{2}{|c|}{ Surface area } & \multirow[b]{2}{*}{ Reference } \\
\hline & & & $\left(\mathrm{ft}^{2}\right)$ & $\left(m^{2}\right)$ & \\
\hline Hengelo, Netherlands & Urban road & Paving blocks & $\begin{array}{l}8,100- \\
13,000\end{array}$ & $\begin{array}{l}750- \\
1,200\end{array}$ & Overman, 2009 \\
\hline Milan, Italy & $\begin{array}{l}\text { Parking } \\
\text { garage }\end{array}$ & $\begin{array}{l}\text { Spray coating on } \\
\text { asphalt }\end{array}$ & 43,000 & 4,000 & $\begin{array}{l}\text { Crispino \& } \\
\text { Vismara, } 2010\end{array}$ \\
\hline Forli-Cesena, Italy & Highway & $\begin{array}{l}\text { Spray coating on } \\
\text { asphalt }\end{array}$ & 27,000 & 2,500 & $\begin{array}{l}\text { Crispino \& } \\
\text { Vismara, } 2010\end{array}$ \\
\hline Cantù and Monza, Italy & Urban road & $\begin{array}{l}\text { Spray coating on } \\
\text { asphalt }\end{array}$ & -- & -- & $\begin{array}{l}\text { Crispino \& } \\
\text { Vismara, } 2010\end{array}$ \\
\hline Ferrara, Italy & Urban road & $\begin{array}{l}\text { Spray coating on } \\
\text { asphalt }\end{array}$ & 140,000 & 13,000 & $\begin{array}{l}\text { Crispino \& } \\
\text { Vismara, } 2010\end{array}$ \\
\hline Milan, Italy & $\begin{array}{l}\text { Road within } \\
\text { tunnel }\end{array}$ & $\begin{array}{l}\text { Spray coating on } \\
\text { asphalt }\end{array}$ & 120,000 & 11,000 & $\begin{array}{l}\text { Crispino \& } \\
\text { Vismara, } 2010\end{array}$ \\
\hline $\begin{array}{l}\text { Multiple locations, } \\
\text { Japan }\end{array}$ & $\begin{array}{l}\text { Sidewalks } \\
\text { and urban } \\
\text { roads }\end{array}$ & Paving blocks & 260,000 & 25,000 & $\begin{array}{l}\text { Beeldens \& } \\
\text { Cassar, } 2011\end{array}$ \\
\hline $\begin{array}{l}\text { Baton Rouge, LA, } \\
\text { United States }\end{array}$ & Urban road & $\begin{array}{l}\text { Spray coating on } \\
\text { concrete }\end{array}$ & -- & -- & $\begin{array}{l}\text { Hassan \& Okeil, } \\
2011\end{array}$ \\
\hline $\begin{array}{l}\text { Den Hoek 3, Wijnegem, } \\
\text { Belgium }\end{array}$ & $\begin{array}{l}\text { Industrial site } \\
\text { road }\end{array}$ & $\begin{array}{l}\text { Concrete, two-lift } \\
\text { construction }\end{array}$ & -- & -- & $\begin{array}{l}\text { Beeldens \& Elia, } \\
2012\end{array}$ \\
\hline
\end{tabular}

For the studies listed, the reports by Ballari and Brouwers (2013) and Guerrini and Peccati (2007) provide the most detailed data. The report by Ballari and Brouwers (2013) included $\mathrm{NO}_{\mathrm{x}}$ monitoring prior to installation of the photocatalytic pavement, within a photocatalytic pavement test section, within a control test section, and at a background site. Notably, the first monitoring attempt found no significant decrease in $\mathrm{NO}_{x}$ concentration within the photocatalytic section, which was constructed using commercially available paving blocks having a $\mathrm{TiO}_{2}$ content of $0.59 \%$ by weight. In an attempt to obtain results, the researchers sprayed the roadway with a $\mathrm{TiO}_{2}$ suspension at a rate of $2.67 \mathrm{~g} \mathrm{TiO}_{2} \cdot \mathrm{m}^{-2}$. Photoactivity was observed after this coating; however, it was lost after 2.5 months of exposure. A second spray coating also resulted in increased photoactivity; in this instance the activity was lost after 11 months. Observations made during period when the pavement was photocatalytically active found an average $\mathrm{NO}_{\mathrm{x}}$ reduction of $19 \%(\mathrm{~s}=18 \%$ ). When only afternoon measurement were considered, average $\mathrm{NO}_{\mathrm{x}}$ reduction rose to $28 \%(\mathrm{~s}=20 \%$ ). Ballari and Brouwers (2013) hypothesized that these higher results were obtained because relative humidity was lower and the blocks were no longer wet from morning dew. 
The Borgo Palazzo (Bergamo, Italy) study authored by Guerrini and Peccati (2007) found that during low irradiance hours, concentration at the photocatalytic pavement and control pavement sections were not measurably different. For daylight hours, when both irradiance and traffic markedly increased, the change in concentration between the test sections ranged from $20-66 \%$. The report also noted that soiling caused by construction traffic caused a decreased in photocatalytic activity. Guerrini and Peccati (2007) also reported that peak values of $\mathrm{NO}_{\mathrm{x}}$ concentration-associated with high traffic volume-were substantially diminished in observations from the photocatalytic section.

Although a variety of field research has been completed to assess the effectiveness of photocatalytic pavement, there is still a need for additional data from field sites in northern and continental climates similar to those in the United States. In addition, reports have largely been made from short-term observations. In an effort to begin to provide the data needed to evaluate the effectiveness of photocatalytic pavements at a field scale, this study used both short-term and long-term methods to monitor $\mathrm{NO}_{\mathrm{x}}$ and $\mathrm{NO}$ concentration in a newly constructed roadway, which featured a photocatalytic test section.

\section{Materials and Methods}

\subsection{Site Description}

The field site selected for this study was situated on a newly-constructed portion of Missouri Rte. 141. This segment of highway is located within Chesterfield, Missouri, a city in the western St. Louis metropolitan region. As displayed in Figure 7.1, the site's general north-south alignment was bound by Olive Road (Rte. 340) and Ladue Road, respectively. One-thousand five-hundred ft TX Active and conventional concrete pavement sections were placed within the highway's southbound lanes. 


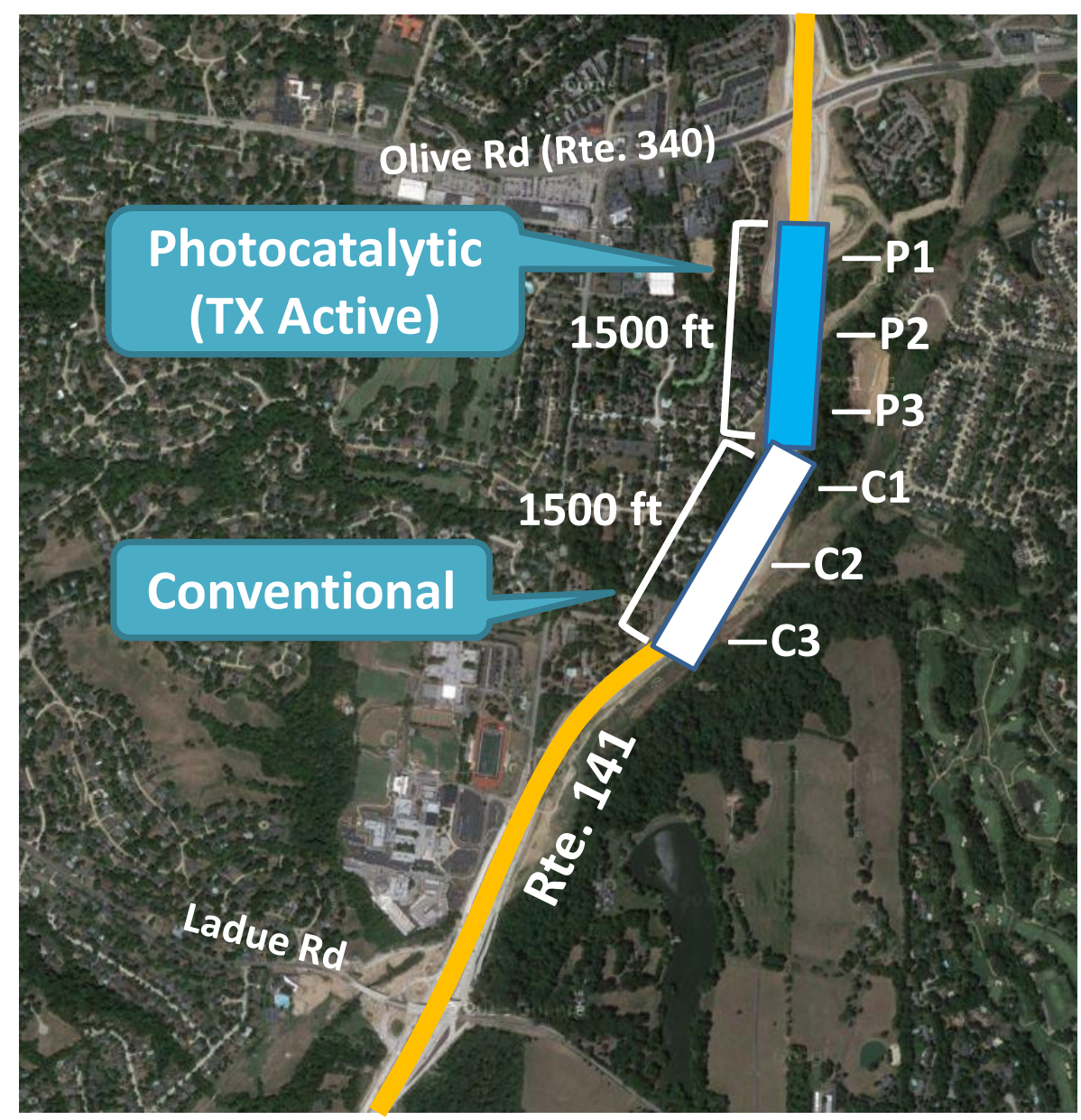

Figure 7.1. Field site overview within St. Louis metropolitan region (Google Maps, 2013).

Prior to construction of this 6-lane divided highway segment, Rte. 141 was located approximately one-quarter of a mile west on Wood Mills Road, a 2-lane roadway. Construction of this new highway segment, therefore, provided significant improvements, including enhancements to traffic flow and vehicular safety.

Missouri Department of Transportation (MoDOT) projected that the annual average daily traffic (AADT) for this highway segment will be approximately 46,000 . When originally evaluating this location, the authors concluded that this traffic density would generate an ambient $\mathrm{NO}_{2}$ concentration that would allow for evaluation of the effectiveness by which the pavement catalyzed oxidation of $\mathrm{NO}_{\mathrm{x}}$. As reported in Cape et al. (2004), $\mathrm{NO}_{2}$ concentrations can be expected to increase dramatically between an ADT of 0 and 26,000. However, above 26,000, $\mathrm{NO}_{2}$ concentration increases only slightly with increases in AADT. At the projected AADT of 46,000 , sufficient ambient $\mathrm{NO}_{\mathrm{x}}$ should be present to permit evaluation of the pavement. 
As noted above, the TX Active pavement section measured 1,500 ft in length. In this section, the width of TX Active pavement was $38 \mathrm{ft}$, creating an overall photocatalytic area of $57,000 \mathrm{ft}^{2}\left(5,300 \mathrm{~m}^{2}\right)$. This area is slightly smaller than comparable studies in Segrate, Italy and Vanves, France, which measured 75,000 and 65,000 $\mathrm{ft}^{2}$ (7,000 and 6,000 $\mathrm{m}^{2}$ ) respectively (Essroc, 2009; Italcementi, 2009). However, given the siting of the wall (see Figure 7.2. Rte. 141 test site profile schematic (shldr = shoulder).Figure 7.2), which provide a buffer against $\mathrm{NO}_{x}$ dilution by cross winds, this test section was considered appropriate for the project. In order to promote similar environmental conditions (e.g., wind conditions, sunlight incidence angles, and sound wall shading impacts), the pavement test sections were placed at the northern edge of the project boundaries, immediately south of the southbound ramp from Olive Rd. Admittedly, the researchers did have a related concern about variable vehicle speeds for traffic on the southbound lanes which had entered the highway from Olive Rd. Changes in vehicle speeds cause changes in engine fuel consumption, which then increase or decrease the rate of $\mathrm{NO}_{\mathrm{x}}$ emission. However, it was concluded that these vehicles would have reached a near-steady speed by the time they entered the first set of environmental testing stations, approximately $2000 \mathrm{ft}$ beyond the end point of the Olive Rd. onramp.

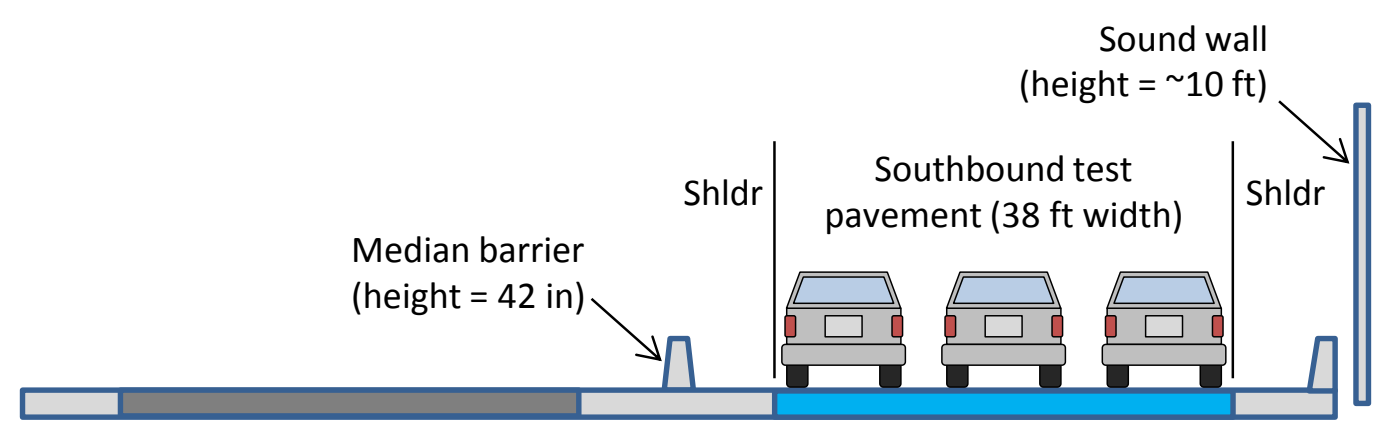

Figure 7.2. Rte. 141 test site profile schematic (shldr = shoulder).

\subsection{Pavement Description}

Concrete mixtures placed at the field site are described by Table 7.3. These mixtures were developed by Fred Weber Inc. (Maryland Heights, MO) with guidance from Essroc Italcementi Group (Nazareth, PA) regarding use of the TX Active material. The coarse aggregate used was St. Louis formation limestone with a MoDOT " $D$ " gradation and the fine aggregate was Missouri River sand. The photocatalytic section was constructed using a two-lift procedure. The bottom lift was 8 inches thick and poured using the conventional mixture. The top lift featured the photocatalytic mixture, measured 2 inches in thickness, and was textured by dragging burlap in a longitudinal direction. 
Table 7.3. Photocatalytic and conventional concrete mixture proportions.

\begin{tabular}{lcc}
\hline & \multicolumn{2}{c}{$\begin{array}{c}\text { Mixture proportions }\left(\mathbf{l b ~ y d ~}^{-3}\right)^{\mathbf{i}} \\
\text { Photocatalytic }\end{array}$} \\
\hline Type I/II cement & 345 & 0 \\
TX Active cement & 0 & 541 \\
Fly ash "C" & 115 & 0 \\
Coarse aggregate & 1888 & 1882 \\
Fine aggregate & 1369 & 1226 \\
Water & 193 & 227 \\
Air & $6 \%$ & $6 \%$ \\
\hline
\end{tabular}

${ }^{\mathrm{i}} 1 \mathrm{lb} \mathrm{yd}^{-3}=0.59 \mathrm{~kg} \mathrm{~m}^{-3}$

ii Manufactured by Essroc Italcementi Group, Nazareth, PA

\subsection{Construction and Data Collection Chronology}

The highlights of the construction process and $\mathrm{NO}$ and $\mathrm{NO}_{\mathrm{x}}$ monitoring schedule are provided by Table 7.4. As will be discussed in Section 4, nearly 8 months passed between the time of the first pour of photocatalytic pavement and the opening of the highway section to traffic. The time period between construction and the testing period (which began after roadway opening) could provide observations of a loss of photoactivity similar to those of Ballari and Brouwers (2013). 
Table 7.4. Construction chronology and highlights.

\begin{tabular}{|c|c|}
\hline Date & Construction Highlights \\
\hline October 24, 2011 & $\begin{array}{l}\text { - The two travel lanes of the photocatalytic pavement test section (1500 ft x } \\
24 \mathrm{ft} \text { ) were poured. }\end{array}$ \\
\hline November 1, 2011 & $\begin{array}{l}\text { - The auxiliary lane of the photocatalytic pavement test section (1500 ft x } 14 \\
\mathrm{ft} \text { ) was poured. }\end{array}$ \\
\hline Winter 2011-2012 & $\begin{array}{l}\text { - A portion of the remaining control and non-research highway sections were } \\
\text { poured. }\end{array}$ \\
\hline Spring 2012 & $\begin{array}{l}\text { - Photocatalytic pervious concrete shoulder was poured (this section was } \\
\text { studied in other research efforts). } \\
\text { - Remaining control and non-research highway sections were poured. } \\
\text { - Sound wall adjacent to test section was placed. }\end{array}$ \\
\hline May 14, 2012 & $\begin{array}{l}\text { - Beginning of background } \mathrm{NO} \text { and } \mathrm{NO}_{\mathrm{x}} \text { monitoring with Ogawa passive } \\
\text { samplers }\end{array}$ \\
\hline July 14, 2012 & $\begin{array}{l}\text { - Highway section was opened to traffic. } \\
\text { - Beginning of } \mathrm{NO} \text { and } \mathrm{NO}_{\mathrm{x}} \text { monitoring with Ogawa passive samplers at all } \\
\text { data collection locations }\end{array}$ \\
\hline October 10, 2012 & $\begin{array}{l}\text { - End of } \mathrm{NO} \text { and } \mathrm{NO}_{\mathrm{x}} \text { monitoring with Ogawa passive samplers at all data } \\
\text { collection locations. }\end{array}$ \\
\hline November 7-8, 2012 & $\begin{array}{l}\text { - Active } \mathrm{NO} \text { and } \mathrm{NO}_{x} \text { monitoring with } 2 \mathrm{~B} \text { Technologies } \mathrm{NO} / \mathrm{NO}_{\mathrm{x}} \text { monitor for } \\
\text { 20-hr period. }\end{array}$ \\
\hline
\end{tabular}

\subsection{Data Collection Locations}

Both the control and photocatalytic (TX Active) sections each contained 3 locations for data collection. Figure 7.3 provides each location's number, the highway's associated station numbers, and the distance between data collection locations. Within the 1,500 ft photocatalytic test section, the first data collection location (P1) was placed $250 \mathrm{ft}$ south from the north edge. This length was selected to minimize the impact of diluting effects of unreacted vehicle exhaust pulled into the zone from the preceding non-photocatalytic pavement. The second location (P2) was placed at the section's midpoint. The third data collection location (P3) was placed $225 \mathrm{ft}$ north from the south edge of the test section. This placement was chosen for the purpose of centering this data collection location at the midpoint of a pervious concrete shoulder section, which was used for other research efforts. The first data collection location in the control section (C1) was placed $50 \mathrm{ft}$ south from section's north edge. This placement was also chosen to center this location at the midpoint of a pervious concrete shoulder section. The second location (C2) was placed at the section's midpoint. The third data collection location (C3) was placed 250 $\mathrm{ft}$ north from the south edge of the test section. 


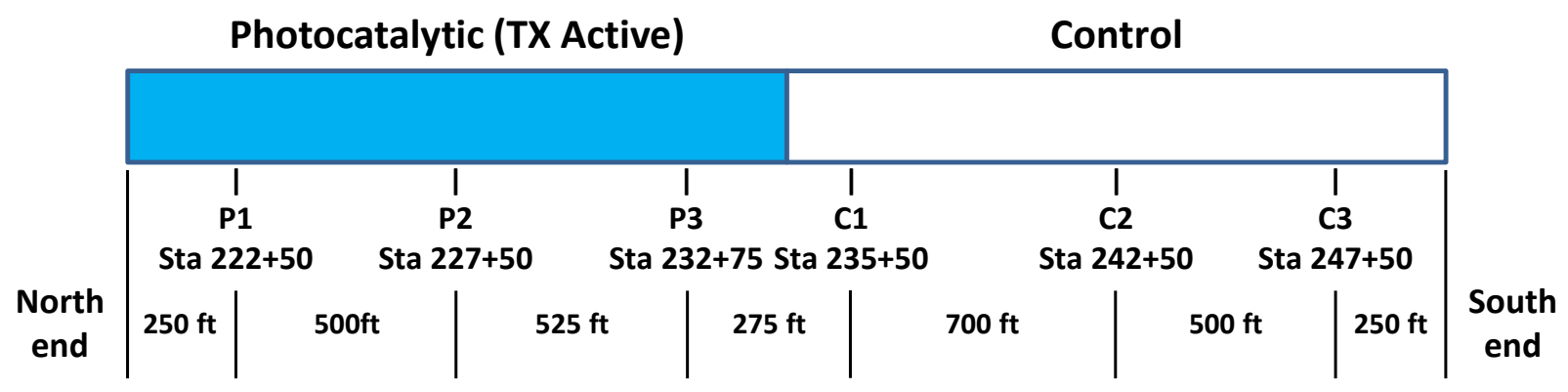

Figure 7.3. Data collection locations, numbering, and station numbers ( $P 3$ and $C 1$ were placed at the midpoint of a pervious concrete shoulder section used for other research efforts).

\subsection{NO and $\mathrm{NO}_{x}$ monitoring}

\subsubsection{Ogawa Passive Ambient Air Quality Monitoring}

Passive methods were not used in the prior photocatalytic pavement field trials reported by other researchers. Instead, previous studies used sets of chemiluminescent monitors placed within the control and photocatalytic test sections. The authors contemplated using such monitors; however they were dissuaded by the cost of use on a long-term basis. Instead, after reviewing literature which validated the passive samplers to reference methods (Hagenbjörk-Gustafsson et al., 2009; Mukerjee et al., 2009; Sather et al., 2007), the researchers selected Ogawa \& Co. USA, Inc. (Pompano Beach, FL) passive samplers as the primary $\mathrm{NO}$ and $\mathrm{NO}_{\mathrm{x}}$ monitoring method for this project (see Figure 7.4a). When installed in the field, pollutants flowed from the ambient environment, through a diffuser and adsorbed on a paper disc housed within the sampler body. This disc was coated with triethanolamine (TEA) to trap $\mathrm{NO}_{2}$ and discs coated with TEA and an oxidizing agent were used to trap $\mathrm{NO}_{\mathrm{x}}$ species. Subsequent dissolution in water (Type I reagent grade, Barnstead Nanopure II, Thermo Fisher Scientific, Waltham, MA) under the guidance of Ogawa (2006), analysis for nitrite according to Hach Company (2007) with a spectrophotometer (DR 2700, Hach Company, Loveland, Colorado), and blank adjustments permitted identification of the mass of the pollutant which had been trapped on the disc. Further calculations, which are detailed in Ogawa (2006) and required knowledge of the time the sampler was placed in the field along with the average relative humidity and temperature over that period, allowed the average ambient concentration of $\mathrm{NO}_{2}$ or $\mathrm{NO}_{\mathrm{x}}$ to be determined. Average $\mathrm{NO}$ concentration was calculated by subtracting the $\mathrm{NO}_{2}$ concentration from the $\mathrm{NO}_{x}$ concentration. 


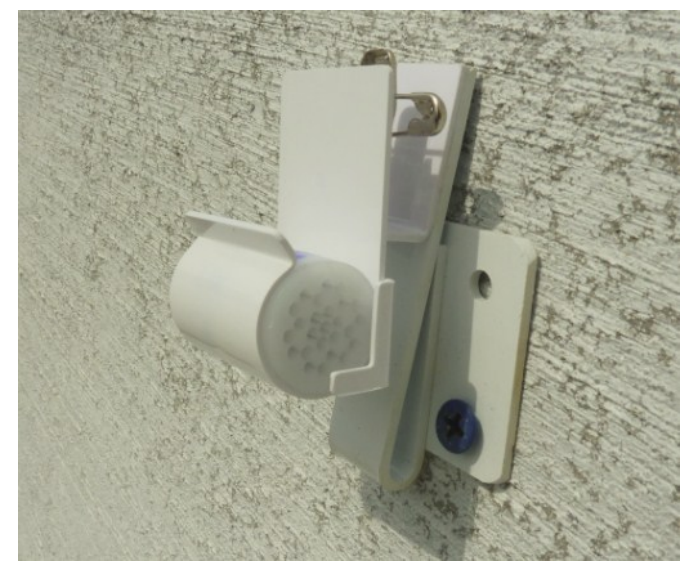

a.

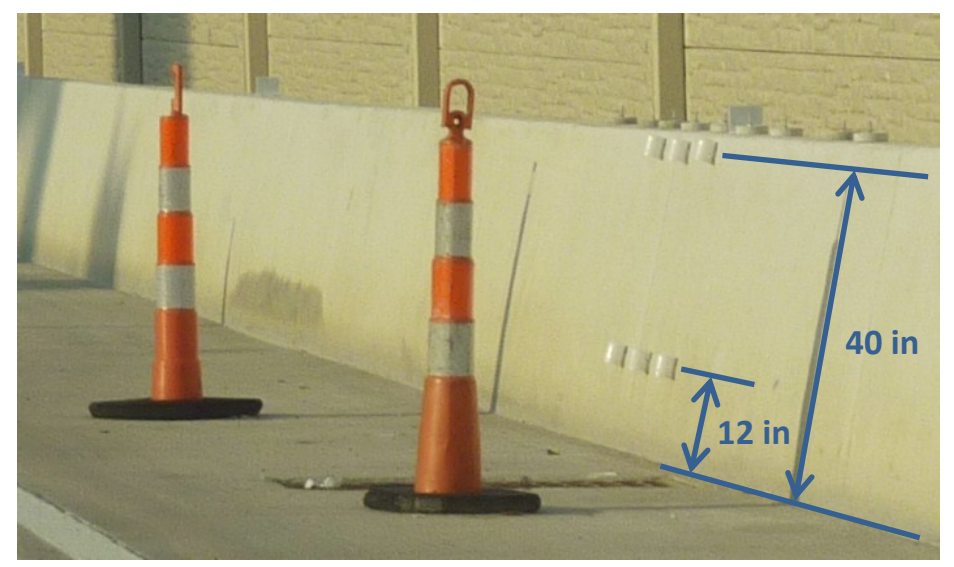

b.

Figure 7.4. Ogawa passive sampler installation and mounting on concrete barrier (12 in spacing between samplers).

Six samplers were mounted on the barrier curb at each data collection location (see Figure 7.4b). Previous work by Guerrini and Peccati (2007) had reported that the decrease in NO concentration associated with photocatalytic activity was less evident at an increased elevation. To provide data to investigate this finding, the researchers placed 3 samplers $30 \mathrm{~cm}$ above the pavement and 3 samplers $100 \mathrm{~cm}$ above the pavement.

Work to install the samplers occurred prior to the roadway's opening in order to provide data on NO and $\mathrm{NO}_{\mathrm{x}}$ concentration prior to the influence of traffic. Following opening, samplers were set in place for 14- to 35-day periods. At the end of each period, samplers were removed and replaced with fresh sampling discs. Removed samplers were stored in refrigerated conditions $\left(2-4^{\circ} \mathrm{C}\right)$ and analyzed within 30 d.

\subsubsection{B Technologies Active Ambient Air Quality Monitoring}

Although passive monitoring constituted the majority of air quality monitoring efforts at the project site, an active method was also used to determine if a difference between the ambient $\mathrm{NO}$ and $\mathrm{NO}_{\mathrm{x}}$ concentration at photocatalytic and control locations was observable on a short-term basis. The active monitors selected (Model 410 Nitric Oxide Monitor and Model $401 \mathrm{NO}_{2}$ Converter) were devices manufactured by 2B Technologies, Inc. (Boulder, CO). Unlike chemiluminescence instruments, which detect the light produced when NO reacts with ozone $\left(\mathrm{O}_{3}\right)$, the $2 \mathrm{~B}$ Technologies monitor measures the change in UV absorbance at $254 \mathrm{~nm}$ when $\mathrm{O}_{3}$ is consumed upon reaction with NO. UV absorbance is an 
absolute method; therefore, the analyzer requires calibration annually to correct for non-linearity that exists in the photodiode response and associated electronics.

Use of $2 \mathrm{~B}$ Technologies monitors to provide data for the assessment of $\mathrm{NO}_{\mathrm{x}}$ mitigation occurred in a manner similar to that of previous field studies. One monitor was placed at the midpoint of the photocatalytic section (data collection location P2) and another monitor was placed at the midpoint of the control section (data collection location C2). At these locations, sampling tubes were secured to the pavement surface and extended into the test section, within $3 \mathrm{ft}$ of the traffic lane. Once the tubes were secured, the monitors were set to measure $\mathrm{NO}$ or $\mathrm{NO}_{x}$ at rolling 15 -minute intervals for a period of approximately $20 \mathrm{hr}$.

\subsection{Complimentary Laboratory Assessment}

\subsubsection{Experimental Apparatus and Testing Procedure}

The experimental apparatus used for laboratory complementary assessments consisted of a flowthrough photoreactor, NO test gas supply system, UV-A light source, and $\mathrm{NO} / \mathrm{NO}_{\mathrm{x}}$ analyzer (see Chapter 4 for a detailed description). The international standard, ISO 22197-1:2007(E), provided information on the construction and operation of the set-up (ISO, 2007). The test gas, which flowed through the photoreactor at a rate of $3 \mathrm{~L} \cdot \mathrm{min}^{-1}$, was a mixture of breathing air (Grade D, Airgas USA, LLC, North Central Region, West Chicago, IL) and $51.6 \pm 1 \%$ ppmv NO balanced in nitrogen (EPA protocol gas, Praxair, Inc., Danbury, CT) adjusted to a NO concentration of 1000 ppb and $20 \%$ relative humidity. Flow of the test gas over the surface area of the coupon was ensured by placing the specimen within a rigid foam holder. Photocatalytic properties of the coupons were activated by directing a UV-A light (XX15BLB, Ultra-Violet Products, LLC, Upland, CA) at the UV-A-transparent optical window located at the top of the photoreactor. The emissions spectrum from this light features a primary peak at $365 \mathrm{~nm}$. As measured by a $365 \mathrm{~nm}$ UV sensor and radiometer (CX-365 and VLX-3W, Vilber Lourmat, Marne-laVallée, France), the irradiance at the location of the slab surface was $1.0 \times 10^{1} \mathrm{~W} \cdot \mathrm{m}^{-2}$. The $2 \mathrm{~B}$ Technologies $\mathrm{NO} / \mathrm{NO}_{\mathrm{x}}$ monitor, used for the active field monitoring, completed the experimental apparatus. The monitor recorded the gas concentrations at $10 \mathrm{~s}$ intervals and was set to measure NO.

Operation of the experimental apparatus was divided into two phases: parameter setting and testing. While in the parameter setting phase, the test gas flowed through the photoreactor; however, the slab was not irradiated by UV-A light. This phase was used to set airflow rate, relative humidity, and 
pollutant concentration to the values noted in the preceding paragraph. After adjusting parameters to desired values, gas flow was maintained through the photoreactor for a period sufficient to reach steady-state conditions. The testing period comprised two steps during which UV light off and UV light on concentrations of $\mathrm{NO}$ and $\mathrm{NO}_{x}$ were measured.

\subsubsection{Evaluation of Coupons Placed at Field Site}

To provide data to evaluate the impact of blinding by roadway pollutants or a change in the performance of the pavement over time, removable photocatalytic mortar slabs were placed within the TX Active test section. The following subsections detail procedures used to manufacture these coupons, placement at the project site, and the analytical approach used to assess the NO oxidation rate of this material.

\subsubsection{Coupon Manufacture}

Coupons used in this study were cylindrical in shape with surface area of $15 \mathrm{in}^{2}$ (see Figure 7.5). The proportions of the photocatalytic cement (TX Active, Essroc Italcementi Group, Nazareth, PA), water, and fine aggregate (ASTM C778 standard sand, U.S. Silica Co., Frederick, MD) were recorded as $1052 \mathrm{lb}$ $\mathrm{yd}^{-3}\left(624 \mathrm{~kg} \mathrm{~m}^{-3}\right), 442 \mathrm{lb} \mathrm{yd}^{-3}\left(262 \mathrm{~kg} \mathrm{~m}^{-3}\right)$, and $2380 \mathrm{lb} \mathrm{yd}^{-3}\left(1412 \mathrm{~kg} \mathrm{~m}^{-3}\right)$ respectively. Given the small volume of the coupons constructed, the mix did not include coarse aggregate. Except for the coarse aggregate, the relative proportions of materials used to manufacture the mortar coupons were similar to that of the field site's pavement. Following the pour, a damp cloth and plastic sheet were laid over the coupon surface for a $24-\mathrm{h}$ period while the slab cured. Following this initial curing period, the slabs were removed from forms and placed in a $100 \%$ humidity room for the duration of a 14-d curing period. 


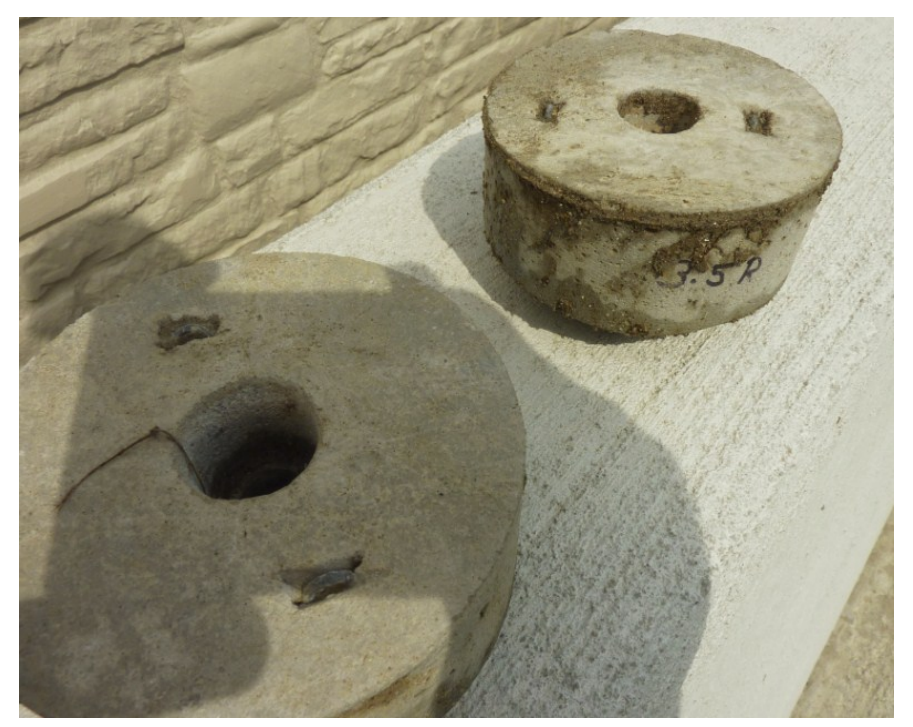

Figure 7.5. Coupon samples placed within TX Active test section.

\subsubsection{Placement at Project Site}

To complement passive air quality monitoring efforts, coupons placed in the photocatalytic test section were also placed at two elevations within each of the three photocatalytic section data collection points: atop the concrete barrier (which is 42 in above the roadway) and set in wells formed in the concrete shoulder (see Figure 7.6). Once placed, coupons were removed after deployments of approximately 30 days. 


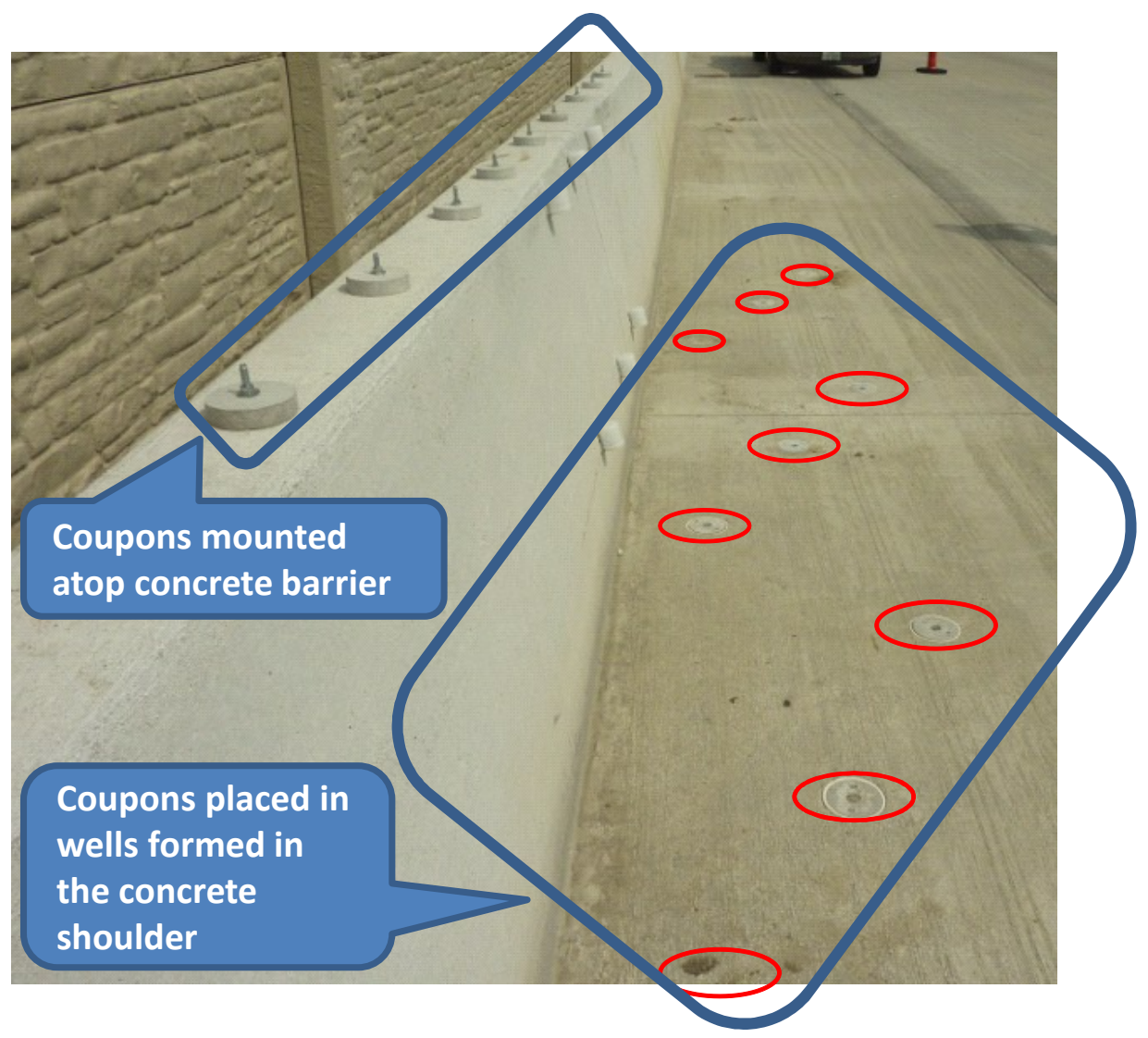

Figure 7.6. Coupon placement atop the concrete barrier (elevation slightly greater than $1 \mathrm{~m}$ above the roadway) and in wells formed in the concrete shoulder.

\subsubsection{Evaluation of fresh and aged mortar slabs}

As noted in Section 3.3, nearly 8 months passed between the time of the first pour of photocatalytic pavement and the opening of the highway section to traffic. To investigate whether this period of time would affect the pavement's NO oxidation rate photocatalytic mortar slabs were selected and evaluated in the photoreactor. Manufacture of these slabs followed the procedure detailed in Section 3.6.2.1; however, the constructed slabs were square with a surface area of $36 \mathrm{in}^{2}$. Two groups of slabs were selected for evaluation. The first group, a 16-sample set of fresh slabs, had ages ranging from 0.2 to 1.1 months. The second group, a 19-sample set of aged slabs, had ages ranging from 6.7 to 12 months. Dividing the slabs into these two categories permitted determination of whether a statistically significant difference existed between fresh and aged samples. 


\section{Results and Discussion}

\subsection{Ogawa Passive Monitoring}

Figure 7.7 and Figure 7.8 display the observed $\mathrm{NO}_{\mathrm{x}}$ and $\mathrm{NO}$ concentration at the data collection locations over the project timeframe. Summary of this data is provided by Table 7.5 and Table 7.6. The timeframe included in these observations includes data both prior to and after the roadway's July 14 opening. 
a. May 14-June 14, 2012 (31 d avg. period)

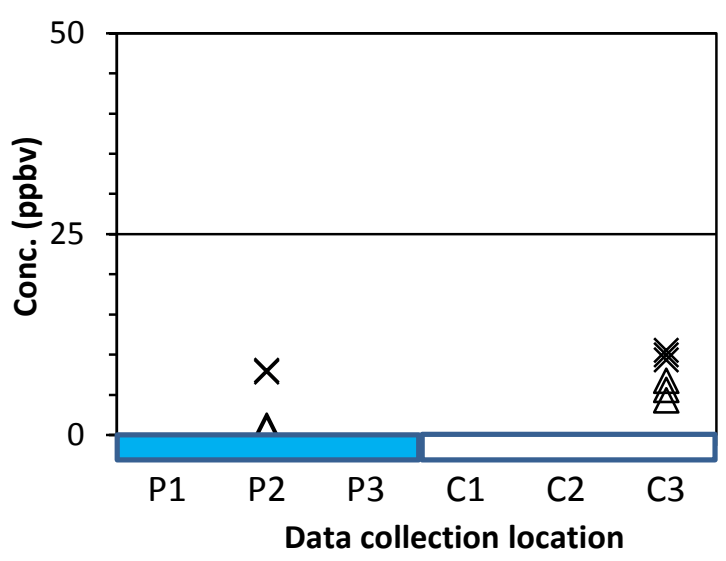

c. July 13-Aug. 1, 2012 (19 d avg. period)

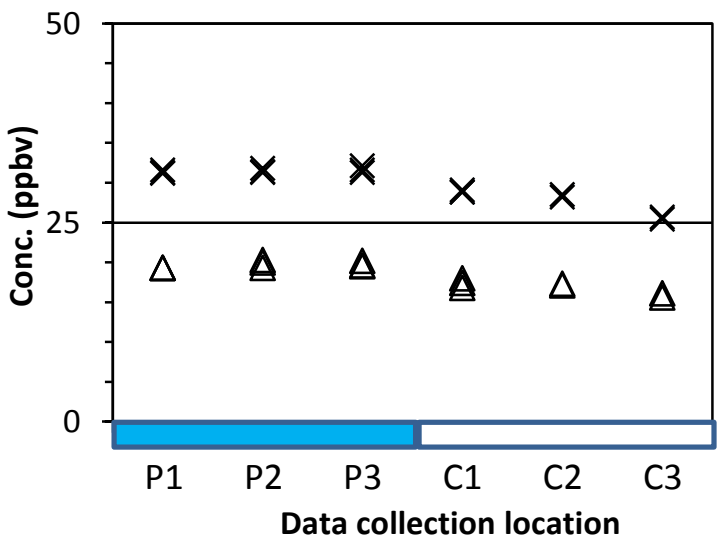

e. Aug. 14-Sep. 18, 2012 (35 d avg. period)

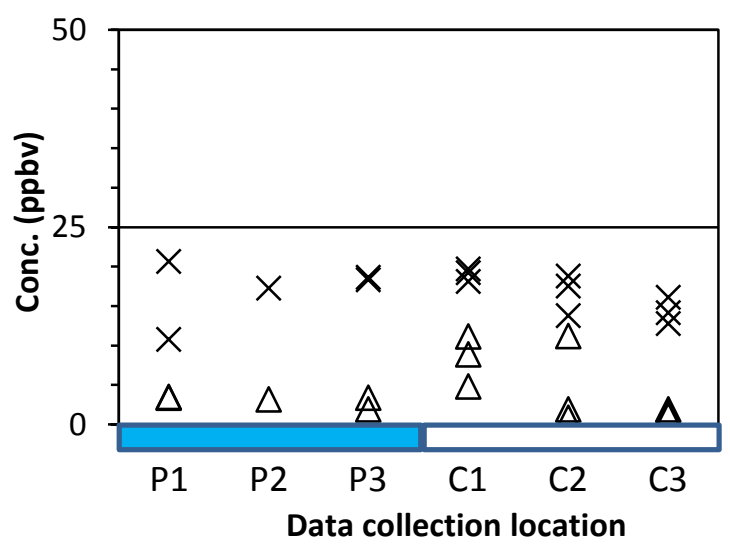

b. June 14-July 13, 2012 (29 d avg. period)

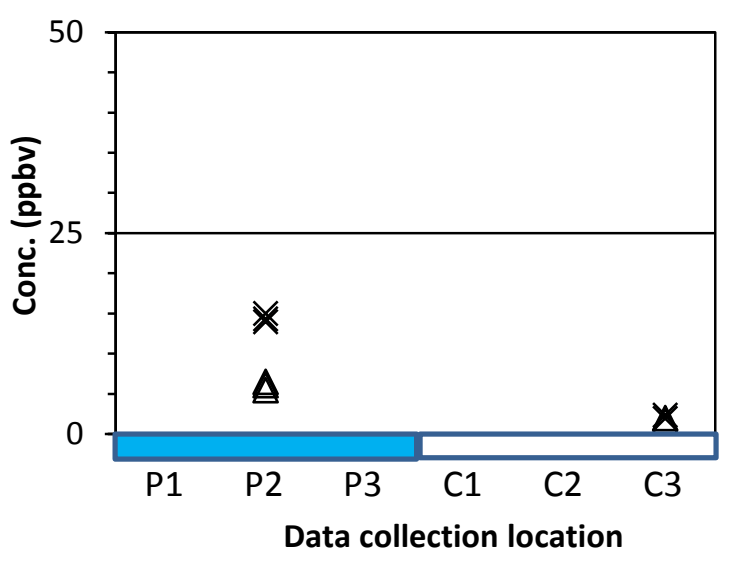

d. Aug. 1-Aug. 14, 2012 (13 d avg. period)

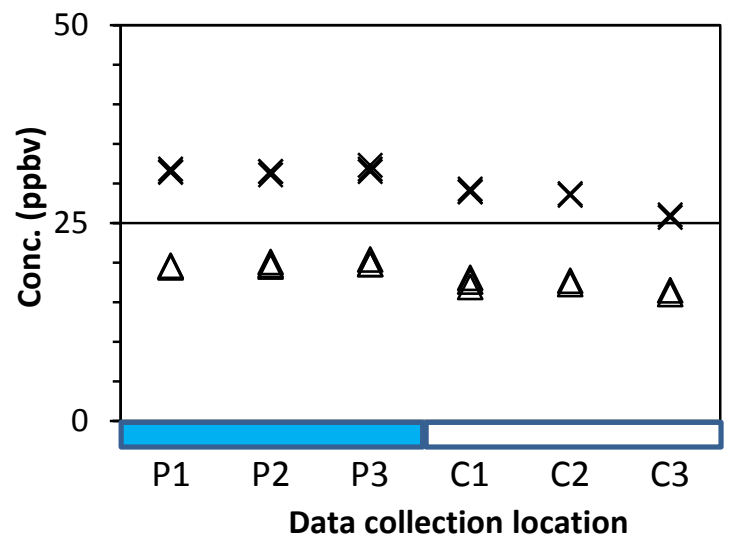

f. Sep. 18-Oct. 10, 2012 (22 d avg. period)

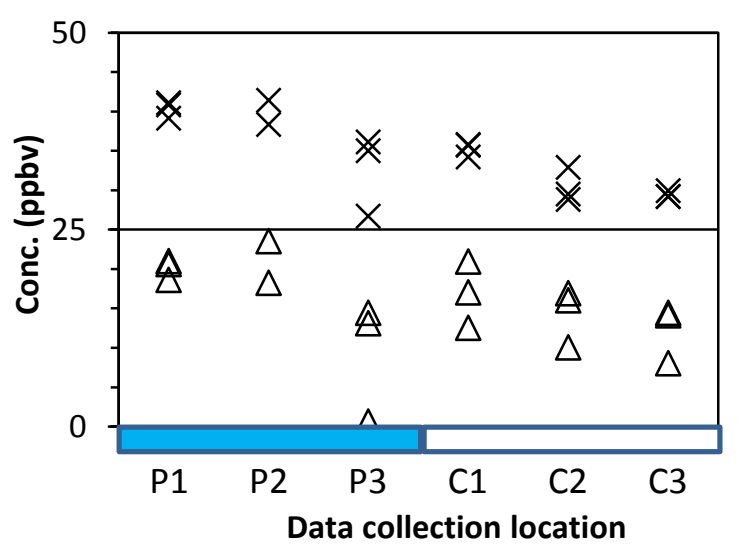

Figure 7.7. Observations of $\mathrm{NO}_{x}(x)$ and $\mathrm{NO}(\Delta)$ concentration at Ogawa passive samplers 12 in above pavement in photocatalytic and control test sections. 
a. July 13-Aug. 1, 2012 (19 d avg. period)

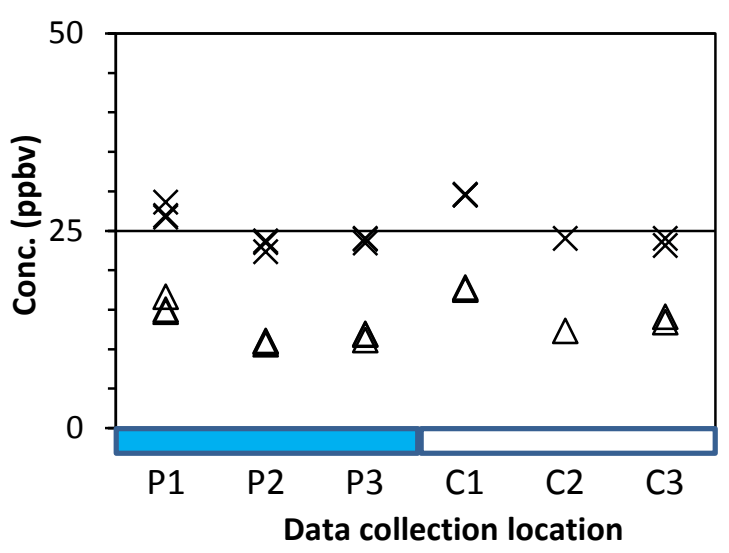

c. Aug. 14-Sep. 18, 2012 (35 d avg. period)

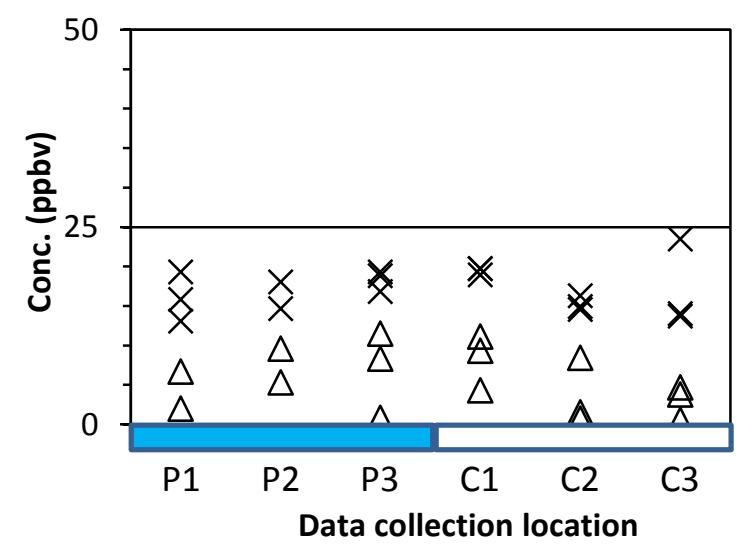

b. Aug. 1-Aug. 14, 2012 (13 d avg. period)

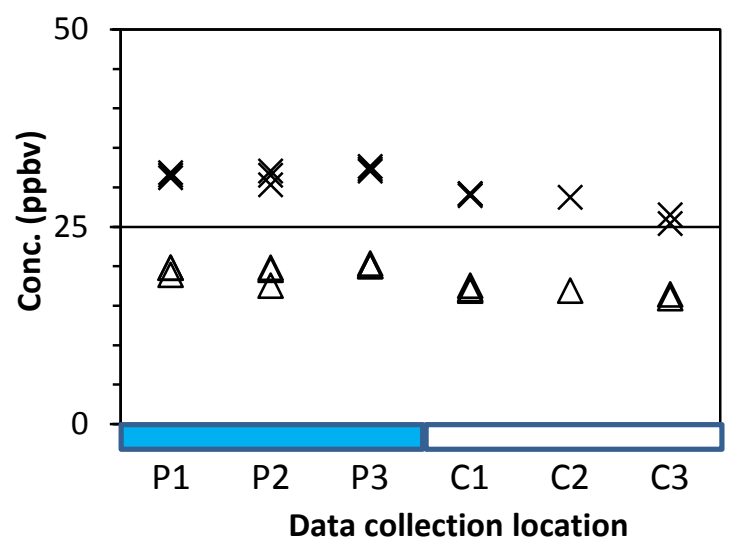

d. Sep. 18-Oct. 10, 2012 (22 d avg. period)

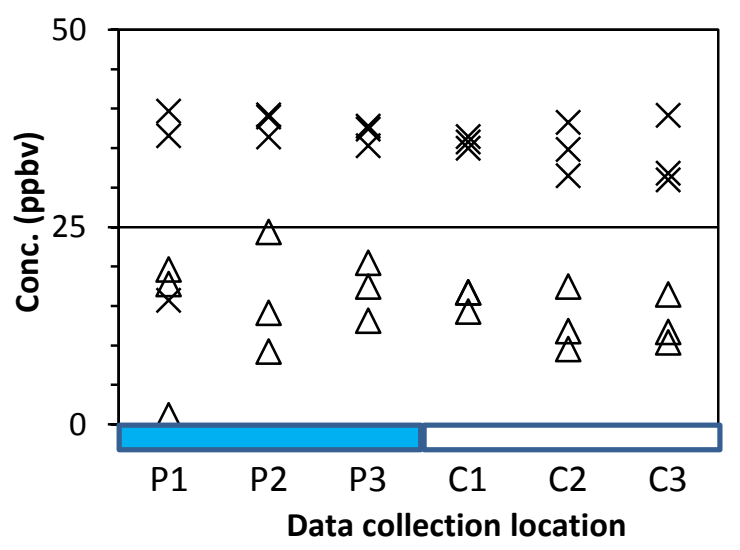

Figure 7.8. Observations of $\mathrm{NO}_{x}(x)$ and $\mathrm{NO}(\Delta)$ concentration at Ogawa passive samplers 40 in above pavement in photocatalytic and control test sections.

Table 7.5. Average $\mathrm{NO}_{\mathrm{x}}$ and $\mathrm{NO}$ concentration and number of observations at Ogawa passive samplers 12 in above pavement in photocatalytic and control test sections $(90 \%$ confidence interval displayed for $\mathrm{NO}_{\mathrm{x}}$ observations).

\begin{tabular}{|c|c|c|c|c|c|c|c|c|c|c|}
\hline \multirow{3}{*}{$\begin{array}{l}\text { Period } \\
\text { May 14-June 14, } 2012\end{array}$} & \multicolumn{5}{|c|}{ Photocatalytic } & \multicolumn{5}{|c|}{ Control } \\
\hline & \multicolumn{3}{|c|}{$\begin{array}{c}\mathrm{NO}_{x} \text { conc. } \\
\text { (ppbv) }\end{array}$} & \multirow{2}{*}{$\begin{array}{c}\text { NO conc. } \\
\text { (ppbv) }\end{array}$} & \multirow{2}{*}{$\frac{\text { Num. obs. }}{2}$} & \multicolumn{3}{|c|}{$\begin{array}{c}\mathrm{NO}_{x} \text { conc. } \\
\text { (ppbv) }\end{array}$} & \multirow{2}{*}{$\begin{array}{c}\text { NO conc. } \\
\text { (ppbv) }\end{array}$} & \multirow{2}{*}{$\frac{\text { Num. obs. }}{3}$} \\
\hline & 7.9 & \pm & 0.57 & & & 9.9 & \pm & 1.0 & & \\
\hline June 14-July 13, 2012 & 14 & \pm & 0.88 & 6.0 & 3 & 2.1 & \pm & 1.2 & 1.8 & 2 \\
\hline July 13-Aug 1, 2012 & 32 & \pm & 0.18 & 20 & 9 & 28 & \pm & 1.1 & 17 & 7 \\
\hline Aug 1-Aug 14, 2012 & 32 & \pm & 0.21 & 20 & 9 & 28 & \pm & 1.1 & 17 & 7 \\
\hline Aug 14-Sep 18, 2012 & 17 & \pm & 3.6 & 3.0 & 5 & 17 & \pm & 1.6 & 4.8 & 9 \\
\hline Sep 18-Oct 10, 2012 & 37 & \pm & 3.3 & 16 & 8 & 32 & \pm & 1.8 & 14 & 9 \\
\hline
\end{tabular}


Table 7.6. Average $\mathrm{NO}_{x}$ and $\mathrm{NO}$ concentration and number of observations at samplers $\mathbf{4 0}$ in above pavement photocatalytic and control test sections $\left(90 \%\right.$ confidence interval displayed for $\mathrm{NO}_{\mathrm{x}}$ observations).

\begin{tabular}{l|ccccc|ccccc}
\hline & \multicolumn{4}{|c|}{ Photocatalytic } & \multicolumn{4}{c}{ Control } \\
Period & \multicolumn{2}{|c|}{$\begin{array}{c}\text { NO } \\
\text { (ppb) }\end{array}$} & $\begin{array}{c}\text { NO conc. } \\
\text { (ppbv) }\end{array}$ & Num. obs. & $\begin{array}{c}\text { No } \\
\text { (ppbv) }\end{array}$ & $\begin{array}{c}\text { NO conc. } \\
\text { (ppbv) }\end{array}$ & Num. obs. \\
\hline July 13-Aug 1, 2012 & 25 & \pm & 1.3 & 13 & 9 & 27 & \pm & 2.6 & 16 & 6 \\
Aug 1-Aug 14, 2012 & 32 & \pm & 0.42 & 19 & 9 & 28 & \pm & 1.3 & 17 & 6 \\
Aug 14-Sep 18, 2012 & 17 & \pm & 1.5 & 6.5 & 8 & 17 & \pm & 2.1 & 5.2 & 9 \\
Sep 18-Oct 10, 2012 & 35 & \pm & 4.6 & 15 & 9 & 35 & \pm 1.8 & 15 & 9 \\
\hline
\end{tabular}

Review of the data collected prior to the roadway's opening found overall low $\mathrm{NO}_{\mathrm{x}}$ concentrations and low NO concentrations. The low values of NO are indicative that these observations do not fall in line with a near-road environment. In these environments, the NO fraction is typically greater in value because $\mathrm{NO}_{\mathrm{x}}$ emissions from tailpipes are 95\% NO (USEPA, 2001). Following the highway's opening, $\mathrm{NO}_{\mathrm{x}}$ concentration increased approximately two-fold and the NO portion of the observed concentration increased to an even greater extent. Both the comparative increase in $\mathrm{NO}_{\mathrm{x}}$ concentration and the higher values of NO evidence the influence of vehicles in the near-road environment.

Table 7.5 and Table 7.6 also present 90\% confidence intervals for average $\mathrm{NO}_{\mathrm{x}}$ measurements. Review of the data collected after the roadway opened to traffic finds no instance in which average $\mathrm{NO}_{\mathrm{x}}$ concentration was significantly lower in the photocatalytic pavement test section when compared to the control pavement section. This data does not provide evidence of the mitigation of air pollution by the photocatalytic pavement. Furthermore, in multiple cases, the concentration in the photocatalytic section was higher than that observed in the control section. These results stand in contrast with some previous studies (e.g., Beeldens, 2008, Guerrini \& Peccati, 2007, Italcementi, 2009); however they are in agreement with the observation of no significant decrease in $\mathrm{NO}_{\mathrm{x}}$ concentration recorded by Ballari and Brouwers (2013) prior to applying a $\mathrm{TiO}_{2}$ spray coating to rejuvenate the installed photocatalytic paving blocks. Possible explanations for these observations are discussed in Section 4.5.

\subsection{B Technologies Active Monitoring}

The $2 \mathrm{~B}$ Technologies monitor collected $\mathrm{NO}_{\mathrm{x}}$ and $\mathrm{NO}$ observations at $10 \mathrm{~s}$ intervals. This data was averaged over 30-minute periods in order to generate the chart displayed in Figure 7.9. Over the monitoring period, the $90 \%$ confidence interval of mean $\mathrm{NO}_{\mathrm{x}}$ and $\mathrm{NO}$ observations in the photocatalytic pavement section was $33 \pm 2.5$ and $21 \pm 2.7$ ppbv, respectively. The $90 \%$ confidence interval of mean 
$\mathrm{NO}_{\mathrm{x}}$ and $\mathrm{NO}$ in the control pavement section was $25 \pm 2.9$ and $18 \pm 3.8 \mathrm{ppbv}$ respectively. Similar to the results from the passively-collected data, these active observations also did not provide evidence of photocatalytic mitigation of $\mathrm{NO}_{x}$ pollution.

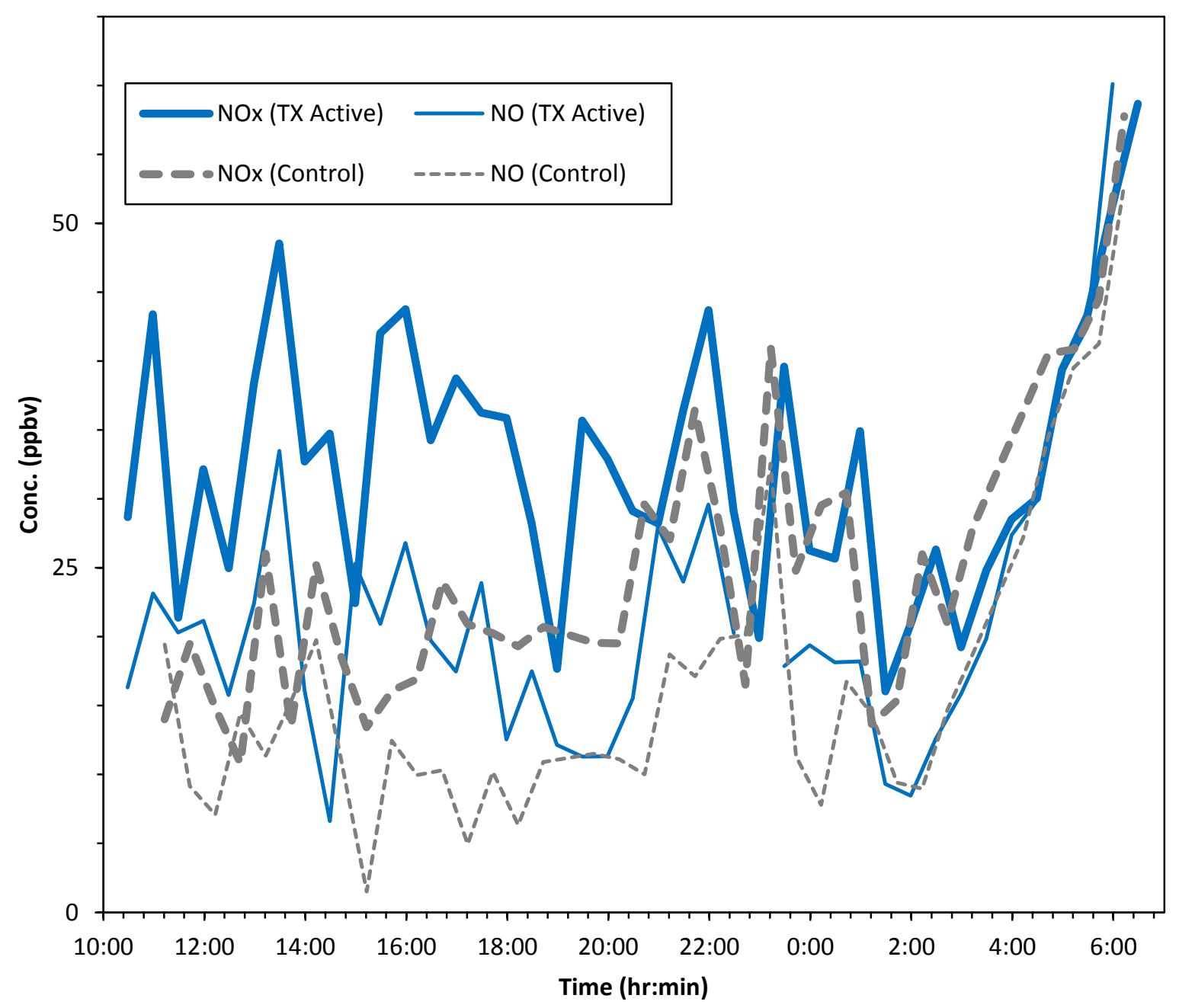

Figure 7.9. 30-minute average of observations of $\mathrm{NO}_{\mathrm{x}}$ and $\mathrm{NO}$ concentration in photocatalytic and control test sections.

In a separate field study in Bergamo, Italy, Guerrini and Peccati (2007) observed that peak values of $\mathrm{NO}_{\mathrm{x}}$ were substantially lower in a photocatalytic section as to a control section. Review of the data set from the Rte. 141 site indicates that the average of the highest 10 observed $\mathrm{NO}_{\mathrm{x}}$ concentrations in the photocatalytic and control sections were 198 and 123 respectively. This difference is substantially larger than the observed difference of the average values reported in the preceding paragraph, and therefore, does not provide additional support for Guerrini' and Peccati's observation. 


\subsection{Comparison of fresh and aged mortar slabs}

Figure 7.10 presents NO oxidation rate versus slab age for the tests completed in this study. Mean oxidation rate for the fresh set of samples measured $33 \pm 5.2 \mathrm{nmole} \cdot \mathrm{m}^{-2} \cdot \mathrm{s}^{-1}$ ( $90 \%$ confidence). Mean oxidation rate for the aged set of samples measured $17 \pm 2.5 \mathrm{nmole} \cdot \mathrm{m}^{-2} \cdot \mathrm{s}^{-1}$ (90\% confidence). These confidence intervals do not overlap, indicating that the populations are significantly different. This conclusion was confirmed with a $t$-test (two-tailed, unequal variances), which rejected a null hypothesis of $0 \mathrm{nmol} \cdot \mathrm{m}^{-2} \cdot \mathrm{s}^{-1}$ difference between the average NO oxidation rate for fresh and aged slabs $(t=4.882$, $\mathrm{df}=21, p=0.000)$.

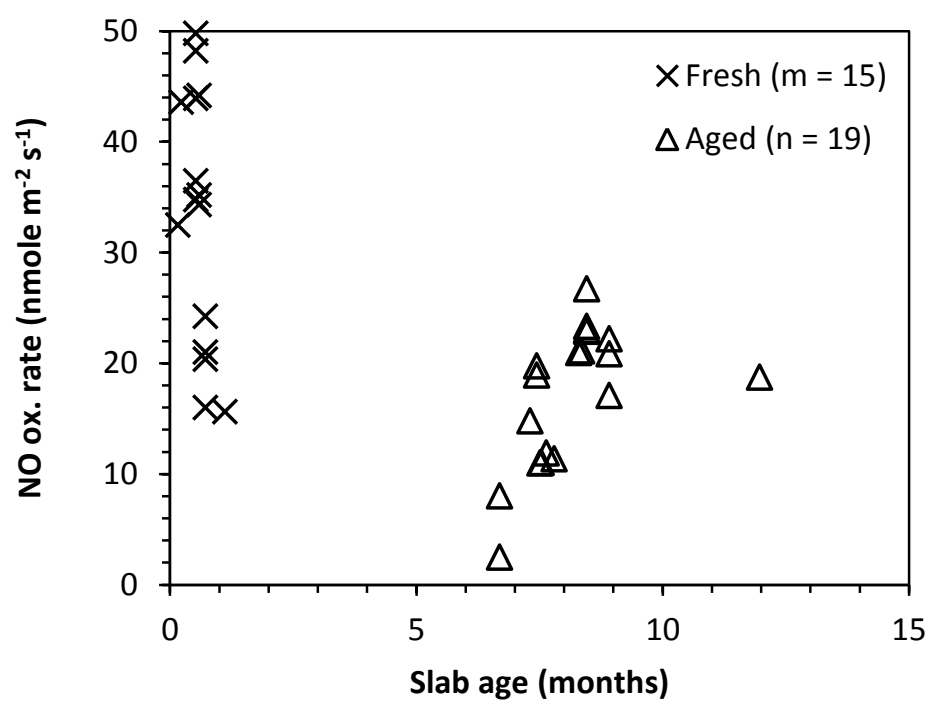

Figure 7.10. NO oxidation rate versus slab age.

For this study, the percent decrease in mean NO oxidation rates between fresh and aged slabs was 48\%. A decrease in NO oxidation rate is not a new finding. Murata and Tobinai (2002) found a $50 \%$ decrease in removal efficiency after setting photocatalytic paving blocks in an outdoor environment for 5 months. These researchers attributed the observed change to dust and organism adhesion. Yu (2003) reported a $36 \%$ to $78 \%$ decrease in removal efficiency over 4 months and a $22 \%$ to $88 \%$ decrease with 12 months of exposure for pavement blocks placed outdoors as part of a pedestrian road. After observing accumulation of particulate matter, oil, and chewing gum, and scratches on the pavement surface, the researchers credited a reduction in photocatalytic surface area as the cause for the decrease. When compared to the studies noted above, this study has a key difference. Rather than placing photocatalytic materials in an outdoor environment where various pollutants would adsorb to 
the surface and block light from reaching active sites, slabs used in this study were stored in a clean environment. The slabs were tested periodically in the photoreactor as part of the researchers' other efforts, but in each instance when the slabs were tested, the slabs were cleaned in accordance with the procedure outlined in Chapter 4. When not in use the researchers stored the slabs in sealed polyethylene bags. These efforts prevented contamination by the species noted by Murata and Tobinai (2002) and Yu (2003). A different explanation is needed to explain the presented results, these will be discussed in Section 4.5.

\subsection{Coupon Assessment}

Assessment of the coupons placed in the field serves a different purpose than the passive and active monitoring efforts described in the previous sections. Assessment of the NO oxidation rate of these coupons within the laboratory-based photoreactor instead provided data useful in explaining the failure of monitoring efforts to provide evidence of photocatalytic mitigation of $\mathrm{NO}_{\mathrm{x}}$ pollution.

The results of the photoreactor analysis appear in Figure 7.11. The NO oxidation rate for coupons placed in the road averaged $7.6 \pm 3.8 \mathrm{nmole} \cdot \mathrm{m}^{-2} \cdot \mathrm{s}^{-1}(90 \%$ confidence). At an average NO oxidation rate of $14 \pm 1.9 \mathrm{nmole} \cdot \mathrm{m}^{-2} \cdot \mathrm{s}^{-1}$ (90\% confidence), the coupons atop the barrier exhibited a substantially higher level of reactivity after substantial field exposure. This difference can be attributed to a blinding by roadway pollutants. Although both sets of coupons are within the near-road environment, the coupons placed in-road were observed to have substantially greater levels of blinding. This soiling from various environmental contaminants blocks UV light from reaching photocatalytically active sites; thereby reducing the NO oxidation rate (see Chapter 6). Furthermore, the observed NO oxidation rate for coupon samples is substantially lower than the $33 \pm 5.2 \mathrm{nmole} \cdot \mathrm{m}^{-2} \cdot \mathrm{s}^{-1}(90 \%$ confidence) oxidation rate for fresh mortar slabs (reported in Section 4.3), indicating that another process also reduced the oxidation rate after the samples were placed in the field. 


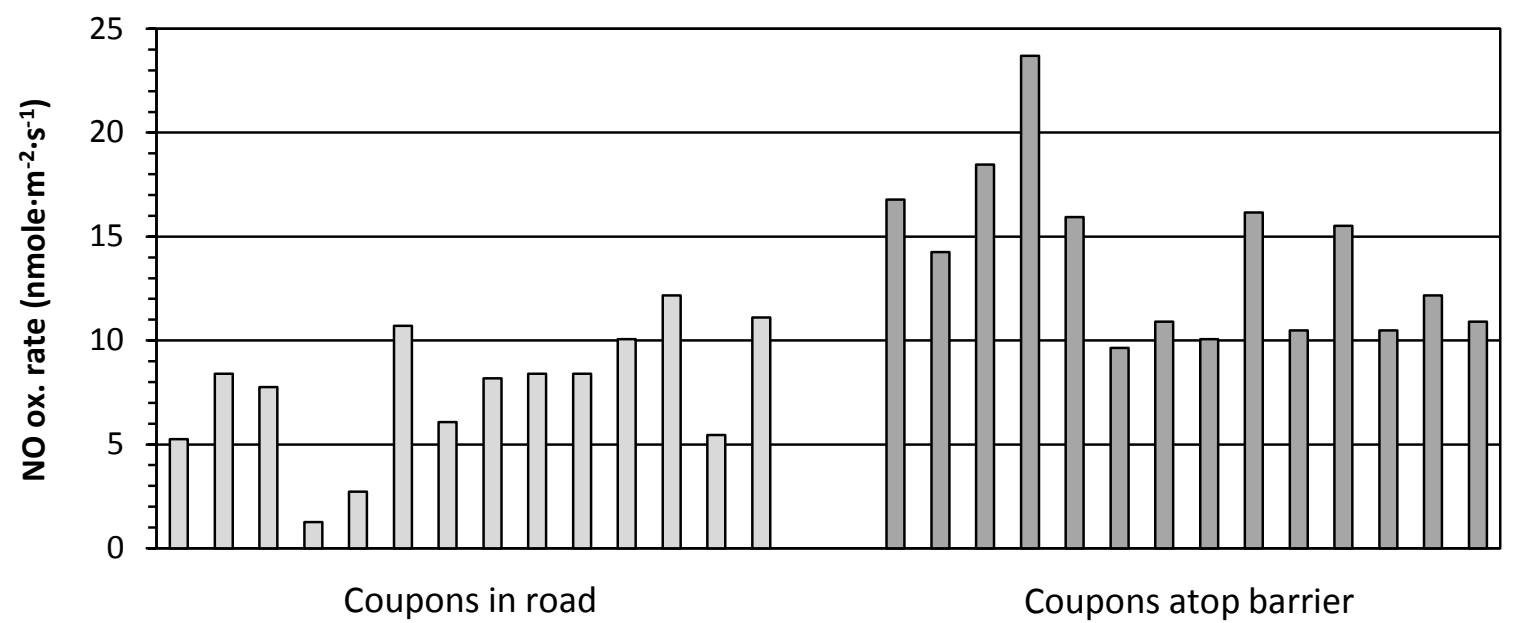

Figure 7.11. NO oxidation rate of photocatalytic coupons placed in road and atop the roadway barrier.

\subsection{Discussion}

Considered as a whole the data from passive and active field monitoring efforts do not provide evidence of photocatalytic mitigation of $\mathrm{NO}_{x}$ pollution at a field scale. Multiple reasons exist that could explain this result, including the following: UV-light blocking by calcium carbonate, high humidity levels, decrease in slab water content, insufficient traffic-generated pollution, fouling by roadway pollutants, excess vibration when placing the pavement, and insufficient NO oxidation rate.

\subsubsection{Calcium Carbonate}

The surface of recently-placed concrete contains calcium hydroxide $\left(\mathrm{Ca}(\mathrm{OH})_{2}\right)$. With exposure to the atmosphere, carbon dioxide $\left(\mathrm{CO}_{2}\right)$ sorbs on the pavement's surface and $\mathrm{Ca}(\mathrm{OH})_{2}$ is transformed into calcium carbonate $\left(\mathrm{CaCO}_{3}\right)$ (Fernández Bertos et al., 2004). As $\mathrm{CaCO}_{3}$ forms on the pavement's surface, $\mathrm{TiO}_{2}$ particles (and photocatalytically active sites) could be covered over. $\mathrm{TiO}_{2}$-based photocatalytic materials are also super-hydrophilic. As a result, water that is on the surface spreads out into a microlayer (Fujishima et al., 2008). This micro-layer would magnify the possible coverage of active sites by $\mathrm{CaCO}_{3}$ because the layer would increase surface area for both $\mathrm{CO}_{2}$ sorption and dissolution of excess $\mathrm{Ca}(\mathrm{OH})_{2}$. The fact that a significant decrease in performance was observed when comparing the fresh and aged mortar slabs (see Section 4.3), indicates that $\mathrm{CaCO}_{3}$ formation may be a significant factor. Although the researchers did make efforts to store the slabs in a clean environment, no effort was made to prevent carbonation. The polyethylene bag used for storage impedes the sorption of $\mathrm{CO}_{2}$ onto the slab surface. However, because polyethylene is a porous material, transfer of gases from the local atmosphere to the slab was not prevented. It is probable that formation of $\mathrm{CaCO}_{3}$ on the slab's surface 
contributed to some of the observed decrease in NO oxidation rate for both the laboratory tests and field observations.

\subsubsection{Relative Humidity}

During the course of this field study, relative humidity levels averaged nearly $70 \%$. As documented in Chapter 4 , the rate of NO oxidation decreases by almost $50 \%$ when relative humidity increases from $20 \%$ to $70 \%$. The high level of relative humidity observed at the field site, would have substantially diminished oxidation of the target pollutant, decreasing the effectiveness of the test section.

\subsubsection{Slab Water Content}

The photocatalytic reactions that result in the oxidation of $\mathrm{NO}_{\mathrm{x}}$ are driven by the hydroxyl radicals $\left({ }^{\circ} \mathrm{OH}\right)$. This radical is generated by oxidation of the hydroxyl ion $\left({ }^{-} \mathrm{OH}\right) .{ }^{-} \mathrm{OH}$ arises from water adsorbed on active sites. Previous research had assumed that the atmosphere is the source of adsorbed water. However, data presented in Chapter 4 found that a substantial decrease in photocatalytic activity occurs as water evaporates, indicating that water contained within the pores of a pavement also serves as a ${ }^{-}$ $\mathrm{OH}$ source. At the time of placement, these pores can become filled with water. As hydration occurs and pores become filled with air, water that is available as a ${ }^{-} \mathrm{OH}$ source decreases. With the high level of humidity observed at the site, the rate of water loss was likely slowed; therefore, it is unlikely that the loss of slab water was a substantial contributor to the pavement's poor performance.

\subsubsection{Traffic-Generated Pollution}

During the project, traffic flow was measured to be 12,400 vehicles over a $12 \mathrm{hr}$ daylight period. This value is substantially lower than the 46,000 AADT projected for the roadway. A variety of reasons could explain this discrepancy, including construction on the site, lane closures, etc. However, due to this low traffic volume, $\mathrm{NO}_{\mathrm{x}}$ pollution observed was likely substantially lower than it would be at the projected traffic volume. At these low pollution values, a decrease in pollution due to photocatalytic activity was in all likelihood more difficult to observe. Furthermore, observations at the traffic site noted that the majority of southbound traffic entered Rte. 141 from Olive Rd. This portion of traffic may still have been accelerating when entering the test section, leading to the observed higher value of $\mathrm{NO}_{\mathrm{x}}$ at these data collection points. Once traffic increases to a value closer to the projected AADT, the portion of traffic that enters Rte. 141 from Olive Rd. will diminish and future observations may not repeat the presented observations. 


\subsubsection{Blinding by Roadway Pollutants}

As documented in Chapter 6, roadway pollutants can dramatically reduce the rate of NO oxidation. Furthermore, Chapter 6 found that regeneration of photocatalytic activity was not readily achieved with simulated power washing or power washing. The photocatalytic test section was poured in October and November 2011, but the roadway did not open to traffic until July 2013. In the time between these dates, the test section was thoroughly soiled by construction traffic. Although the roadway was power brushed prior to opening, this cleaning activity may not have been sufficient to adequately regenerate the pavement's activity.

\subsubsection{Excess Vibration}

In comparison to other constituents in the concrete mixture, the anatase form of $\mathrm{TiO}_{2}$, with a density of $3.9 \mathrm{~g} \cdot \mathrm{cm}^{-3}$ is relatively heavy (consider that silica sand has a density of $2.6 \mathrm{~g} \cdot \mathrm{cm}^{-3}$ ). As a concrete mixture is placed, vibrators agitate and consolidate the mixture. Excess vibration tends to cause heavy constituents to settle and lighter constituents to rise to the mixture's surface. It is possible that when the pavement was placed, vibration occurred for a period of time sufficient enough to diminish the concentration of $\mathrm{TiO}_{2}$ on the pavement's surface. As reported by Hanson (2013), this diminished concentration negatively affects the pavement's air cleaning properties.

\subsubsection{NO Oxidation Rate}

Comparison of the estimated rate of $\mathrm{NO}_{\mathrm{x}}$ emission from vehicles to the anticipated rate of $\mathrm{NO}$ oxidation by the photocatalytic pavement does not provide strong evidence that the test section will have a substantial impact on ambient $\mathrm{NO}_{x}$ concentration. USEPA (2008) reported that the as of July 2008, the average emissions from the in-use fleet of passenger cars was 0.69 grams per mile driven. Assuming this emissions value, a three 12 -ft lanes, and the observed 12,400 vehicles over a $12 \mathrm{hr}$ period, emissions can be expressed as $239 \mathrm{~g} \cdot$ lane-mile ${ }^{-1} \cdot \mathrm{hr}^{-1}$ (where 1 lane-mile equals 63,400 $\mathrm{ft}^{2}$ ). Chapter 4 reported that the NO oxidation rate at $100 \mathrm{ppbv}$ was $4.0 \mathrm{~g} \cdot$ lane-mile ${ }^{-1} \cdot \mathrm{hr}^{-1}$. Convection and dispersion will quickly dilute these emissions; however, with the projected rate of oxidation being so much lower than that of the rate of emission, it is not immediately evident that ambient $\mathrm{NO}_{\mathrm{x}}$ concentration will be substantially diminished due to the effect of the photocatalytic pavement. 


\section{Conclusions}

The research efforts of the Missouri Rte. 141 did not provide evidence that the $\mathrm{NO}_{\mathrm{x}}$ pollution generated by on-road motor vehicles was mitigated by a photocatalytic concrete pavement constructed using TX Active cement. Once opened to traffic, passive observations of $\mathrm{NO}_{\mathrm{X}}$ documented no instance in which average $\mathrm{NO}_{x}$ concentration was significantly lower (90\% confidence) in the photocatalytic pavement test section when compared to the control pavement section. Active observations conducted over a $20-\mathrm{hr}$ period found that $\mathrm{NO}_{x}$ photocatalytic and control pavement test sections averaged $33 \pm 2.5$ and $25 \pm 2.9 \mathrm{ppbv}$ (90\% confidence), respectively. A variety of explanations exist to explain the failure to observe photocatalytic mitigation of $\mathrm{NO}_{\mathrm{x}}$ pollution including UV-light blocking by calcium carbonate, high humidity levels, decrease in slab water content, insufficient traffic-generated pollution, blinding by roadway pollutants, excess vibration when placing the pavement, and insufficient NO oxidation rate. Laboratory-based evaluation found that the NO oxidation rate of fresh (ages ranging from 0.2 to 1.1 months) photocatalytic mortar slabs was $33 \pm 5.2 \mathrm{nmole} \cdot \mathrm{m}^{-2} \cdot \mathrm{s}^{-1}$ ( $90 \%$ confidence). However, the oxidation rate of aged slabs (ages ranging from 6.7 to 12 months) measured $17 \pm 2.5 \mathrm{nmole} \cdot \mathrm{m}^{-2} \cdot \mathrm{s}^{-1}(90 \%$ confidence), a $48 \%$ decrease. This data indicates that factors such as the formation of calcium carbonate on the pavement surface and the loss of slab water content could provide explanation for the field observations. Lab evaluation of photocatalytic mortar coupons placed in the roadway found a NO oxidation rate of $7.6 \pm 3.8 \mathrm{nmole} \cdot \mathrm{m}^{-2} \cdot \mathrm{s}^{-1}$ (90\% confidence). This value is substantially lower than the NO oxidation rate reported for fresh mortar slabs, indicating blinding by roadway pollutants. In addition, ongoing work also suggests that the failure to observe $\mathrm{NO}_{\mathrm{x}}$ mitigation can also be explained by excess vibration, and insufficient NO oxidation rate. Stakeholders seeking to use this pollution mitigation technology should carefully consider the expense and existing uncertainty associated with this product before proceeding with large-scale installations of this photocatalytic concrete pavement.

\section{References}

Ballari, M. M., \& Brouwers, H. J. H. (2013). Full scale demonstration of air-purifying pavement. [Article]. Journal of Hazardous Materials, 254, 406-414. doi: 10.1016/j.jhazmat.2013.02.012

Beeldens, A. (2007, October 8-9). Air Purification by Road Materials: Results of the Test Project in Antwerp. Paper presented at the International RILEM Symposium on Photocatalysis, Environment and Construction Materials - TDP 2007, Florence, Italy.

Beeldens, A. (2008). Air purification by pavement blocks: final results of the research at the BRRC. Ljubljana, Slovenia. 
Beeldens, A., \& Boonen, E. (2012). A double layered photocatalytic concrete pavement: a durable application with air-purifying properties. Paper presented at the 10th International Conference on Concrete Pavements, Quebec City, Canada.

Cape, J. N., Tang, Y. S., Van Dijk, N., Love, L., Sutton, M. A., \& Palmer, S. C. F. (2004). Concentrations of ammonia and nitrogen dioxide at roadside verges, and their contribution to nitrogen deposition. Environmental Pollution, 132(3), 469-478.

Crispino, M., \& Vismara, S. (2010). Innovative Photocatalytic Pavements Presentation at International Sustainable Pavements Workshop. Airie, VA.

Essroc. (2008). LEED-NC ${ }^{\circledR} 2.2$ Guide:Using TX Arca $^{\circledR}$ and TX Aria ${ }^{\circledR}$ Photocatalytic Cements for New Construction and Major Renovations Nazareth, PA.

Essroc. (2009). TX Active, Photocatalytic Concrete Technology. Retrieved from http://www.mnconcretecouncil.com/ftpgetfile.php?id=50

Fernández Bertos, M., Simons, S. J. R., Hills, C. D., \& Carey, P. J. (2004). A review of accelerated carbonation technology in the treatment of cement-based materials and sequestration of $\mathrm{CO} 2$. Journal of Hazardous Materials, 112(3), 193-205. doi: 10.1016/j.jhazmat.2004.04.019

Fujishima, A., Zhang, X. T., \& Tryk, D. A. (2008). TiO(2) photocatalysis and related surface phenomena. [Review]. Surface Science Reports, 63(12), 515-582. doi: 10.1016/j.surfrep.2008.10.001

Gignoux, L., Christory, J. P., \& Petit, J. F. (2010). Concrete roadways and air quality -- Assessment of trials in Vanes in the hear of the Paris region. Paper presented at the 12th International Symposium on Concrete Raods, Sevilla Spain.

Google Maps. (2013). [Chesterfield, MO] Retrieved June 24, 2013, from https://www.google.com/maps/preview\#!q=Chesterfield\%2C+MO\&data=!1m4!1m3!1d18520!2 d-90.4905315!3d38.6712067!2m1!1e3!4m10!1m9!4m8!1m3!1d12592!2d$\underline{96.1741689 ! 3 \mathrm{~d} 43.0765185 ! 3 \mathrm{~m} 2 ! 1 \mathrm{i} 1920 ! 2 \mathrm{i} 1139 ! 4 \mathrm{f} 35 \& \mathrm{fid}=7}$

Guerrini, G. L., \& Peccati, E. (2007, October 8-9). Photocatalytic Cementitious Roads for Depollution. Paper presented at the International RILEM Symposium on Photocatalysis, Environment and Construction Materials - TDP 2007, Florence, Italy.

Hach Company. (2007). Nitrite, Diazotization LR Method 8507. Loveland, CO: Hach Company.

Hagenbjörk-Gustafsson, A., Eriksson, K., \& Forsberg, B. (2009). Field Evaluation of the Ogawa Diffusive Sampler for NO2/NOx in a Cold Climate. Epidemiology, 20(6), S161 110.1097/1001.ede.0000362548.0000383420.d0000362547. 
Hanson, S. \& Tikalsky, P. (2013, May 6-8). Fabrication Techniques for Concrete Containing TiO2 Photocatalytic Particles. Paper presented at the 2013 International Concrete Sustainability Conference, San Francisco, CA.

Hassan, M. M., \& Okeil, A. (2011). Field and Laboratory Investigation of Photocatalytic Pavements: Final Report. Baton Rouge, LA: Gulf Coast REsearch Center for Evacuation and Transportation Resiliency.

ISO. (2007). Fine ceramics (advanced ceramics, advanced technical ceramics) -- Test method for airpurification performance of semiconducting photocatalytic materials -- Part 1: Removal of nitric oxide (Vol. 22197-1:2007): ISO.

Italcementi. (2006). TX Active by Italcementi. Bergamo, Italy.

Italcementi. (2009). TX Active, The Photocatalytic Active Principle: Technical Report. Retrieved from http://www.italcementigroup.com/NR/rdonlyres/96036B14-4C6D-4E07-98541B1CE1AD6593/0/TXactivetechnicalreport2009.pdf

Mukerjee, S., Oliver, K. D., Seila, R. L., Jacumin Jr, H. H., Croghan, C., Daughtrey Jr, E. H., . . Smith, L. A. (2009). Field comparison of passive air samplers with reference monitors for ambient volatile organic compounds and nitrogen dioxide under week-long integrals. Journal of Environmental Monitoring, 11(1), 220-227.

Murata, Y., \& Tobinai, K. (2002). Influence of various factors on NOx removal performance of permeable interlocking block based on photocatalysis. Journal of Structural and Construction Engineering(Transactions of AIJ)(555), 9-15.

Ogawa. (2006). $\mathrm{NO}, \mathrm{NO}_{2}, \mathrm{NO}_{\mathrm{x}}$ and $\mathrm{SO}_{2}$ Sampling Protocol Using The Ogawa Sampler. Pompano Beach, FL: Ogawa \& Co., USA, Inc.

Overman, H. T. J. (2009). Simulation model for NOX distributions in a street canyon with air purifying pavement. (Master: Civil Engineering \& Management), University of Twente, Eschede, Netherlands.

Rousseau, P., Drouadaine, I., \& Mazé, M. (2009, May-June). Le procédé NOxer ${ }^{\circledR}$ : du développement aux mesures de dépollution sur site. Revue générale des routes et de l'aménagement.

Sather, M., Slonecker, E., Mathew, J., Daughtrey, H., \& Williams, D. (2007). Evaluation of Ogawa passive sampling devices as an alternative measurement method for the nitrogen dioxide annual standard in El Paso, Texas. Environmental Monitoring and Assessment, 124(1), 211-221-221. doi: 10.1007/s10661-006-9219-4

USEPA. (2001). National Air Quality and Emissions Trends Report, 1999. (EPA 454/R-01-004). Washington, D.C. 
USEPA. (2008). Average Annual Emissions and Fuel Consumption for Gasoline-Fueled Passenger Cars and Light Trucks. (EPA420-F-08-024). Washington, D.C.: Retrieved from http://www.epa.gov/otaq/consumer/420f08024.pdf.

Yu, J. C. (2003). Deactivation and Regeneration of Environmentally Exposed Titanium Dioxide (TiO2 ) Based Products Hong Kong. 


\section{CHAPTER 8. KEY FINDINGS}

Photocatalytic pavements have been proposed to address degradation of ambient air quality that occurs in near-road environments due to motor-vehicle traffic. The following summaries describe the key findings resulting from the work reported within this dissertation.

Fundamental environmental variables: Lab-scale photoreactor studies reported in Chapter 4 confirmed that NO oxidation rates were positively correlated with NO inlet concentration and irradiance and negatively correlated with relative humidity. Comparison to other studies found that in some instances, the slope of linear regression lines through collected data points was not significantly different than previous reports; whereas in other instances, the slope was significantly different. These results indicate that materials variables also must be evaluated and can substantially impact a pavement's performance. Slab water loss-a previously unstudied variable-was found to positively correlate with NO oxidation rate at losses of $0-2 \%$ of saturated mass; however, at losses greater that $2 \%$ a negative correlation was observed. A positive correlation was documented for slab temperature. This finding contrasts previous assertions which considered this variable insignificant. For the tests conducted, removal rate ranged from 6.2-57 nmole $\cdot \mathrm{m}^{-2} \cdot \mathrm{s}^{-1}\left(4.0-36 \mathrm{~g} \cdot\right.$ lane-mile $\left.\mathrm{m}^{-1} \cdot \mathrm{hr}^{-1}\right)$. NO emissions from a highway (10 twelve-foot-wide lanes, AADT $=250,000)$ were conservatively estimated to be $720 \mathrm{~g} \cdot$ lane$\mathrm{mile}^{-1} \cdot \mathrm{hr}^{-1}$. Convection and dispersion will quickly dilute these emissions; however, at the NO oxidation rate values reported, it is not immediately clear that ambient $\mathrm{NO}_{\mathrm{x}}$ concentration will be substantially diminished due to the effect of photocatalytic pavements.

Pervious pavement: Chapter 5 detailed laboratory evaluations of pervious and mortar slabs. These slabs were constructed with the same type of photocatalytic cement (TX Active) and water-to-cement ratio in order to provide a valid basis for comparison. Contrasting prior speculation that the increased specific surface area of pervious concrete would result in increased performance, at $90 \%$ confidence the study did not find a significant difference in the average NO oxidation rate of the pervious and mortar slabs $\left(44.2 \pm 4.18\right.$ and $40.9 \pm 6.04 \mathrm{nmol} \cdot \mathrm{m}^{-2} \cdot \mathrm{s}^{-1}$, respectively). The study also found no evidence of a correlation between NO oxidation rate and photocatalytic layer depth in slabs manufactured with a twolift technique at a confidence level greater than $90 \%$. This finding also contrasts prior speculation, which had hypothesized a positive correlation due to the excitation of additional active sites as UV-A light penetrated below the pavement's surface. The study did not provide evidence that photocatalytic pervious concrete pavements perform at a superior level; however, they do represent another material 
that could be used to positively impact air quality. Furthermore, ongoing research may reveal that photocatalytic pervious materials have the added benefit of positively impacting the quality of stormwater discharges.

Blinding by reaction products and roadway pollutants: An investigation of reaction product blinding, reported in Chapter 6, found that oxidation rates decreased by $39 \%$ and $34 \%$ over 5 - and 20 hour periods, respectively. The decrease did approach an asymptotic value; indicating that the formation of reaction products will not cause the complete loss of a concrete's air-cleaning properties. Prior lab studies had predicted that blinding by roadway pollutants would result in up to an $88 \%$ decrease in NO oxidation. With exception of sodium chloride, at normally observed levels of pollutant loading, the decrease in NO oxidation rate was less than 25\%; therefore, this article disputes these claims. Of all pollutant species tested, the impact of blinding by sand was of the least significance. Oil, which competes with NO for photocatalytic oxidation, had the greatest impact on a per-mass basis. Attempts to regenerate photoactivity with power brushing and power washing treatments were inconclusive. Literature had claimed that rain or surface washing is sufficient to regenerate photocatalytic activity; therefore, this result is significant.

Field: Considered as a whole, the data collected did not supply evidence of photocatalytic oxidation of $\mathrm{NO}_{\mathrm{x}}$ by TX Active pavement. Following the roadway's opening to traffic, Ogawa-based passive observations of $\mathrm{NO}_{\mathrm{x}}$ documented no instance in which average $\mathrm{NO}_{\mathrm{x}}$ concentration was significantly lower $(90 \%$ confidence) in the photocatalytic pavement test section when compared to the control pavement section. A 2B Technologies monitor used to conduct active observations over a 20 -hr period found that $\mathrm{NO}_{x}$ photocatalytic and control pavement test sections averaged $33 \pm 2.5$ and $25 \pm 2.9$ ppbv (90\% confidence), respectively. Laboratory-based comparison of fresh and aged photocatalytic mortar slabs found a $48 \%$ decrease in NO oxidation rate, indicating that the field results could be explained by factors such as the formation of calcium carbonate on the pavement surface and the loss of slab water content. Lab evaluation of photocatalytic mortar coupons placed in the roadway found a NO oxidation rate of $7.6 \pm 3.8 \mathrm{nmole} \cdot \mathrm{m}^{-2} \cdot \mathrm{s}^{-1}$ (90\% confidence). This value was more than $75 \%$ less than the oxidation rate of fresh slabs, providing evidence of blinding by roadway pollutants.

Overall conclusions: The insights reported in this study can serve as an underpinning for future work. This future work should distill this knowledge into a predictive model that simplifies the efforts required for a potential stakeholder to both evaluate whether environmental conditions are appropriate 
for the application of photo pavements for $\mathrm{NO}_{\mathrm{x}}$ mitigation and predict the impact that the photocatalytic pavement will have on air quality at specific locations. Furthermore, additional knowledge must be developed to ensure that materials are handled and placed in a manner that efficiently uses the $\mathrm{TiO}_{2}$ contained. 